$9 \operatorname{sid}^{19 x}(1$

SAND93-7026 UC-236

Unlimited Release

Printed January 1994

\title{
A Compendium of \\ Solar Dish/Stirling Technology
}

William B. Stine, Ph.D.

Professor, Mechanical Engineering

California State Polytechric University

Pomona, CA 91768

Richard B. Diver, Ph.D.

Solar Thermal Technology Department

Sandia National Laboratories

Albuquerque, NM 87185-0703

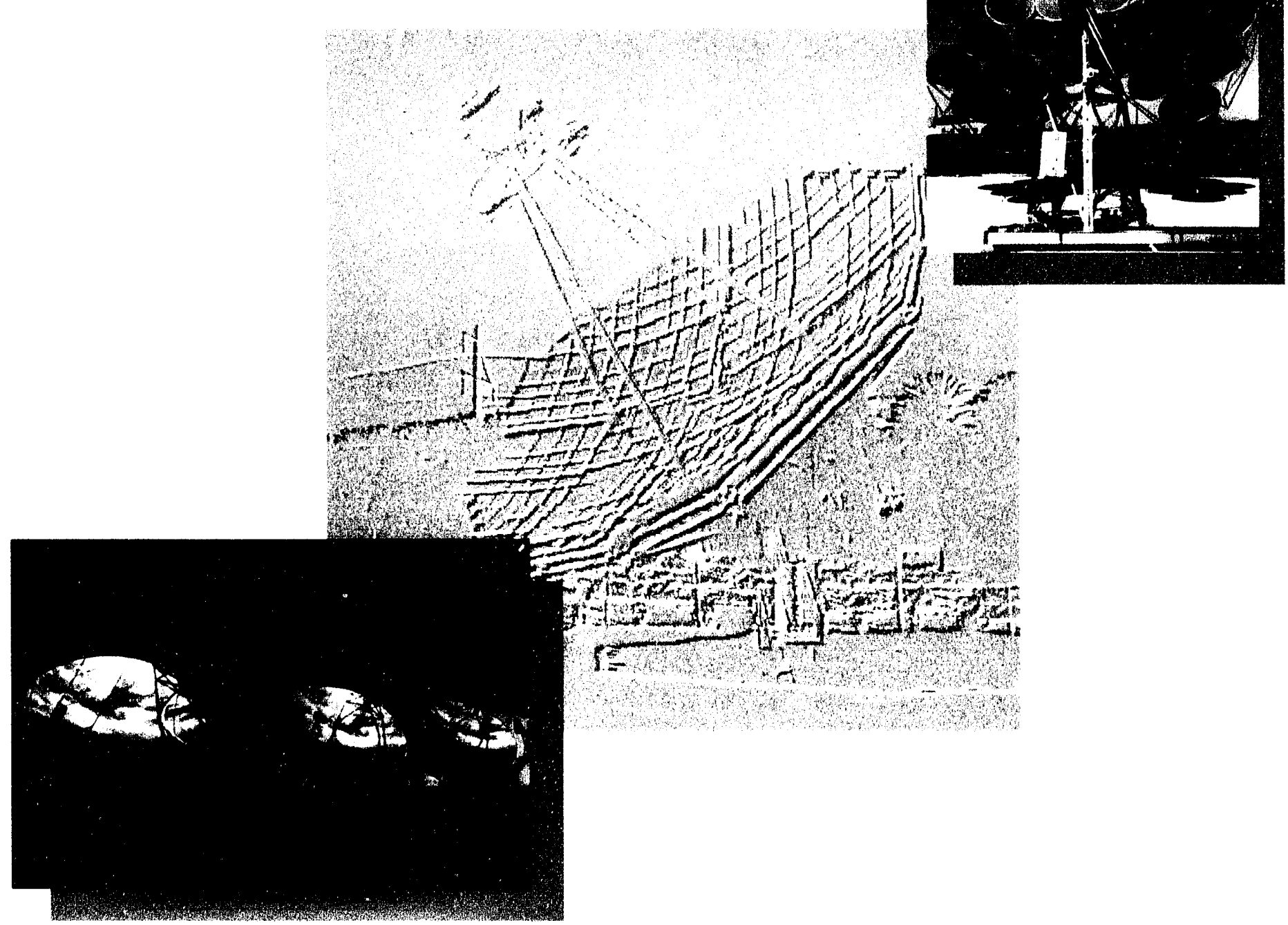


Issued by Sandia National Laboratories, operated for the United States Department of Energy by Sandia Corporation.

NOTICE: This report was prepared as an account of work sponsored by an agency of the United States Government. Neither the United States Government nor any agency thereof, nor any of their employees, nor any of their contractors, subcontractors, or their employees, makes any warranty, express or implied, or assumes any legal liabiiity or responsibility for the accuracy, completeness, or usefulness of any information, apparatus, product, or process disclosed, or represents that its use would not infringe privately owned rights. Reference herein to any specific commercial product, process, or service by trade name, trademark, manufacturer, or otherwise, does not necessarily constitute or imply its endorsement, recommendation, or favoring by the United States Government, any agency thereof or any of their contractors or subcontractors. The views and opinions expressed herein do not necessarily state or reflect those of the United States Government, any agency thereof or any of their contractors.

Printed in the United States of America. This report has been reproduced directly from the best available copy.

Available to DOE and DOE contractors from

Office of Scientific and Technical Information

PO Box 62

Oak Ridge, TN 37831

Prices available from (615) 576-8401, FTS 626-8401

Available to the public from

National Technical Information Service

US Department of Commerce

5285 Port Royal Rd

Springfield, VA 22161

NTIS price codes

Printed copy: A06

Microfiche copy: A01 
SAND93-7026 UC-236

Unlimited Release

Printed January 1994

\section{A Compendium of Solar Dish/Stirling Technology}

William B. Stine, Ph.D.

Professor, Mechanical Engineering

California State Polytechnic University

Pomona, CA 91768

Richard B. Diver, Ph.D.

Solar Thermal Technology Department

Sandia National Laboratories

Albuquerque, NM 87185-0703

ABSTRACT

This technology compendium, which is international in scope, presents the results of a survey on the technology status, system specifications, performance, and operation of parabolic dish solar collectors that use Stiring engines to generate electrical power. Technical information on the engines used or to be used in dish/Stirling systems is also presented. This study uses consistent terminology to document the design characteristics of dish concentrators, receivers, and Stirling engines for electric generating applications, thereby enabling comparison of dish/Stirling technologies at both a system and component level. Development status and operating experience for each system and an overview of dish/Stirling technology are also presented.

Prepared by

Sandia National Laboratories

Albuquerque, New Mexico 87185 and Livermore, California 94550

for the United States Department of Energy

under Contract No. 67-3678 


\section{Acknowledgments}

This compendium required the efforts of many people. The authors are especially grateful for the editorial support of Dan Scott of Tech Reps, Inc. The handsome graphics and presentations in this compendium are to a large extent the result of Dan's talents and support by staff of the Tech Reps Illustration Department.

We would also like to acknowledge the contributions of the dish/Stirling community. We are indebted to the time, effort, and patience of many people.

We would like to dedicate the compendium to the dish/Stirling enthusiast - past, present, and future - by whose efforts this important technology will ultimately be commercialized. 


\section{Contents}

Glossary

Introduction 1

Dish/Stirling's Contribution to Solar Thermal Electric Technology ...................................................... 1

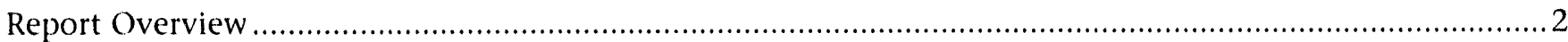

\section{PART I: TECHNOLOGY OVERVIEW}

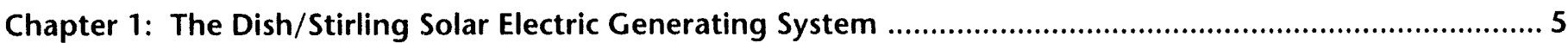

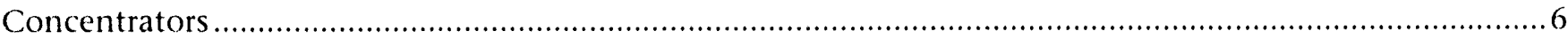

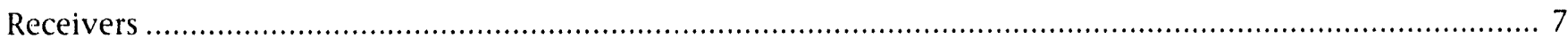

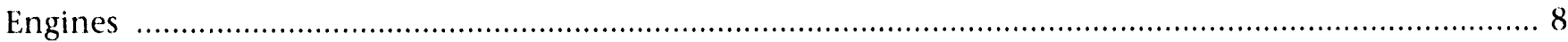

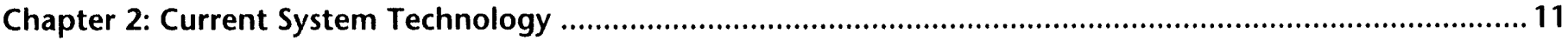

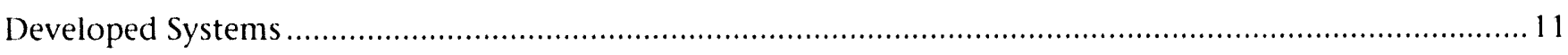

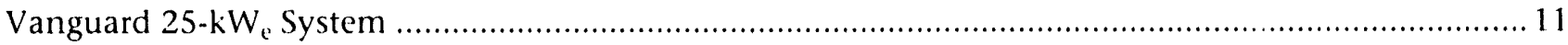

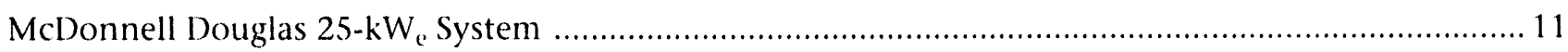

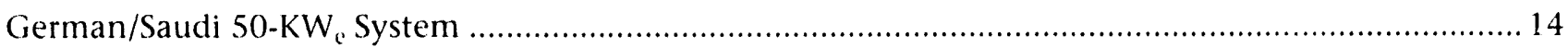

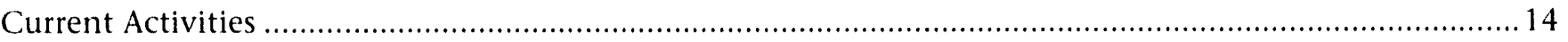

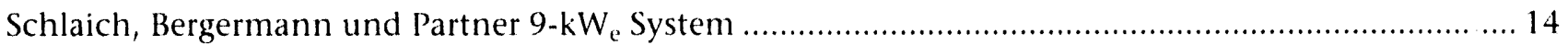

Cummins Power Generation 7.5-kW. System ....................................................................... 16

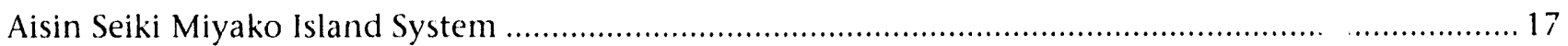

Stirling Thermal Motors $25-\mathrm{kW}_{\mathrm{t}}$ Solar Power Conversion System .................................................. 17

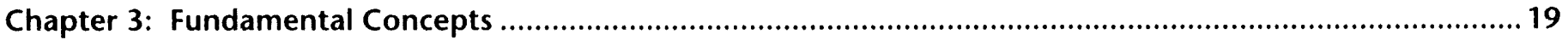

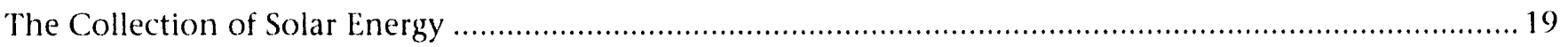

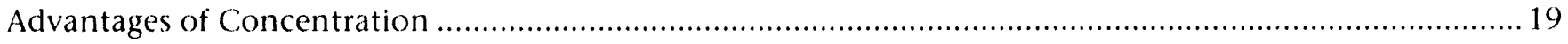

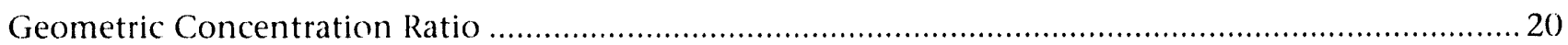

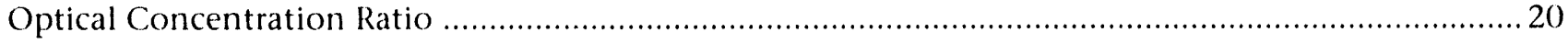

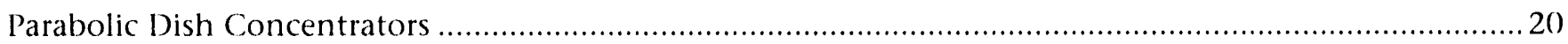

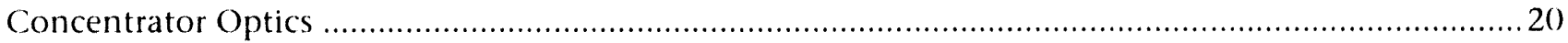

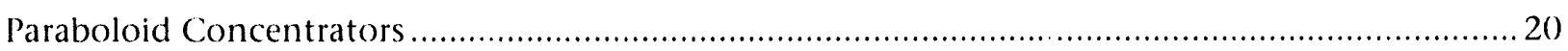

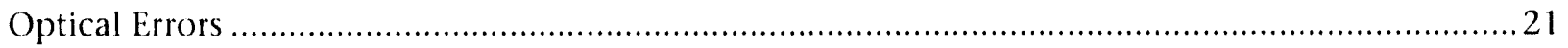

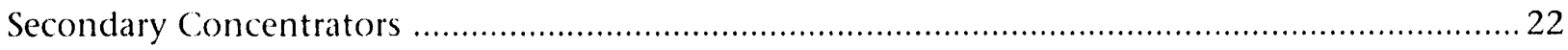

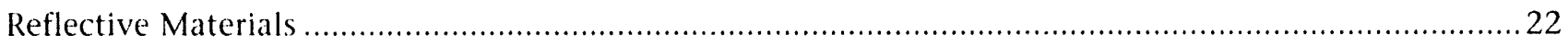

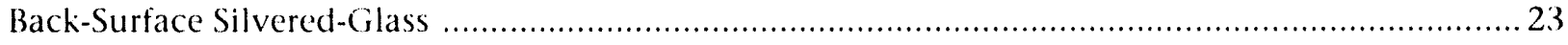

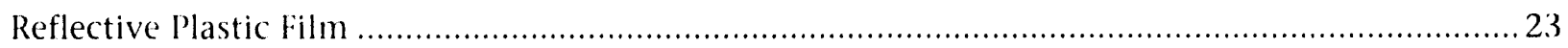

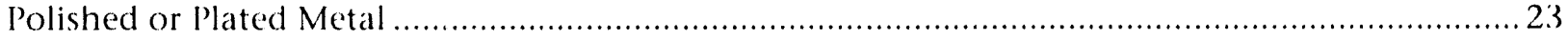




\section{Chapter 3: Fundamental Concepts (continued)}

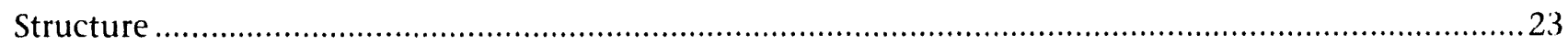

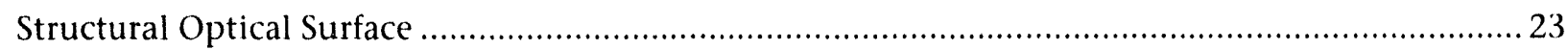

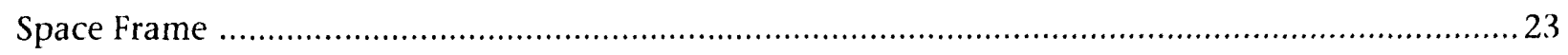

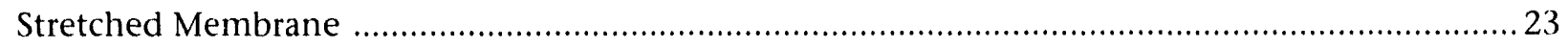

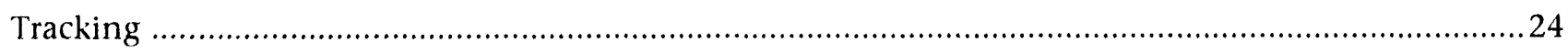

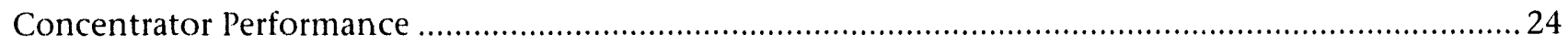

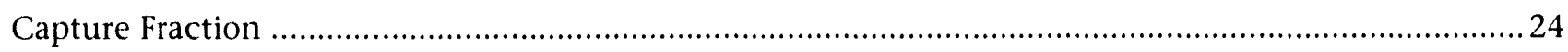

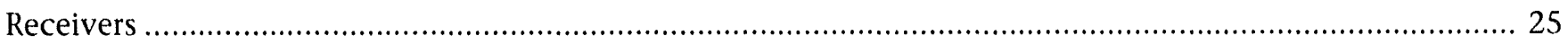

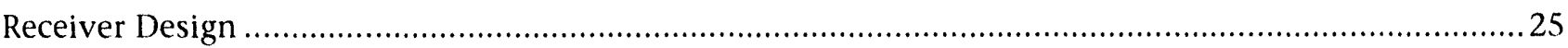

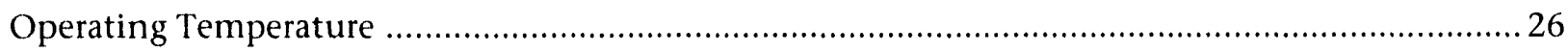

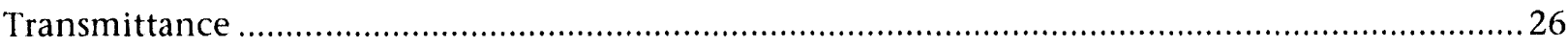

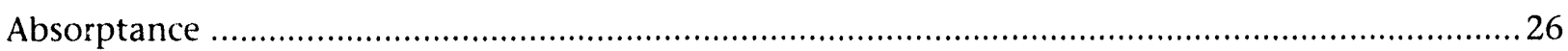

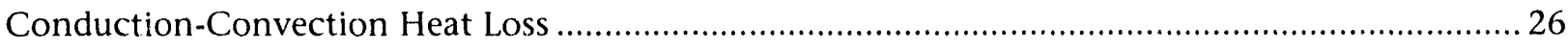

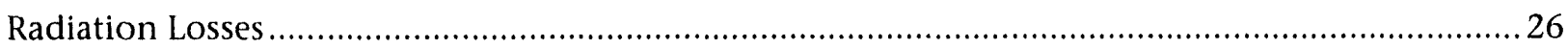

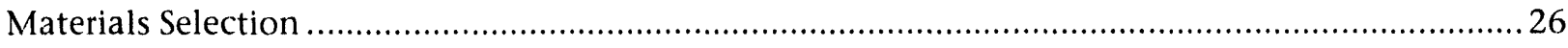

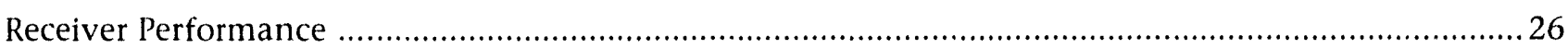

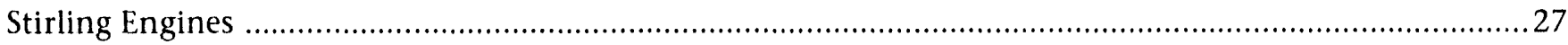

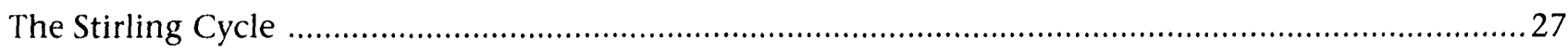

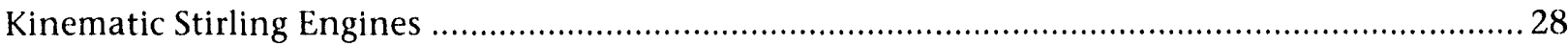

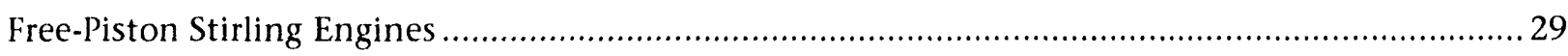

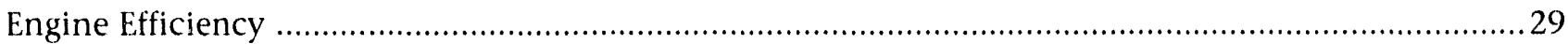

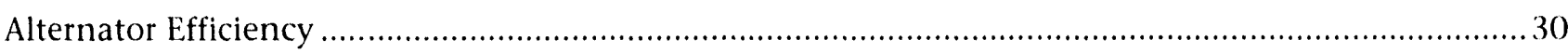

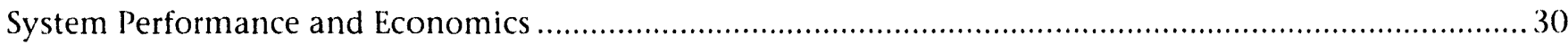

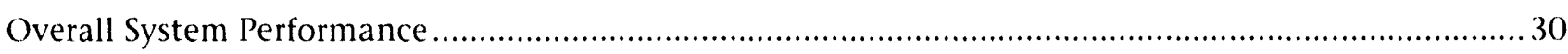

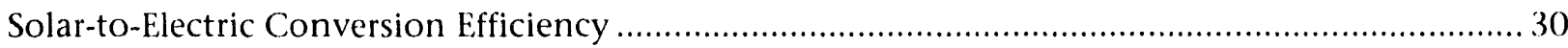

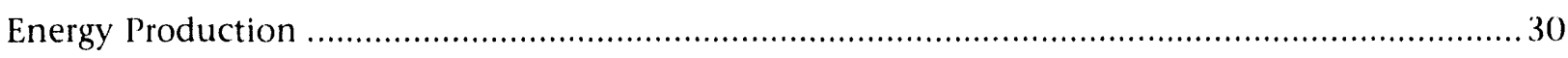

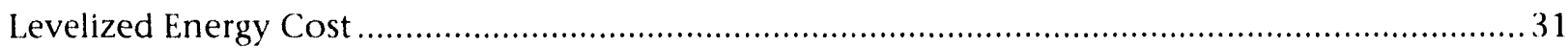

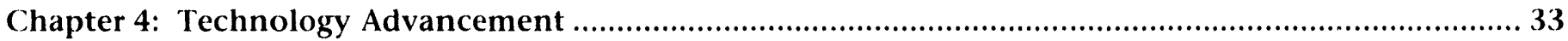

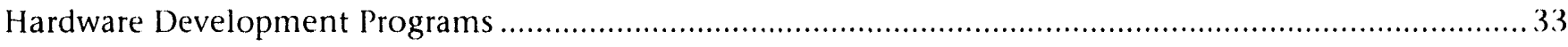

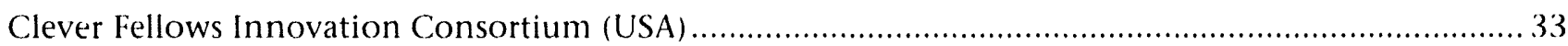

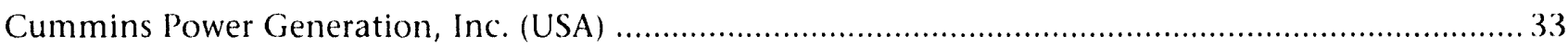

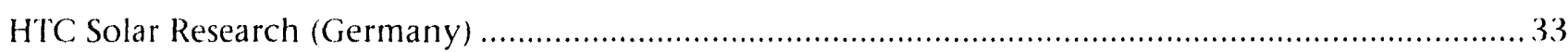

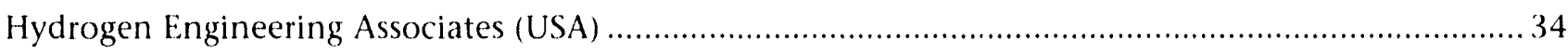

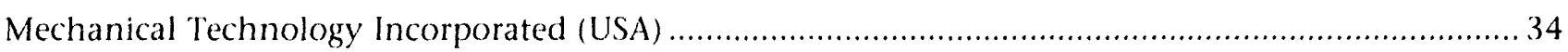

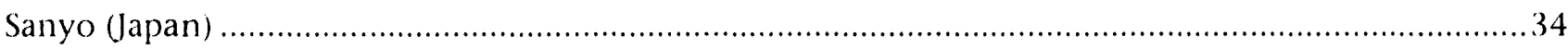

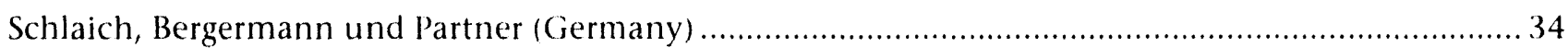

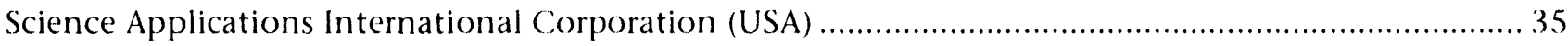

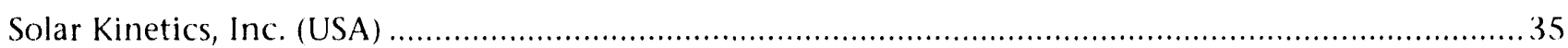

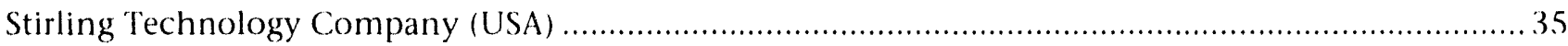




\section{Chapter 4: Technology Advancement (continued)}

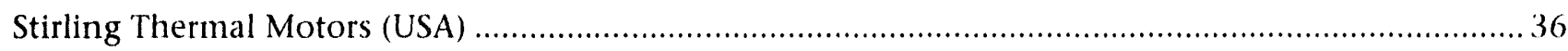

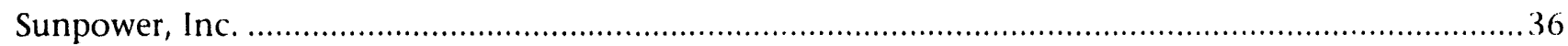

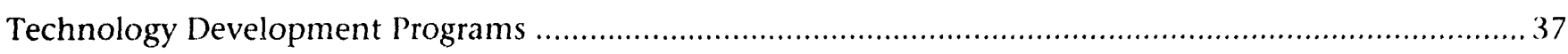

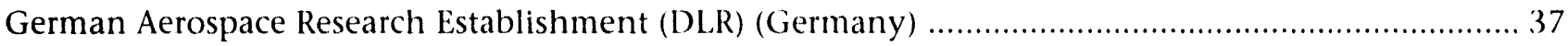

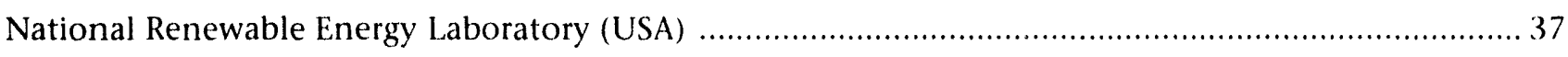

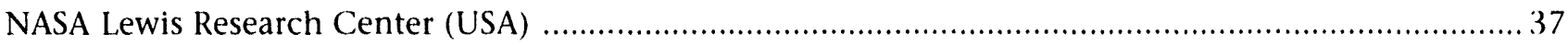

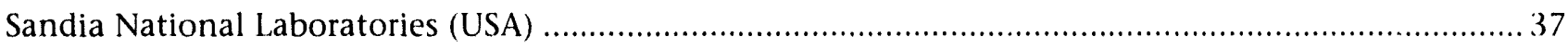

Solar and Hydrogen Energy Research Center (ZSW) (Germany) .................................................. 38

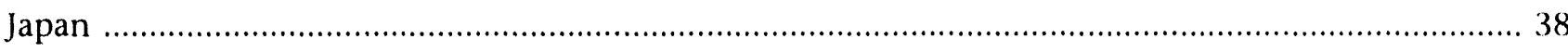

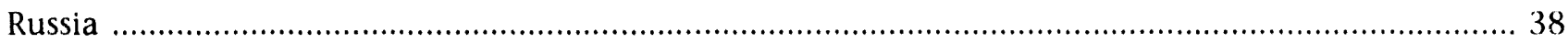

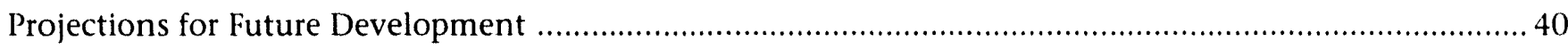

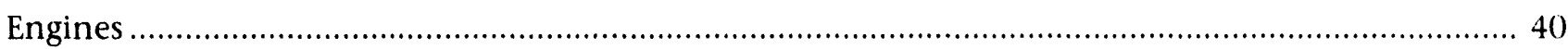

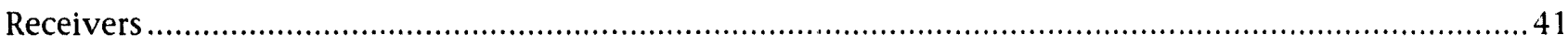

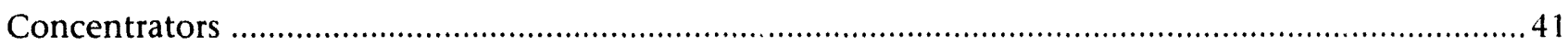

\section{PART II: COMPONENT DESCRIPTION}

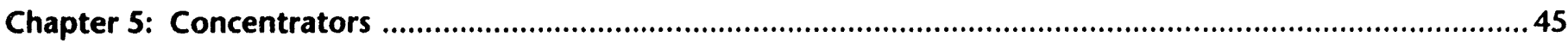

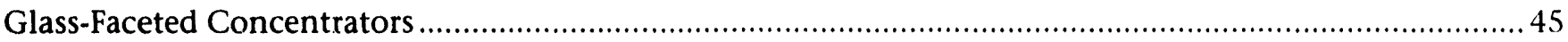

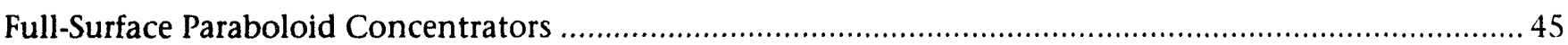

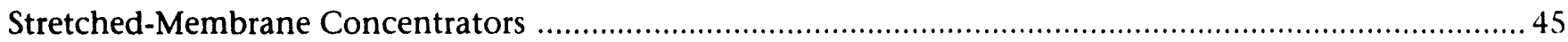

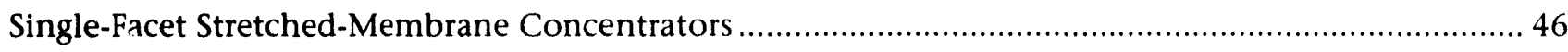

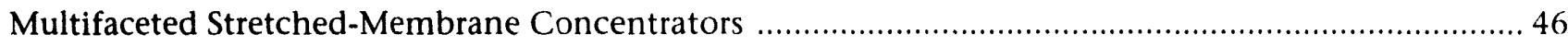

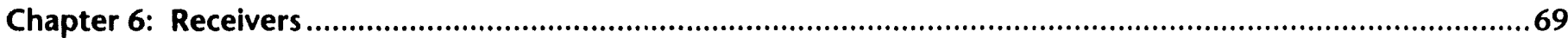

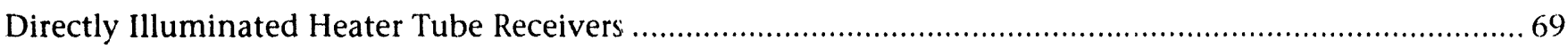

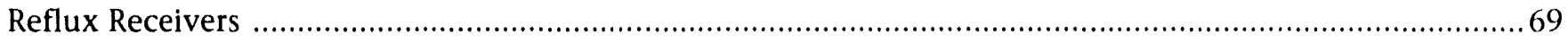

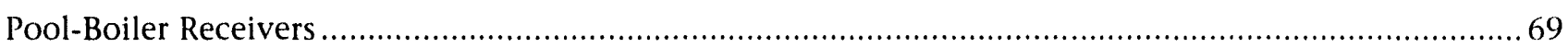

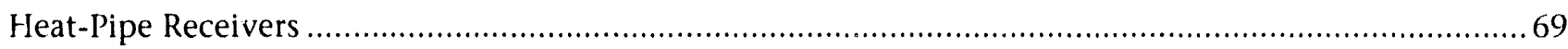

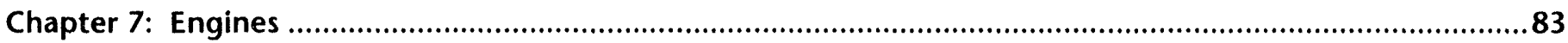

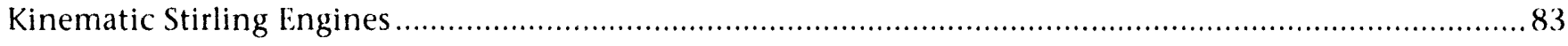

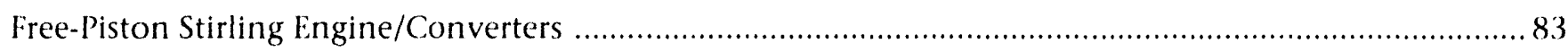

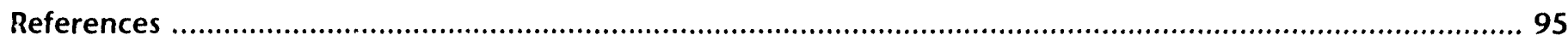

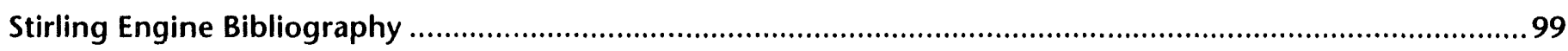

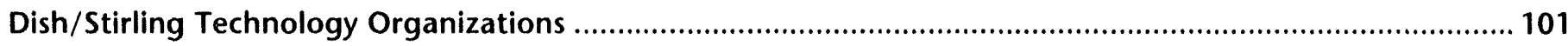




\section{Figures}

1-1. Artist's conception of a dish/Stirling system showing its three basic components: concentrator, receiver, and engine/alternator.

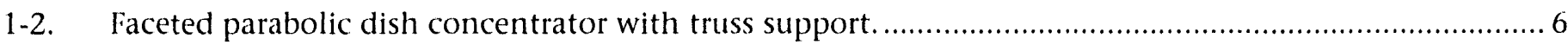

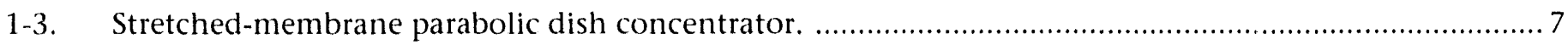

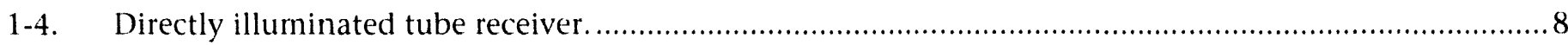

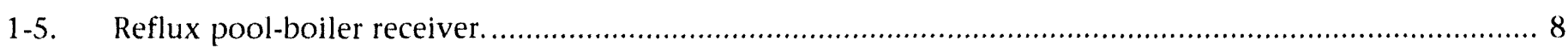

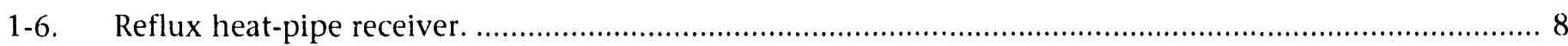

1-7. Kinematic Stirling engine with a directly illuminated tube receiver. ................................................... 9

1-8. Free-piston Stirling engine with linear alternator and liquid-metal heat-pipe receiver. ........................ 10

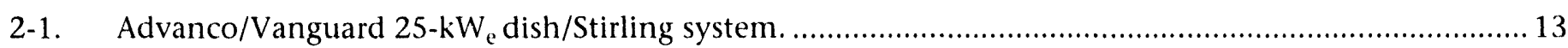

2-2. McDonnell Douglas/Southern California Edison 25-kW dish/Stirling system.................................. 13

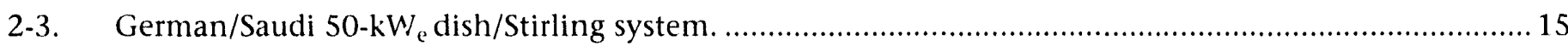

2-4. Schlaich, Bergermann und Partner 9-kW $\mathrm{e}_{\mathrm{e}}$ dish/Stirling system. ..................................................... 15

2-5. Cummins Power Generation 5-kW e prototype free-piston engine dish/Stirling system. ....................... 16

2-6. Stirling Thermal Motors $25-\mathrm{kW}_{\mathrm{e}}$ solar power conversion system package under test at Sandia

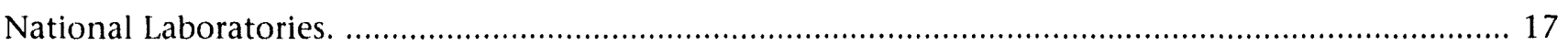

3-1. The paraboloid is a surface generated by rotating a parabola around the $z$-axis................................ 21

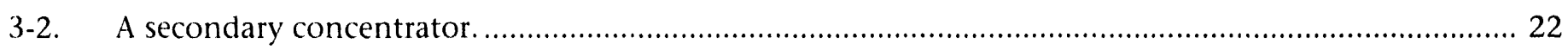

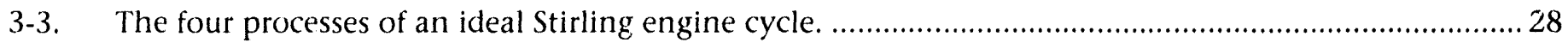

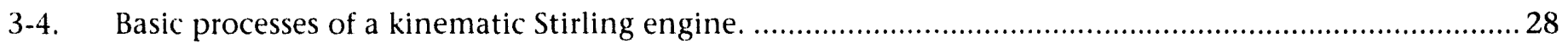

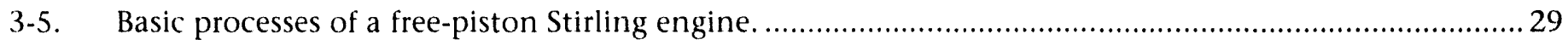

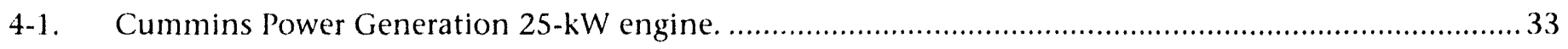

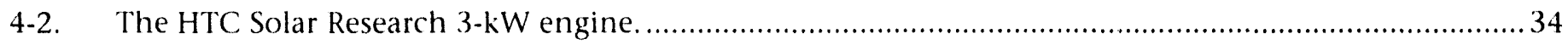

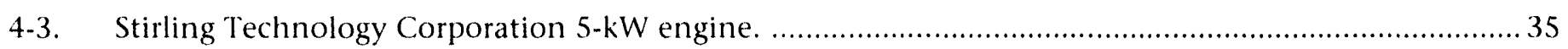

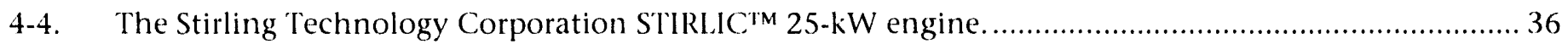

4-5. Stirling Technology hybrid receiver in a test cell using radiant lamp solar simulation. ........................ 36

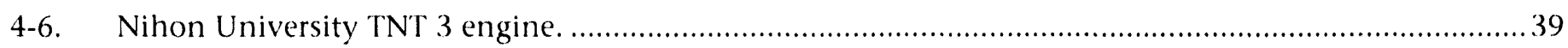

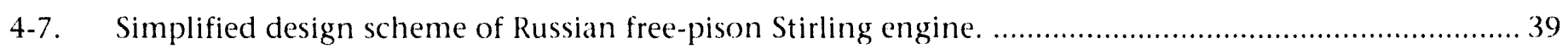

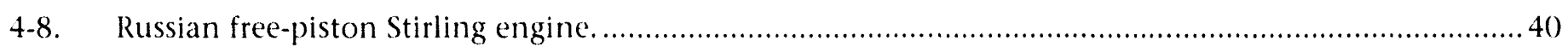

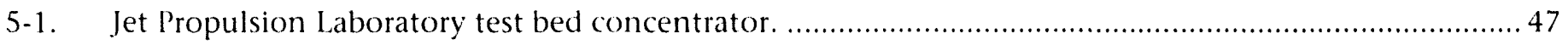

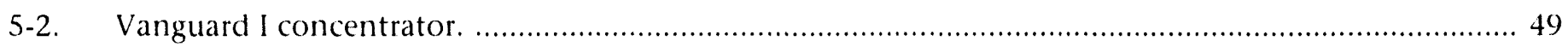

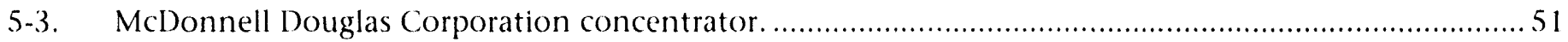

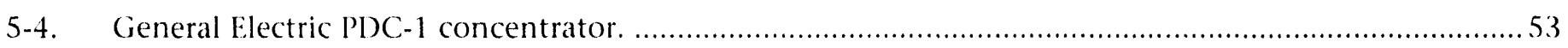

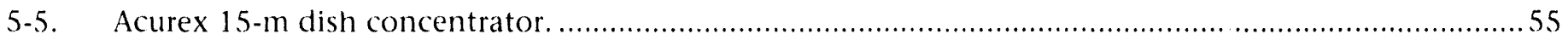

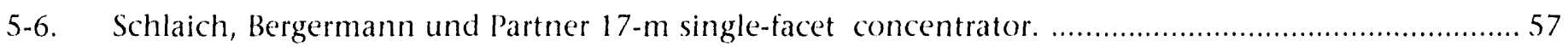

5-7. Schlaich, Bergermann und Partner 7.5-m single-facet concentrator. ............................................59

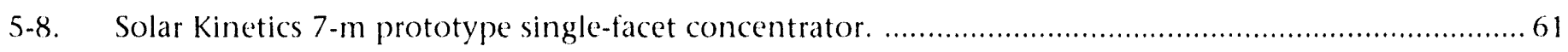

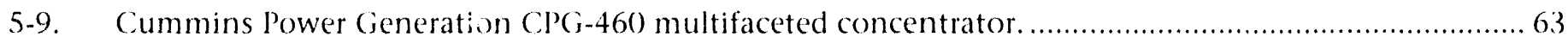




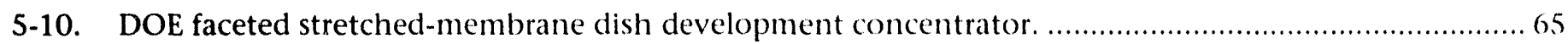

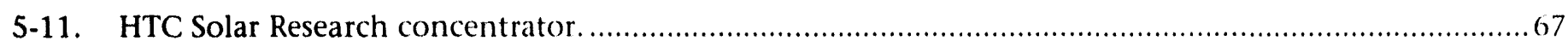

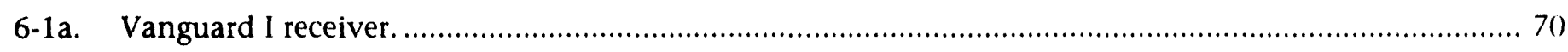

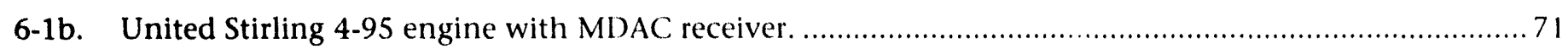

6-2. United Stirling 4-275 receiver (German/Saudi project). ............................................................... 72

6-3. Schlaich, Bergerman und Partner V-160 receiver installed in system (left photo) and apart from

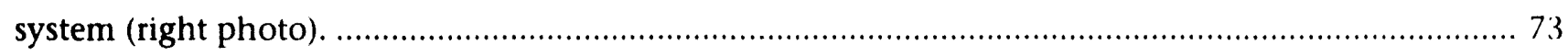

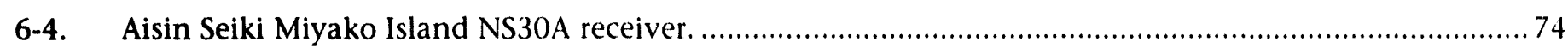

6-5. Stirling Thermal Motors 4-120 (STM4-120) direct illumination receiver. ............................................ 75

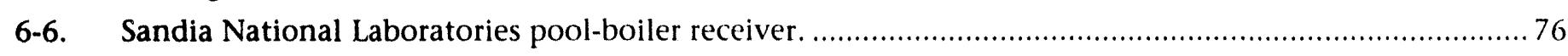

6-7. Sandia National Laboratories second-generation pool-boiler receiver .............................................. 77

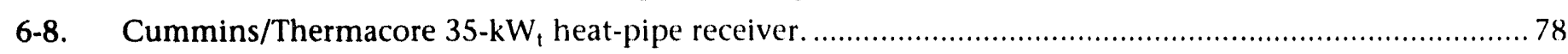

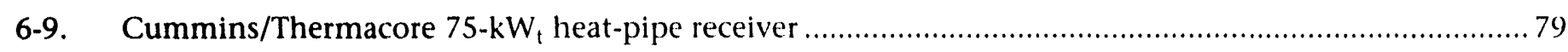

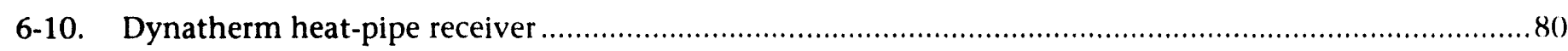

6-11. German Aerospace Research Establishment (DLR) V-160 heat-pipe receiver (Mod 1).........................81

6-12. German Aerospace Research Establishment (DLR) V-160 heat-pipe receiver (Mod 2)......................... 82

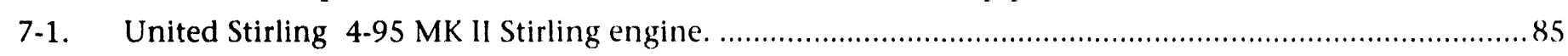

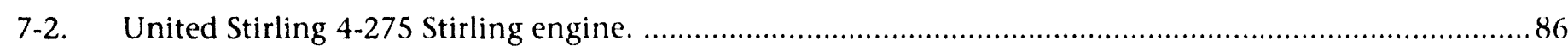

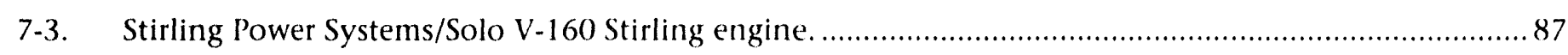

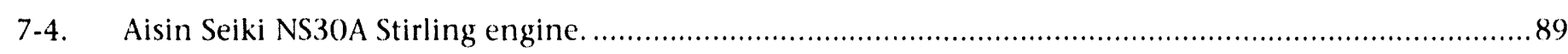

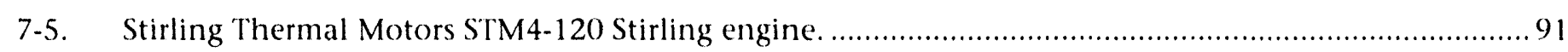

7-6. Cummins Power Generation (CPG) 6-kW prototype free-piston Stirling engine/converter (similar in design to the $9-\mathrm{kW}$ production version). 


\section{Tables}

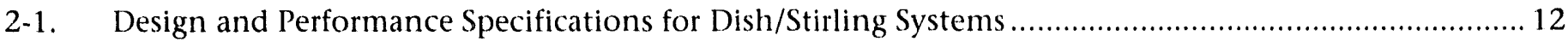

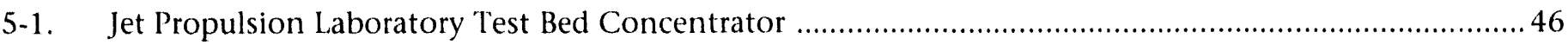

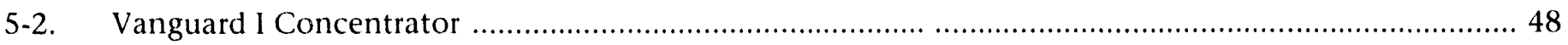

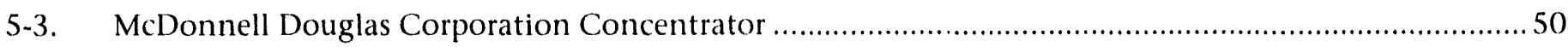

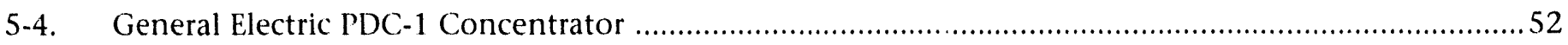

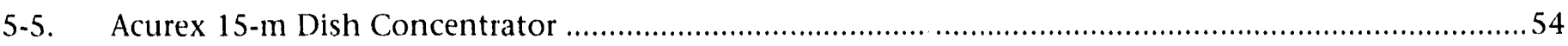

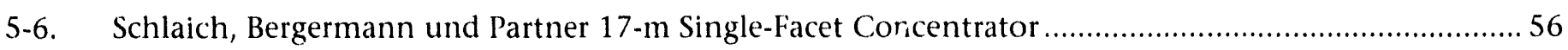

5-7. Schlaich, Bergermann und Partner 7.5-m Single-Facet Concentrator ................................................ 58

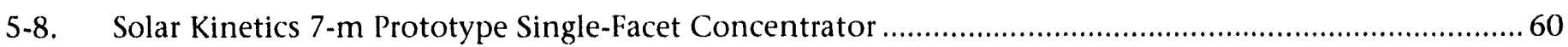

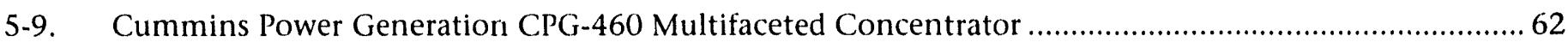

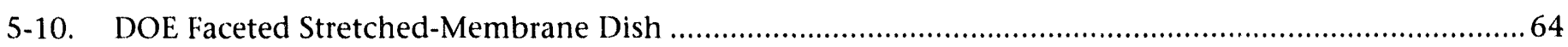

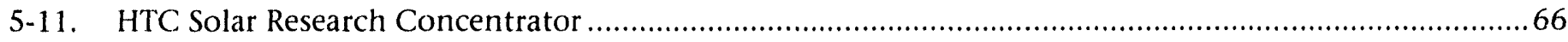

6-1. United Stirling 4-95 Receiver (Vanguard and MDAC) …............................................................... 71

6-2. United Stirling 4-275 Receiver (German/Saudi Project) ................................................................ 72

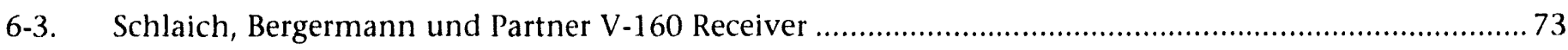

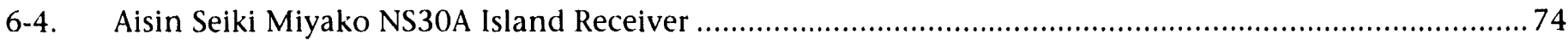

6-5. Stirling Thermal Motors 4-120 (STM4-120) Direct Illumination Receiver ............................................ 75

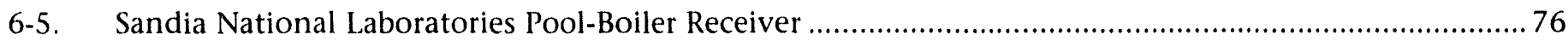

6-6. Sandia National Laboratories Second-Generation Pool-Boiler Receiver ............................................... 77

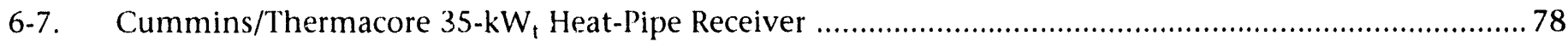

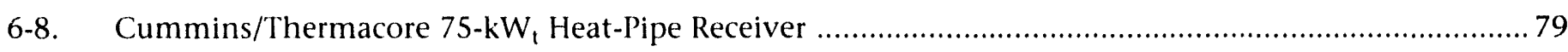

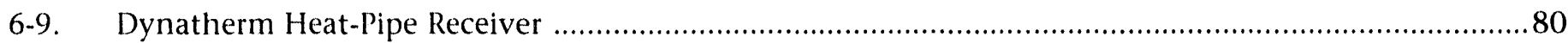

6-10. German Aerospace Research Establishment (DLR) V-160 Heat-Pipe Receiver (Mod 1) ..........................81

6-11. German Aerospace Research Establishment (DLR) V-160 Heat-Pipe Receiver (Mod 2) ......................... 82

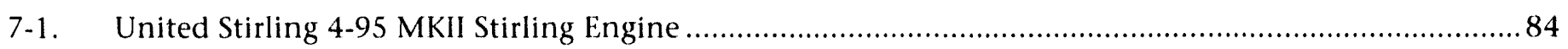

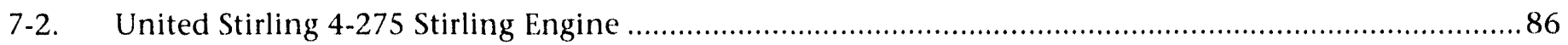

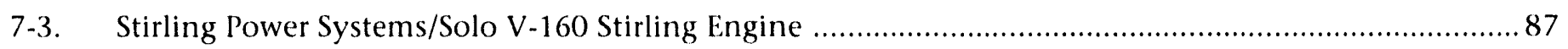

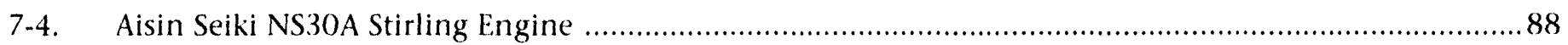

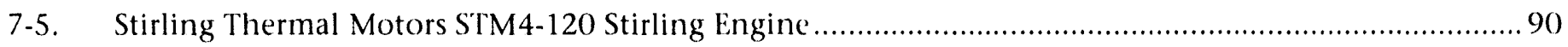

7-6. Cummins Power Generation 9-kW Free-Piston Stirling Engine/Converter .......................................... 92 


\section{Glossa!y}

Abbreviations:

ASCS advanced Stirling conversion systems

ASE Automotive Stirling Engine

CPG Cummins Power Generation, Inc.

DLR Deutsche Forschungsanstalt für Luft und Raumfahrt, the German Aerospace Research Establishment

DOE --.---a---- United States Department of Energy

FPSE ---.---.------- free-piston Stirling engine

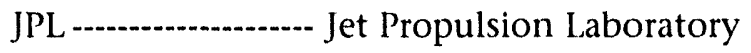

LANSIR --.--.-.-.-.-- large aperture near specular imaging reflectometer

LEC levelized energy cost

MDAC McDonnell Douglas Corporation

MTI Mechanical Technology Incorporated

NASA National Aeronautics and Space Administration

NASA LeRC NASA Lewis Research Center

NEIDO New Energy and Industrial Development Organization

NREL National Renewable Energy Laboratory

PCS power conversion system

PCU power conversion unit

SAIC Science Applications International Corporation

SBP Schlaich, Bergermann und Partner

SCE Southern California Edison Co.

SHOT Scanning Hartmann Optical Test

SKI Solar Kinetics Incorporated

SNL Sandia National Laboratories

SPDE space power demonstrator engine

SPRE space power research engines

SPS Stirling Power Systems

STC Stirling Technology Corporation

STM Stirling Thermal Motors, Inc.

TBC test bed concentrator

USAB United Stirling of Sweden $\mathrm{AB}$

ZSW Zentrum für Sonnenenergie-und Wasserstoff, Germany's Center for Solar Energy and Hydrogen Research. 
Symbols/Units of Measure:

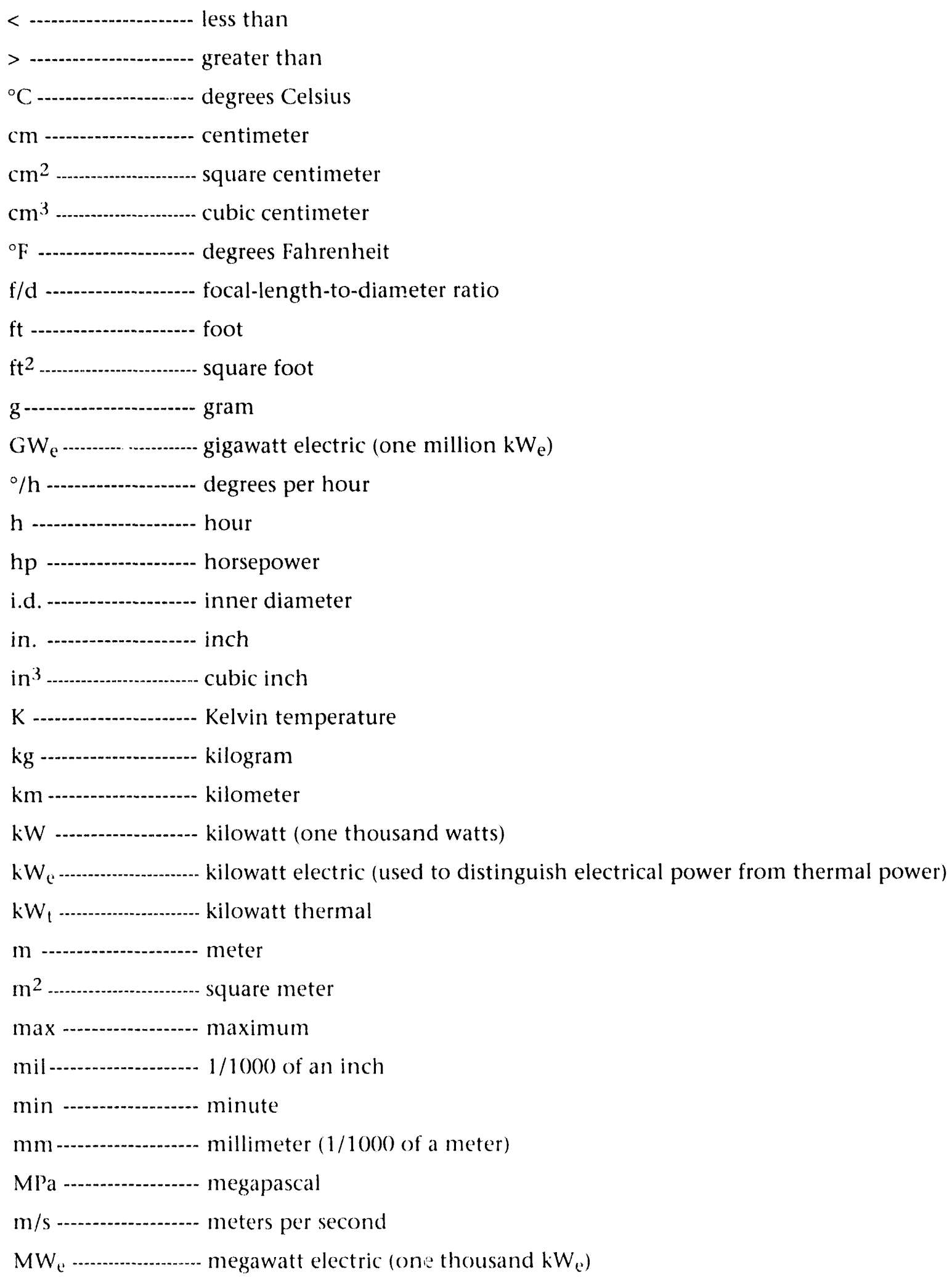




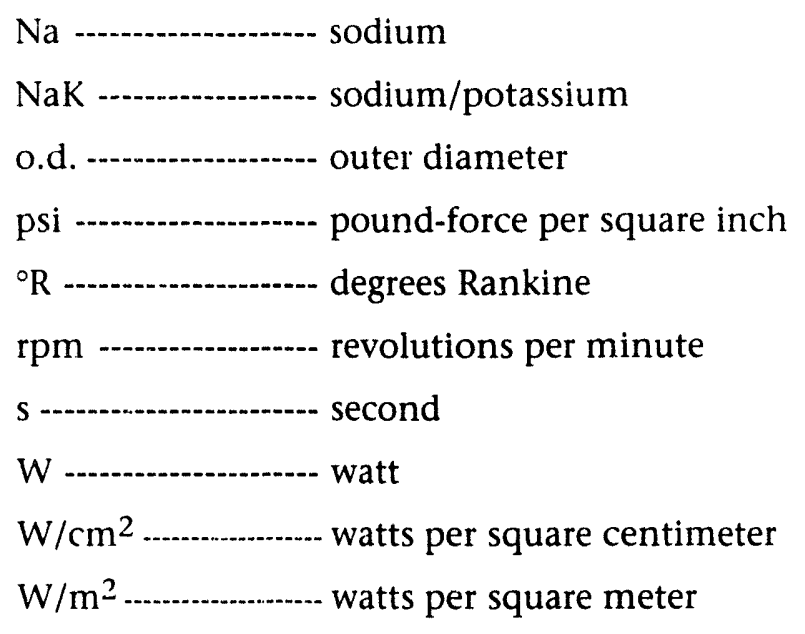


Notes 


\section{Introduction}

\section{Dish/Stirling's Contribution to Solar Thermal Electric Technology}

Considerable worldwide electrical generation capacity will be added before the end of this century and during the first decade of the twenty-first century (US DOE:, 1991 and DLR et al., 1992). Many of the new and replacement power plants providing this capacity are expected to be located in regions with large amounts of sunshine. Furthermore, much of this capacity growth will occur in areas where power grid infrastructure for distribution of electricity from large central power plants does not exist. Environmental concerns about pollution and carbon dioxide generation are becoming driving forces in the selection of the technologies suitable for this buildup. Therefore, a significant fraction of this new and replacement electric power generation capacity can and should be produced using solar electric technologies.

Studies show that solar thermal electric technology can play a significant role in meeting the demand for clean electric power:

- The results of a German government/industry study of growth in demand for new electricity and plant replacement in the Mediterranean area indicate that, even using "cautious assumptions," it is technically and economically possible to integrate $3.5 \mathrm{GW}_{\mathrm{f}}$ of solar thermal power plant output into these national supply grids by the year 2005 and 23 GW $_{\mathrm{c}}$ by the year 2025 (1)LR et al., 1992).

- A United States Department of Energy (I)()E) study predicts that the U.S. will require approximately $100 \mathrm{GW}_{\mathrm{c}}$ of new electric power generating capacity before the end of this century and an adrlitional 90) (jW $W_{0}$ in the first decade of the next centu. (U.S. DOE, 1991). I)( E) projects total installation of over $8\left(\mathrm{SW}_{\mathrm{a}}\right.$ worldwide of solar electric technologies by the year 2000() (U.S. DO)E, 1992), and believes that much of this new capacity can be created using solar thermal electric technology (U.S. 1)()L, 199.3).
Dish/Stirling systems, the subject of this report, form a solar thermal electric technology that can play an important role in meeting these anticipated power generation demands.

Solar thermal electric power generating systems incorporate three different design architectures:

(1) line-focus systems that concentrate sunlight onto tubes running along the line of focus of a parabolicshaped reflective trough

(2) point-focus central reciver (power tower) systems that use large fields of sun-tracking reflectors (heliostats) to concentrate sunlight on a receiver placed on top of a tower

(3) point-focus dish systems that use parabolic dishes to reflect light into a receiver at the dish's focus.

Exceptional performance has been demonstrated by dish/Stirling systems, which belong to the third design architecture described above. In 1984, the Advanco Vanguard-I system, using a $25-\mathrm{kW}_{\mathrm{c}}$ Stirling engine, converted sunlight to electrical energy with $29.4 \%$ efficiency (net). 'This system conversion efficiency still stands as the record for all solar-to-electric systems.

All three of the above solar thermal electric technologies have proven themselves as practical answers to concerns about instabilities in the supply of traditional power plant fuels and environmental degradation. Today line-focus concentrators predominate in commercial solar power generation and are being considered for applications in developing countries where mature technologies are required (U.S. 1)()L, 1993). However, pointfocus concentrator systems, such as power towers and dish/Stirling systems, can achieve higher conversion efficiencies than can line-focus concentrators because they operate at higher temperatures.

While central receiver systems are projected to reach sizes of 100 to $200 \mathrm{MW}_{\mathrm{c}}$, dish/Stirling systems are smaller, typically about $5 \mathrm{to} 25 \mathrm{~kW}$.. At this size, one or 
a few systems are ideal for stand-alone or other decentralized applications, such as replacement of diesel generators. Dish/Stirling plants with outputs from 1 to $20 \mathrm{MW}_{\mathrm{e}}$ are expected to meet moderate-scale gridconnected applications (Klaiss et al., 1991).

Small clusters of dish/Stirling systems could be used in place of utility line extensions, and dish/Stirling systems grouped together could satisfy load-center/ demand-side power options $\left(<10 \mathrm{MW}_{\mathrm{c}}\right)$. In addition, they can be designed to run on fossil fuels for operation when there is no sunshine. Dish/Stirling systems have been identified as a technology that has the potential of meeting cost and reliability requirements for widespread sales of solar electric power generating systems (Stine, 1987).

\section{Report Overview}

This report surveys the emerging dish/Stirling technology. It documents - using consistent terminology the design characteristics of dish concentrators, receivers, and Stirling engines applicable to solar electric power generation. Development status and operating experience for each system and an overview of dish/ Stirling technology are also presented. This report enables comparisons of concentrator, receiver, and engine technologies. Specifications and performance data are presented on systems and on components that are in use or that could be used in dish/Stirling systems.

This report is organized into two parts:

- The first part (Chapters 1 through 4 ) provides an overview of dish/Stirling technology - the dish/ Stirling components (concentrator, receiver, and engine/alternator), current technology, basic theory, and technology development.

- The second part (Chapters 5 through 7) provides a detailed survey of the existing dish/Stirling concentrators, receivers, and engine/alternators.

Some of the performance and design parameters found in this report have been gathered from a wide range of sources. Every attempt has been made to ensure the reliability and accuracy of this information. However, many of the performance parameter values - for example, those dealing with heat flux and temperature are difficult to define with single values and therefore should be considered representative. 


\section{Part I: Technology Overview}

- The Dish/Stirling Solar Electric

Generating System

- Current System Technology

- Fundamental Concepts

- Technology Advancement 
$\frac{2}{0}$ 


\section{Chapter 1: The Dish/Stirling Solar Electric Generating System}

A solar dish/Stirling electric power generation system consists of a concave parabolic solar concentrator (or dish), a cavity receiver, and a Stirling heat engine with an electric generator or alternator (Figure 1-1). The roles of these components are as follows:

- A sun-tracking system rotates the solar concentrator about two axes to keep its optical axis pointed directly toward the sun. The concentrator's shape allows the concentrator to reflect the sun's rays into a cavity receiver located at the concentrator's focus.

- The cavity receiver absorbs the concentrated solar energy. Thermal energy then heats the working gas in the Stirling engine.
- The Stirling engine consists of a sealed system filled with a working gas (typically hydrogen or helium) that is alternately heated and cooled. It is called a working gas because it is continually recycled inside the engine and is not consumed. The engine works by compressing the working gas when it is cool, and expanding it when it is hot. More power is produced by expanding the hot gas than is required to compress the cool gas. This action produces a rising and falling pressure on the engine's piston, the motion of which is converted into mechanical power. Some Stirling engines rely on a separate electric generator or alternator to convert the mechanical power into electricity, while others integrate the alternator into the engine. The resulting engine/alternator with its

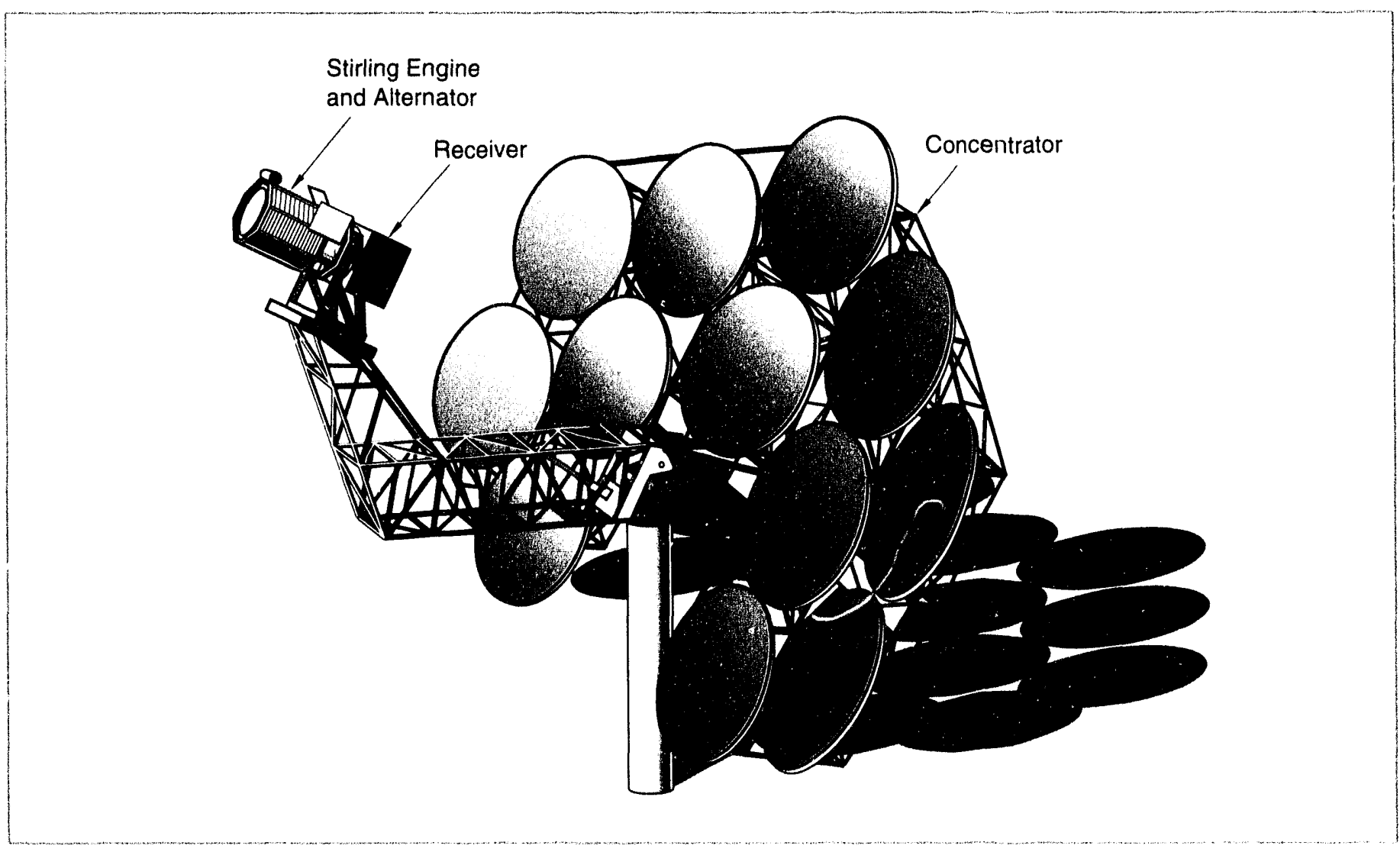

Figure 1-1. Artist's conception of a dish/Stirling system showing its three basic components: concentrator, receiver, and engine/alternator. 


\section{Chapter 1}

ancillary equipment is often called a converter or a power conversion unit.

An introductory discussion of these three components follows. Chapter 3 explains basic theory of operation of the three dish/Stirling components.

\section{Concentrators}

Solar concentrators used for dish/Stirling applications are generally point-focus parabolic dish concentrators. A reflective surface - metallized glass or plastic reflects incident sunlight to a small region called the focus. Because they concentrate solar energy in two dimensions, these collectors track the sun's path along two axes.

The size of the solar collector (i.e., concentrator) for dish/Stirling systems is determined by the power output desired at maximum insolation levels (nominally $1,000 \mathrm{~W} / \mathrm{m}^{2}$ ) and the collector and power-conversion efficiencies. With current technologies, a $5-k W_{c}$ dish/Stirling system requires a dish of approximately 5.5 meters ( 18 feet) in diameter, and a $25-k_{\mathrm{e}}$ system requires a dish approximately 10 meters ( 33 feet) in diameter.

Concentrators use reflective surfaces of aluminum or silver, deposited either on the front or back surface of glass or plastic. Thin-glass mirrors with a silvered back surface have been used in the past. Some current designs use thin polymer films with aluminum or silver deposited on either the front or back surface of the film.

The ideal shape for the reflecting surface of a solar concentrator is a paraboloid. (See Chapter 3 for a discussion of the paraboloid.) This shape is ideal because a reflecting paraboloid concentrates all solar radiation coming directly from the sun to a very small region at the concentrator's focal point. In practice, however, it is often easier to fabricate multiple spherically shaped surfaces. Spherically shaped surfaces also concentrate solar radiation. As Chapter 3 explains, the focusing capability of spherically shaped mirrors approaches that of a paraboloid-shaped mirror when the region of concentration is many mirror diameters away from the reflecting surface (i.e., the mirror is only slightly curved).

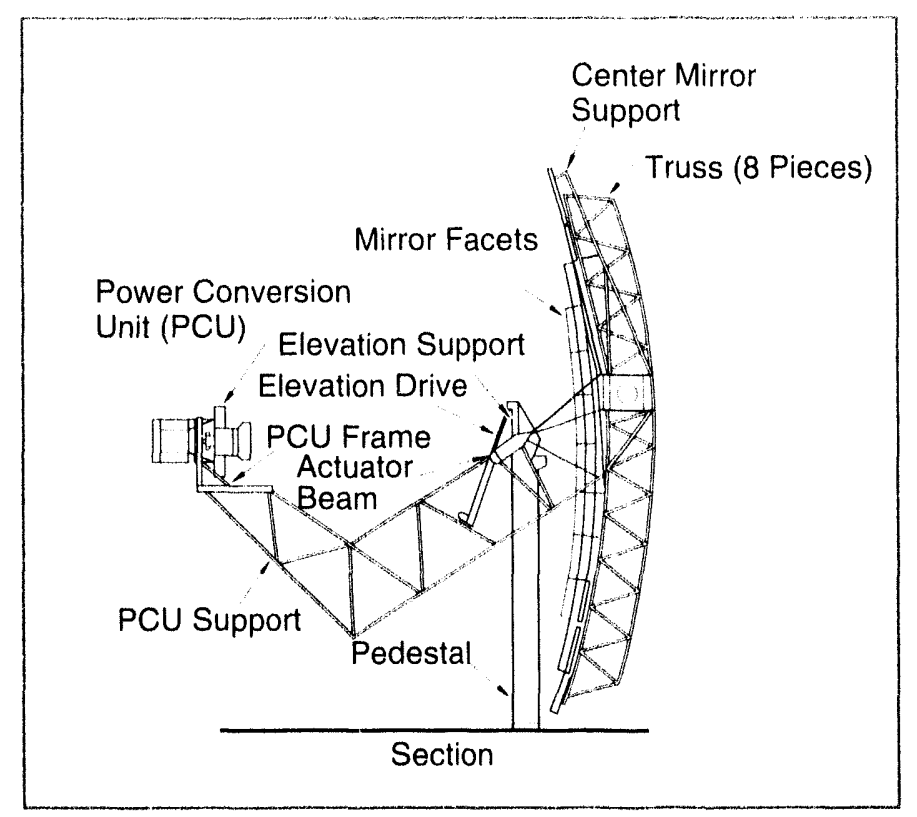

Figure 1-2. Faceted parabolic dish concentrator with truss support.

Some concentrators for dish/Stirling systems used multiple spherically shaped mirror facets supported by a truss structure (Figure 1-2), with each facet individually aimed so as to approximate a paraboloid. This approach to concentrator design makes very high focusing accuracy possible.

A recent innovation in solar concentrator design is the use of stretched membranes. Here, a thin reflective membrane is stretched across a rim (or hoop), with a second membrane closing off the space behind. A partial vacuum is drawn in this space, bringing the reflective membrane into an approximately spherical shape. If many facets are used (as shown in ligure 1-1), their focal region will be a number of facet diameters away, and the spherical shape of the facets provides adequate solar concentration for dish/Stirling applications.

If only one or a few stretched membranes are used (Figure 1-3), the surface shape should approximate a paraboloid. This approximation can be achieved by initially forming the membrane into a near paraboloid, and using the pressure difference between front and back to support the surface and maintain its shape.

In addition to having adequate reflective materials and shape, effective dish/Stirling concentrators focus the 


\section{The Dish/Stirling Solar Electric Generating System}

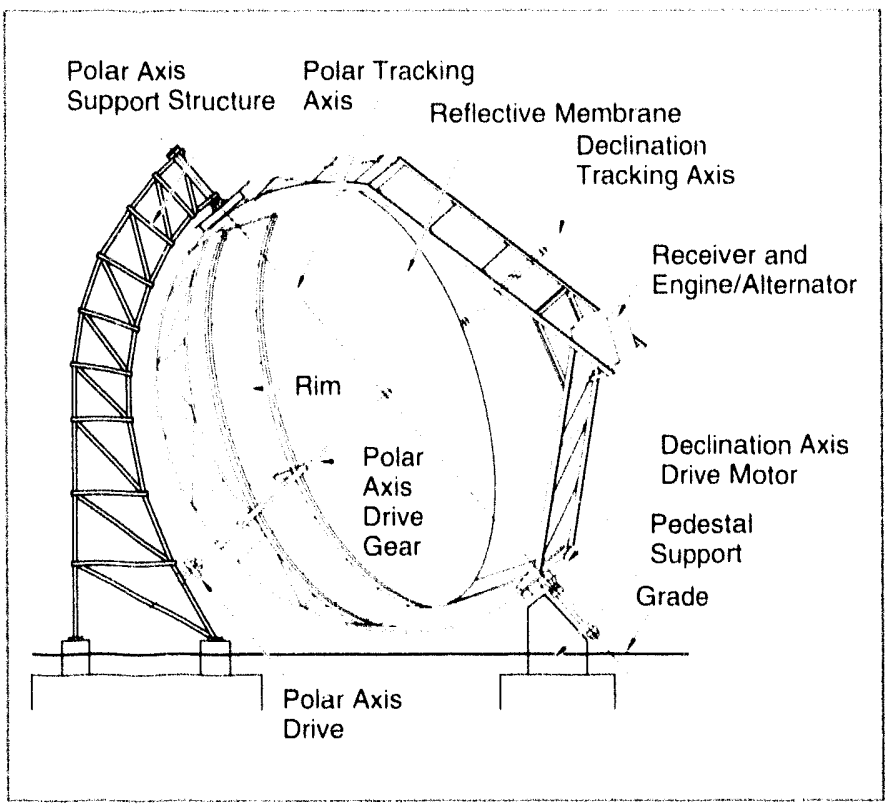

Figure 1-3. Si-atched-membrane parabolic dish concentrator.

maximum available light by tracking the sun's path. In order to track the sun, concentrators must be capable of moving about two axes. Cenerally, there are two ways of implementing this, both having advantages:

- The first is azimuth-elevation tracking, in which the dish rotates in a plane parallel to the earth (azimuth) and in another plane perpendicular to it (elevation). This gives the collector up/down and left/right rotations. Rotational rates about both axes vary throughout the day but are predictable. The faceted concentrator in ligure 1-2 uses an azimuth-clevation tracking mechanism.

- In the polar tracking method, the collector rotates about an axis parallel to the earth's axis of rotation. The collector rotates at a constant rate of 1.5 degrees per hour, the same rotation rate as the earth's. The other axis of rotation, the declination axis, is perpendicular to the polar axis. Movement about this axis occurs slowly and varies by $\pm 2.31 / 2$ degrees over a year (a maximum rate of 0.016 degrees per hour). The stretched-membrane concentrator in ligure 1-3 uses a polar tracking mechanism.

See Stine and Harrigan (1985) and Adkins (1987) for discussion of tracking methods.

\section{Receivers}

The receiver has two functions: (1) absorb as much of the solar badiation reflected by the concentrator as possible and (2) transfer this energy as heat to the engine's working gas.

Although a perfect reflecting paraboloid reflects paralled rays to a point, the sun's rays are not quite parallel because the sun is not a point source. Also, anly real concentrator is not perfectly shaped. Therefore, concentrated radiation at the focus is distributed over a small region - with the highest concentration of flux in the center, decreasing exponentially towards the edge.

Receivers for dish/Stirling systems are cavity receivers with a small opening (aperture) through which concentrated sunlight enters. The absorber is placed behind the aperture to reduce the intensity of concentrated solar flux. The insulated cavity between the aperture and absorber reduces the amount of heat lost. The receiver aperture is optimized to be just large enough to admit most of the concentrated sunlight but small enough to limit radiation and convection loss (Stine and Harrigan, 1985).

In a receiver, two methods are used to transfer absorbed solar radiation to the working gas of a Stirling engine. In the first type of receiver, the directly illuminated tube receiver, small tubes through which the engine's working gas flows are placed directly in the concentrated solar flux region of the receiver (ligure 1-4). The tubes form the absorber surface. The other type of receiver uses a liquid-metal intermediate heat-transfer fluid (liggures 1-5 and 1-6). The liquid metal is vaporized on the absorber surface and condenses on tubes carrying the engine's working gas. This second type of receiver is called a reflux receiver because the vapor condenses and flows back to be heated again.

For receiver designs in which licyuid metal is used as an intermediate heat transfer fluid, two methods of supplying liquid metal to the absorber are under development: pool boilers and heat pipes. With the first method, a pool of liquid metal is always in contact with the absorbing surface, as shown in ligure $1-5$. The second method involves a wick attached to the back of the absorber. The capillary fores in the wick draw licpuid metal over the surface of the abserber, where it vaporizes. This method is illustrated in ligure 1-6. 


\section{Chapter 1}

\section{Engines}

The Stirling engine was patented in 1816 by the Rev. Robert Stirling, a Scottish minister, and the first solar application of record was by John Ericsson, the famous British/American inventor, in 1872. Since its invention, prototype Stirling engines have been developed for automotive purposes; they have also been designed and tested for service in trucks, buses, and boats (Walker, 1973). The Stirling engine has been proposed as a propulsion engine in yachts, passenger ships, and road vehicles such as city buses (Meijer, 1992). The Stirling engine has also been developed as an underwater power unit for submarines, and the feasibility of using the Stirling engine for high-power spaceborne systems has been explored by NASA (West, 1986).

In theory, the Stirling engine is the most efficient device for converting heat into mechanical work; however, it requires high temperatures. Because concentrating solar collectors can produce the high temperatures necessary for efficient power production, the Stirling engine and the concentrating solar collector are a good match for the production of electricity from the sun.

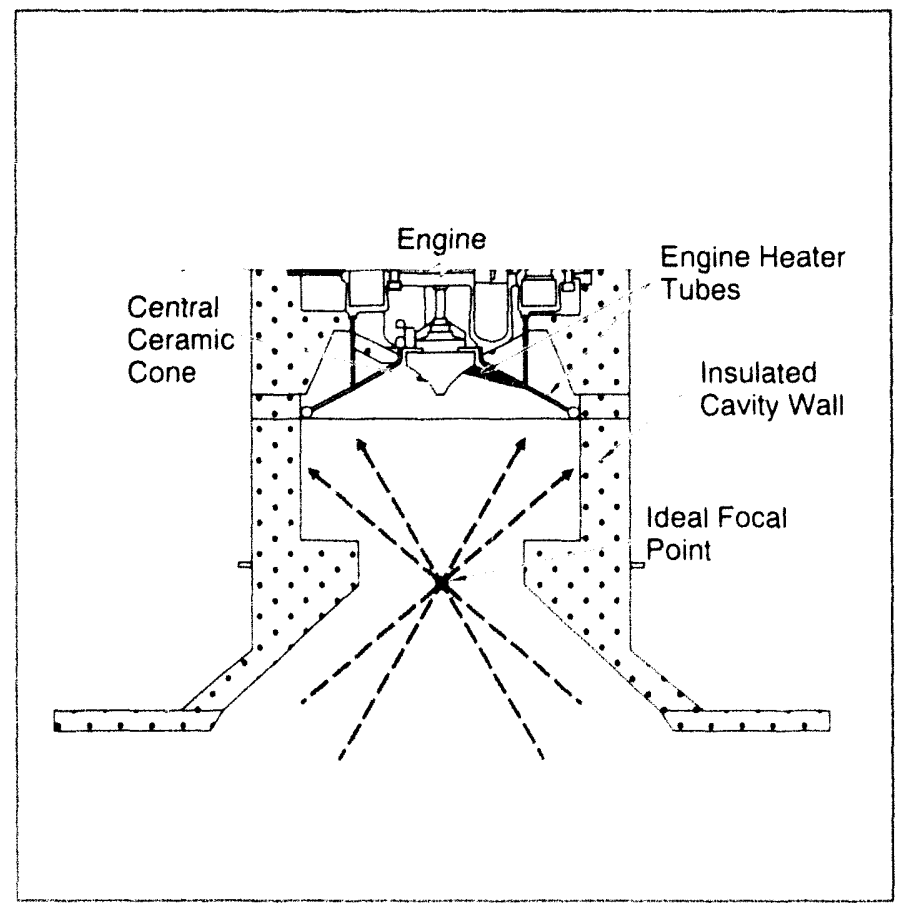

Figure 1-4. Directly illuminated tube receiver.

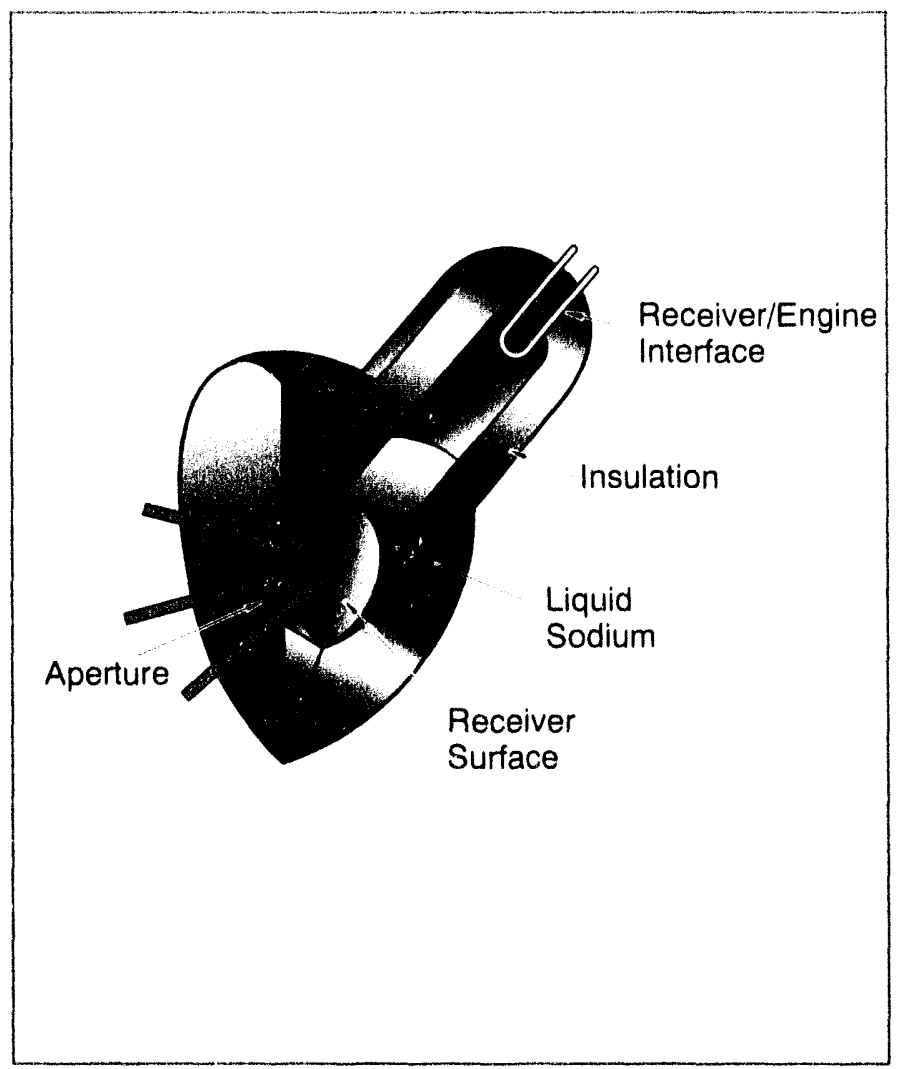

Figure 1-5. Reflux pool-boiler receiver.

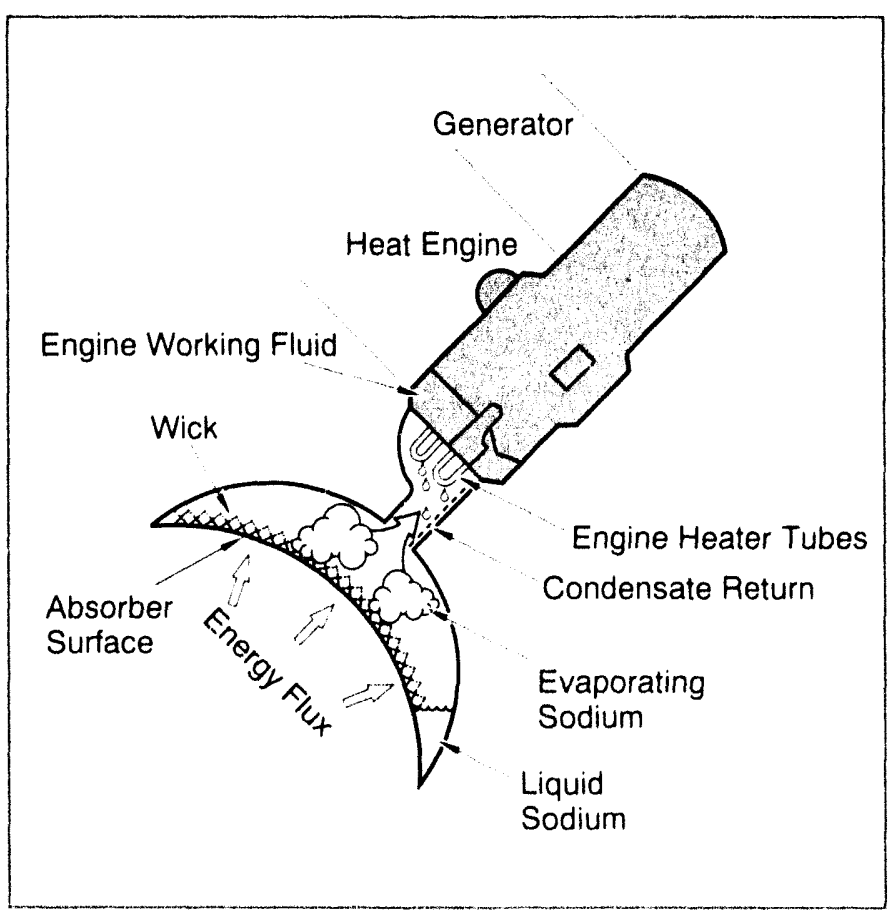

Figure 1-6. Reflux heat-pipe receiver. 
An efficient engine provides more output for a given size concentrator, leading to lower-cost electricity. The high-efficiency Stirling engine is the leading candidate for concentrating parabolic dish solar concentrators. Because Stirling engine efficiency increases with hot end temperature, it is a goal to operate engines at as high a temperature as possible. Temperatures beyond the operating capabilities of existing engines are easily obtained by solar concentration. Stirling engins s therefore generally operate at the thermal limits of the materials used for their construction. Typical temperatures range from $650^{\circ}$ to $800^{\circ} \mathrm{C}\left(1200^{\circ}\right.$ to $\left.1470^{\circ} \mathrm{F}\right)$, resulting in engine conversion efficiencies of around $30 \%$ to $40 \%$.

Because of their high heat-transfer capabilities, hydrogen and helium have been used as the working gas for dish/ Stirling engines. Hydrogen, thermodynamically a better choice, generally results in more efficient engines than does helium (Walker, 198()). Helium, on the other hand, has fewer material compatibility problems and is safer to work with.

To maximize power, engines typically operate at high pressure, in the range of 5 to $20 \mathrm{MPa}$ (72.5 to 2900 psi). Operation at these high gas pressures makes gas sealing difficult, and seals between the high pressure region of the engine and those parts at ambient pressure have been problematic in some engines. New designs to reduce or eliminate this problem are currently being developed.

lingine designs for dish/Stirling applications are usually categorized as either kinematic or free-piston (ligures $1-7$ and 1-8, respectively). The power piston of

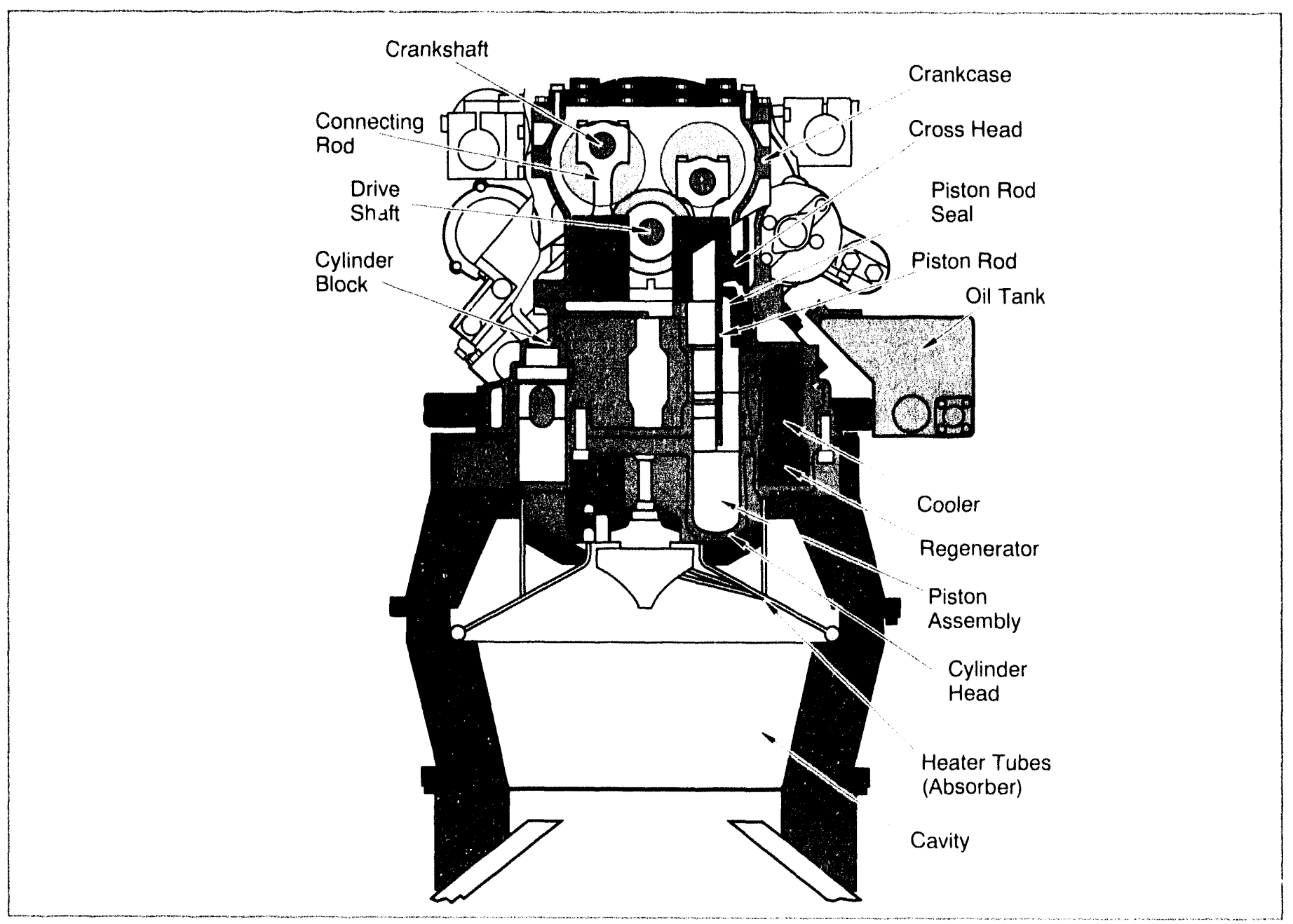

Figure 1.7. Kinematic Stirling engine with a directly illuminated tube receiver. 


\section{Chapter 1}

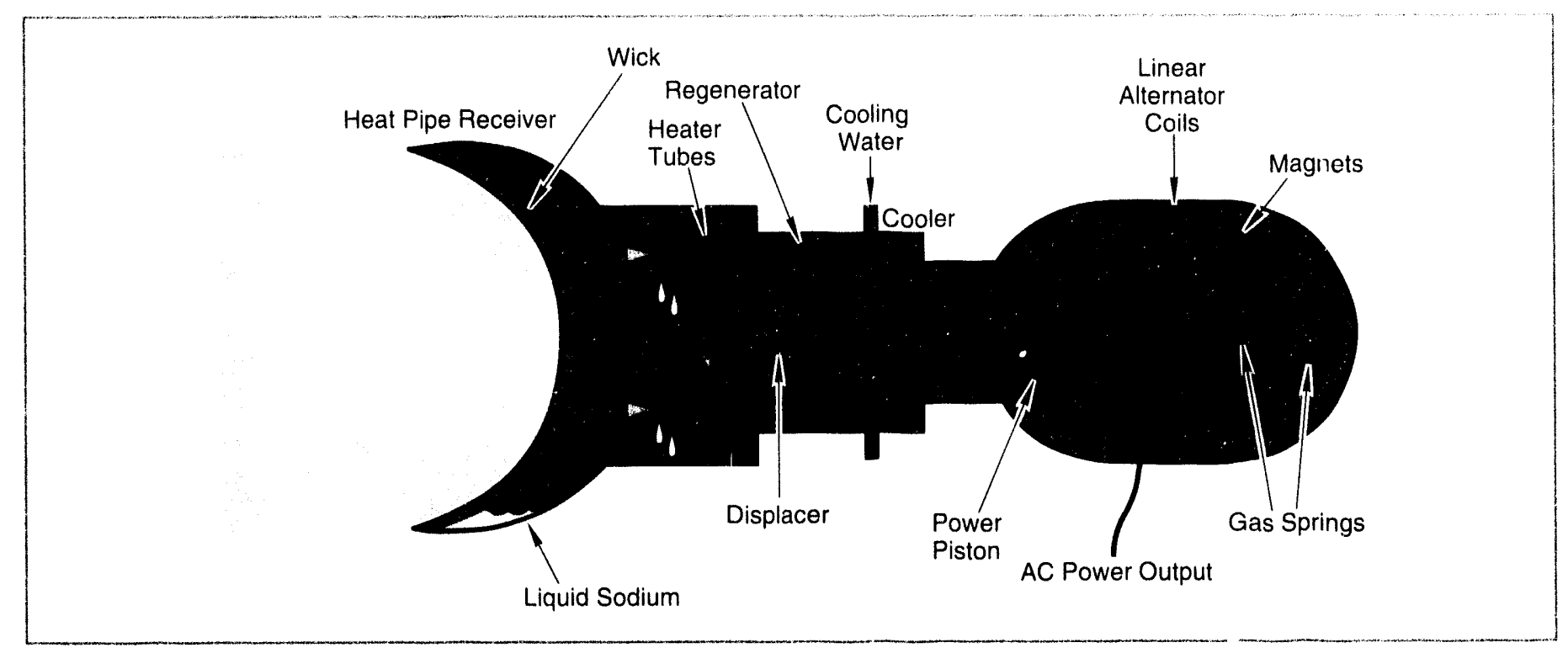

Figure 1-8. Free-piston Stirling engine with linear alternator and liquid-metal heat-pipe receiver.

a kinematic Stirling engine is mechanically connected to a rotating output shaft. If there is a separate gas displacer piston, it is also mechanically connected to the output shaft.

The power piston of a free-piston Stirling engine is not mechanically connected to an output shaft. It bounces alternately between the space containing the working gas and a spring (usually a gas spring). In most designs, the displacer piston is also free to bounce on gas or mechanical springs. Piston frequency and the timing between the two pistons are established by the dynamics of the spring/mass system. To extract power, a magnet is attached to the power piston and electric power is generated as it moves past stationary coils. Other schemes for extracting power from free-piston engines, such as driving a hydraulic pump, have also been considered.

Dish/Stirling engine systems require long-life designs. To make systems economical, a system lifetime of at least 20 years with minimum maintenance is generally required. Desired engine lifetimes for electric power production are 40,000 to 60,000 hours - approximately 10 times longer than that of a typical automotive internal combustion engine. Maior overhaul of engines, including replacement of seals and bearings, may be necessary within the 40,000 - to 60,000 -hour lifetime, which adds to the operating cost. A major challenge, therefore, in the design of dish/Stirling engines is to reduce the potential for wear in critical components or create novel ways for them to perform their tasks. 


\section{Chapter 2: Current System Technology}

It was not until the oil embarge of 1973 that medern dish/Stirling systems came out of the labolatery and began being developed for commercial applications. Because dish/Stirling systems have high solar-to-elecetric conversion efficiency and can be mass-produced, they can be used in modular installations that produce $510100,0000 \mathrm{~kW}$ of electrical power from the sun (Stinc, 1989). This chapter describes dish/stirling systems that have been developed or that are currently being developed.

\section{Developed Systems}

This section summarizes the major systems and components that have had extensive testing and represent milestones in the development of dish/Stirling systems. Table 2-I summarizes the design and performance characteristics of these systems. Specifications and more detailed descriptions of each component are provided in Part 11 of this report (chapters 5 through 7 ). lach of these systems was developed for a commercial market. In the final analysis, it is generally believed that eocenomics is the key issue for the commercialization of dish/Stirling systems.

\section{vanguard 25-kW System}

Advanco (corporation (now defunct), building on the work done at the Jet l'repulsion laboratory (JPl.), integrated the 25-kW. Vanguard dish/Stirling system in 1984. It produced the highest recorded net conversion of sunlight into electricity, 29.4\% (including parasitic power) (1)roher and Squier, 1986). (Inly one of these systems was built. The complete system, installed at Rancho Mirage, Californial, is shown in ligure $2-1$.

The Vanguard concentrator is approximately 11 meters (36 feet) in diameter and is made up of 336 minror facets mounted on a truss structure; each facet measures 45 by 60) $\mathrm{cm}(18$ by $24 \mathrm{in.}$. The facets are shaped foamglass with glass back-surface mirroms bonded to them. The mirrors are mechanically bent inle a shallow spleerical curvature. Iwo different curvatures are used on the Vanguard concentlator. Trateking is by an innowative exocentric gimbal mechamism that reduces lorque requirements and provides rapid emergency detracking.
The United Stirling AB (USAB) Moxled t-95 Mark II engine used in this system is a four-eylinder stirling, engine with a displacement of $95 \mathrm{~cm}^{3}(5.8$ inc) per cylinder. Its four cylinders are paralled and arranged in a sefuare. They are intercomeneded through the heatere regeneratere, and cooler and use double-acting pistoms. (lither side is pressurized during different parts of the cycle.) This is often called the Siemens arrangemente the working gas is hydrogen (helium could also have been used) at a maximum mean working pressure of 20) Ml'a (290) psi) and temperature of 720 (: (: $(13.30 \%)$. lingine power is controlled by varying the pressure of

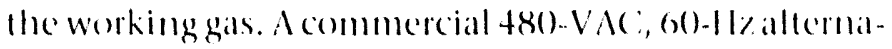
tor is comnected to the output shatt.

The Adranco/Vanguard system's receiver is direclly illuminated. Many small-diameter heater tubes arranged in a conical geometry insicle a cavity absorb the concentrated sunlight and transfer heat directly to the hydrogen working gas in the engine.

\section{MCDonnell Douglas $25 \mathrm{~kW}$ system}

Mclomnell louglas (orp., Acrospace l)ivision, of lluntington Beach, California (MI)A(.), developed a 25-kW. dish/Stirling system incorporating the Inited Stirling 4-9.5 Mark II engine as used in the Vanguard system. Shown in ligure 2-2, six of these systems were prodeced and installed at sites around the United States for operattional testing.

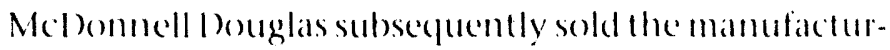
ing and marketing rights for the system to Southern (alifornia lidison (o. (SCli) of Rosemead, California, in 1986 (l.eper and Stone, 1992). Southern (atifomia lidison continued to evaluate and improve the dish/ Stirling system at their Solar ()ne facility near Barstow, Califormia, through september log8. Curronlly, Southern (alifornia lidison is disposing of their dish/ Stirling assets.

The $88-\mathrm{m}^{2}$ (94-4te) dish concentrater comsists of 82 spherically curved glass mirror faceds, ach measuring 9) by 122 (mol (36 by 48 in.). laceds have me of five ditferent corvatures, depending on the ir locationom the dish. These lacets are attached and aligned in the factory. The mirror support hame is stofled at the 
Chapter 2

Table 2-1. Design and Performance Specifications for Dish/Stirling Systems

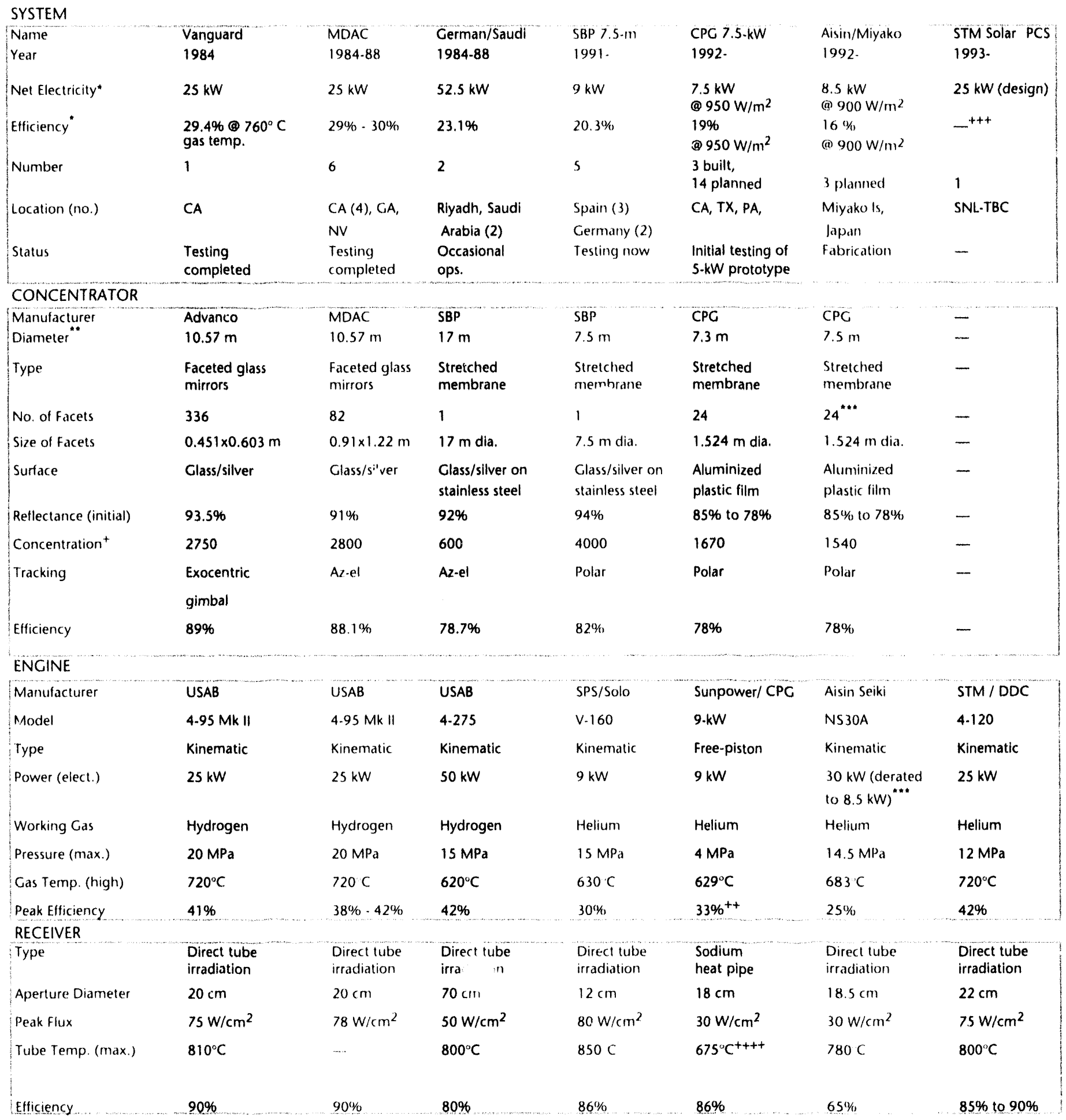

* At $1000 \mathrm{~W} / \mathrm{m}^{2}$ unless otherwise noted

** Equivalent disk

*** 32 for temporary high output

$+\quad$ Geometric concentration ratio, defined in Chapter 3

+ Includes alternator

+++ Depends on concentrator used

${ }^{+++}$Heat pipe internal temperature (Na vapor) 


\section{Current System Technology}
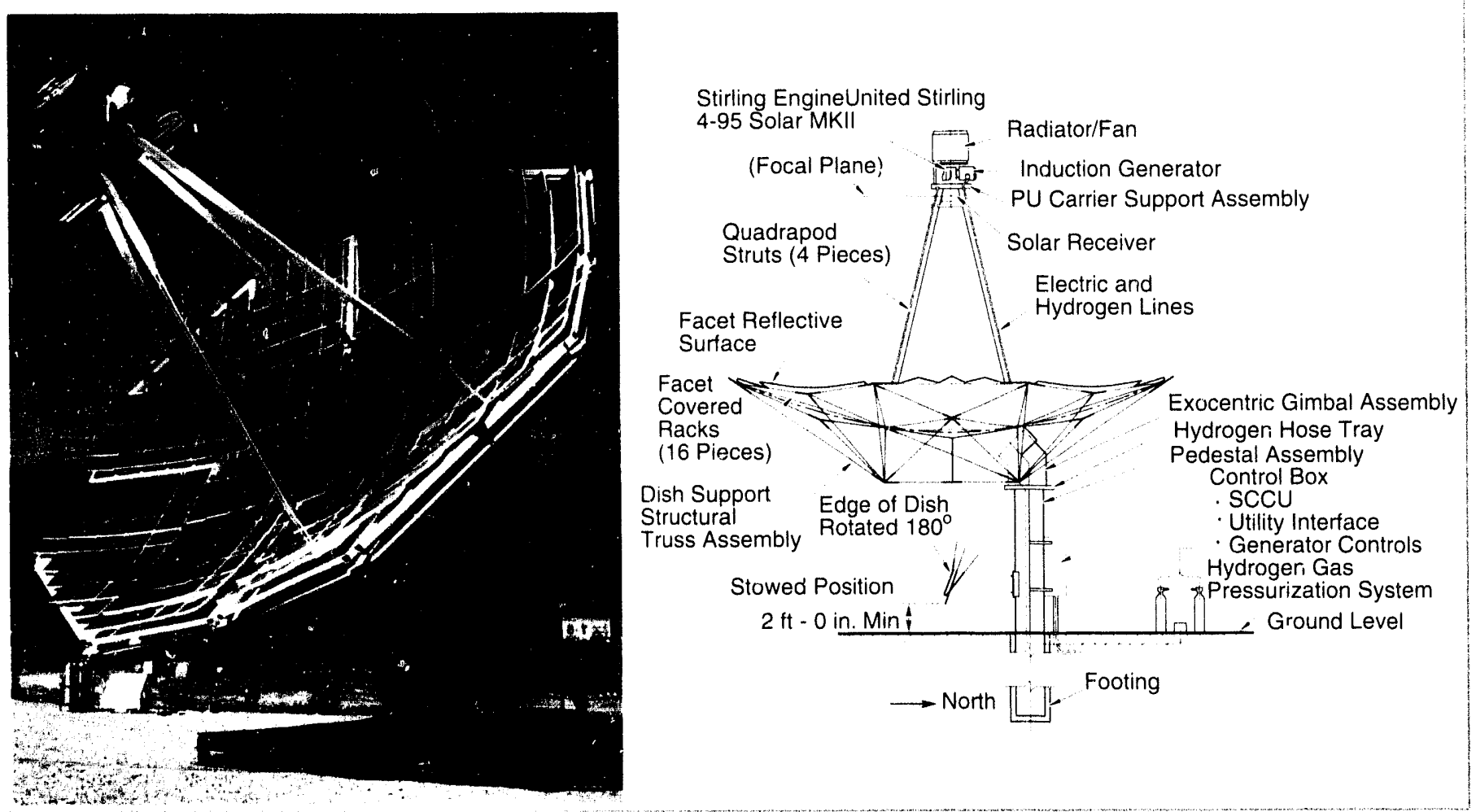

Figure 2-1. Advanco/Vanguard $25-\mathrm{kW}_{e}$ dish/Stirling system.

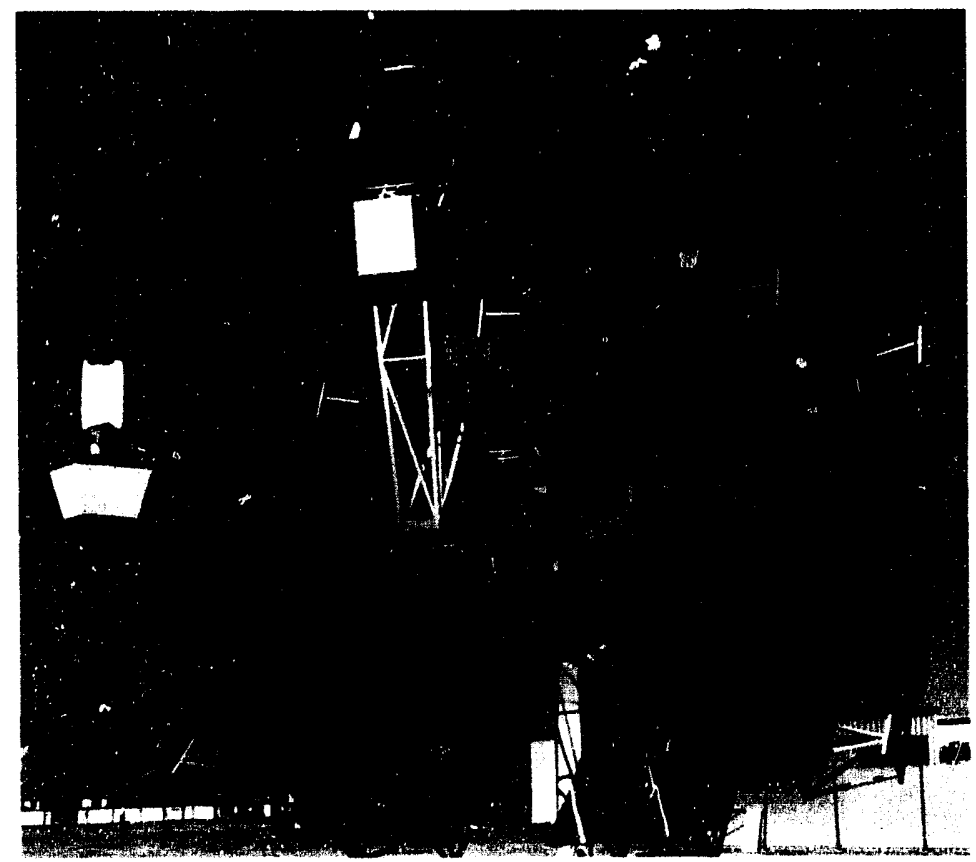

Center Mirror Support

Truss (8 Pieces)

Mirror Facets

Power Conversion

Unit (PCU)

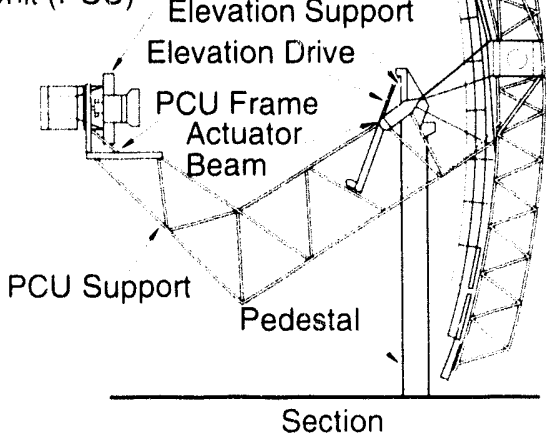

Section

Figure 2-2. McDonnell Douglas/Southern Californis Edison 25-kW dish/Stirling system. 


\section{Chapter 2}

bottom so the power conversion unit can be lowered for servicing. This arrangement also allows the concentrafor drives to be located near the balance point of the concentrator and power conversion unit. The glass reflective surfaces can be washed with conventional equipment. This arrangement also allows vertical stowing to minimize soiling of the glass surface of the concentrator.

The United Stirling 4-95 Mark 11 engine uses hydrogen as the working gas at a set-point temperature of $720^{\circ} \mathrm{C}$ : $\left(1330^{\circ} \%\right)$. At the maximum gas pressure of $20 \mathrm{MPa}$ $12900 \mathrm{psi}$ ), this engine delivered $25 \mathrm{~kW}$ net output at $1000 \mathrm{~W} / \mathrm{m}^{2}$ insolation. The entire $\mathrm{Mcl}$ )onnell Douglas dish/Stirling system has a maximum net solar-to-electric efficiency of $29 \%$ to $30 \%$ (Stone et al., 1993).

\section{German/Saudi 50-kW "System}

Three 17-meter (56-foot) dishes with 50-kW United Stirling 4-275 engines were constructed by Schlaich, Bergermann und Partner (SBP) of Stuttgart, (iermany, and tested with the aid of the Cierman Aerospace Research Establishment (I)I.R) (Noyes, 199()). The first of these systems was located in lampoldshausen, Germany, in 1984, and it was the first large-scale dish/ Stirling system to operate in Europe. The lampoldshausen stirling engine is no longer operational, but the Lampoldshausen concentrator is still being used for research.) The other two systems, shown in ligure 2-3, are located in the Solar Village of the Saudi Arabian National Center for Science and Technology near Riyadh. The Riyadh systems have achieved a net clectrical output of $53 \mathrm{~kW}$ and a solar-to-electric efficiency of $2.3 \%$ at an insolation of $1000 \mathrm{~W} / \mathrm{m}^{2}$.

The Schlaich concentrator is a single-facet stretchedmembrane dish 17 meters (56 feet) in diameter. The membranc is a thin $0.5-\mathrm{mm}$ (20)-mil) sheet of stainless steed stretched on a rim with a second membrane on the back (resembling a drum). A vacuum between the two membranes plastically deforms the front membrane to its final shape, which is neither a paraboloid nor spherieal. Thin-glass mirrors are bonded to the membrane. The shape is maintained by a partial vacuum. The concentrator is set into a frame allowing arimuth/ elevation tracking.

The Schlaich dish/Stirling system hais at its focus a United Stirling $4-275$ engine using hydrogen as the working gas with maximum operating conditions of $620(., 1120) 1$ and 15 MPa $(217.5$ psi). The $4-27.5$ is a four-cylinder, double-acting Stirling engine with a displacement of $27.5 \mathrm{~cm}^{3}\left(16.8 \mathrm{in}^{3}\right)$ per cylinder. The Schlaich dish/Stirling receiver is a directly illuminated tube receiver that has many small-diameter heater tubes located in the back of the receiver cavity to absorb the concentrated sunlight.

\section{Current Activities}

The design and performance of four terrestrial dish/ Stirling systems (three complete systems and one solar power conversion system that can be integrated to a variety of concentrators) currently being developed are described below and are also summarized in Table 2-1. specifications and more detailed descriptions of each component are given in lart II of this report.

\section{Schlaich, Bergermann und Partner 9. $\mathrm{kW}$. System}

Schlaich, Bergermann und lartner (SBP) of Stuttgart, Germany, has developed a dish/Stirling system, shown in ligure 2-4, incorporating a single-facet 7.5 -meter (25-foot) stretched-membrane dish and a 9-kW Stirling engine. Currently five of these systems are undergoing testing (Keck et al., 1990).

The Schlaich concentrator is 7.5 meters (25 feet) in diameter and is made of a single preformed stainless steel stretched membrane that is $0.23 \mathrm{~mm}$ (9 mil) thick. Thin-glass mirrors are bonded to the stainless steel membrane. The membrane is prestretched beyond its elastic limit using a combination of water weight on the front and vacuum on the back, to form a nearly ideal paraboloid. A slight vacuum between the front and back membrane maintains the reflector shape. The membrane drum is mounted in a frame that permits tracking about the earth's polar axis with corrections for changes in declination angle.

The $V-160$ engine was originally produced by Stirling Power Systems (now defunct) under a license from United Stirling of Sweden (USAB). Subsequently, Schlaich Bergermann und Partner received a license from USAB and gave a sublicense to Solo Kleinmotoren of Sindelfingen, (iermany, for manufacturing this engine (Schicl, 1992). This engine incorporates a 160 - $\mathrm{cm}^{3}$ (10-in') swept volume shared between a compression and expansion cylinder. This engine uses helium as a working gas at $630(2(1170 \%)$. Varying the working gas pressure from $+101.5 \mathrm{MPa}(580)(02200$ p) 5 i) controls the 


\section{Current System Technology}
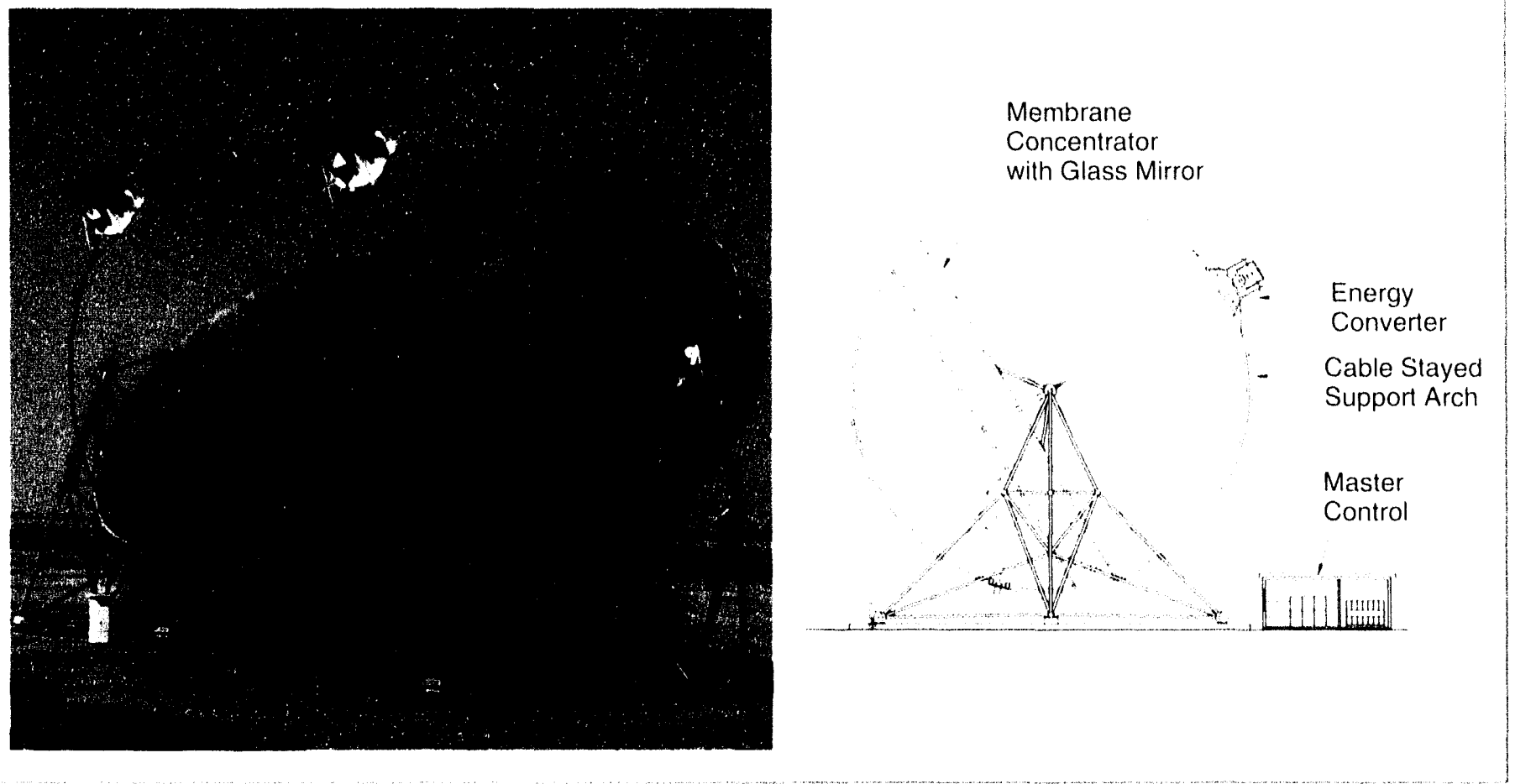

Figure 2-3. German/Saudi 50-kWe dish/Stirling system.
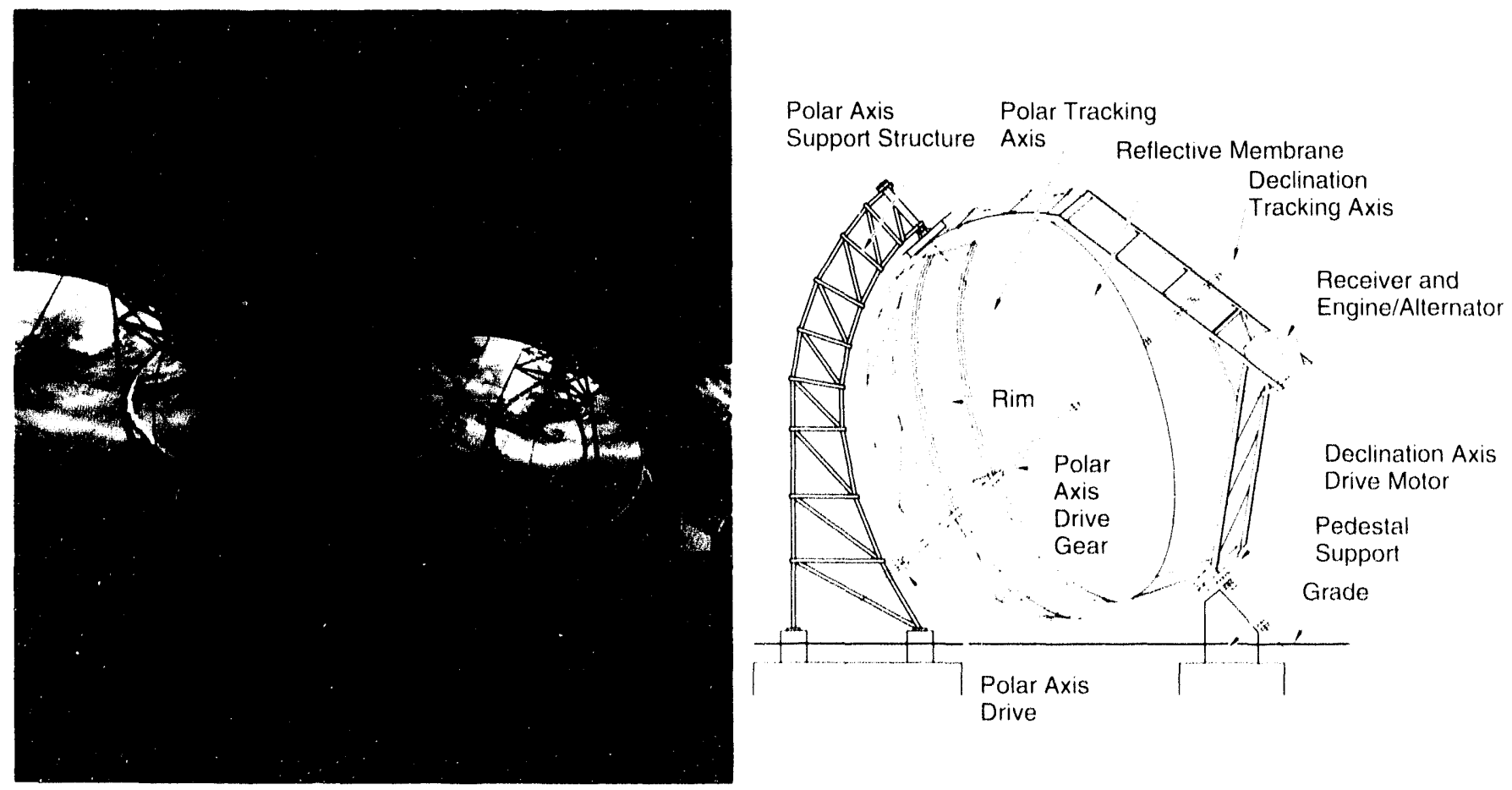

Figure 2-4. Schlaich, Bergermann und Partner 9-kW dish/Stirling system. 


\section{Chapter 2}

engine output power. The engine has an efficiency of $30 \%$. The overall solar-to-electric system conversion efficiency is $20.3 \%$. Six of these $7.5-\mathrm{m}$ systems have been erected. Three are currently in operation at the Plataforma Solar in Almería, Spain, with the goal being to test the system's long-term reliability under everyday operating conditions (Schiel, 1992). A fourth Schlaich dish/Stirling unit is in operation in Pforzheim, Germany. Two more units have been installed in Stuttgart, Germany: a prototype on the campus of the University of Stuttgart (now dismantled) and another unit at the Center for Solar Energy and Hydrogen Research (ZSW) test facility.

\section{Cummins Power Generation 7.5-kW System} Cummins Power Generation, Inc. (CPG), of Columbus, Indiana, a subsidiary of Cummins Engine Company, is the first company in the world to put together and operate on-sun a dish/Stirling system that uses a freepiston Stirling engine for solar electric power generation. This is also the first application of a liquid-metal heat-pipe receiver. Cummins is currently testing three $5-\mathrm{kW}_{\mathrm{e}}$ (net) "concept validation" prototypes of this system. The rated net electrical output of the production system will be $7.5 \mathrm{~kW}_{\mathrm{c}}$. The $5-\mathrm{kW}_{\mathrm{e}}$ prototype system is pictured in Figure 2-5. Cummins Power Generation is operating three $5-\mathrm{kW}_{\mathrm{e}}$ prototype systems and plans to produce fourteen $7.5-\mathrm{kW}_{\mathrm{e}}$ systems for testing at different locations (Bean and Diver, 1992). The system's design goal for solar-to-electric efficiency is over 19\% net (Bean and Diver, 1993).

The CPG-460 concentrator incorporates 24 stretchedmembrane facets mounted on a space frame. Each fact $i$ is 1.52 meters ( 5 feet) in diameter. Thin $0.18-\mathrm{mm}$ ( $7-\mathrm{mil}$ ) aluminized polymer membranes are stretched on either side of a circular rim. A slight vacuum is drar $r n$ between the two membranes to obtain an approxir.lately spherical shape. The concentrator incorporates a polar tracking system.

Sunpower, Inc. is developing the $9-\mathrm{kW}_{\mathrm{e}}$ free-piston Stirling engine with a linear alternator for use in this system. The working gas is helium at $629^{\circ} \mathrm{C}\left(1164^{\circ} \mathrm{F}\right)$. Because the linear alternator is contained inside the engine housing, the unit can be hermetically sealed

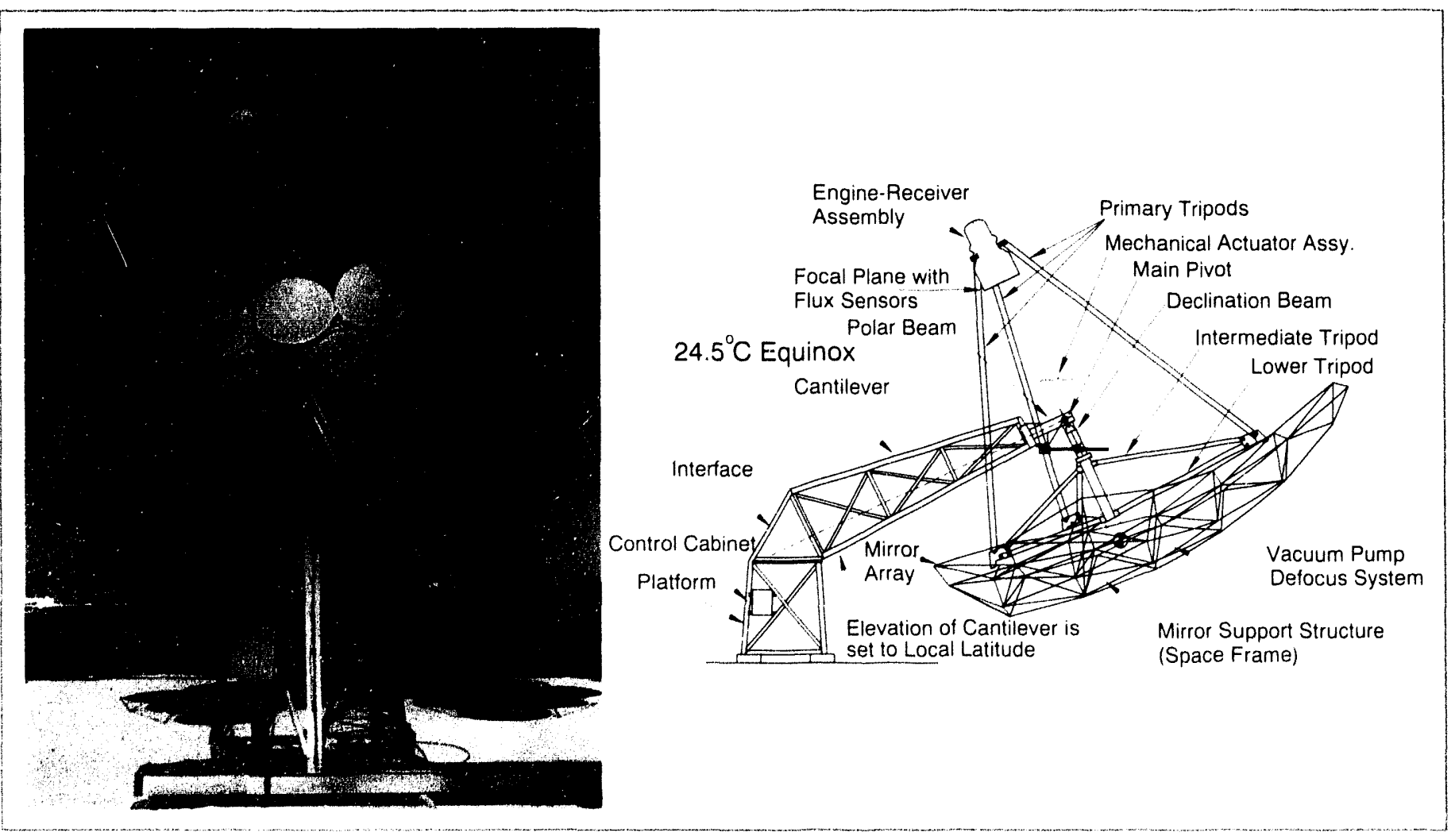

Figure 2-5. Cummins Power Ceneration 5-kW $W_{e}$ prototype free-piston engine dish/Stirling system. 


\section{Current System Technology}

with only electrical connections penetrating the casing. The only two moving parts are the power and the displacer pistons. The design life goal of the system is 40,000 hours with a 4000-hour mean time between failures. A goal of $33 \%$ for engine/alternator efficiency has also been set.

The Cummins Power Generation system incorporates a heat-pipe cavity receiver designed by 'Thermacore, Inc., that uses sodium as an intermediate heat transfer fluid. The operating temperature of the receiver is $675^{\circ} \mathrm{C}\left(1250^{\circ} \mathrm{F}\right)$.

\section{Aisin Seiki Miyako Island System}

Aisin Seiki Co., Ltd., of Kariya City, Japan, built the NS30A 30-kW engine under the Japanese government's New Energy and Industrial Development Organization (NEIDO) project. It is a four-piston double-acting engine using a fixed-angle swashplate drive. The engine operates on helium at $683^{\circ} \mathrm{C}\left(1260^{\circ} \mathrm{F}\right)$ and 14.5 MPa (1740 psi). Aisin Seiki modified one of these engines for solar operation and has been testing it with a McDonnell Douglas solar concentrator at their facility at Kariya City.

Aisin is assembling three dish/Stirling systems for generating electric power on Miyako Island $(290 \mathrm{~km}$ (180 mi) southwest of Okinawa). The concentrators are Cummins Power Generation CPG-460 stretched-membrane dishes. Aisin Seiki's NS30A 30-kW four-cylinder fixed swashplate kinematic engine will be used, derated to $8.5 \mathrm{~kW}$ for this application. The engine has a directly illuminated tube-type receiver.

To provide power after sunset and during cloud transients, Aisin is incorporating novel $30-\mathrm{kWh}$ electrochemical batteries to each dish/engine/alternator system (one battery for each system). Developed by Meidensha Corporation of Japan, these are zinc-bromine batteries incorporating two pumped-circulation and tank-storage loops.

In addition to the Miyako Island project, Aisin Seiki is currently testing a 200-W prototype free-piston Stirling engine designed for space applications. Aisin is doing on-sun testing of this engine with a $C P \mathrm{P}_{\mathrm{J}}-460$ dish at their French subsidiary, IMRA, near Sophia-Antipolis. The IAS-200 prototype engine is a free-piston Stirling engine with a single motor-driven displacer and two power pistons, each incorporating a linear alternator.
As a final note, Aisin has incorporated a small (approximately 100-W) free-piston dish/Stirling electric generator into three solar-powered competition vehicles to aid the output of their photovoltaic cell arrays. One of the competition vehicles, a solar-powered electric boat, entered a race in Japan in 1988. Another competition vehicle, a photovoltaically powered car that entered the 1990 World Solar Challenge race across Australia, also incorporated this same kind of dish/Stirling unit. Aisin Seiki is building the third competition vehicle, another solar-powered car, for the 1993 World Solar Challenge race across Australia that will again incorporate the small dish/Stirling generator to aid the photovoltaic cell array power output.

\section{Stirling Thermal Motors $25 \mathrm{~kW}$, Solar Power Conversion System}

Stirling Thermal Motors, Inc., of Ann Arbor, Michigan, and Detroit Diesel Corporation of Detroit, Michigan, have designed and tested a solar power conversion system incorporating the STM4-120 Stirling engine. The STM4-120 is rated at $25 \mathrm{~kW}^{\circ}$ (gross) at $1800 \mathrm{rpm}$ and $800^{\circ} \mathrm{C}$ heater-tube temperature. This completely selfcontained package is suitable for integration with a variety of solar concentrators. Pictured in Figure 2-6

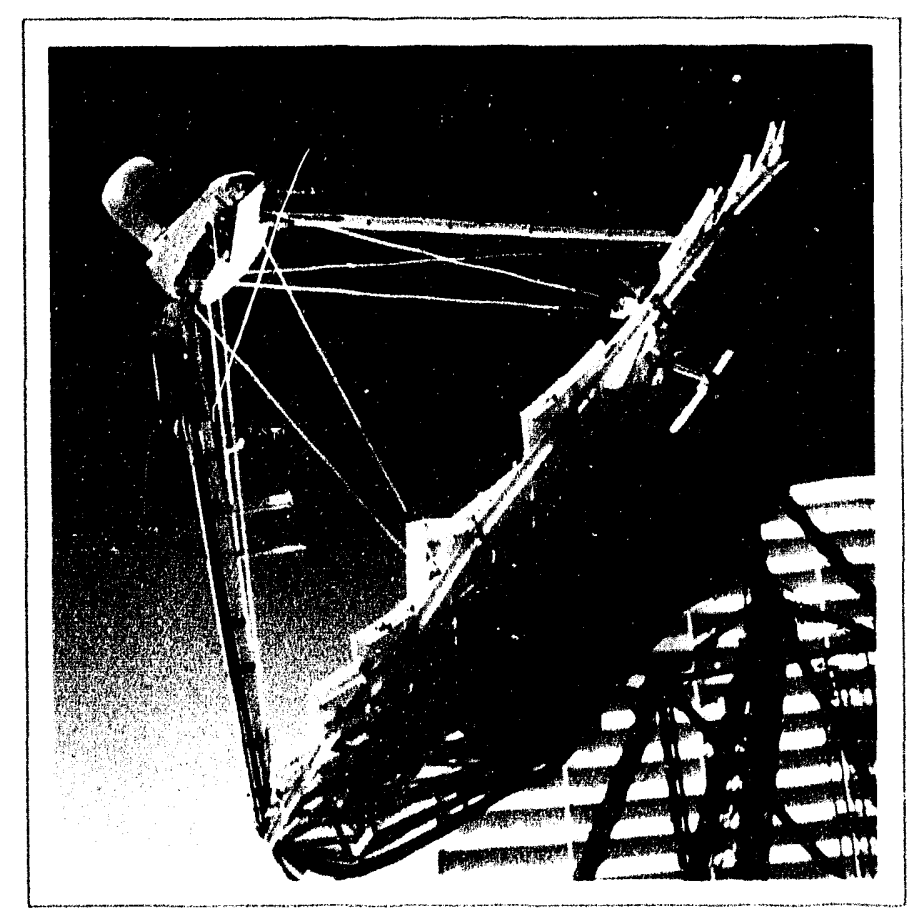

Figure 2-6. Stirling Thermal Motors $25-k W_{e}$ solar power conversion system package under test at Sandia National Laboratories. 


\section{Chapter 2}

mounted on Sandia National Laboratories' Test Bed Concentrator, the first prototype package began on-sun testing in 1993 (Powell and Rawlinson, 1993).

The Stirling Thermal Motors solar power conversion system package includes the STM4-120 engine incorporating variable displacement power control. The power conversion system also includes a directly irradiated tube-bank receiver, an alternator, and the engine cooling system. Its dimensions are $86 \mathrm{~cm} \times 86 \mathrm{~cm} \times 198 \mathrm{~cm}$ ( $34 \mathrm{in} . \times 34 \mathrm{in} . x 78 \mathrm{in}$.$) , and it weighs 725 \mathrm{~kg}(1600 \mathrm{lb})$. The engine can accommodate NEMA 284/286 singlebearing generators for SAE \#5 Flywheel Housings (Godett, 1993a). 


\section{Chapter 3: Fundamental Concepts}

This discussion of the principles underlying the design of dish/Stirling systems is intended to provide the reader the following:

- an understanding of fundamental dish/Stirling design issues

- an appreciation of why certain design choices are made

- an understanding of the importance of current development activities.

More detailed discussions of this material may be found in Stine (1989), Stine and Harrigan (1985), Kreider (1979), Kreider and Kreith (1981), Kreith and Kreider (1978), and Dickinson and Cheremisinoff (1980).

\section{The Collection of Solar Energy}

The concentrator of a dish/Stirling electric system intercepts radiation from the sun over a large area and concentrates it into a small area. The receiver absorbs this energy and transfers most of it to the Stirling engine. The amount of heat going to the engine may be called usefiul heat $\left(\left(_{\text {usetul }}\right)\right.$.

A simple energy balance equation, called the findume'ntal solar collection equation, describes the theory underlying many aspects of concentrator and receiver design. This equation governs the performance of all solar energy collection systems and guides the design of dish/Stirling systems. The fundamental solar collection equation is

$$
\begin{aligned}
Q_{\text {useful }}= & I_{b, n} A_{\text {app }} E\left(\cos \theta_{i}\right) \rho \phi \tau \alpha \\
& -A_{\text {rec }}\left[U\left(T_{\text {rec }}-T_{\text {ambl }}\right)\right. \\
& \left.+\sigma F\left(T_{\text {rec }}^{+}-T_{\text {ambl }}^{4}\right)\right],
\end{aligned}
$$

where:

$A_{\text {app }}=$ area of the concentrator aperture
$A_{\text {rW }}$
$=$ arcal of the receiver aperture
E
$=$ fraction of concentrator aperture area not shaded by receiver, struts, and so on
$F$
$l_{1, n}$
$=$ equivalent radialive conductance
= beam normal solar radiation (insolation)
$Q_{\text {usetul }}=$ instantaneous rateof themalenergyecom- ing from the receiver
$T_{\text {imbl }}=$ ambient temperature
$T_{\text {rec }}=$ receiver operating temperature
$U=$ convection-conduction heat-loss coeffi- cient for air currents within the receiver cavity, and conduction through receiver walls
$\alpha=$ receiver absorptance
$\tau=$ transmittance of anything between the reflector and the absorber (such as a win- dow covering the receiver)
$\theta_{i}=$ the angle of incidence (angle between the sun's rays and a line perpendicular to the concentrator aperture; for parabolic dish concentrators, this angle is 0 degrees)
$\rho=$ concentrator surface reflectance
$\sigma=$ Stefan-Boltzmann radiant-energy-transfer constant
$\phi \quad$ capture fraction or intercept fraction of energy leaving the reflector that enters the receiver).

Fquation 3-1 shows that the amount of solar radiation reaching the receiver depends upon the amount available (determined by $I_{b, n}$ and $\theta_{i}$ ), the effective size of the concentrator (determined by $A_{\text {app }}$ and $E$ ), and the concentrator surface reflectance (p). Receiver thermal performance depends on receiver design (determined by $\tau$ and $(x)$ and convection, conduction, and radiation heat losses.

\section{Advantages of Concentration}

The dish/Stirling system's parabolic dish is a concentrating collector; it collects solar energy through a large aperture area and reflects it onto a smaller receiver area to be absorbed and converted into heat. The advantage of concentration is evident from the fundamental solar thermal collection equation. In order to maximize 


\section{Chapter 3}

$Q_{\text {useful }}, A_{\text {app }}$ should be large and $A_{\text {rec }}$ as small as possible. The amount of concentration can be described in terms of geometric concentration ratio and optical concentration ratio, which are defined below.

\section{Geometric Concentration Ratio}

The extent to which the aperture area of the receiver is reduced relative to that of the concentrator is called the geometric concentration ratio, which can be expressed as

$$
C R_{g}=A_{\text {app }} / A_{\text {rec }} .
$$

A fundamental trade-off exists, however, between increasing the geometric concentration ratio and reducing the cost of the collector because collectors with high concentration ratios must be manufactured precisely. Generally, a direct correlation exists between the accuracy of the concentrator and its cost.

\section{Optical Concentration Ratio}

The geometric concentration ratio defined above is a measure of the average ideal concentration of solar flux if it is distributed uniformly over the receiver aperture area. Real concentrators do not produce this uniform flux. They instead produce a complex series of high and low flux levels distributed around the receiver aperture area. Generally, the profile of concentrated flux peaks at the center and decreases toward the edges of the receiver aperture. Flux concentration at a point is defined in terms of the optical concentration ratio, $C R$, which is the ratio of the flux at a point to the incident solar flux:

$$
C R=I / I_{b, n} .
$$

Here $I$ is the flux intensity at the point of interest. Peak concentration ratios of three to five times the geometric concentration ratio are typical.

\section{Parabolic Dish Concentrators}

The function of the concentrator is to intercept sunlight with a large opening (aperture) and reflect it to a smaller area. The fundamental solar collection equation is repeated here with parameters related to concentrator design shaded:

$$
\begin{aligned}
& Q_{\text {useful }}=I_{1, n} A_{\text {app }} E\left(\cos \theta_{i}\right) \rho \phi \tau \alpha \\
& -A_{\mathrm{rec}}\left[U\left(T_{\mathrm{rec}}-T_{\mathrm{ambl}}\right)\right. \\
& \left.+\sigma F\left(T_{\text {rec }}^{+}-T_{\text {amb }}^{4}\right)\right] .
\end{aligned}
$$

The parameters associated with the design of the concentrator are summarized below:

- concentrator aperture area $A_{\text {app }}$

- receiver aperture area $A_{\text {rec }}$

- unshaded concentrator aperture area fraction $E$

- angle of incidence $\theta_{i}$ (zero for parabolic dishes)

- $\quad$ surface reflectance $\rho$

- capture fraction $\phi$ (this is a parameter of both the concentrator design and the receiver design).

The remaining parameters in the fundamental solar collection equation are related to receiver design and operating conditions.

\section{Concentrator Optics}

Paraboloid Concentrators

The paraboloid is a surface generated by rotating a parabola about its axis and is shown in Figure 3-1. The resulting surface is shaped so that all rays of light parallel to its axis reflect from the surface through a single point, the focal point. The parabolic dish is a truncated portion of a paraboloid and is described in an $x, y, z$ coordinate system by

$$
x^{2}+y^{2}=4 f z
$$

where $x$ and $y$ are coordinates in the aperture plane, $z$ is the distance from the vertex parallel to the axis of symmetry of the paraboloid, and $f$ is the focal length.

The focal-length-to-diameter ratio $\mathrm{f} / \mathrm{d}$ (Figure 3-1) defines the shape of a paraboloid and the relative location of its focus. This shape can also be described by the rim 


\section{Fundamental Concepts}

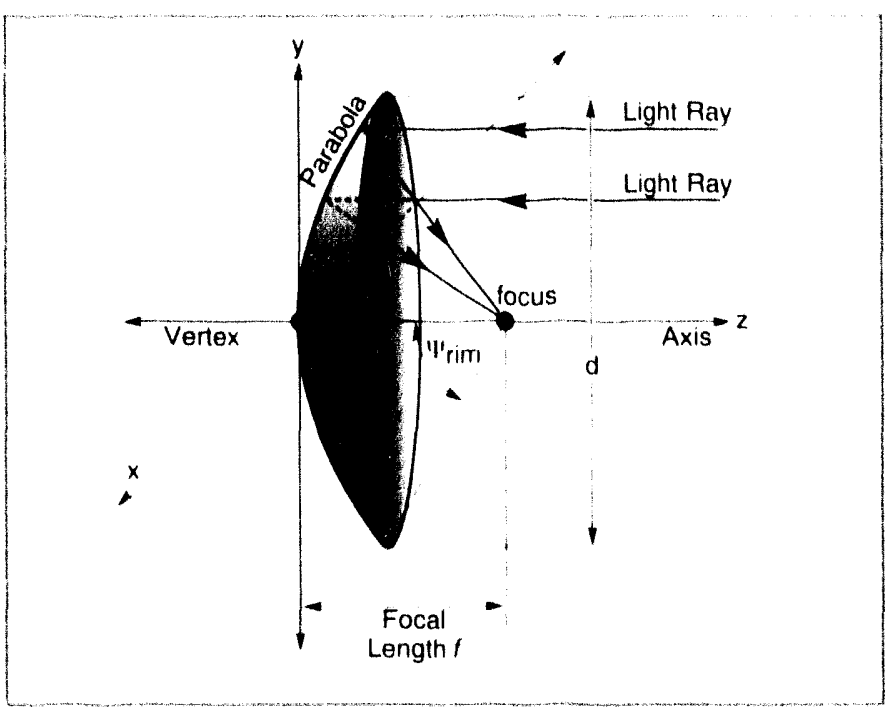

Figure 3-1. The paraboloid is a surface generated by rotating a parabola around the z-axis

angle $W_{\text {rim }}$ - the angle measured at the focus from the axis to the rim where the paraboloid is truncated. Paraboloids for solar applications in general have rim angles from less than 10 degrees to more than 90 degrees. At small rim angles, a paraboloid differs little from a sphere. Faceted dish designs typically use spherical mirrors.

The relationship between $f / d$ and the rim angle $\Psi_{\text {rim }}$ is

$$
f / d=\frac{1}{4 \tan \left(\Psi_{\text {rim }} 2\right)}
$$

For example, a paraboloid with a rim angle of 45 degrees has an $f / d$ of 0.6 . The ratio $f / d$ increases as the rim angle $\Psi_{\text {rim }}$ decreases. A paraboloid with a very small rim angle has very little curvature, and the focal point and the receiver must be placed far from the concentrator surface. Paraboloids with rim angles less than 50 degrees are used when the reflected radiation passes into a cavity receiver, whereas paraboloids with larger rim angles are best suited for external receivers. Because dish/Stirling systems do not use external receivers, their rim angles are less than 50 degrees.
Opticaltroms

Operating concentrators typically have several optical errors that cause them to deviate from the theoretical optics of a paraboloid. Some optical errors are random and cause the optical image of the sun to spread at the focus. Reducing these errors usually increases concentrator cost, creating one of the major trade-offs in designing parabolic dish systems.

liven the best concentrator surfaces deviate from the ideal curve to which they are manufactured. This deviation, called slope error, is a measure of the angle by which the actual surface sope deviates from ideal. Because the slope error varies over the surface, it is typically specified statistically as one standard deviation from the mean and is expressed in milliradians. In general, the smaller the error in the optical surface, the more the collector costs. Well-manufactured parabolic dish concentrator surfaces can have a slope error of 2.5 milliradians (about 0.1 .5 degrees). The use of multiple facets results in an approximation of a paraboloid and in itself reduces the amount of concentration obtainable. In addition, when a paraboloid is approximated by multiple facets, an error similar to slope error, called the facet alignment error, is introduced because the individual facets cannot be perfectly aimed.

A second source of optical error is the reflective surface itself. When a beam of parallel rays hits an optical surface, the reflected beam can be diffused. The extent to which this diffusion happens is called nomspeculur reflectemce. For example, polished metal or a reflectivecoated polymer will diffuse incident light more than a glass mirror.

Two optical alignment errors dislocate the actual focus from where it should be. One is the error in mechanically aligning the receiver relative to the concentrator. The other, called traking error, occurs when the concentrator axis does not point directly at the sun. Although not completely random, tracking errors are sometimes treated as such for simplicity.

One final factor that cannot be corrected by improving manufacturing quality is the apparent width of the sun. Because the sun is not a point source, its rays 


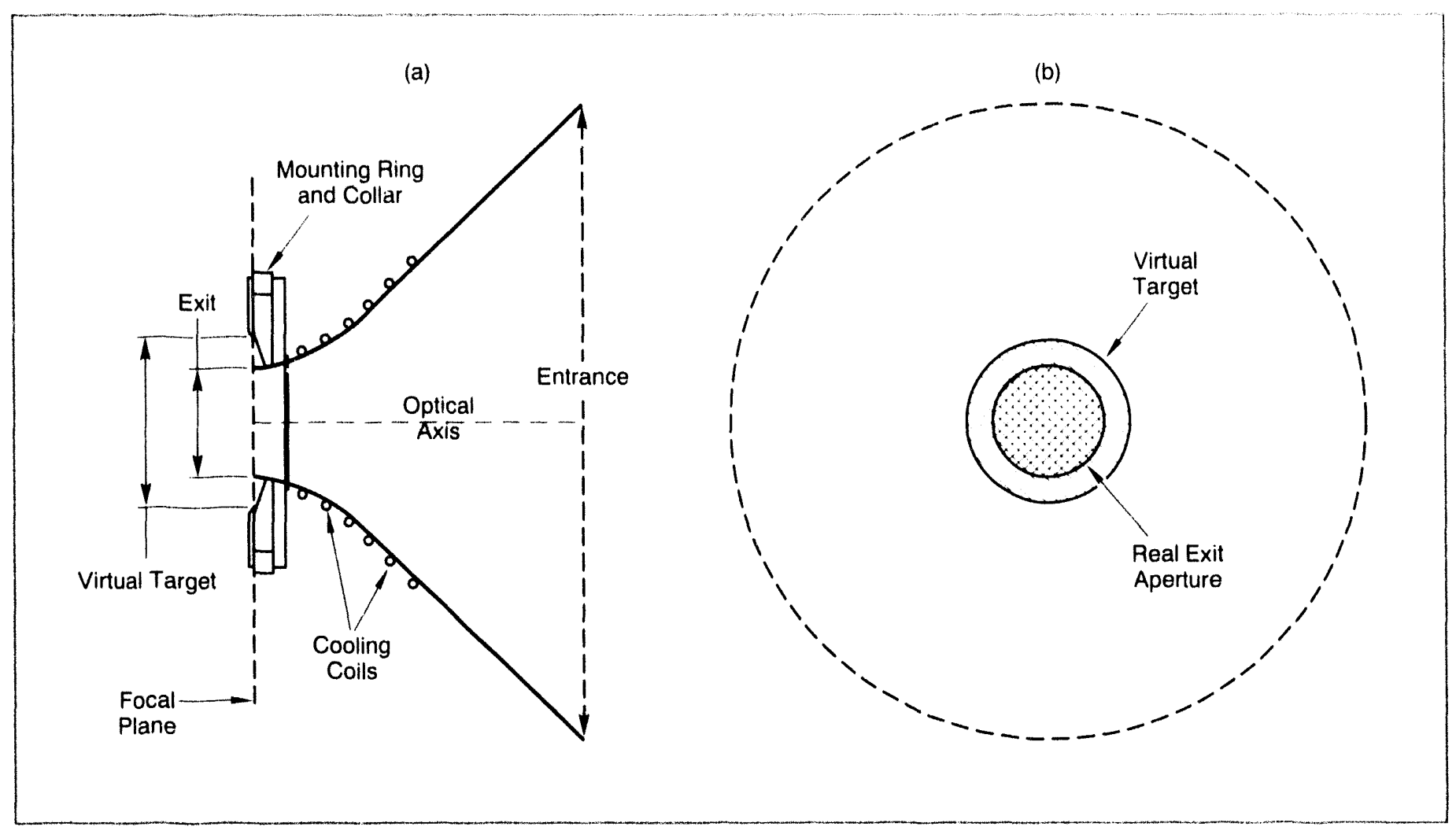

Figure 3-2. A secondary concentrator with side view (a) and head-on view (b).

are not parallel and therefore the reflected image spreads in a cone approximately 9.31 milliradians (0.533 degrees) wide. Called sunshape, this size increases and the edges become less defined with increased moisture or particulates in the atmosphere. The effect of sunshape is similar to the other optical errors and spreads the reflected radiation at the focus.

Secondary Concentrators

A secondary concentrator at the receiver aperture can be used to increase capture fraction without increasing receiver aperture size or to reduce aperture diameter for a given capture fraction. This highly reflective, trumpet-shaped surface (see Figure 3-2) "funnels" reflected radiation from a wide area through the cavity receiver aperture. The net result is an increase in the capture fraction without an increase in the receiver aperture area.

A secondary concentrator generally improves the performance of a parabolic dish. The addition of a secondary concentrator can reduce the negative effects of any or all of the components of optical error. However, a secondary concentrator adds to the collector cost. Also, because the secondary concentrator is located in a high flux density region, it must have high reflectance and welldesigned cooling.

\section{Reflective Materials}

Most concentrators depend on a reflective surface to concentrate the rays of the sur to a smaller area. The surfaces are either polished aluminum or silver or aluminum on either the front or back surface of glass or plastic. When silver or aluminum is deposited on the back surface of a protective transparent material, it is called a back-surtaced or second surfice mirror. The quality of a reflective surface is measured by its reflectance and specularity. Reflectance is the percentage of incident light that is reflected from the surface. Speculcurity is a measure of the ability of a surface to reflect light without dispersing it at angles other than the incident angle. An ideal surface reflects all incident light rays at an angle equal and opposite to the angle of incidence. 


\section{Fundamental Concepts}

Most reflective surfaces are metal. Under laboratory conditions, polished silver has the highest reflectance of any metal surface for the solar energy spectrum. Aluminum reflects most of the solar spectrum but does not have the high reflectance of silver.

Back Surluce Silvered Cilas

Back-surface silvered-glass mirrors are made by silver plating the surface of a glass sheet and applying protective copper plating and protective paint to the silver coating. This technique has been used for numerous domestic applications, such as bathroom mirrors, for many years. For traditional mirrors, the glass is thick, making it heavy and difficult to bend into a concentrating shape. These mirrors typically have a low transmittance because common glass contains iron. Although a polished silver surface has a reflectance of almost $98 \%$, the resulting mirror does not have this high reflectance because incident light must pass twice through the thick, low-transmittance glass.

To increase solar applications of back-surfaced glass mirrors, thin-glass mirrors have been developed. The glasses used are usually iron-free and do not absorb strongly in the solar spectrum. These mirrors can have a solar reflectance of $9.5 \%$.

Reflective Phatic film

Aluminized plastic films are used in many current concentrator designs. A variety of plastic films with an evaporative deposited aluminum coating on the back surface have been used for many years for solar concentrator reflective surfaces. Although the optical and mechanical properties of most plastics degrade after long exposure to ultraviolet rays, adding stabilizers effectively slows this degradation. Low-cost, flexible, and lightweight silvered plastic films with a high reflectance 196\% with high specularity) promise to be the reflective surface of choice for many new designs.

A drawback of metallized plastic films, however, is that they cannot be mechanically washed like glass. Some hard coatings for polymer films are being investigated (Jorgenson, 199.3; Stine, 1989)

The reflective surface used in some early concentrators was polished aluminum sheet. These sheels are available in large sizes and are relatively inexpensive. Their major disadvantage is that they have only a moderate specular reflectance (85\% when new). Another disadvantage is their poor weallherability.

A recent concept under development is the application of a silver reflective coating directly to a structural surface of stainless steel or aluminum. These surfaces must be protected from atmospheric corrosion by some form of transparent coating. ()ne example is a coating known as sol-gel. This coating can be applied like paint and, when cured, forms a thin glass-like coating. This and other novel processes are under development.

\section{Structure}

The challenge for concentrator designers is to cover a large area with reflective material while making the supporting structure rigid enough to hold its desired shape, and strong enough to survive the forces of nature, especially wind. Most current designs fall into the three categories described below.

Senuctural Optical Surtare

One common design option is to combine the optical elements with the structural elements. (One design used stamped metal gores (pie-shaped elements) bolted together along their edges. Alternative designs use laminated gore panels with honeycomb, foamglass, balsa wood, or corrugated sheet metal as a spacer between an outer face sheet and an inner face sheet that serves as the optical surface. These designs can suffer from heavy, inefficient structural members and result in large-scale warpage.

Shine trime

Another design option separates the optical elements from the structure. In this case, efficient tubular structural elements or truss segments carry the reflective mirror facets. Although lightweight and structurally efficient, this design requires considerably more fabrication and alignment than the structural gore.

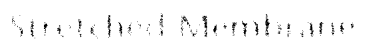

Atmospheric pressure canbe used to form the curvature of the reflective surface. Stretching a thin, reflective shin like a drumbead on a hoop and slightly evacuating the region behind it results in a concase, concentrating shape. Because a hoop in uniform compression is a highly efficient structural element, an extremely light weight supporting structure is possible. The lightweight reflective surface and the structural eflicience of a 


\section{Chapter 3}

stretched-membrane concent rator significantly reduces design, fabrication, and alignment costs.

The major disadvantage of this design is that the reflective membrane becomes spherical when the back side is evacuated. To compensate optically for this shape, long focal lengths (at which the spherical reflector approaches a paraboloid reflector) must be used. Concentrators using long-focal-length spherical mirrors can be designed. They either incorporate many small reflecting membrane facets mounted on a space frame with each aimed at a single focal point, or a single-membrane reflector with the receiver located far from it.

A concept currently being developed makes it possible to reduce the focal length of stretched-membrane facets, thereby decreasing the number of facets in a concentrator. In the case of a single facet concentrator, the space frame can be eliminated altogether. This approach involves preforming a thin metal membrane beyond its elastic limit using nonuniform loading so that when the space behind it is evacuated, the membrane forms a paraboloid rather than a spherical shape. The single paraboloidal stretched-membrane concentrator, however, presents a challenge with regard to tracking structure design.

\section{Tracking}

Parabolic dish concentrators must track about two independent axes so the rays of the sun remain parallel to the axis of the concentrator. There are two common implementations of two-axis tracking; azimuth-ele'vition (azel) and polar (equatorial) tracking. Azimuth-elevation tracking allows the concentrator to move about one tracking axis perpendicular to the surface of the earth (the azimuth axis) and another axis parallel to it (the elevation axis). Polar tracking uses one tracking axis aligned with the axis of rotation of the earth (the polar axis) and another axis perpendicular to it the declination axis). For either tracking method, the angle of incidence $H_{\text {, }}$ in Equation 3-1 remains zero throughout the day.

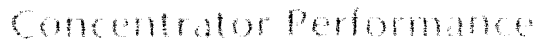

The primary measure of concentrator performance is how much of the insolation arriving at the collector aperture passes through an aperture of a specified size located at the focus of the concentrator. This measure is called concentrator or optical efficiency and is defined as:

$$
\Pi_{1 \mathrm{~m}}=E\left(\cos \theta_{i}\right) p \phi .
$$

Unshaded aperture area fraction $E$ is typically more than 95\% in most designs, and, as noted previously, the angle of incidence for a parabolic dish is zero, making its cosine 1.0. Therefore, the two critical terms in this equation are reflectance and capture fraction ( $\rho$ and $\phi)$. Because reflectance was discussed above, the remaining term defining the optical performance of a dish concentrator is the capture fraction $\phi$, which is discussed below.

\section{Capture Fraction}

The most important factor in matching a concentrator to a receiver is the coupture fruction (or intercept) $\phi$, the fraction of energy reflected from the concentrator that enters the receiver. This is defined for a certain receiver aperture, $A_{\text {rec, }}$ and is affected by the concentrator optical errors, tracking accuracy, mirror and receiver alignment accuracy, and the apparent size of the sun.

To ensure a high capture fraction, concentrator errors discussed previously must be small or receiver area must be large to allow capture of most energy reflected from the concentrator. However, a large receiver area means high heat losses. On the other hand, a small receiver area means lower heat losses, but concentrated energy is blocked from entering. Equation 3-1 shows that reducing receiver aperture area $A_{\text {rec }}$ for a given concentrator aperture area (i.e., increasing the concentration ratio $A_{\text {app }} / A_{\text {rec }}$ ) directly reduces heat loss because the surface area from which heat is lost is reduced. It is also seen that it is important to maximize the capture fraction $\phi$ since it directly affects the rate of energy production.

There is a direct relationship between capture fraction $\phi$ and receiver aperture area $A_{\text {rec }}$. Since increasing capture fraction by increasing aperture area increases the heat loss term, the benefit of the additional energy captured is often offset by increased energy losses. An important design trade-off is balancing these two factors.

If a concentrator has high optical errors, the receiver area must be large. The size of the receiver aperture can be reduced for a given capture fraction by using a secondary concentrator. As discussed above, a secondary concentrator collects reflected radiation from an area near the focus of the "primary" concentrator and "funnels" it into a smaller receiver aperture area. 


\section{Fundamental Concepts}

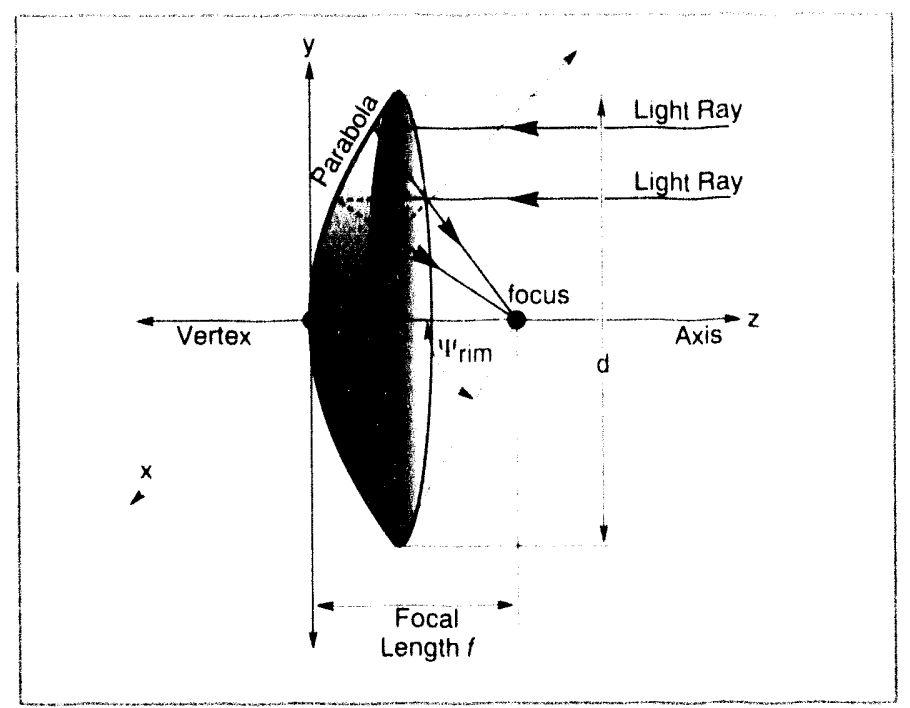

Figure 3-1. The paraboloid is a surface generated by rotating a parabola around the z-axis

angle $\Psi_{\text {rim }}$ - the angle measured at the focus from the axis to the rim where the paraboloid is truncated. Paraboloids for solar applications in general have rim angles from less than 10 degrees to more than 90 degrees. At small rim angles, a paraboloid differs little from a sphere. Faceted dish designs typically use spherical mirrors.

The relationship between $f / d$ and the rim angle $\Psi_{\text {rim }}$ is

$$
f / d=\frac{1}{4 \tan \left(\Psi_{\mathrm{rim}} 2\right)}
$$

For example, a paraboloid with a rim angle of 45 degrees has an $f / d$ of 0.6 . The ratio $f / d$ increases as the rim angle $\Psi_{\text {rim }}$ decreases. A paraboloid with a very small rim angle has very little curvature, and the focal point and the receiver must be placed far from the concentrator surface. Paraboloids with rim angles less than 50 degrees are used when the reflected radiation passes into a cavity receiver, whereas paraboloids with larger rim angles are best suited for external receivers. Because dish/Stirling systems do not use external receivers, their rim angles are less than 50 degrees.
Opencalteror

Operating concentrators typically have several optical errors that cause them to deviate from the theoretical optics of a paraboloid. Some optical errors are random and cause the optical image of the sun to spread at the focus. Reducing these errors usually increases concentrator cost, creating one of the major trade-offs in designing parabolic dish systems.

Even the best concentrator surfaces deviate from the ideal curve to which they are manufactured. This deviation, called slope error, is a measure of the angle by which the actual surface slope deviates from ideal. Because the slope error varies over the surface, it is typically specified statistically as one standard deviation from the mean and is expressed in milliradians. In general, the smaller the error in the optical surface, the more the collector costs. Well-manufactured parabolic dish concentrator surfaces can have a slope error of 2.5 milliradians (about 0.15 degrees). The use of multiple facets results in an approximation of a paraboloid and in itself reduces the amount of concentration obtainable. In addition, when a paraboloid is approximated by multiple facets, an error similar to slope error, called the facet alignment error, is introduced because the individual facets cannot be perfectly aimed.

A second source of optical error is the reflective surface itself. When a beam of parallel rays hits an optical surface, the reflected beam can be diffused. The extent to which this diffusion happens is called nomspecular reflectance. For example, polished metal or a reflectivecoated polymer will diffuse incident light more than a glass mirror.

Two optical alignment errors dislocate the actual focus from where it should be. (One is the error in mechanically aligning the receiver relative to the concentrator. The other, called tracking error, occurs when the concentrator axis does not point directly at the sun. Although not completely random, tracking errors are sometimes treated as such for simplicity.

One final factor that cannot be corrected by improving manufacturing quality is the apparent width of the sun. Because the sun is not a point source, its rays 


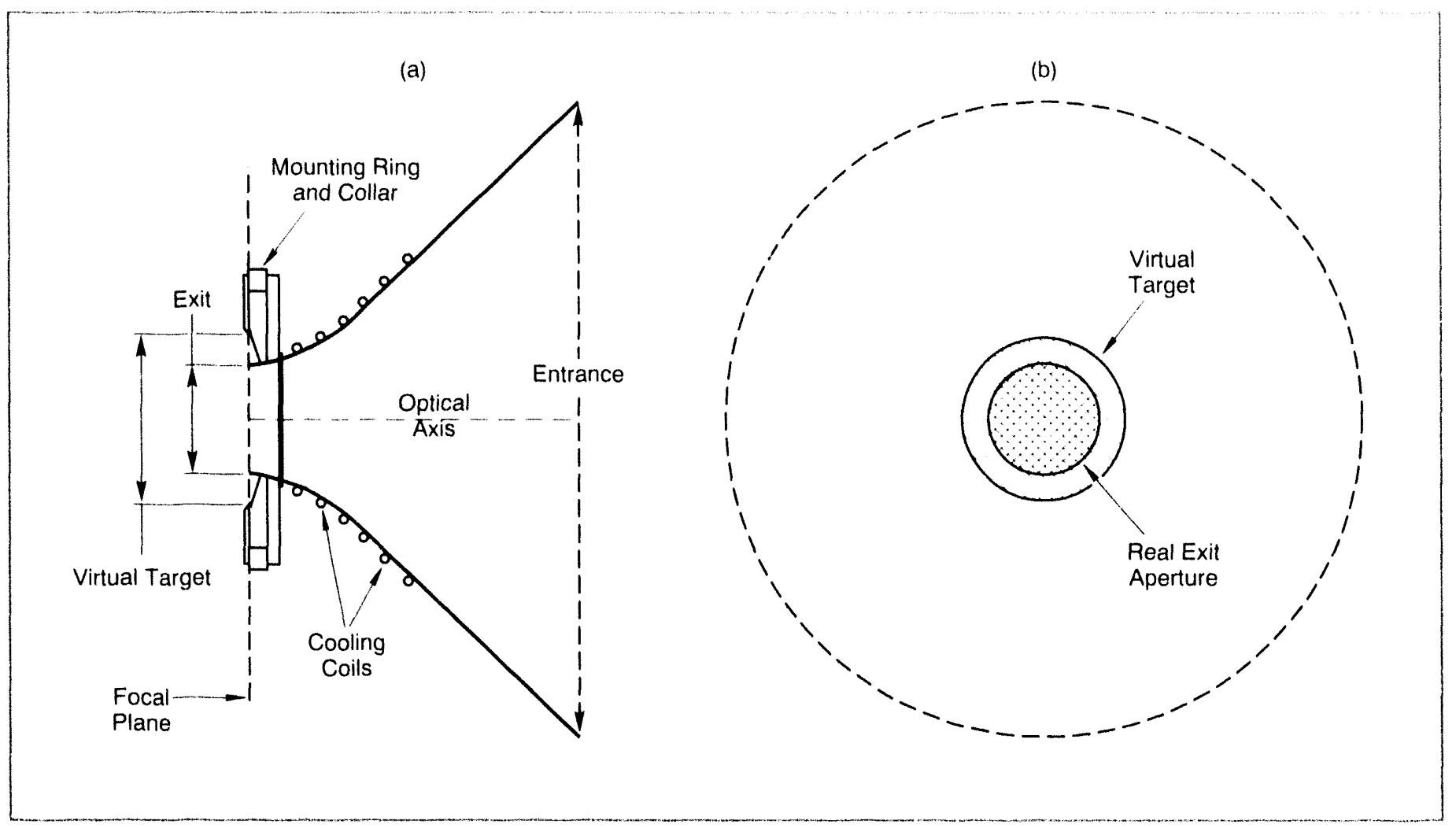

Figure 3-2. A secondary concentrator with side view (a) and head-on view (b).

are not parallel and therefore the reflected image spreads in a cone approximately 9.31 milliradians (0.533 degrees) wide. Called sumshape, this size increases and the edges become less defined with increased moisture or particulates in the atmosphere. The effect of sunshape is similar to the other optical errors and spreads the reflected radiation at the focus.

Secondary Concentrators

A secondary concentrator at the receiver aperture can be used to increase capture fraction without increasing receiver aperture size or to reduce aperture diameter for a given capture fraction. This highly reflective, trumpet-shaped surface (see ligure 3-2) "funnels" reflected radiation from a wide area through the cavity receiver aperture. The net result is an increase in the capture fraction without an increase in the receiver aperture area.

A secondaryconcentrator generally improves the performance of a parabolic dish. The addition of a secondary concentrator can reduce the negative effects of any or all of the components of optical error. However, a secondary concentrator adds to the collector cost. Also, because the secondary concentrator is located in a high flux density region, it must have high reflectance and welldesigned cooling.

\section{Reflective Materials}

Most concentrators depend on a reflective surface to concentrate the rays of the sun to a smaller area. The surfaces are either polished aluminum or silver or aluminum on either the front or back surface of glass or plastic. When silver or aluminum is deposited on the back surface of a protective transparent material, it is called a back-surfaced or second surface mirror. The quality of a reflective surface is measured by its reflectance and specularity. Reflectance is the percentage of incident light that is reflected from the surface. Specularity is a measure of the ability of a surface to reflect light without dispersing it at angles other than the incident angle. An ideal surface reflects all incident light rays at an angle equal and opposite to the angle of incidence. 


\section{Fundamental Concepts}

Most reflective surfaces are metal. Under laboratory conditions, polished silver has the highest reflectance of any metal surface for the solar energy spectrum. Aluminum reflects most of the solar spectrum but does not have the high reflectance of silver.

Back-Surface Silvered Glas;

Back-surface silvered-glass mirrors are made by silver plating the surface of a glass sheet and applying protective copper plating and protective paint to the silver coating. This technique has been used for numerous domestic applications, such as bathroom mirrors, for many years. For traditional mirrors, the glass is thick, making it heavy and difficult to bend into a concentrating shape. These mirrors typically have a low transmittance because common glass contains iron. Although a polished silver surface has a reflectance of almost $98 \%$, the resulting mirror does not have this high reflectance because incident light must pass twice through the thick, low-transmittance glass.

To increase solar applications of back-surfaced glass mirrors, thin-glass mirrors have been developed. The glasses used are usually iron-free and do not absorb strongly in the solar spectrum. These mirrors can have a solar reflectance of $95 \%$.

Reflective Plastic film

Aluminized plastic films are used in many current concentrator designs. A variety of plastic films with an evaporative deposited aluminum coating on the back surface have been used for many years for solar concentrator reflective surfaces. Although the optical and mechanical properties of most plastics degrade after long exposure to ultraviolet rays, adding stabilizers effectively slows this degradation. Low-cost, flexible, and lightweight silvered plastic films with a high reflectance (96\%) with high specularity) promise to be the reflective surface of choice for many new designs.

A drawback of metallized plastic films, however, is that they cannot be mechanically washed like glass. Some hard coatings for polymer films are being investigated (Jorgenson, 1993; Stine, 1989)

The reflective surface used in some early concentrators was polished aluminum sheet. These sheets are available in large sizes and are relatively inexpensive. Their major disadvantage is that they have only a moderate specular reflectance $(85 \%$ when now). Another disadvantage is their poor weatherability.

A recent concept under development is the application of a silver reflective coating directly to a structural surface of stainless steel or aluminum. These surfaces must be protected from atmospheric corrosion by some form of transparent coating. One example is a coating known as sol-gel. This coating can be applied like paint and, when cured, forms a thin glass-like coating. This and other novel processes are under development.

\section{Structure}

The challenge for concentrator designers is to cover a large area with reflective material while making the supporting structure rigid enough to hold its desired shape, and strong enough to survive the forces of nature, especially wind. Most current designs fall into the three categories described below.

Structural Optical Surface

One common design option is to combine the optical elements with the structural elements. One design used stamped metal gores (pie-shaped elements) bolted together along their edges. Alternative designs use laminated gore panels with honeycomb, foamglass, balsa wood, or corrugated sheet metal as a spacer between an outer face sheet and an inner face sheet that serves as the optical surface. These designs can suffer from heavy, inefficient structural members and result in large-scale warpage.

Space frame

Another design option separates the optical elements from the structure. In this case, efficient tubular structural elements or truss segments carry the reflective mirror facets. Although lightweight and structurally efficient, this design requires considerably more fabrication and alignment than the structural gore.

Structed Membram

Atmospheric pressure can be used to form the curvature of the reflective surface. Stretching a thin, reflective skin like a drumbead on a hoop and slightly evacuating the region behind it results in a concave, concentrating shape. Because a hoop in uniform compression is a highly efficient structural element, an extremely lightweight supporting structure is possible. The lightweight reflective surface and the structural efficiency of a 


\section{Chapter 3}

stretched-membrane concentrator significantly reduces design, fabrication, and alignment costs.

The major disadvantage of this design is that the reflective membrane becomes spherical when the back side is evacuated. To compensate optically for this shape, long focal lengths (at which the spherical reflector approaches a paraboloid reflector) must be used. Concentrators using long-focal-length spherical mirrors can be designed. They either incorporate many small reflecting membrane facets mounted on a space frame with each aimed at a single focal point, or a single-membrane reflector with the receiver located far from it.

A concept currently being developed makes it possible to reduce the focal length of stretched-membrane facets, thereby decreasing the number of facets in a concentrator. In the case of a single facet concentrator, the space frame can be eliminated altogether. This approach involves preforming a thin metal membrane beyond its elastic limit using nonuniform loading so that when the space behind it is evacuated, the membrane forms a paraboloid rather than a spherical shape. The single paraboloidal stretched-membrane concentrator, however, presents a challenge with regard to tracking structure design.

\section{Tracking}

Parabolic dish concentrators must track about two independent axes so the rays of the sun remain parallel to the axis of the concentrator. There are two common implementations of two-axis tracking; azimuth-elevation lazel) and polar (equatorial) tracking. Azimuth-elevation tracking allows the concentrator to move about one tracking axis perpendicular to the surface of the earth (the azimuth axis) and another axis parallel to it (the elevation axis). Polar tracking uses one tracking axis aligned with the axis of rotation of the earth (the polar axis) and another axis perpendicular to it the declination axis). For either tracking method, the angle of incidence 1, in Equation $3-1$ remains zero throughout the day.

Concentrator pertomance

The primary measure of concentrator performance is how much of the insolation arriving at the collector aperture passes through an aperture of a specified size located at the focus of the concentrator. This measure is called comientrator or optical efficiency and is defined as:

$$
\eta_{\mathrm{con}}=E\left(\cos \theta_{i}\right) \mu \phi .
$$

Unshaded aperture area fraction $E$ is typically more than $95 \%$ in most designs, and, as noted previously, the angle of incidence for a parabolic dish is zero, making its cosine 1.0. Therefore, the two critical terms in this equation are reflectance and capture fraction ( $\rho$ and $\phi)$. Because reflectance was discussed above, the remaining term defining the optical performance of a dish concentrator is the capture fraction $\phi$, which is discussed below.

\section{Capture Fraction}

The most important factor in matching a concentrator to a receiver is the capture fraction (or intercept) $\phi$, the fraction of energy reflected from the concentrator that enters the receiver. This is defined for a certain receiver aperture, $A_{\text {rec, }}$ and is affected by the concentrator optical errors, tracking accuracy, mirror and receiver alignment accuracy, and the apparent size of the sun.

To ensure a high capture fraction, concentrator errors discussed previously must be small or receiver area must be large to allow capture of most energy reflected from the concentrator. However, a large receiver area means high heat losses. On the other hand, a small receiver area means lower heat losses, but concentrated energy is blocked from entering. Equation 3-1 shows that reducing receiver aperture area $A_{\text {rec }}$ for a given concentrator aperture area (i.e., increasing the concentration ratio $A_{\text {app }} / A_{\text {rec }}$ ) directly reduces heat loss because the surface area from which heat is lost is reduced. It is also seen that it is important to maximize the capture fraction $\phi$ since it directly affects the rate of energy production.

There is a direct relationship between capture fraction $\phi$ and receiver aperture area $A_{\text {rec. }}$. Since increasing capture fraction by increasing aperture area increases the heat loss term, the benefit of the additional energy captured is often offset by increased energy losses. An important design trade-off is balancing these two factors.

If a concentrator has high optical errors, the receiver area must be large. The size of the receiver aperture can be reduced for a given capture fraction by using a secondary concentrator. As discussed above, a secondary concentrator collects reflected radiation from an area near the focus of the "primary" concentrator and "funnels" it into a smaller recejver aperture area. 


\section{Fundamental Concepts}

\section{Receivers}

The receiver is the interface between the concentrator and the engine. It absorbs concentrated solar flux and converts it to thermal energy that heats the working gas of the Stirling engine. The absorbing surface is usually placed behind the focal point of a concentrator so that the flux density on the absorbing surface is reduced. An aperture is placed at the focus to reduce radiation and convection heat loss from the receiver. The cavity walls between receiver aperture and absorber surface are refractory surfaces. The size of the absorber and cavity walls is typically kept to a minimum to reduce heat loss and receiver cost. (A summary of receiver development for dish/Stirling systems may be found in Diver et al. [1990]).

Receiver operation can be understood in terms of the shaded portions shown below of the fundamental solar collection equation, which was introduced at the beginning of this chapter:

$$
\begin{aligned}
Q_{\mathrm{useful}}= & I_{b, n} A_{\mathrm{app}} E\left(\cos \theta_{i}\right) \rho \phi \tau \alpha \\
& -A_{\mathrm{rec}}\left[U\left(T_{\mathrm{rec}}-T_{\mathrm{amb}}\right)\right. \\
& \left.+\sigma F\left(T_{\mathrm{rec}}^{4}-T_{i \mathrm{mb}}^{4}\right)\right] .
\end{aligned}
$$

(See the beginning of this chapter for complete definitions of all the parameters in Equation 3-8.) The following parameters in the fundamental solar collection equation (which are shaded in Equation 3-8) are affected by receiver design:

- transmittance $\tau$

- absorptance $\alpha$

- receiver aperture area $A_{\text {rec }}$

- convection-conduction heat loss coefficient $U$

- equivalent radiation conductance $F$

- receiver operating temperature $T_{\text {rec }}$.

The first two terms (transmittance and absorptance) are optical parameters and should be maintained as close as possible to their maximum value of 1.0. The remaining parameters are found in the subtractive terms on the right-hand side of the equation, which represents the heat lost from the receiver. A receiver design objective is to minimize these values.

\section{Receiver Design}

In general, two types of receivers could be used with parabolic dish concentrators: external (omnidirectional) and cavity receivers. External receivers have absorbing surfaces in direct view of the concentrator and depend on direct radiation absorption. Cavity receivers have an aperture (opening) through which reflected radiation passes. The cavity ensures that most of the entering radiation is absorbed on the internal absorbing surface.

External receivers are usually spherical and absorb radiation coming from all directions. The apparent size of an external (spherical) receiver is the same for sunlight being reflected from any part of the reflecting surface. This is different from a cavity receiver aperture, which appears smaller and therefore captures less reflected sunlight from areas toward the outer rim of a concentrator. Concentrators matched to spherical external receivers, therefore, can have wide rim angles, more than 90 degrees. This provides some advantages for concentrator design such as short focal length and structural support across the aperture.

Because they generally have lower heat loss rates at high operating temperatures, only cavity receivers (instead of external receivers) have been used in dish/Stirling systems to date. (External receivers, however, have been used in lower temperature parabolic dish applications.) Concentrated radiation entering the receiver aperture diffuses inside the cavity. Most of the energy is directly absorbed by the absorber, and most of the remainder is reflected or reradiated within the cavity and is eventually absorbed.

A major advantage of cavity receivers is that the size of the absorber may be different from the size of the aperture. With a cavity receiver, the concentrator's focus is usually placed at the cavity aperture and the highly concentrated flux spreads inside the cavity before encountering the larger absorbing surface area. This spreading reduces the flux (rate of energy deposited per unit surface area) incident on the absorber surface. When incident flux on the absorbing surface is high, it is difficult to transfer heat through the surface without thermally overstressing materials. 


\section{Chapter 3}

A second advantage of cavity receivers is reduced convection heat loss. The cavity enclosure not only provides protection from wind but also, depending on its design and angle, can reduce natural convection. However, because the internally heated surface area of a cavity (both absorber and uncooled refractive walls) is usually large, and the aperture typically tilted, strong buoyancy forces cause natural convection currents that draw cool ambient air into the cavity. Despite these currents, however, the cavity receiver generally has lower overall heat loss and is preferable to the external receiver for hightemperature applications such as dish/Stirling systems.

\section{Operating Temperature}

While high operating temperature means high solarto-electric conversion efficiency for engines, a fundamental trade-off exists between the advantages of high receiver temperatures and the disadvantage of lower receiver efficiency resulting from these high temperatures. Equation 3-1 demonstrates that increasing the operating temperature increases heat loss, thereby reducing the useful energy supplied by the collector. With the exception of the Stefan-Boltzmann constant $\checkmark$, the parameters that multiply the receiver temperature $\left(A_{\mathrm{rec}}, U\right.$, and $\left.F\right)$ are functions of receiver design and can be reduced to lower heat loss.

\section{Transmittance}

Convective loss from inside a cavity receiver could be eliminated by covering the aperture with a transparent window. A window, however, reduces incoming energy by the transmittance term $\mathrm{T}$ in Equation 3-1. Transmittance is simply the fraction of energy that gets through the cover. For clean fused quartz, the value of this term is about 0.9 .

\section{Absorptance}

Generally, tals used for absorber surfaces rapidly darken and at.uin relatively high absorptance ( $(\alpha)$ levels when exposed to the atmosphere at the higt: operating temperatures of dish/Stirling systems. Coating the absorbing surface with a material with a high absorptance value for radiation in the solar (visible) spectrum enhances receiver performance. Typically these coatings are dull black. Coatings are available that have an absorptance of over 0.90 and can withstand temperatures as high as $6000^{\circ} \mathrm{C}$. The effective absorptance of the cavity receiver is always greater than the absorptance of the interior surface coating but is never greater than 1.().
Conduction Comvedion Heat loss

Decreasing the convection-conduction heat-losscoefficient $l$ in liquation $3-1$ can also improve receiver performance. Wind velocity and receiver attitude affect the convection component of $U$, and their effects can be reduced by putting a window at the aperture of a cavity receiver, but not without reducing transmittance (see discussion above).

Two conduction loss paths in the receiver affect the conduction component of $U$. These are heat loss from the cavity through the surrounding insulated walls and heat conduction through the receiver's supporting structure.

\section{Radiation Losses}

The equivalent radiative conductance $(F)$ combines the ability of a surface to lose energy by radiation with the ability of the surroundings to absorb this energy. This parameter is mostly affected by the emittance of the surfaces within the receiver; high emittance values give high equivalent radiative conductance values. The apparent emittance of the receiver's aperture is higher than the emittance of the absorber because of the cavity effect.

Surface coatings, called selective coatings, have been designed that have high absorptance for solar radiation but low emittance values for long-wavelength (thermal) radiation. However, many of these coatings degrade rapidly in the high-flux environment of a parabolic dish receiver. These work best when the radiation temperature is low. For dish/Stirling systems, selective surface coatings are less effective since there is a significant overlap between the solar spectrum being absorbed and the $700^{\circ}$ to $8000^{\circ} \mathrm{C}$ radiation spectrum of dish/Stirling systems.

\section{Materials Selection}

A factor important to receiver design is thermal fittigue of receiver components. Thermal fatigue is caused by temperature cycling from ambient to operating temperature, both from daily start-up and shutdown, and during variable-cloud weather. This cycling can cause early receiver failures. Receiver designs that incorporate thin walls and operate at uniform temperatures during insolation transients typically have fewer problems with thermal fatigue. long-term creep of receiver materials and oxidation from the surrounding air are also important considerations in material selection. 


\section{Fundamental Concepts}

\section{Receiver Performance}

The performance of a receiver is defined by the receiver thermal efficiency. Receiver thermal efficiency is defined as the useful thermal energy delivered to the engine divided by the solar energy entering the receiver aperture. Using terms from the fundamental solar collection equation, receiver thermal efficiency can be written as:

$$
\eta_{\text {rec }}=\tau \alpha-\frac{U\left(T_{\mathrm{rec}}-T_{\mathrm{amb}}\right)+\sigma F\left(T_{\mathrm{rec}}^{4}-T_{\mathrm{amb}}^{4}\right)}{\eta_{\mathrm{conc}} C R_{\mathrm{g}} I_{l, n}} .
$$

As can be seen in Equation 3-9, receiver efficiency can be enhanced by increasing cover transmittance, increasing surface absorptance, reducing operating temperature, or reducing the capacity of the cavity to lose heat by conduction, convection, and radiation (the $U$ and $F$ terms).

\section{Stirling Engines}

Stirling cycle engines used in solar dish/Stirling systems are high-temperature, externally heated engines that use a hydrogen or helium working gas. In the Stirling cycle, the working gas is alternately heated and cooled by constant-temperature and constant-volume processes. Stirling engines usually incorporate an efficiencyenhancing regenerator that captures heat during constant-volume cooling and replaces it when the gas is heated at constant volume.

There are a number of mechanical configurations that implement these constant-temperature and constantvolume processes. Most involve the use of pistons and cylinders. Some use a displacer (piston that displaces the working gas without changing its volume) to shuttle the working gas back and forth from the hot region to the cold region of the engine. For most engine designs, power is extracted kinematically by a rotating crankshaft connected to the piston(s) by a connecting rod. An exception is the free-piston configuration, where power piston and aisplacer bounce back and forth on springs, and power is extracted from the power piston by a linear alternator or pump. These configurations are described below.

For dish/Stirling applications, an electric generator or alternator is usually connected to the mechanical out- put of the engine. (These combined engine/alternators are called converters.) Generally, alternators are commercially available and adapt directly to the output shaft of the engine. The exception is the free-piston Stirling engine, which in some designs incorporates a linear alternator. Alternator efficiencies are typically well over $90 \%$.

\section{The Stirling Cycle}

In the ideal Stirling cycle, a working gas is alternately heated and cooled as it is compressed and expanded. Gases such as helium and hydrogen, which permit rapid heat transfer and do not change phase, are typically used in the high-performance Stirling engines used in dish/Stirling applications. The ideal Stirling cycle combines four processes, two constant-temperature processes and two constant-volume processes. These processes are shown in the pressure-volume and temperature-entropy plots provided in Figure 3-3. Because more work is done by expanding high-pressure, high-temperature gas than is required to compress low-pressure, low-temperature gas, the Stirling cycle produces net work, which can drive an electric alternator.

In the ideal cycle, heat is rejected and work is done on the working gas during the constant temperature compression process $1-2$. The amount of work required for this process is represented by the area $a-1-2-b$ in the pressure-volume $(p-v)$ diagram, and the amount of heat transferred from the working gas by the area a-1-2-b on the temperature-entropy ( $T-s)$ diagram. The next process is constant-volume heat addition (2-3), where the working gas temperature is raised from the heat input temperature $T_{L}$ to the heat rejection temperature $T_{I I}$. No work is done in this process. This heat addition is represented by the area b-2-3-c in the $T-s$ diagram. Following this is the constant-temperature expansion process (3-4), where work is done by the working gas as heat is added. This work is represented by the area b-3$4-a$ in the $p-v$ diagram and the heat addition by the area $c-3-4-d$ in the $T-s$ diagram. The cycle is completed by a constant-volume heat rejection process (4-1), where no work is done and the heat rejected is represented by the area a-1-4-d in the $T$-s diagram.

Work is done on or produced by the cycle only during the constant-temperature processes, but heat is transferred during all four processes. The net amount of work done is represented by the area $1-2-3-4$ in the $p-1$, 


\section{Chapter 3}

diagram. Because energy - be it in the form of heat or work - is conserved (the first law of thermodynamics), there is also a net amount of heat that must be added to the cycle to produce this work. This heat is represented by the area $1-2-3-4$ in the $T-s$ diagram.

An important advantage of the Stirling cycle is the capability of using a regenerator to full effect (i.e., eliminating all inefficient heat transfer). As shown graphically on the $T$-s diagram, the heat rejected during the constant volume heat rejection (area a-1-4-d) can be reused in the constant volume heating process (area b-2$3-c)$. Heat is, therefore, only added or rejected in efficient constant-temperature processes, which is the basis for the extremely high performance potential of the Stirling cycle. In fact, with regeneration, the efficiency of the Stirling cycle equals that of the Carnot cycle, the most efficient of all ideal thermodynamic cycles. (See West (1986) for further discussion of the thermodynamics of Stirling cycle machines.)

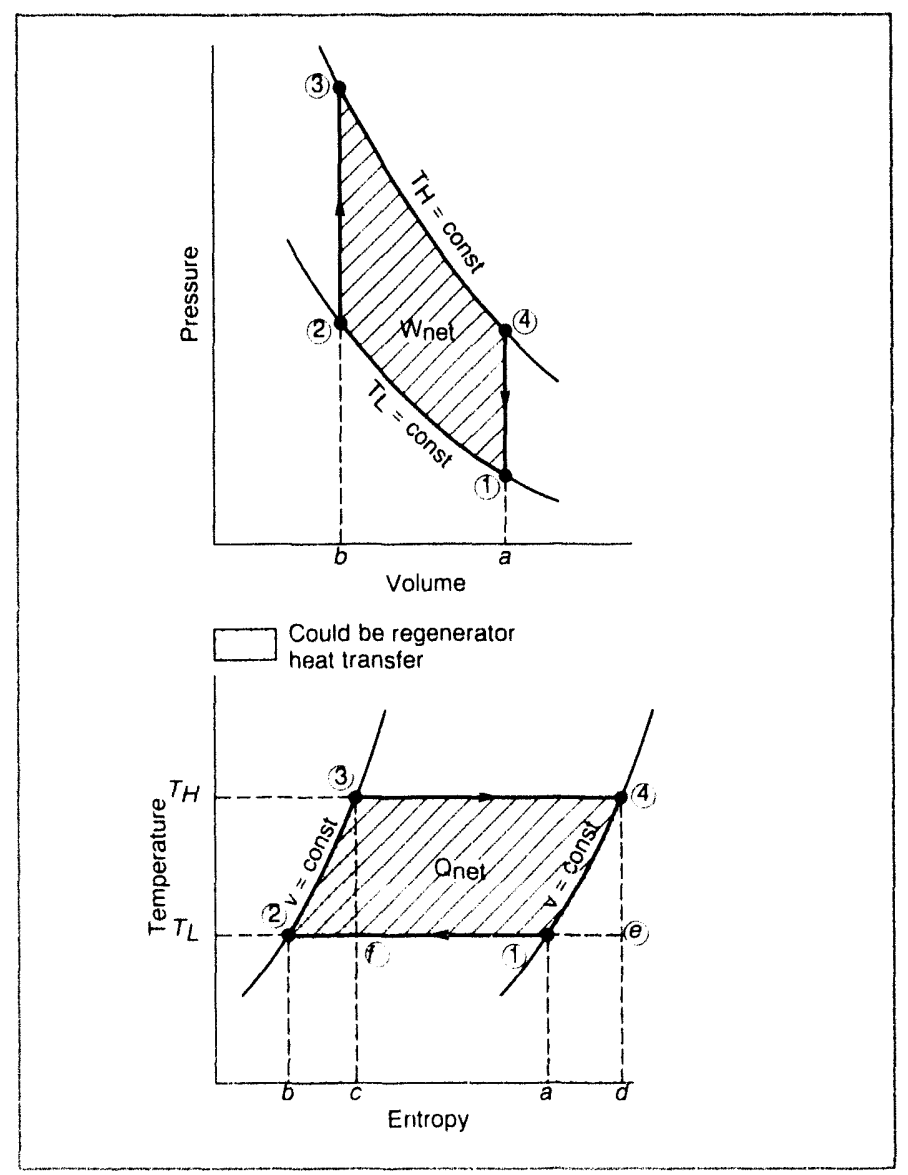

Figure 3-3. The four processes of an ideal Stirling engine cycle (Stine and Harrigan, 1985).
Kinematic Stirling Engines

The processes described above are shown in ligure 3-4 as they occur in a kinematic (mechanically driven piston and cylinder type) Stirling engine. Although there are different configurations for implementing the four basic processes in a real engine, the configuration shown is typical and similar to that used in the United Stirling 4-95 and other engines described later. In process 1-2, the left-hand or cold piston compresses the working gas while it is cooled. The cool gas is then pushed through the regenerator in process $2-3$, regaining heat stored there in the previous cycle, while the right-hand or hot piston moves back to maintain constant volume (therefore requiring no work). The working gas is then heated as it expands against the hot piston (process 3-4), thereby producing work. Finally, in process 4-1, the hot gas is shuttled back through the regenerator (with no change in volume), giving up heat to the regenerator and reentering the low-temperature part of the engine.

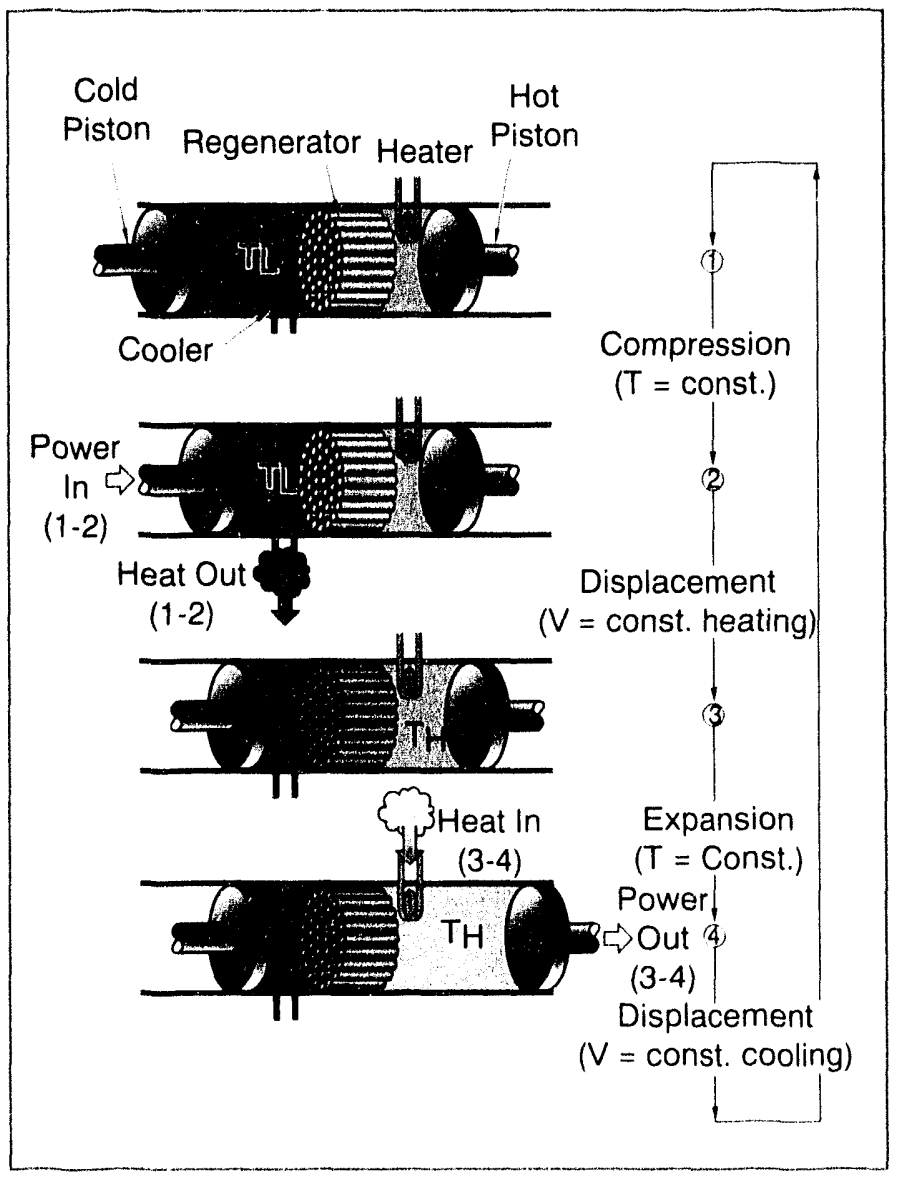

Figure 3-4. Basic processes of a kinematic Stirling engine. (Numbers refer to states in Figure 3-3.) 
In dish/Stirling systems, the high-temperature heat is transferred into the engine from the receiver. Heat is transferred out of the engine and rejected to the atmosphere by a cooling system. Dish/Stirling cooling systems are similar to those used on automobiles, typically involving a pumped ethylene glycol/water coolant and a radiator.

Free Piston Stirling Engines

An innovative way of accomplishing the Stirling cycle is employed in the free-pistom engine. ligure 3-5 is a schematic representation showing the mechanical operation and thermodynamics of these engines. $A$ heat- pipe receiver is also shown in ligure $3-5$. The thermodynamic operation of the free-piston stirling engine is identical to that of the kinematic Stirling engine. The freepiston engine, however, operates without mechanical linkages, and gas or mechanical springs are used to impart the correct motions to the reciprocating pistons. liree-piston engines have the potential advantages of simplicity, low cost and ultrareliability.

\section{Engine Efficiency}

Heat engine efficiency is the fraction of thermal energy provided by the receiver that can be converted into mechanical work. The efficiency of a

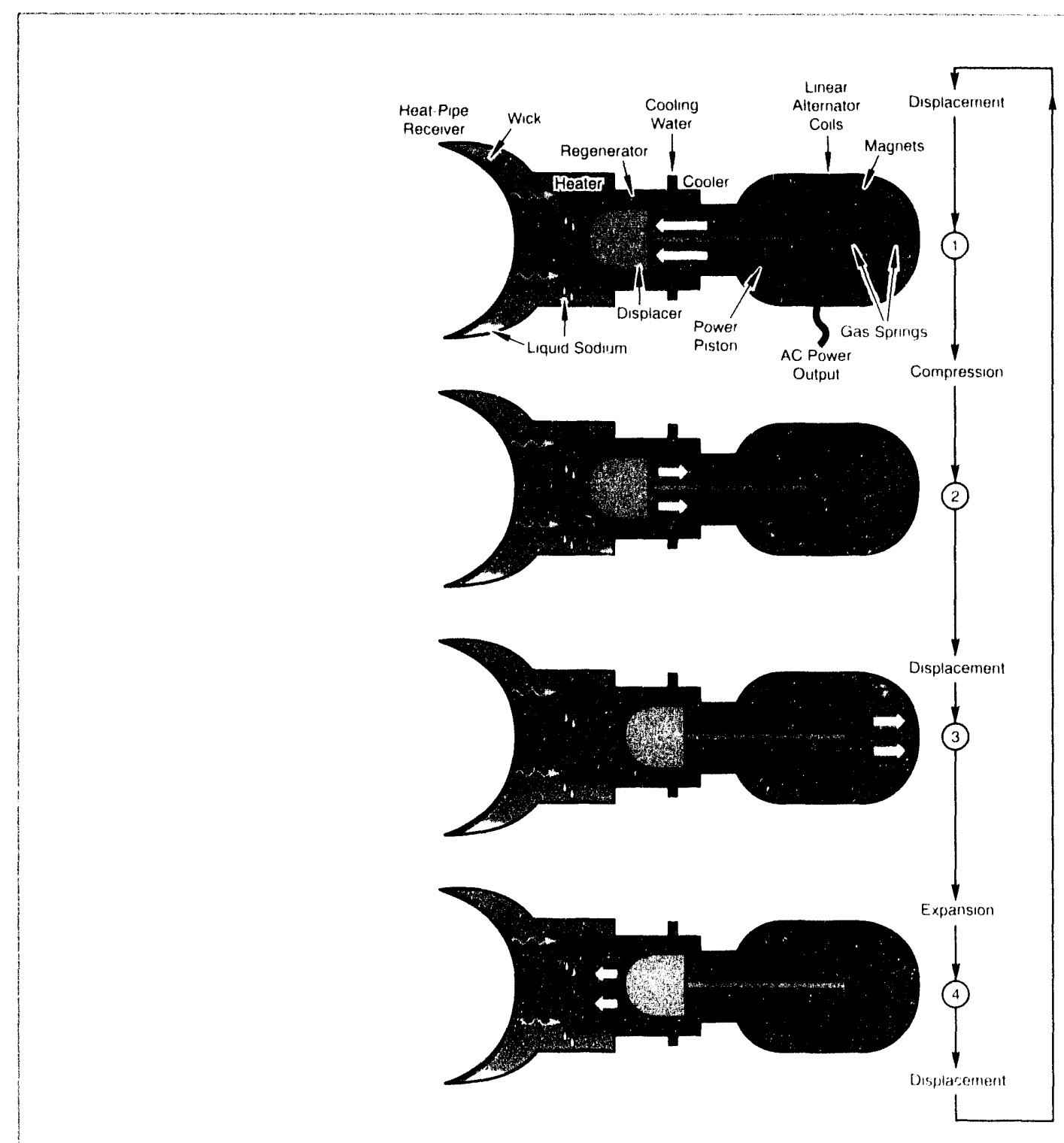

Figure 3-5. Basic processes of a free-piston Stirling engine. (Numbers refer to states in Figure 3-3.) 
thermal conversion cycle/engine is limited by the Carnot cycle (ideal engine) efficiency derived from the second law of thermodynamics. Carnot cycle efficiency' is a function of only the temperatures at which heat is transferred to and from the engine and forms a theoretical limit to the efficiency of any engine.

The efficiency of a real engine, called engine efficiency, can be written in terms of Carnot cycle efficiency as

$$
\eta_{\mathrm{eng}}=\beta_{\text {Carnot }}\left(1-T_{L} / T_{H}\right)
$$

where:

$$
\begin{aligned}
& \beta_{\text {Carnot }}=\text { the ratio of actual engine efficiency to } \\
& \text { Carnot cycle efficiency } \\
& T_{H} \quad=\text { heat input temperature (absolute tem- } \\
& \text { perature - i.e., }{ }^{\circ} \mathrm{R} \text { or } \mathrm{K} \text { ) } \\
& T_{L} \quad=\quad \text { heat rejection temperature (also absolute } \\
& \text { temperature). }
\end{aligned}
$$

The term $\left(1-T_{l} / T_{H}\right)$ is the Carnot cycle efficiency.

Equation 3-10 shows that raising the heat input temperature improves engine efficiency. Regardless of the size of the collector or how much energy is being converted for a fixed heat rejection temperature (usually close to ambient temperature), the higher the temperature of thermal energy input, the higher the engine efficiency.

Equation 3-10 also shows that lowering the cooling temperature improves engine efficiency. In the design of dish/Stirling systems, considerable effort is spent designing cooling systems that reject heat at temperatures as close as possible to ambient temperature.

\section{Alternator Efficiency}

Because dish/Stirling systems produce electrical power, an alternator or generator is connected to the engine. Altermator efficiency, $\eta_{a l t}$, is defined in terms of the mechanical power required to generate electrical power:

$$
\eta_{\text {alt }}=\frac{\text { electrical power output }}{\text { mechanical power input }} \text {. }
$$

Generally, alternator efficiencies are high, well above $90 \%$. Efficiencies approaching $100 \%$ are possible, but generally at prohibitive cost.

\section{System Performance and Economics}

\section{Overall System Performance}

Solar-to-electric conversion efficiency is one of the most important parameters affecting the cost of the electricity from a dish/Stirling system. It is determined by the combined solar collector and Stirling engine efficiencies, along with parasitic losses.

Solar-to-Electric Conversion Efficiency Gross solar-to-electric conversion efficiency is the product of Equations 3-7, 3-9, 3-10 and 3-11:

$$
\eta_{\text {conv,gross }}=\eta_{\text {conc }} \eta_{\text {rec }} \eta_{\text {eng }} \eta_{\text {alt }} \text {. }
$$

However, the most important measure of dish/Stirling system performance is the net solar-to-electric conversion efficiency (Stine and Powell, 1993). For this parameter, the electric power consumed to operate the system, called parasitic power ( $\left.P_{\text {parasitics }}\right)$, must be subtracted from the gross output of the alternator. In mathematical terms, net solar-to-electric conversion efficiency is

$\eta_{\text {conv, net }}=\eta_{\text {conv,gross }}-\frac{P_{\text {parasitics }}}{l_{b, n} A_{\text {app }}}$.

Parasitic power includes electrically driven cooling fans, cooling pumps, controls, and tracking motors.

\section{Energy Production}

Up to this point, the instantaneous performance of a dish/Stirling system has been presented. Power is the instantaneous measure of how fast energy is being produced at any given time. Ultimately, one is interested in how much electrical chergy is produced by the system over a period of time. For example, a system may produce $25 \mathrm{~kW}$ of electrical power at noon when the insolation is $1,000 \mathrm{~W} / \mathrm{m}^{2}$; however, of more interest to the user is whether the system was able to produce $250 \mathrm{kWh}$ (kilowatt-hours) of electrical energy during that day. 
If power output is constant, a simple multiplication of power times the length of time it is produced is all that is necessary to calculate the energy produced. However, if power varies over a period of time, the power must be integrated over that period to obtain energy. Figution 3-14 shows this integration todetermine the net amount of energy $E$ produced over a year:

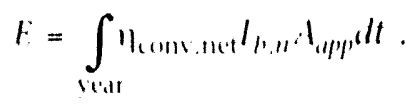

Compared to other solar electric conversion systems, dish/Stirling systems have the ability to produce large amounts of energy over a day (or a year). This is mainly because of the inherent high efficiency of dish/ Stirling systems. In addition, because components generally have low thermal inertia, dish/Stirling systems respond rapidly to transients (to take advantage of available sunlight) and have minimal energy loss during cooldown.

Levelized Energy Cost

The ultimate goal in developing dish/Stirling systems is to reduce the average cost of energy delivered over the lifetime of the system. Called levelized energy cost (l.tic), this is the fundamental parameter defining the economics of a dish/Stirling (or any other) energy producing system. l.t. is the cost of producing energy divided by the amount of energy produced.

The cost of producing electricity is the cost to operate the system for a typical year plus the yearly payment required to pay back the initial cost of building the system (capital cost) divided into equal installments at a specified interest rate (Stine, 1989). Total energy produced for a year is the net electrical power output of the system integrated (summed) over a year. Llic can therefore be expressed mathematically as

$$
\text { LEC }=\frac{\text { OMC +CC [ }\left[\begin{array}{c}
i(1+i)^{n} \\
(1+i)^{n}-1
\end{array}\right]}{E}
$$

where C( is the total capital cost of the system, ()MC: is the yearly operating and maintenance cost of the system, and $l$ is the net amount of energy produced overa year (liquation 3-14). The ferms iand 1 in liquation 3-1.5 are the interest rate on capital and the life of the system in years, respectively.

Equation 3-1.5 shows that to reduce the cost of solarderived energy from a dish/Stirling system, the system must be in a region of high insolation, incorporalle efficient concentrators and power conversion systems, and have a low capital and operating cost and a long lifetime. In addition, because dish/Stirling systems (like all solar energy systems) are capital intensive, the cost of electricity is strongly dependent on the cost of money, $i$.

A well-designed dish/Stirling system is an optimum balance between cost, performance, and reliability. consequently, trends in the design of its components must be judged for their economic benefit. This means incorporating their cost and performance into system trade-off studies where levelized energy cost is calculated. Valid comparisons between efficiency versus lifetime, initial cost versus efficiency, or initial cost versus subsequent maintenance costs can then be made.

In the end, it is the cost of the energy produced by a dish/ Stirling system that matters for commercialization. Advanced components only make sense if the Llic of the energy produced by that system is reduced. 
Chapter 3

Notes 


\section{Chapter 4: Technology Advancement}

This chapter surveys advancement of dish/Stirling technology under way in industrial hardware development and government-led technology development programs. Projections for future development of dish/Stirling components are also examined in this chapter.

\section{Hardware Development Programs}

Clever Fellows Innovation Consortium (USA) Engineers previously employed in Stirling programs at Mechanical Technologies Incorporated (MTI) founded Clever Fellows Innovation Consortium, Inc., of Troy, New York. They provide research and development and prototype manufacturing services to manufacturers of Stirling engine and alternator systems. Currently, they are providing support to Cummins Power Generation for the development of $7.5 \mathrm{~kW}$ and $25-\mathrm{kW}$ engines. Clever Fellows is also building test machinery and linear alternators for the space power engine of NASA Lewis Research Center.

Cummins Power Generation, Inc. (USA)

Cummins Power Generation, Inc. (CPG), of Columbus, Indiana, has been developing not only a $7.5-\mathrm{kW}_{\mathrm{k}}$ dish/ Stirling system for the remote-applications market, but also a $25-\mathrm{kW}$ free-piston Stirling engine for terrestrial power generation (Figure 4-1) under the NASA Advanced Stirling Conversion Systems (ASCS) program (Shaltens and Schreiber, 1990). The preliminary engine design has a single cylinder and incorporates a linear alternator that permits the entire engine and alternator to be hermetically sealed. The working gas is helium at $10.5 \mathrm{MPa}(1520 \mathrm{psi})$ and the maximum heater head temperature is $700^{\circ} \mathrm{C}\left(1300^{\circ} \mathrm{F}\right)$. A sodium heat-pipe receiver is used in this design.

\section{HTC Solar Research (Germany)}

HTC: Solar Forschungs-Centrum (imbH (Solar Research Center) (formerly Bomin Solar) of Lörrach, Germany, is developing two dish/Stirling systems. The first HTC Solar Research dish/Stirling system will use a stretchedmembrane concentrator and HTC's $3-\mathrm{kW}$ kinematic Stirling engine. The engine is a hermetically sealed $75-\mathrm{cm}^{3}\left(4.6-\mathrm{in}^{3}\right)$ single-cylinder engine with a dry, pressurized crankcase and permanently lubricated and sealed

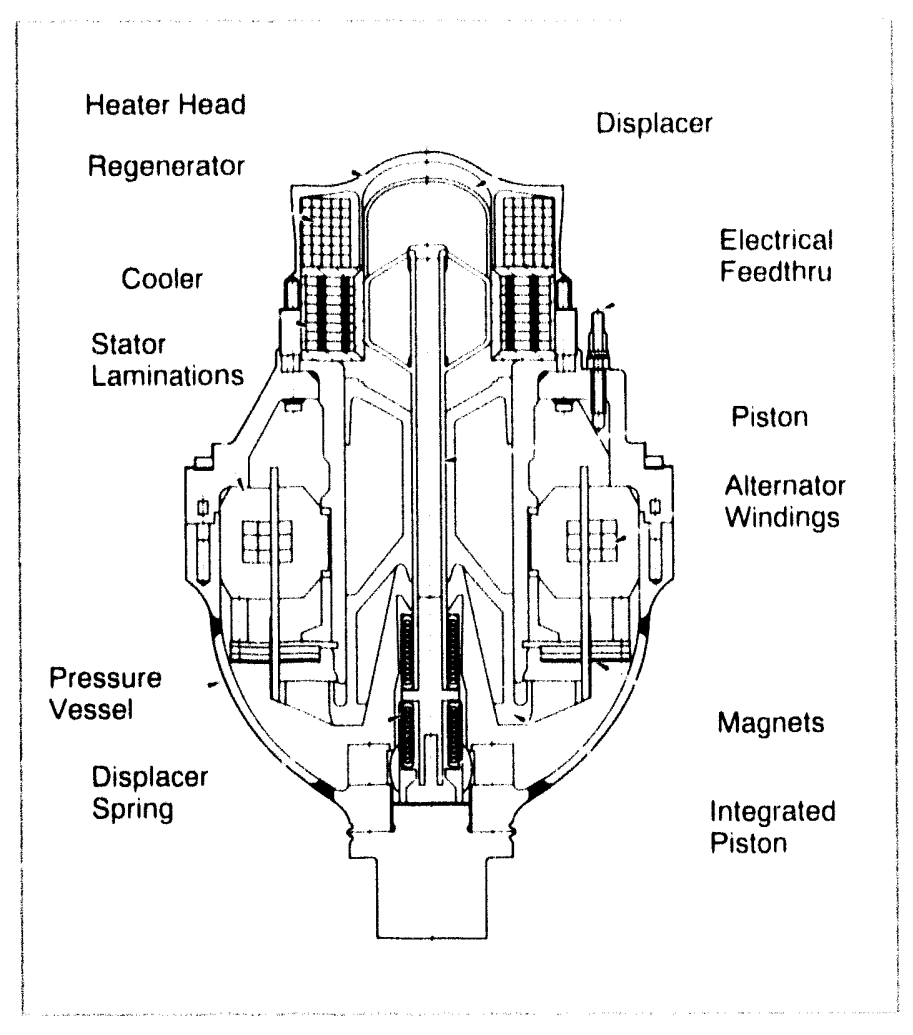

Figure 4-1. Cummins Power Generation 25-kW engine.

bearings (ligure 4-2). Power extraction through the pressurized casing is accomplished with either magnetic couplings through the pressure housing or with integrated generators inside the pressure housing.

The second HTC: Solar Research Center dish/Stirling system uses HTC's fixed-focus concent rator (focal point remains fixed while paraboloidal segments track the sun). At the focus is a heat-pipe recciver that transfers heat to both a Stirling engine and to magnesium hydride thermal storage. Excess heat not used by the engine drives off hydrogen from the magnesium hydride. This hydrogen goes to a lower-temperature titanium hydride storage where domestic hot water may be heated as the gas is absorbed. At night, the process reverses, providing cooling (for refrigeration) at the lowtemperature storage, and heating at the high-temperature storage, which can be used either to cont inue operation of the Stirling engine or to provide heat for cooking. 


\section{Chapter 4}

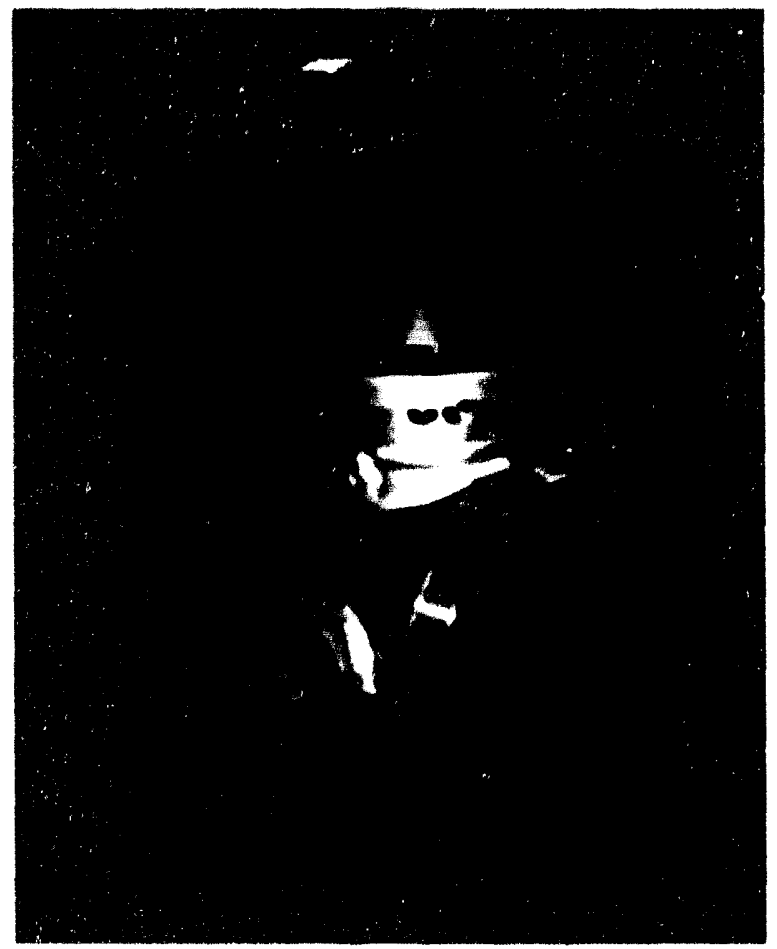

1) Heater Tubes

2) Displacer Piston

3) Regenerator

4) Cooler

5) Power Piston

6) Generators

7) Drive
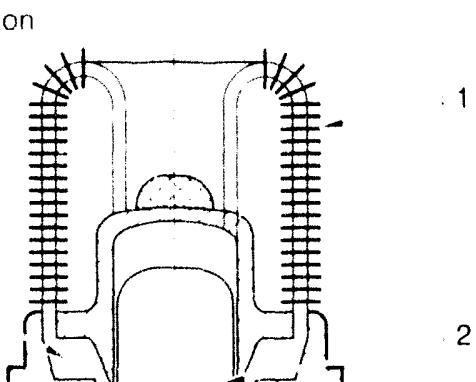

3

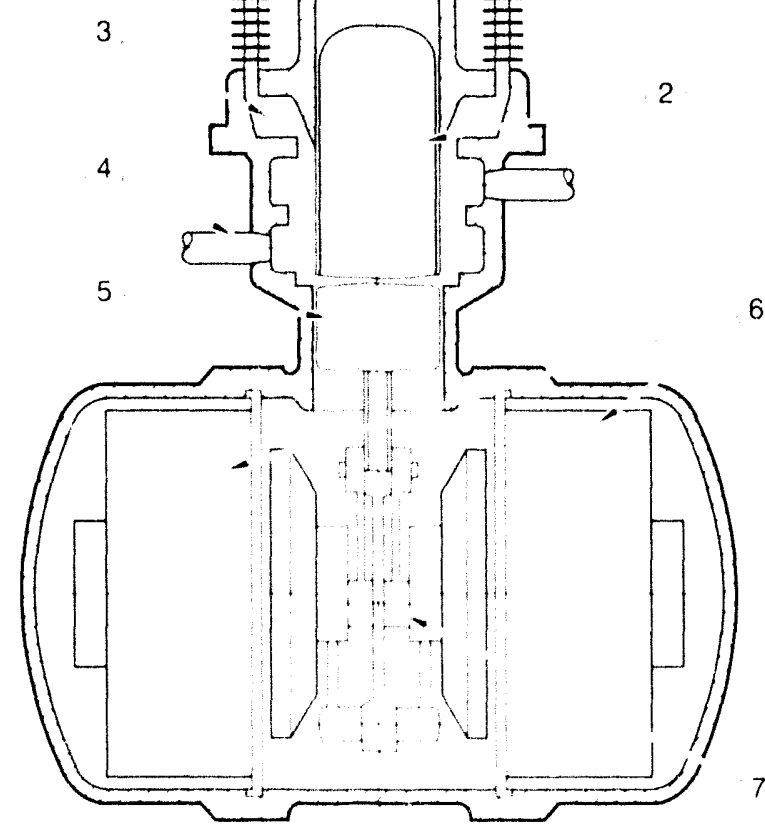

Figure 4-2. The HTC Solar Research 3-kW engine.

Hydrogen Engineering Associales, (USA)

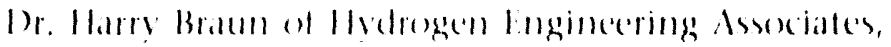

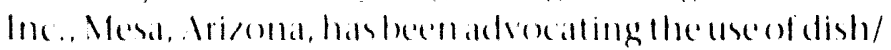
stirling systems in the southwest high desert areas to poride edectrical powere to produce hyclrogen. To this end, the companty is purchasing the manufacturing

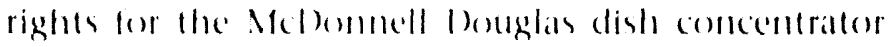
trom Southern Calitornia fidison. Braun feels that, becallse many components of dish/Stirling systems are similar to those manutactured for antomobiles, these systems lend themselverstomass production fechnicpues and therefore can supply inexpensive electrical power (Braun, 1092).

\section{Mechanical Technology Incorporated (USA)}

Mechanical Technology Incorporalled (MTl) of Latham, New York, has been developing Stirling engine technology since the mid-197()s, including both kinematic and free-piston engines (cairelli et al., 1991). Kinematic Stirling engine development has focused on applications for automotive and stationary generators, hybrid vehicles, and air-independent undersea engines. Freepiston Stirling technology has been directed at space power comversion and residential heat pumps. MTl's free-piston Stirling component lechnology power converter achieved design power $\left(1.3 \mathrm{~kW}_{\mathrm{t}}\right.$ ) and efficiency $\left(>22^{\%} \%\right.$ between $677^{\circ}$ and $1.52\left(.(125)^{\circ}\right.$ and $\left.306^{\circ} \%\right)$. This power converter has subsequently been successfully coupled with a heat pipe. Mll has also worked on free-piston Stirling engine designs for terrestrial solar applications.

\section{Sanyo (Japan)}

The NS30S engine is a 30 -kW four-piston double-acting engine developed by Sanye flectric (o), lidd., under the Japanese govermment's Moonlight project. It has four parallel $1+5-\mathrm{cm}^{3}(8.8$-in' $)$ cylinders with a dual-crankshaft drive and operates on helium at $680^{\circ}(: 260)$ and 15.4 Ml'a (22.30 psi). Lorly of these engines were built. A total of 3,300 hours of test time was accumulated, with 500 hours on a single engine. Sekiya et al. (1992) recently studied the suitability of this engine for potential solar powergencrattion applications and found that it was suitable for terrestrial applications.

\section{Schlaich, Bergermann und Partner (Germany)}

Schlaich, Bergermann mond Rartner of Stultgart, ciermany, comtinuestodeveloptheir 7.5 -m stretched-membrancesstem with the goal ef mass preduction. current 
hardware developments include a heat-pipe receiver (in conjunction with DLR) and a hybrid receiver for their system in conjunction with ZSW.

\section{Science Applications International}

\section{Corporation (USA)}

Science Applications International Corp. (SAIC) of San Diego, California, and Golden, Colorado, has fabricated 12 prototype facets that are 3 meters $(9.8$ feet) in diameter for the DOE faceted stretched-membrane dish at Sandia National Laboratories (SNL), Albuquerque, New Mexico (SAIC, 1991). The SAIC design uses a vacuum to elastically deform a thin $0.08-\mathrm{mm}$ (3-mil) stainless steel membrane. A silvered polymer reflective film covers the membrane. The facets have been successfully tested on the DOE faceted stretched-membrane dish.

Solar Kinetics, Inc. (USA)

Solar Kinetics, Inc. (SKI), of Dallas, Texas, has designed and tested a single-element 7-meter (23-foot) stretchedmembrane concentrator as a prototype for larger production dishes (SKI, 1991). The dish is made by stretching a thin $0.10-\mathrm{mm}(4-\mathrm{mil})$ sheet of stainless steel on a steel rim. Alternately applying water and vacuum loads plastically forms the membrane to approximate a paraboloidal shape. An aluminized polyester membrane covers the top of the formed paraboloidal dish and is held in place by a vacuum behind the membrane.

Solar Kinetics has also designed and fabricated twelve 3 -meter $(9.8-\mathrm{ft})$ diameter prototype facets for the DOE faceted stretched-membrane dish at Sandia National Laboratories, Albuquerque, New Mexico (Schertz et al., 1991).

\section{Stirling Technology Company (USA)}

Stirling Technology Company (STC) of Richland, Washington, is designing two Stirling engines for solar applications (White, 1993). The first STC engine is a $5-\mathrm{kW}$ reciprocating kinematic engine (Figure 4-3). Its hermetically sealed crankcase is based on a Stirling cycle cryocoder design and is at an advanced stage of development, with extensive endurance testing already completed. The hot-end development of the engine is not yet under way. This engine design employs two cornpressor pistons and one displacer and is of the Kıngbom configuration. The $5-\mathrm{kW}$ engine uses helium at $600{ }^{\circ} \mathrm{C}$ $\left(1100^{\circ} \mathrm{F}\right)$ and $4.5 \mathrm{MPa}(650 \mathrm{psi})$. Internal hermetic metal bellows seals separate the engine working space from the crankcase. A rotary induction generator is located within the crankcase and the entire unit is hermetically sealed. This SIC engine is expected to have a $50,0(0)$ hour life.

The second STC engine, a $25-\mathrm{kW}$ tree-piston Stirling hydraulic (STIRI.ICIM) engine (ligure 4-4), has completed the final phases of design under the U.S. Department of Energy's Advanced Stirling (onversion Systems (ASCS) program. The helium working gas operates at $700^{\circ} \mathrm{C}\left(13000^{\circ} \mathrm{F}\right)$ and $18.3 \mathrm{MPa}(26.50 \mathrm{psi})$. Metal bellows hermetically separate the helium working gas from a hydraulic region. Counter-oscillating free intensifier pistons in the hydraulic region pump hydraulic fluid from $0.3 \mathrm{MPa}(40 \mathrm{psi})$ to $20.7 \mathrm{MPa}(3000) \mathrm{psi}$ ). The high-pressure hydraulic fluid drives a hydraulic motor that in turn drives a three-phase induction generator. Both motor and generator are commercially available items. An alternate version of this engine with the hydraulic pump replaced by a linear alternator has also been designed. Planar spring-type flexure bearings are used to support the piston and displacer, with close clearance seals for the cylinders. Since there is no rubbing contact, no lubricant is required.

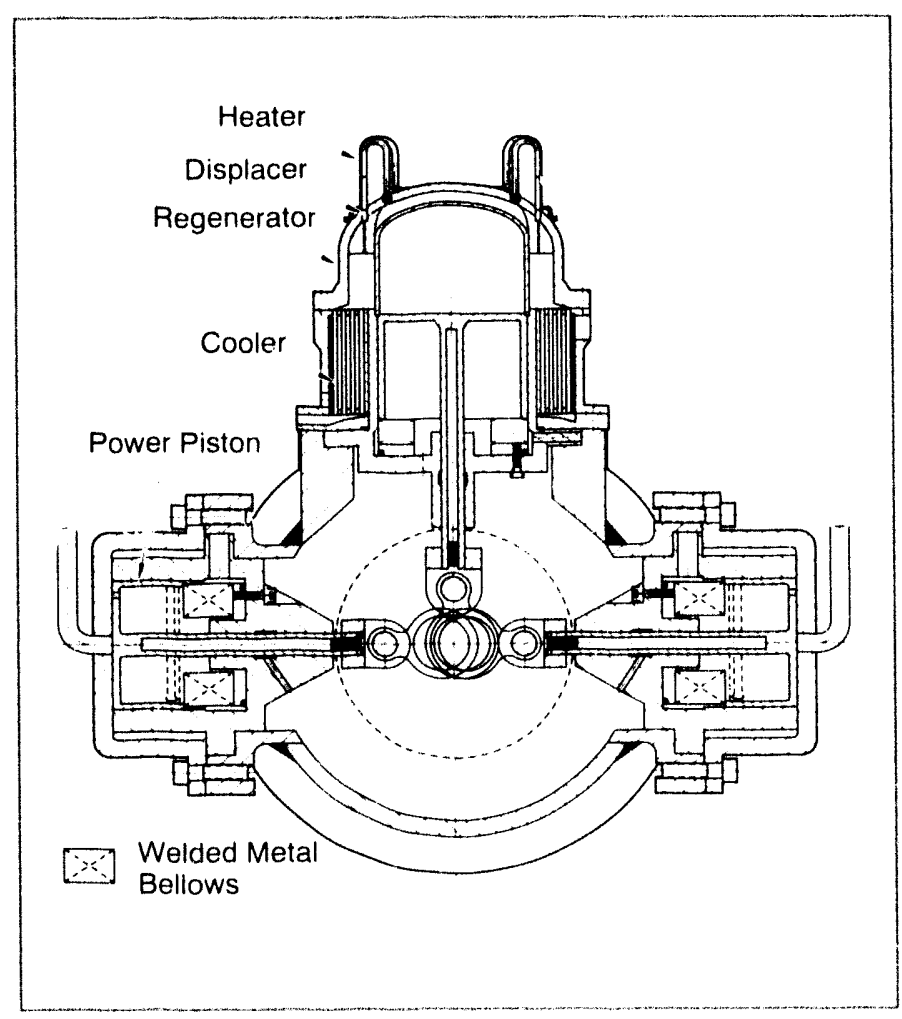

Figure 4-3. Stirling Technology Corporation 5-kW engine. 


\section{Chapter 4}

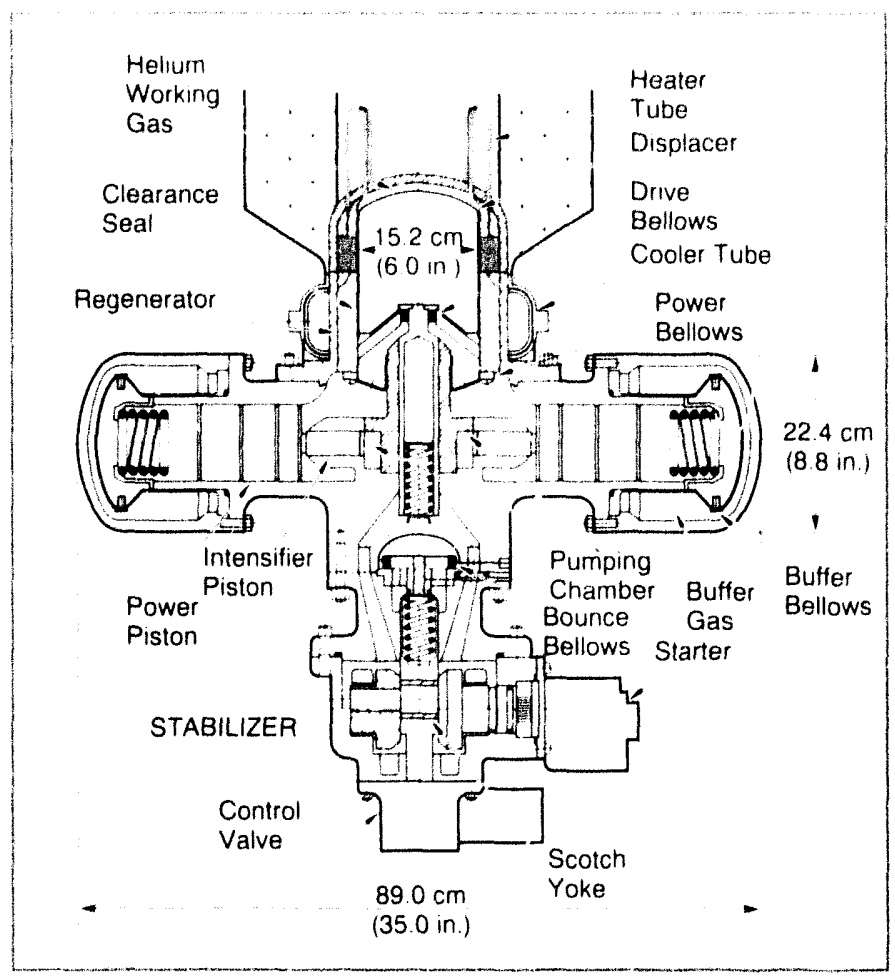

Figure 4-4. The Stirling Technology Corporation STIRLICIM 25-kW engine.

Receivers for both STC engines are liquid-metal pool boilers using a sodium/potassium eutectic (NaK-78) that has a melting point of $-12.6^{\circ} \mathrm{C}\left(9.3^{\circ} \mathrm{F}\right)$. A $10-\mathrm{kW}$ solar/natural gas hybrid receiver demonstration unit is being separately developed under contract to the National Renewable Energy Laboratory (NREL).

The STC/NREI. receiver is designed to accept independently or simultaneously solar and natural gas heat input at levels between $25 \%$ and $100 \%$ of full power. It is thus capable of operating at full power in either mode or at reduced levels of solar insolation. Preliminary fullpower testing of the hybrid receiver was successfully initiated in 1993. A photograph of the hybrid receiver in a test cell using radiant lamp solar simulation is shown in Figure 4-5.

\section{Stirling Thermal Motors (USA)}

Stirling Thermal Motors (STM) of Ann Arbor, Michigan, has been developing and testing a general-purpose Stirling engine designated the STM4-120). This engine was designed to produce $25 \mathrm{~kW}$ of power at a speed of $1800 \mathrm{rpm}$. It features a four-cylinder, double-acting configuration and has a high power-to-weight ratio. Variable displacement power control through a variable-angle swashplate mechanism provides high efficiency over a wide power range.

Stirling Thermal Motors and I)etroit Diesel Corporation have a cooperative agreement to develop, manufacture and market the SIM4-120 for commercial products including solar dish/Stirling applications (Bennethum et al., 1991). They are currently engaged in a comprehensive engine design, manufacturing, and testing program with plans to fabricate and test 100 engines for selected applications over the next several years.

Sunpower, Inc.

William Beal, inventor of the free-piston Stirling engine, founded Sunpower, Inc., of Athens, Ohio, to develop and market Stirling engine technology.

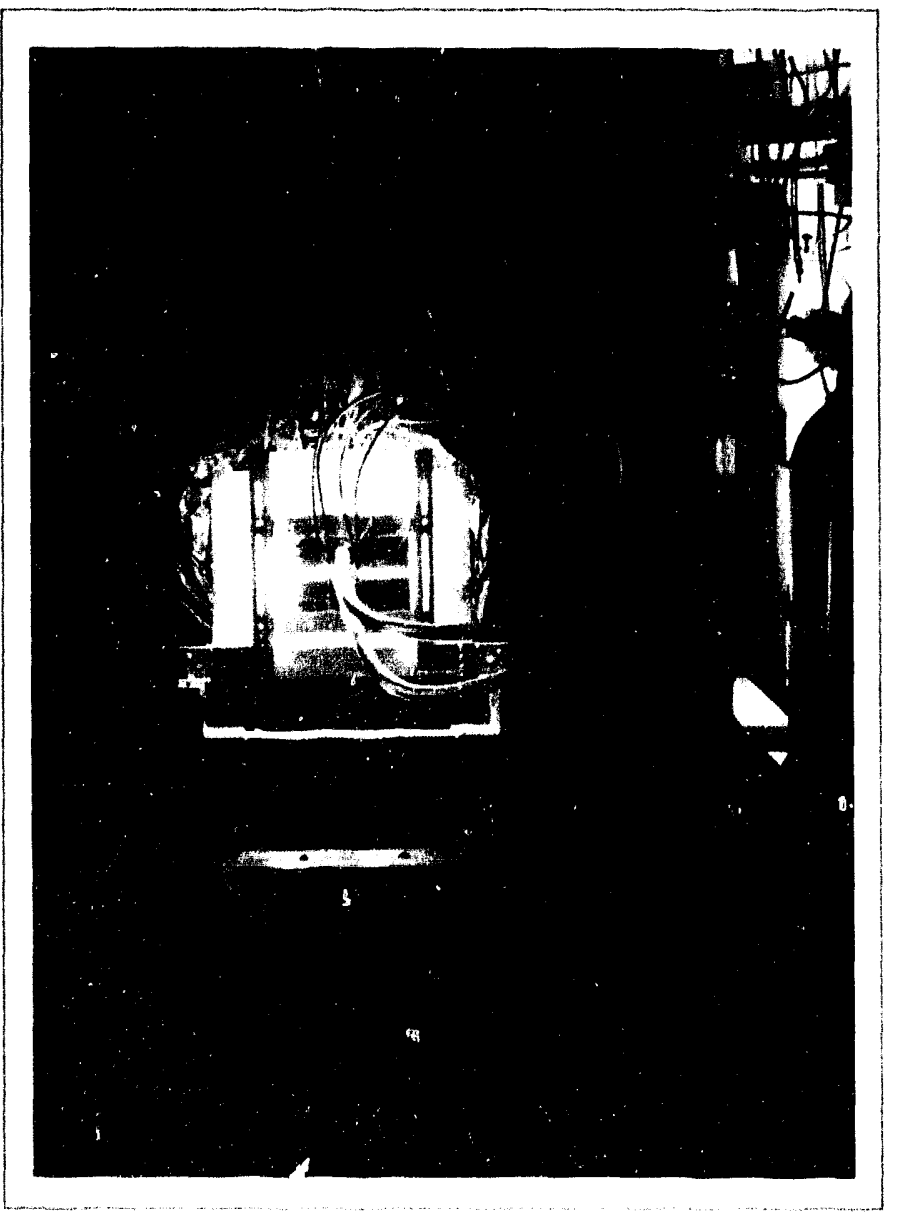

Figure 4-5. Stirling Technology hybrid receiver in a test cell using radiant lamp solar simulation. 


\section{Technology Advancement}

They are currently working with Cummins Power Generation, Inc., to develop both the $9-\mathrm{kW}$ and 25 $\mathrm{kW}$ free-piston engines that Cummins will produce and market.

\section{Technology Development Programs}

\section{German Aerospace Research Establishment (DLR) (Germany)}

Deutsche Forschungsanstalt für Luft und Raumfahrt e.V. (DLR), the German Aerospace Research Establishment, is currently developing liquid metal heat-pipe receivers for use with dish/Stirling applications. A DLR receiver using liquid sodium has been built and tested on-sun with a Stirling engine (Laing and Goebel, 1991) and testing of a second design is currently under way (Goebel and Laing, 1993).

\section{National Renewable Energy Laboratory (USA)} The major thrust of work related to dish/Stirling systems at the National Renewable Energy Laboratory (NREL) is the development of inexpensive, long-lasting, highly reflective polymer films. The goal is an inexpensive film with a 10-year life and a specular reflectance greater than $90 \%$ into a $4-\mathrm{mrad}$ full-cone acceptance angle.

The National Reneriable Energy Laboratory is involved in optical testing and characterization of concentrators being developed for dish/Stirling engine systems. This includes surface shape characterization using the Scanning Hartmann Optical Test (SHOT) (Wendelin et al., 1991) and material specularity testing using their Large Aperture Near Specular Imaging Reflectometer (LANSIR).

The National Renewable Energy Laboratory is also currently funding the development of hybrid receivers for applications to dish/Stirling systems. Stirling Technology Company (STC) is developing a NaK pool-boiler and Cummins Power Generation (CPG) a sodium heatpipe receiver. Both can be heated by a natural gas flame when adequate solar insolation is not available. This type of receiver can keep the engine operating at constant temperature as a cloud passes, on very cloudy days when full solar operation is not possible, and at night. Cummins Power Generation has completed the design of their heat-pipe receiver and Stirling Technology Corporation has fabricated and begun ground testing their pool-boiler receiver. The CPG hybrid receiver will be tested at Lancaster, Pennsylvania.

\section{NASA Lewis Research Center (USA)}

The National Aeronautics and Space Administration's Lewis Research Center in Cleveland, Ohio (NASA LeRC), is responsible for developing the technologies required for future space power applications of the Stirling power converter (an engine combined with either an alternator, a compressor, or a pump). The need for a strong Stirling infrastructure to enhance the potential success of Stirling converters for future space power applications motivates Lewis Research Center's interest in terrestrial applications of Stirling converter technology.

For these reasons, the Lewis Research Center has provided technical management for the U.S. Department of Energy's Advanced Stirling Conversion Systems (ASCS) terrestrial Stirling converter development project (Shaltens and Schreiber, 1991). Until 1992, this project was developing two free-piston Stirling converters that provide nominally $25 \mathrm{~kW}$ of electric power to a utility grid and meet the Department of Energy's performance and long-term cost goals. These engines incorporate solar cavity receivers with liquid-metal heat transport. Stirling engine programs previously managed by the Lewis Research Center include the Department of Energy-funded Automotive Stirling Engine (ASE) Program and the Space Power Demonstrator Engine (SPDE) program. Additional projects include testing of the Phillips/ United Stirling GPU-3, the P-40, and the MOD-1 kinematic Stirling engines, along with testing of the original RE-1000, the RE-1000 hydraulic output converter, the HP-1000 heat-pipe engine, and the Space Power Research Engine (SPRE) free-piston Stirling converters. Additional facilities at the Lewis Research Center allow research of regenerators, linear alternators, and load interaction and control of free-piston converters (Cairelli et al., 1993).

\section{Sandia National Laboratories (USA)}

Two concentrator development programs are currently proceeding at Sandia National Laboratories (SNL), Albuquerque, New Mexico. One is the development of a dish using multiple stretched-membrane facets. Designated here as the DOE faceted stretched-membrane dish, this design builds on stretched-membrane heliostat technology for central receivers. The approach is to use 12 stretched-membrane facets $3 \mathrm{~m}(10 \mathrm{ft})$ in diameter, the largest size that can be practically transported (Alpert et al., 1991). This concentrator 


\section{Chapter 4}

provides adequate concentrated solar radiation to power a $25-\mathrm{kW}$ Stirling engine. Science Applications International (SAIC) and Solar Kinetics (SKI) are developing the facets for this dish (see above), and WG Associates is designing the concentrator support structure and tracking drives (Mancini, 1991).

The second concentrator development project is a single stretched-membrane concentrator. It is described in the section on the work of Solar Kinetics (SKI).

Sandia National Laboratories is also currently developing two types of liquid-metal reflux receivers (Diver et al., 1990). One type is a pool-boiler receiver and the other is a heat-pipe receiver. Both designs are called reflux receivers because the condensed liquid metal passiveiy returns to the boiling pool or heat-pipe wick by gravity. Sandia has tested both kinds of reflux receivers on a solar concentrator using calorimeter measurements to evaluate their performance (Andraka et al., 1993; Moreno et al., 1993a and 1993b).

In addition, Sandia is testing the Stirling Thermal Motors STM4-120 engine (Linker et al., 1991). This program includes dynamometer testing and on-sun testing of STM's solar power conversion system package on a test bed concentrator.

\section{Solar and Hydrogen Energy Research Center (ZSW) (Germany)}

Zentrum für Sonnenenergie und Wasserstoff Forschung (ZSW), Stuttgart, one of Germany's institutions for solar and hydrogen energy research, was founded in 1988. In the field of solar thermal engineering, ZSW's research activities focus on medium- and high-temperature applications. For dish/Stirling systems, ZSW performs solar testing of components (receivers) and complete systems in its dish/Stirling test facility. It is working on a concept for hybridization of the $\mathrm{V}-160$ engine that would permit use of both solar and fossil heat in parallel operation.

\section{Japan}

Several current research and prototype development activities in Japan are aimed at developing dish/Stirling technology. Four Stirling engines were designed for heat pump or small electric generator applications in a Stirling engine development program sponsored by the New Energy and Industrial Development Organization (NEIDO). These engines may also be used in solar dish/ Stirling applications.
Two of the NEIDO engines are rated at $3 \mathrm{~kW}$ : the NSO3M developed by Mitsubishi - a piston/displacer engine operating at $700^{\circ} \mathrm{C}\left(1300^{\circ} \mathrm{F}\right)$ and $6.2 \mathrm{MPa}(900 \mathrm{psi})-$ and the NSO3T by Toshiba - a $60^{\circ} \mathrm{V}$-cylinder engine operating at $730^{\circ} \mathrm{C}\left(1350^{\circ} \mathrm{F}\right)$ and $6.4 \mathrm{MPa}(930 \mathrm{psi})$. The other two Stirling engines (Sanyo's NS30S and Aisin Seiki's NS30A) are 30-kW engines and are more applicable to dish/Stirling systems. The NS30S produced by Sanyo was described earlier in this chapter and the NS30A produced by Aisin Seiki is described in Chapter 2.

In addition, a significant amount of university research in Japan is in progress at Meiji University (Prof. Fujii) and Nihon University (Prof. Isshiki). Both university researchers are developing internally illuminated solar Stirling engines where concentrated solar radiation passes through a quartz glass window and heats a porous absorbing mesh inside the cylinder (Figure 4-6). Solar testing on engines of this type is beginning.

No known concentrator development for commercial terrestri $c^{!}$applications is taking place in Japan. Both of the above universities have built two Cassegranian-type dish concentrators for powering experimental engines. In addition, a recent system performance study (Sekiya et al., 1992) suggests that a $30-\mathrm{kW}_{\mathrm{e}}$ dish/Stirling system could be economically sited on the island of Okinawa because of the high insolation available.

\section{Russia}

Since 1989, the Russian government has sponsored the development of dish/Stirling systems under their Ecologically Clean Power Engineering program. The goal is to use technological expertise in their atomic, aerospace, and defense industries to develop clean solar-fueled power systems for large-scale power production. A secondary objective is to utilize military equipment to be dismantled under the army reduction program.

Russia's atomic industry - and the Institute of Physics and Power Engineering in particular-has substantial experience with high-temperature heat-transfer fluids such as molten salts and liquid metals. They are applying this expertise to develop heat-transfer systems for Stirling engine designs (Gonnov et. al., 1991). The dish/ Stirling concept was proof-tested under solar operation in Russia in 1990 (Loktionov, 1991; Loktionovet al., 1993). 
Two solar/electric systems are being developed in Russia (Loktionov et al., 1993):

- One will use the 2-kW free-piston Stirling engine and heat-pipe receiver shown schematically in Figure 4-7. The working gas for this engine is helium. Linear alternators provide the power output. The engine will be mounted on a faceted dish concentrator using 21 sheet metal facets that are 0.5 meters ( 1.6 feet) in diameter. The facets are coated with an aluminum film. The dish is mounted on a converted military azimuth-elevation tracking turret.

- The second system uses the 10-kW free-piston Stirling engine/alternator shown in ligure 4-8. The engine has two opposing power pistons incorporating linear alternators and four displacer cylinders. The engine operates using helium at $675^{\circ} \mathrm{C}\left(1250^{\circ} \mathrm{F}\right)$ and

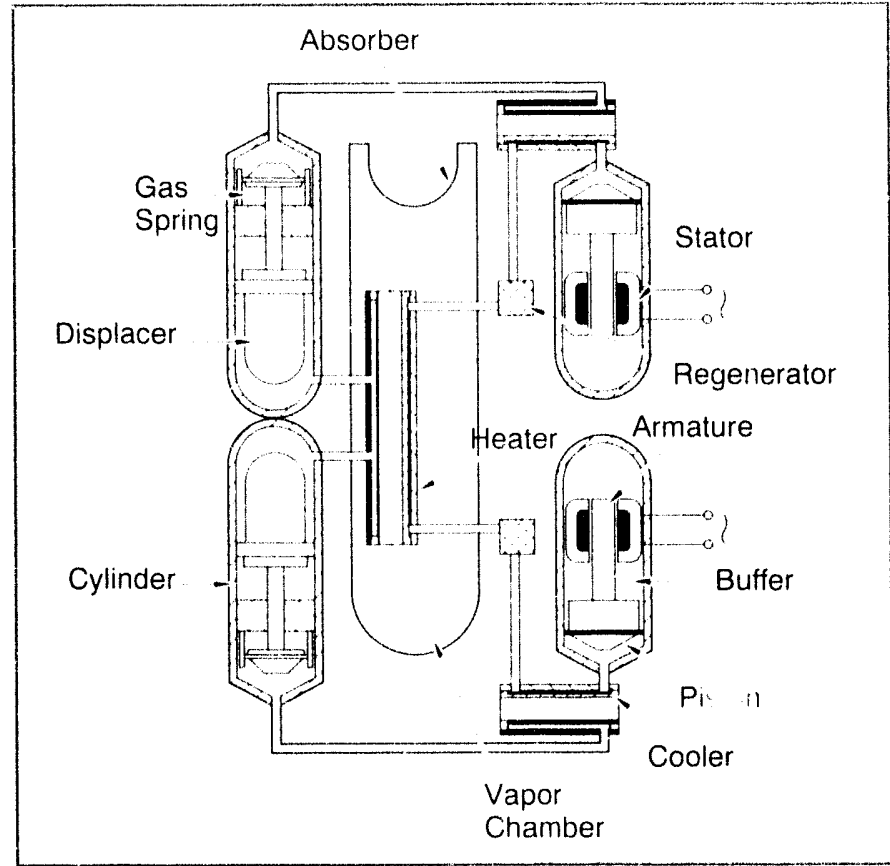

Figure 4-7. Simplified design scheme of Russian freepiston Stirling engine.

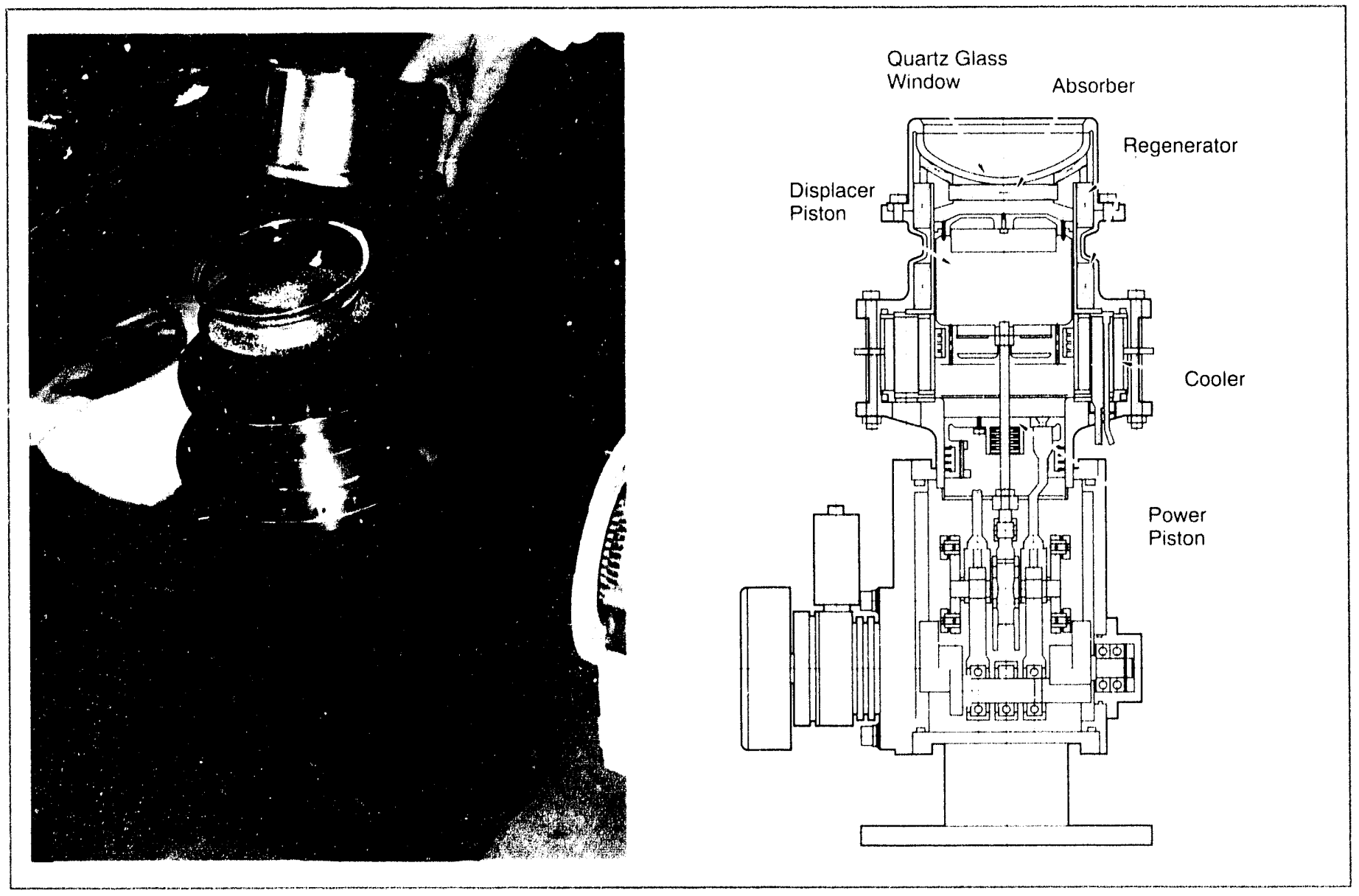

Figure 4-6. Nihon University TNT 3 engine. 


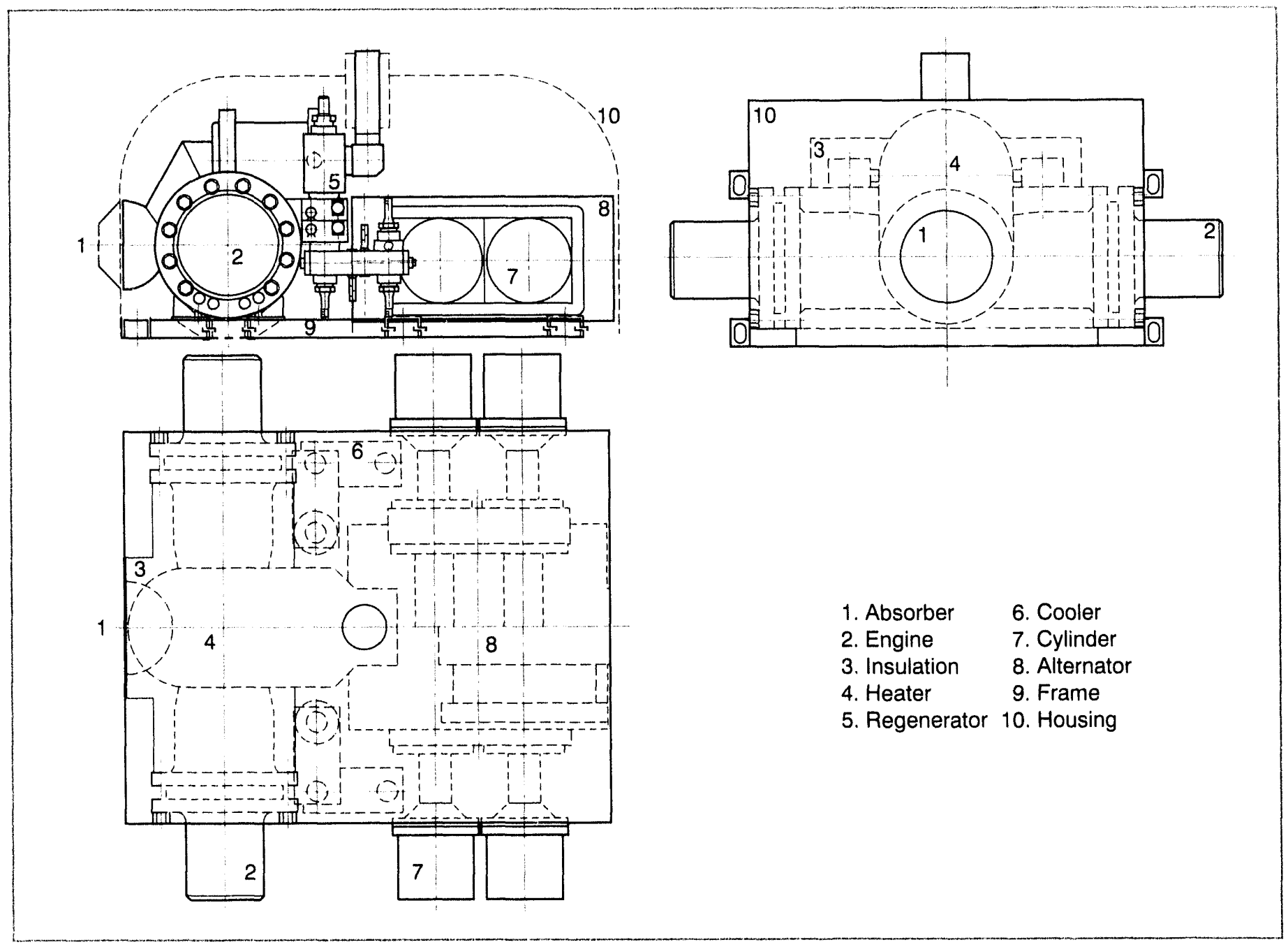

Figure 4-8. Russian free-piston Stirling engine.

$10 \mathrm{MPa}(1450 \mathrm{psi})$ and has an integrated liquidmetal heat-pipe receiver. Components of this engine are currently undergoing bench testing. A double-dish concentrator with a central support pillar is being developed for this engine.

\section{Projections for Future Development}

Renewed interest is evident internationally in developing dish/Stirling systems for generation of electricity with solar energy. Renewed concerns about the vulnerability of traditional energy sources, a growing worldwide concern for the environment, and technical advances have again placed dish/Stirling in the forefront of solar electric power generation strategies. Trends in this renewed evolution are summa- rized below in terms of the major components of a dish/Stirling system.

\section{Engines}

The trend in engine development is toward extending engine lifetime and increasing reliability (Holtz and Uherka, 1988). To increase lifetime and reliability, engine development is following two paths: design improvements in the kinematic Stirling engine and development of the free-piston Stirling engine.

From a manufacturing point of view, kinematic Stirling engines are similar to the internal combustion engine. However, a major issue in the design of these engines is sealing the high-pressure parts of the engine in areas where sliding mechanical seals are required. The use of a pressurized crankcase, such as 
in the STM4-120, is aimed at improving the reliability and life of this critical component.

Designs are being developed for free-piston Stirling engines with noncontacting bearings that eliminate the need for lubrication and the potential for wear. A linear alternator, incorporated within the pressurized envelope, eliminates the necessity for a mechanical seal between the engine and surroundings.

Also, the free-piston engine design lends itself to the use of flexure bearings. Stirling Technology Corp. is experimenting with planar spring-type flexures and Clever Fellows with strap-type flexures. Sunpower is also using planar spring flexures in current engines. The bearings, usually made of thin spring steel, provide for movement in only one dimension without contact friction, are relatively inexpensive, and have predictable lifetimes.

\section{Receivers}

An objective in receiver design is to make receivers smaller to reduce cost and improve performance. The current trend is to use evaporation and condensation of liquid metals to transfer heat from the solar absorber to the engine heater. This approach provides three positive benefits to the system:

- First, evaporating/boiling liquid metals have very high heat flux capabilities. Thereforc, the absorbing surface may be designed smaller.

- Second, when the working gas is heated by condensation on the heater tubes rather than with direct solar flux, heating is uniform and at a constant temperature. Therefore, the engine can operate at a gas temperature closer to the material limit of the absorber.

- Third, using a liquid metal evaporation/condensation interface allows for independent design of the concentrator and the engine, and more readily accommodates hybridization.

\section{Concentrators}

Design trends are toward more cost-effective designs using fewer facets and lower-cost reflective materials. Because the concentrator of a dish/Stirling system has a large surface area, it is important to use inexpensive materials both for the reflective surface and its structural support.
Aluminized or silvered plastic membranes are currently inexpensive and their limited lifetime when exposed to the sun and weather is being extended. Thin silvered glass mirrors remain an alternative. Long lifetimes in the outside environment, along with high and maintainable surface reflectance, make glass a strong design alternative. Both surfaces are being incorporated into current concentrator designs.

Support of reflective surfaces has moved from concentrator designs where (1) many individually shaped and adjusted facets are supported by a strong space frame to (2) thin stretched membranes focused by small vacuums. Designs use one or a few facets, thereby reducing the complexity (and therefore the cost) of mounting and adjustment. As an example, the McDonnell Douglas concentrator design reduced the number of individually mounted and adjusted facets to 82 from the 336 used in the Vanguard concentrator while maintaining high optical performance. 
Chapter 4

Notes 
Part II: Component Description

- Concentrators

- Receivers

- Engines

4.3 
Notes 


\section{Chapter 5: Concentrators}

Concentrators account for about $25 \%$ of the cost of a dish/Stirling system. Concentrators designed in the late 1970 s and early 1980 s were generally very efficient, but were expensive to manufacture. They were typically constructed using multiple glass facets individually mounted on a space frame. In an attempt to increase the cost-effectiveness of solar concentrators, designers have tried forming full paraboloids out of sheet metal and with stretched membranes. Faceted stretched-membrane concentrators have also been developed.

A survey of dish/Stirling concentrators follows. This survey organizes dish/Stirling concentrators into three categories: glass-faceted concentrators, full-surface paraboloid concentrators, and stretched-membrane (singlefacet and multifaceted) concentrators. Photos, drawings, and specifications for these units are provided in the indicated figures and tables.

\section{Glass-Faceted Concentrators}

Glass-faceted concentrators developed for dish/Stirling systems use spherically curved, individually alignable glass mirror facets mounted on parabolic-shaped structures. The Jet Propulsion Laboratory Test Bed Concentrator (TBC) (Table 5-1,* Figure 5-1), the Vanguard concentrator (Table 5-2, Figure 5-2), and the McDonnell Douglas concentrator (Table 5-3, Figure 5-3) are of this type.

Because the individual mirrors have small curvatures, and it is relatively easy to achieve and maintain high accuracy with small mirrors, these designs generally have high concentration ratios. On the other hand, they also tend to be heavy and expensive and require accurate alignment of a large number of mirrors.

\section{Full-Surface Paraboloid Concentrators}

A number of full-surface paraboloid concentrators have been built. In this design, the entire surface forms a paraboloid. Two full-surface paraboloid concentrators have been developed for dish/Stirling applications: the General Electric Pl)(-1 (lable 5-4, Figure 5-4) and the Acurex 15-m dish concentrator (Table 5-5, ligure 5-5). This style of dish concentrator has also been produced for other applications. For one non-dish/Stirling application, a 6-m full-surface paraboloid was designed and manufactured by Omnium-(j in 1978 for use with a steam engine. This concentrator used polished aluminum sheet on polyurethane foam supported by trusses. Testing showed an optical efficiency of about $60 \%$ at a geometric concentration ratio of 800 . In another nondish/Stirling application, General Electric designed and Solar Kinetics fabricated 114 seven-meter-diameter fullsurface dish concentrators. They were made of 21 diestamped aluminum petals, covered with an aluminized acrylic film (3M's FEK 244). These were used to provide thermal energy at $400^{\circ} \mathrm{C}$ for a solar total energy system at Shenandoah, Georgia. These concentrators had a geometric concentration ratio of 234 .

\section{Stretched Membrane Concentrators}

To reduce the cost of large dish concentrators, designs incorporating thin membranes stretched over both sides of a metal ring have been developed. The membranes may be thin reflective plastic sheeting or thin metal sheeting with a reflective coating applied to one of the membranes. A slight vacuum in the space between the two membranes is controlled to provide a concave, focused contour to the reflector. In an emergency, this space can be pressurized to defocus the mirror.

The shape produced by drawing a slight vacuum behind a membrane is not a paraboloid. When creating a stretched-membrane mirror with a small $f / d$ (less than approximately 3 ), it is not possible to form accurate enough mirrors with vacuum alone. Techniques have therefore been developed to preshape the membrane beyond its elastic limit, thus providing a shape approximating that of a paraboloid. An alternative stretchedmembrane concentrator design that is similar to glassfaceted concentrator construction uses a large number of small stretched-membrane facets mounted on a sup)port frame.

* Parameters presented in the tables in this chapter are defined and discussed in Chapter 3. 


\section{Chapter 5}

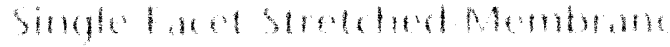

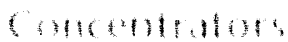

Three single-facet stretched-membrane concentrators have been developed for dish/Stirling applications. Two were developed by the German firm of Schlaich, Bergermann und Partner (SBP), of Stuttgart, Germany: the SBP $17-\mathrm{m}$ single-facet dish (Table 5-6, Figure 5-6) and the SBP 7.5-m singlefacet dish (Table 5-7, Figure 5-7). The third, a 7-m prototype single-facet stretched-membrane concentrator, has been built by Solar Kinetics, Inc. (SKI) (Table 5-8, Figure 5-8). SKI and Sandia are developing an $11-\mathrm{m}$ stretched-membrane design for dish/ Stirling applications.

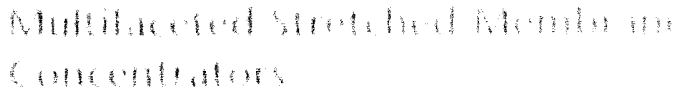

The advantage of multifaceted concentrators is that the $f / d$ ratio for the individual facets is large; therefore, less curvature is required in the facet surface. With stretched-membrane facets, accurate contours without inelastic stretching of the membrane are possible.

Three multifaceted stretched-membrane concentrators have been developed for dish/Stirling applications: the Cummins Power Generation CPG-460 multifaceted concentrator (Table 5-9, Figure 5-9), the DOE faceted stretchedmembrane dish (Table 5-10, Figure 5-10), and the HTC Solar Research concentrator (Table 5-11, Figure 5-11).

\section{Table 5-1. Jet Propulsion Laboratory Test Bed Concentrator}

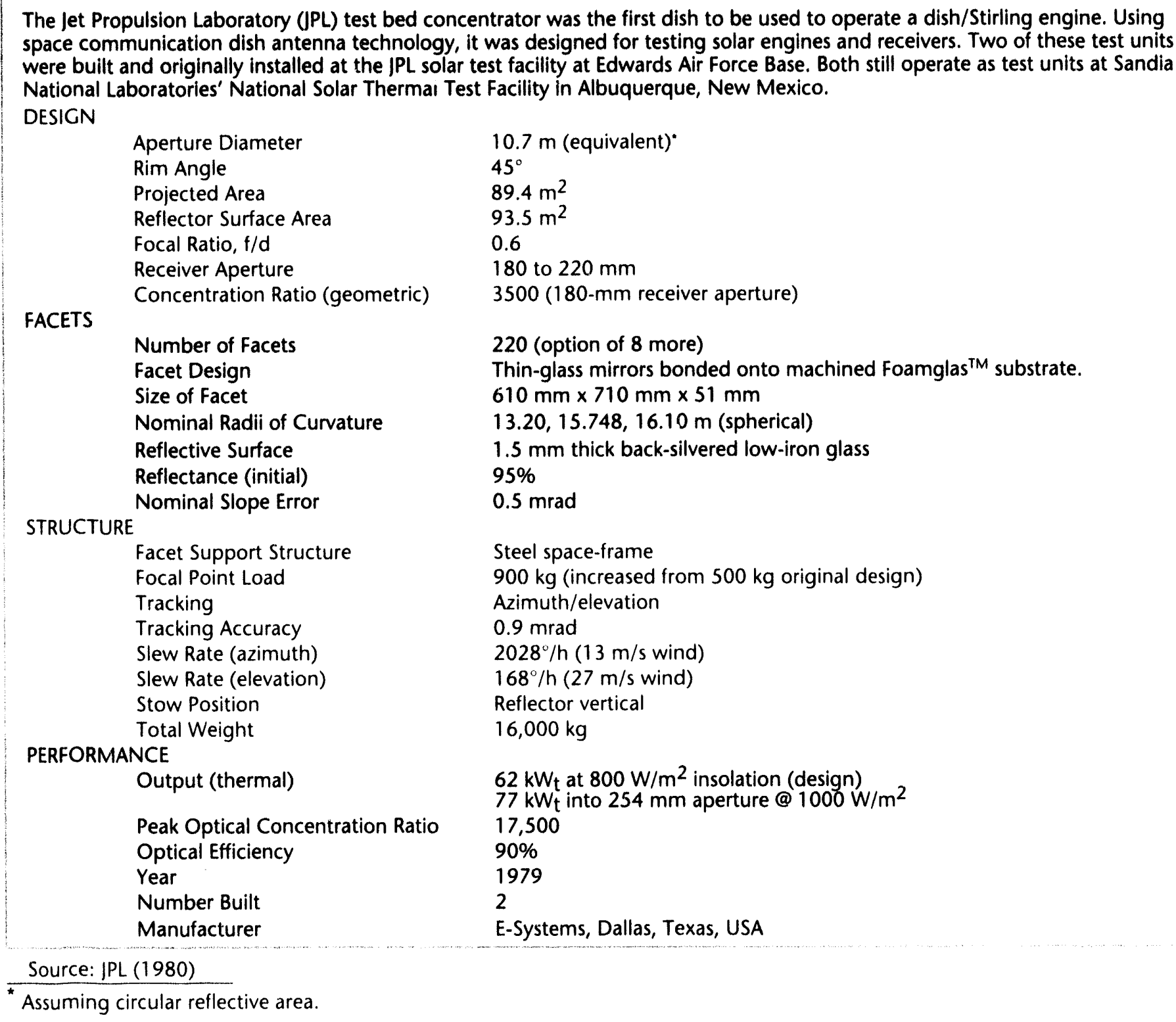

Aperture Diameter

Rim Angle

Projected Area

Reflector Surface Area

Focal Ratio, $f / d$

Receiver Aperture

FACETS

Concentration Ratio (geometric)

Number of Facets

Facet Design

Size of Facet

Nominal Radii of Curvature

Reflective Surface

Reflectance (initial)

Nominal Slope Error

STRUCTURE

Facet Support Structure

Focal Point Load

Tracking

Tracking Accuracy

Slew Rate (azimuth)

Slew Rate (elevation)

Stow Position

PERFORMANCE

Total Weight

Output (thermal)

Peak Optical Concentration Ratio

Optical Efficiency

Year

Number Built

Manufacturer

$10.7 \mathrm{~m}$ (equivalent)

$45^{\circ}$

$89.4 \mathrm{~m}^{2}$

$93.5 \mathrm{~m}^{2}$

0.6

180 to $220 \mathrm{~mm}$

3500 (180-mm receiver aperture)

220 (option of 8 more)

Thin-glass mirrors bonded onto machined Foamglas ${ }^{\mathrm{TM}}$ substrate.

$610 \mathrm{~mm} \times 710 \mathrm{~mm} \times 51 \mathrm{~mm}$

$13.20,15.748,16.10 \mathrm{~m}$ (spherical)

$1.5 \mathrm{~mm}$ thick back-silvered low-iron glass

$95 \%$

$0.5 \mathrm{mrad}$

Steel space-frame

$900 \mathrm{~kg}$ (increased from $500 \mathrm{~kg}$ original design)

Azimuth/elevation

$0.9 \mathrm{mrad}$

$2028^{\circ} / \mathrm{h}(13 \mathrm{~m} / \mathrm{s}$ wind $)$

$168^{\circ} / \mathrm{h}(27 \mathrm{~m} / \mathrm{s}$ wind $)$

Reflector vertical

$16,000 \mathrm{~kg}$

$62 \mathrm{kWt}$ at $800 \mathrm{~W} / \mathrm{m}^{2}$ insolation (design)

$77 \mathrm{~kW}$ into $254 \mathrm{~mm}$ aperture @ $1000 \mathrm{~W} / \mathrm{m}^{2}$

17,500

$90 \%$

1979

2

E-Systems, Dallas, Texas, USA

Source: JPL (1980)

* Assuming circular reflective area. 


\section{Concentrators}

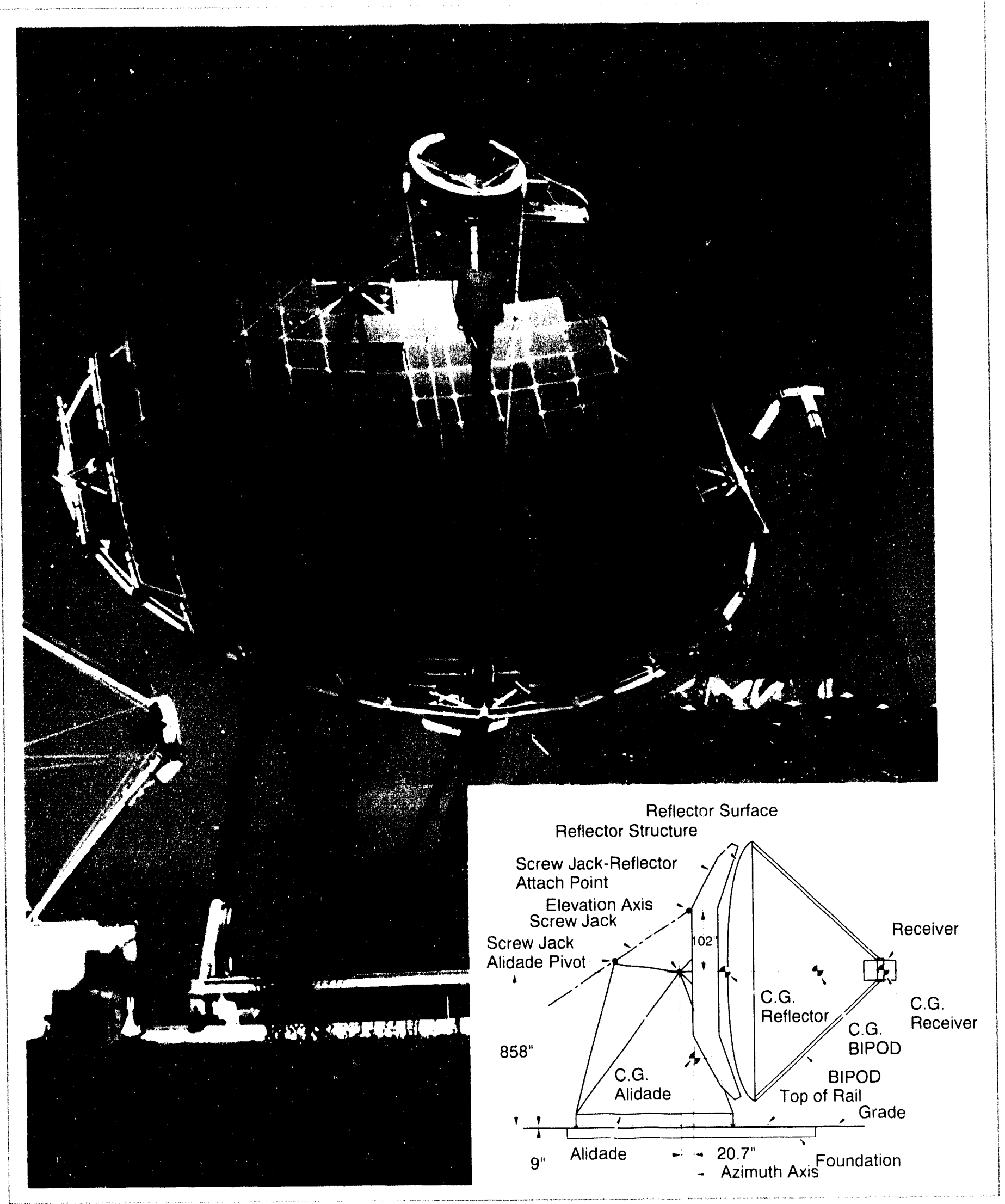

Figure 5-1. Jet Propulsion Laboratory test bed concentrator. 


\section{Chapter 5}

Table 5-2. Vanguard I Concentrator

The first modern commercial venture to produce a dish/Stirling system was the Vanguard I dish/Stirling system developed by Advanco. This concentrator with the USAB 4.95 Stirling engine recorded the "world's record" of $29.4 \%$ for conversion of sunlight to electricity.

DESIGN

$\begin{array}{ll}\text { Aperture Diameter } & 10.57 \mathrm{~m} \text { (equivalent)* } \\ \text { Projected Area } & 86.7 \mathrm{~m}^{2} \\ \text { Reflector Surface Area } & 91.4 \mathrm{~m}^{2} \\ \text { Rim Angle } & 45^{\circ} \\ \text { Focal Ratio, f/d } & 0.6 \\ \text { Receiver Aperture } & 200 \mathrm{~mm} \\ \text { Concentration Ratio (geometric) } & 2800\end{array}$

FACETS

Number of Facets

336

Facet Design

Size of Facet

Nominal Radii of Curvature

Reflective Surface

Reflectance (initial)

Slope Error

STRUCTURE

Facet Support Structure

Focal Point Load

Tracking

Slew Rate

Drive Motors

Thin-glass mirrors bonded onto machined Foamglas substrate.

$451 \mathrm{~mm} \times 603 \mathrm{~mm} \times 50 \mathrm{~mm}$

$13.16 \mathrm{~m}$ and $15.80 \mathrm{~m}$ (spherical)

1.5-mm-thick back-silvered low-iron glass

$93.5 \%$

$0.5 \mathrm{mrad}$

Drive Motor Power (daily average)

Stow Position

Module Weight

PERFORMANCE

Output (thermal)

Optical Efficiency

Year

Space frame truss

$900 \mathrm{~kg}$

Two-axis exocentric gimbal $\left(45^{\circ}\right)$

$3600^{\circ} / \mathrm{h}$ (skew axis) $1800^{\circ} / \mathrm{h}$ (azimuth axis)

$2 @ 0.75 \mathrm{hp}$ with speed reduction

$600 \mathrm{~W}$ ( $390 \mathrm{~W}$ daily average)

Reflector vertical or horizontal

$10,400 \mathrm{~kg}$ (excluding engine/alternator and pedestal)

$76.4 \mathrm{~kW}$ at $1000 \mathrm{~W} / \mathrm{m}^{2}$ insolation

$89 \%$

1984

Number Built

1

Manufacturer

Advanco Corp., Los Angeles, California, USA

Source: Washom (1984); Washom et al. (1984); Droher and Squier (1986)

Assuming circular reflective area. 


\section{Concentrators}

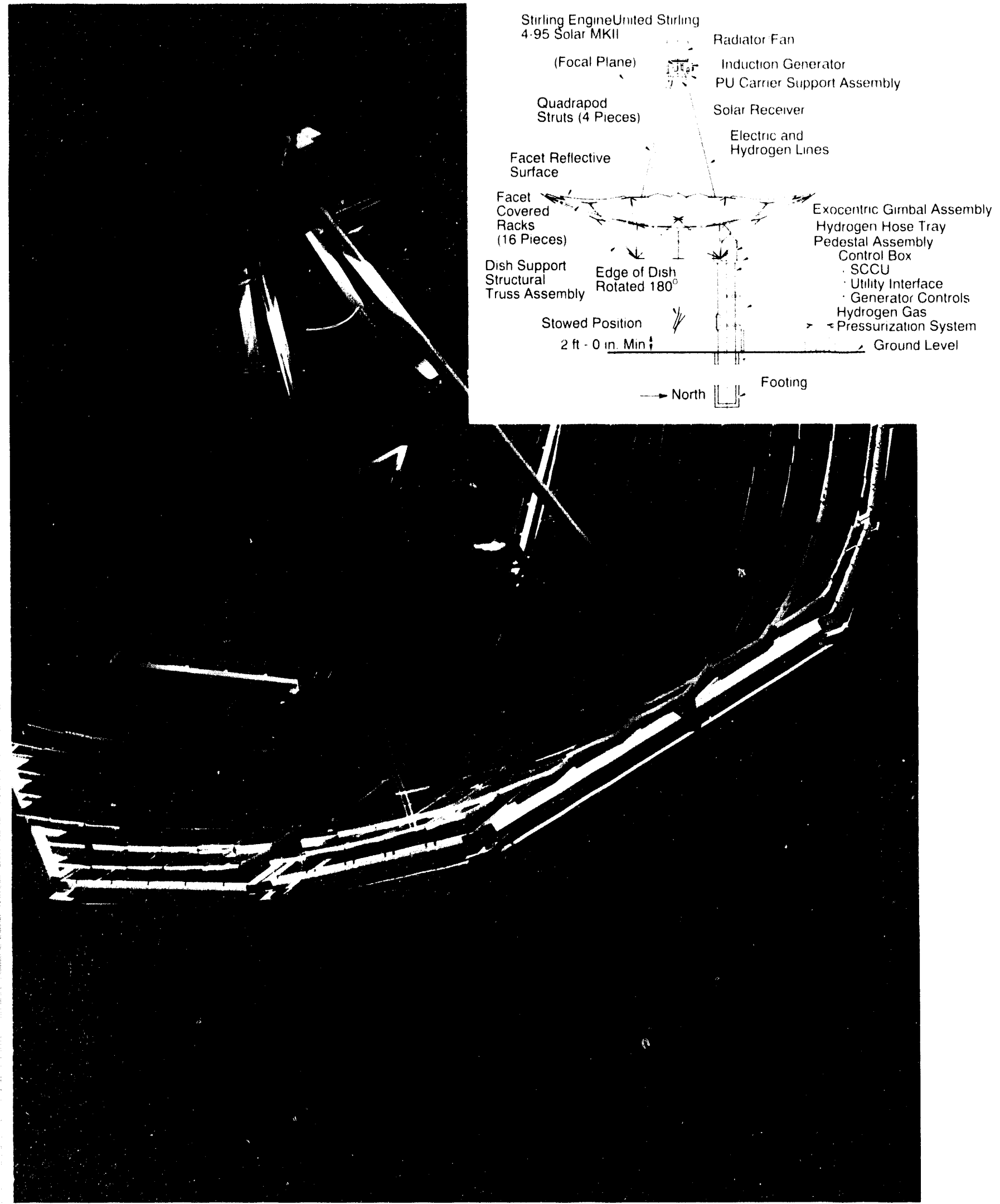

Figure 5-2. Vanguard I concentrator. 


\section{Chapter 5}

Table 5-3. McDonnell Douglas Corporation Concentrator

At about the time of the Vanguard project, McDonnell Douglas Corporation (MDAC) of Huntington Beach, California, designed a commercially oriented faceted dish to be used with the USAB 4-95 Stirling engine. Eight units were built and received extensive testing at different sites. Subsequently, Southern California Edison purchased the marketing and manufacturing rights to this concentrator design.

DESIGN

Aperture Diameter

Projected Area

Reflector Surface Area

Focal Length

Focal Ratio, $\mathrm{f} / \mathrm{d}$

Rim Angle

Receiver Aperture

Concentration Ratio (geometric)

FACETS

Number of Facets

Facet Design

Size of Facet

Nominal Radii of Curvature

Reflective Surface

Reflectance (initial)

Slope Error

STRUCTURE

Facet Support Structure

Module Height

Module Width

Tracking

Tracking Accuracy

Drive Motor Power

Stow Position

Wind Stow Velocity

Total Weight

PERFORMANCE

Output (thermal)

Optical Efficiency

Peak Optical Concentration Ratio

Year

Number Built

Manufacturer

Source: Lopez and Stone (1992)

* Assuming circular reflective area.
$10.57 \mathrm{~m}$ (equivalent)

$87.7 \mathrm{~m}^{2}$

$91.0 \mathrm{~m}^{2}$

$7.45 \mathrm{~m}$

0.7

$39^{\circ}$

$200 \mathrm{~mm}$

2793

82 (option of 6 more)

Thin commercial grade float glass mirrors bonded onto a steel backing sheet bonded to a stretch-formed steel structural substrate.

$910 \times 1220 \mathrm{~mm}$

$15.21,15.65,16.26,16.94$ and $17.73 \mathrm{~m}$ (spherical)

Back-silvered $0.7 \mathrm{~mm}$ glass

91.1\%

$0.6 \mathrm{mrad}$

Truss structure on beam

$11.9 \mathrm{~m}$

$11.3 \mathrm{~m}$

Azimuth/elevation

$0.2 \mathrm{mrad}$

40 to $100 \mathrm{~W}$

Reflector vertical (normal)

Horizontal (high wind)

$16 \mathrm{~m} / \mathrm{s}$

$6934 \mathrm{~kg}$

70 to $80 \mathrm{~kW}$ t at $1000 \mathrm{~W} / \mathrm{m}^{2}$ insolation

$88.1 \%$

7500

1984

6

MCDonnell Douglas Corp., Huntington Beach, CA, USA 


\section{Concentrators}

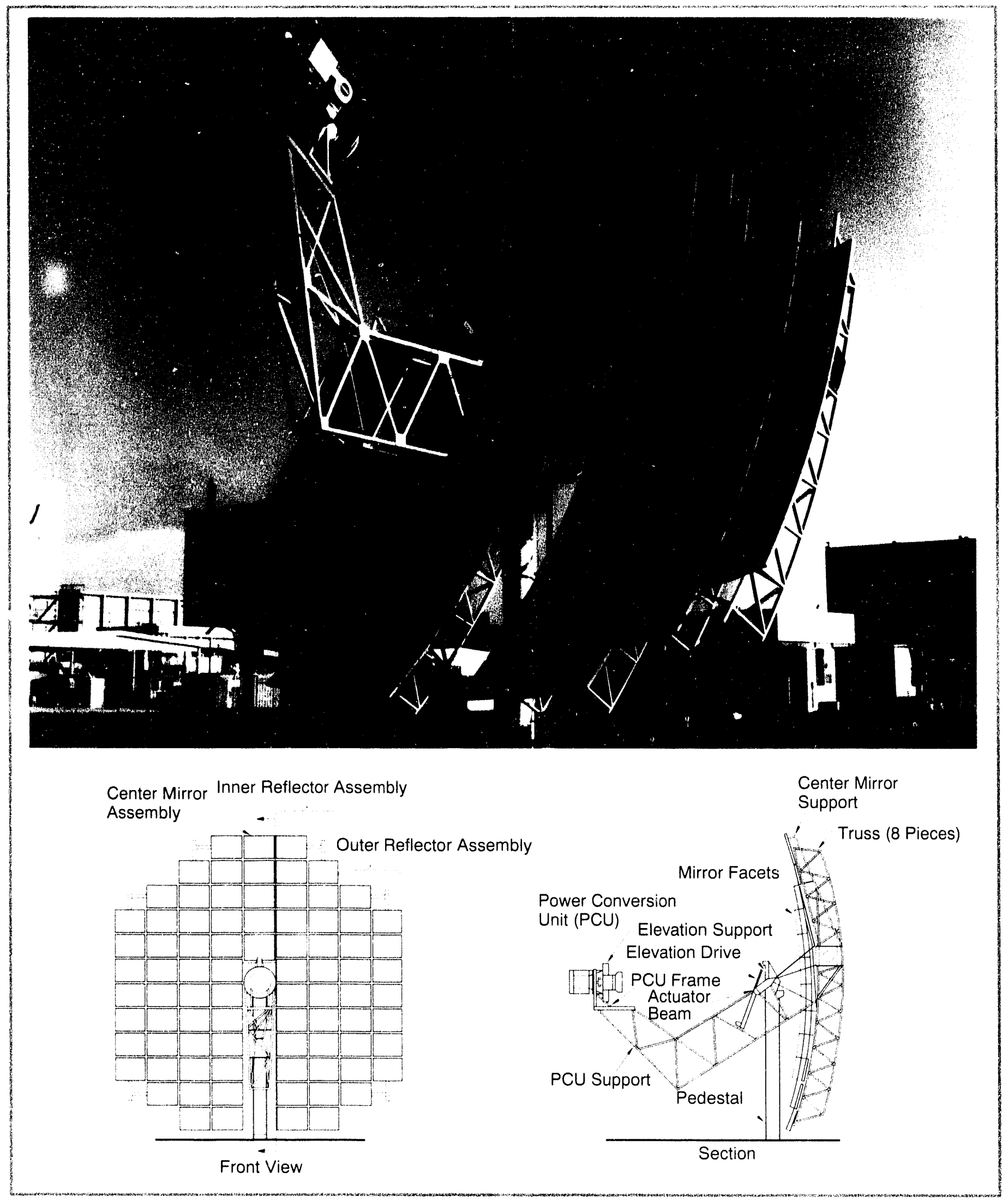

Figure 5-3. McDonnell Douglas Corporation concentrator. 


\section{Chapter 5}

Table 5-4. General Electric PDC-1 Concentrator

\begin{tabular}{|c|c|}
\hline \multicolumn{2}{|c|}{$\begin{array}{l}\text { In } 1979 \text {, the General Electric company designed the PDC-1 under the guidance of the Jet Propulsion Laboratory, which at that } \\
\text { time was leading the parabolic dish development program for the U.S. Department of Energy. Ford Aerospace and Communica- } \\
\text { tions built one unit in } 1982 \text {. This concentrator was designed to be a commercially feasible concentrator for dish/Stirling applica- } \\
\text { tions as well as other solar thermal power systems. }\end{array}$} \\
\hline \multicolumn{2}{|l|}{ DESIGN } \\
\hline Aperture Diameter & $12 \mathrm{~m}$ \\
\hline Focal Ratio, $f / d$ & 0.5 \\
\hline Concentration Ratio (geometric) & 1500 \\
\hline \multicolumn{2}{|l|}{ DISH } \\
\hline Design & $\begin{array}{l}12 \text { radial triangular gores, each comprising inner, center, and outer panels, } \\
\text { attached to } 12 \text { radial steel ribs located in front of the reflective panels. }\end{array}$ \\
\hline Gore Construction & $\begin{array}{l}\text { Aluminized plastic film laminated to a plastic sheet and then bonded to a } \\
\text { molded fiberglass/balsa wood sandwich panel. }\end{array}$ \\
\hline Reflective Surface & Aluminized plastic (Llumar ${ }^{T M}$ ) \\
\hline Reflectance & $85 \%$ (est) \\
\hline \multicolumn{2}{|l|}{ STRUCTURE } \\
\hline Tracking & Azimuth/ elevation \\
\hline Stow Position & Reflector face down \\
\hline Tracking & $0.9 \mathrm{mrad}$ \\
\hline \multicolumn{2}{|l|}{ PERFORMANCE } \\
\hline Output (thermal) & $72.5 \mathrm{~kW}$ at $1000 \mathrm{~W} / \mathrm{m}^{2}$ insolation \\
\hline Optical Efficiency & $76 \%$ \\
\hline Year & 1982 \\
\hline Number Built & 1 \\
\hline Manufacturer & General Electric/Ford Aerospace, USA \\
\hline
\end{tabular}

Source: Panda et al. (1985) 


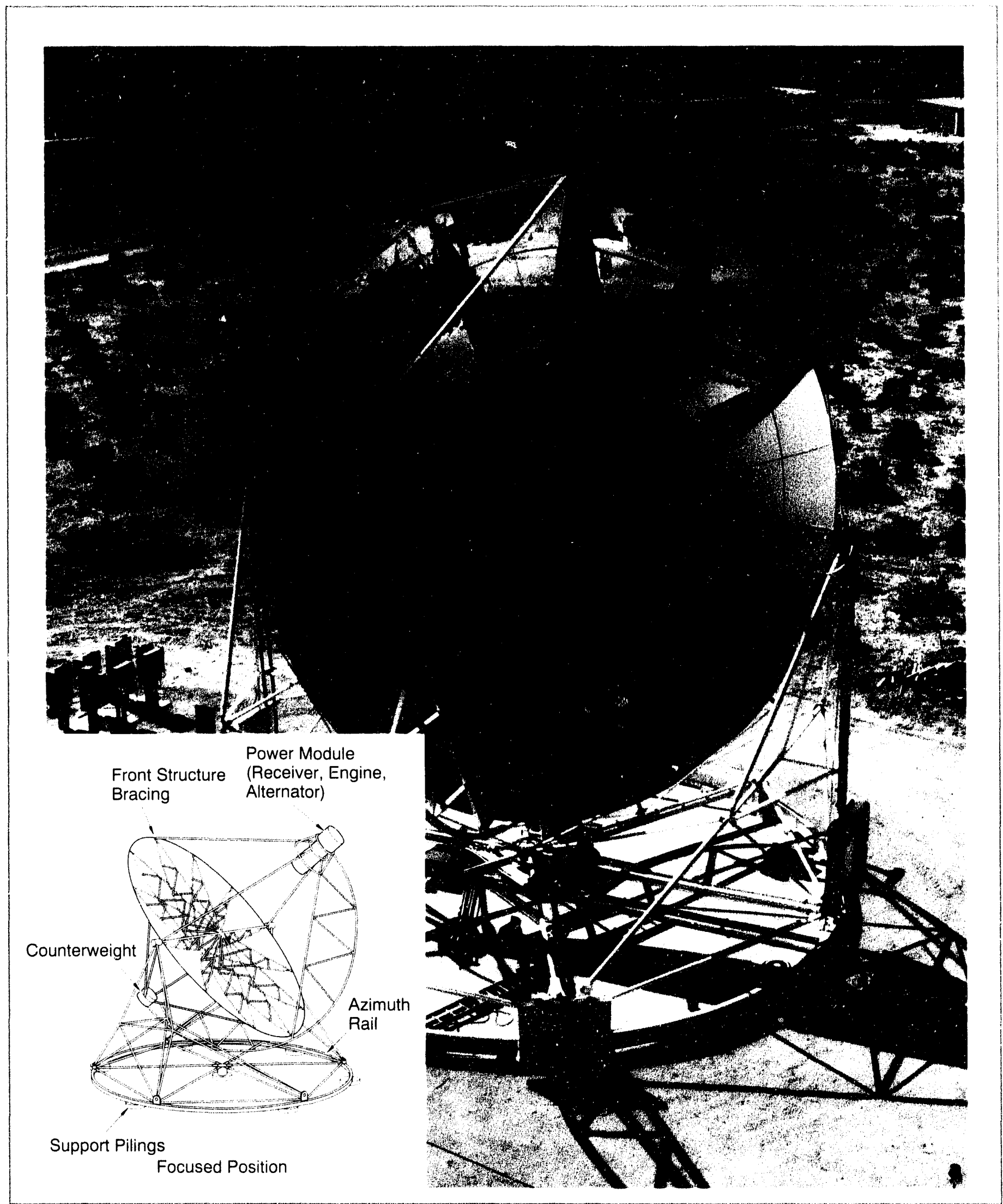

Figure 5-4. General Electric PDC-1 concentrator. 


\section{Chapter 5}

Table 5-5. Acurex 15-m Dish Concentrator

A full-surface paraboloid dish concentrator was built by Acurex Corporation of Mountain View, California. This was part of the Innovative Concentrator design program sponsored by Sandia National Laboratories. A weld failure occurred during a wind storm at the Albuquerque test site just after the concentrator was installed and before performance data could be obtained. The concentrator was not repaired.

DESIGN

Aperture Diameter $\quad 15 \mathrm{~m}$

Focal Ratio, $\mathrm{f} / \mathrm{d} \quad 0.5$

Concentration Ratio (geometric) 1925

DISH

Design

Panel Configuration

Nominal Slope Error

Reflective Surface

Reflectance (initial)

STRUCTURE

Tracking

Weight

PERFORMANCE

Output (thermal)

Optical Efficiency

Year

Number Built

Manufacturer
Stamped sheet-metal reflective panels structurally integrated with panel support structure. Smooth front sheet bonded to stamped back sheet.

Two concentric rings with 40 outer and 20 inner panels.

2-3 mrad (goal)

Silvered acrylic film (3M ECP 300)

$95 \%$

Azimuth/elevation - hydraulic motor drive

$11,406 \mathrm{~kg}$

$162 \mathrm{~kW}$ at $1000 \mathrm{~W} / \mathrm{m}^{2}$ insolation

$92 \%$

1986

1

Acurex Corp., Mountain View, California, USA

Source: Diver (1986) 


\section{Concentrators}

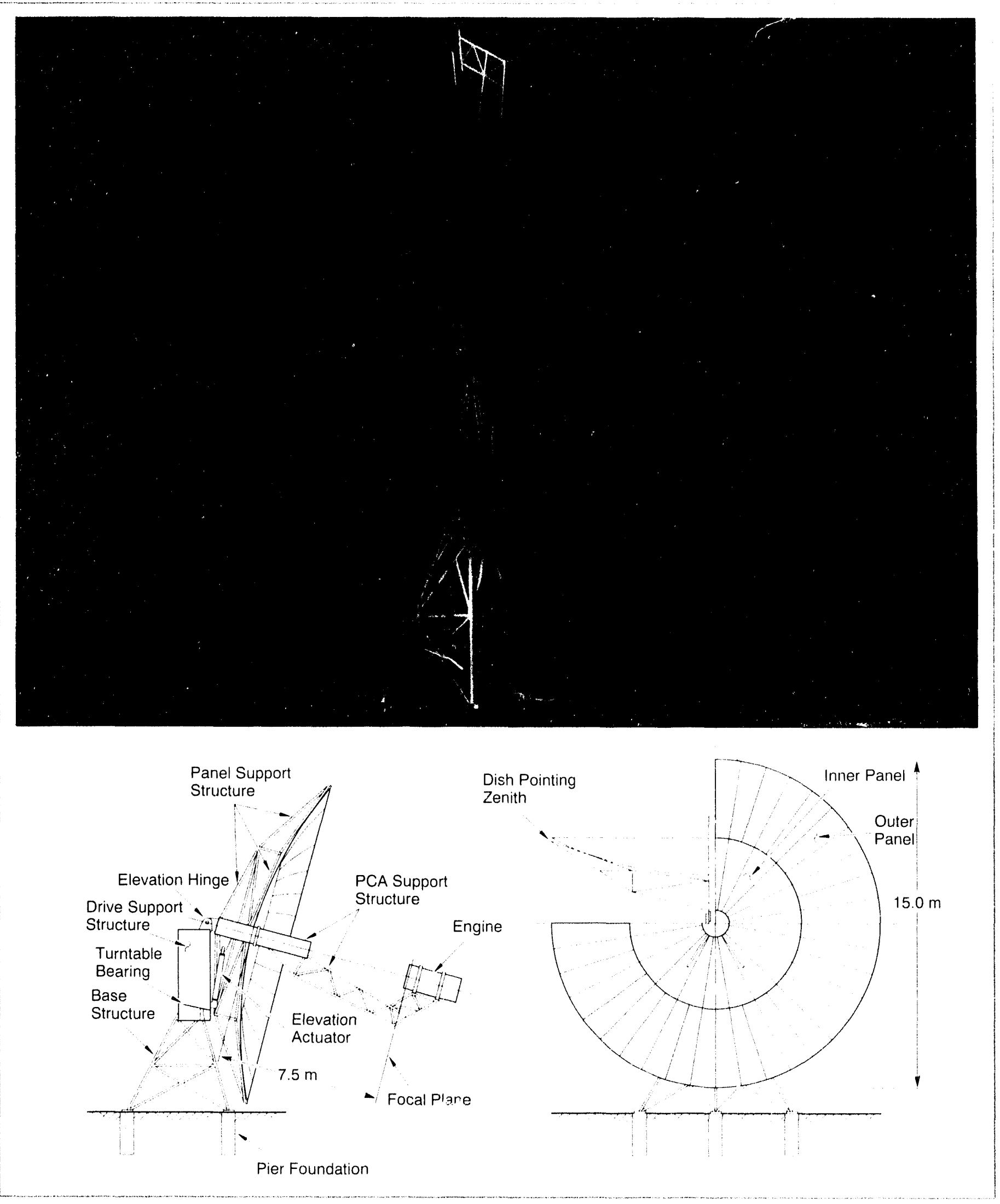

Figure 5-5. Acurex 15-m dish concentrator. 


\section{Chapter 5}

Table 5-6. Schlaich, Bergermann und Partner 17-m Single-Facet Concentrator

Schlaich, Bergermann und Partner developed the technology for fabricating a single-facet stretched-membrane concentrator to be used with United Stirling's 50-kW 4-275 engine. Two of these are in Riyadh, Saudi Arabia, and the other is in Lampoldshausen (near Stuttgart) and is being used for research by the German Aerospace Research Establishment (DLR).

DESIGN

$\begin{array}{ll}\text { Aperture Diameter } & 17 \mathrm{~m} \\ \text { Reflective Area } & 227 \mathrm{~m}^{2} \\ \text { Usable Mirror Area } & 92 \% \\ \text { Focal Length } & 13.6 \mathrm{~m} \\ \text { Focal Ratio, f/d } & 0.80 \\ \text { Receiver Aperture (design) } & 700 \mathrm{~mm} \\ \text { Intercept Factor at Receiver } & 90 \% \\ \text { Concentration Ratio (geometric) } & 600\end{array}$

REFLECTOR

Number of Facets

1

Facet Design

Two sheet-steel mernbranes stretched across a ring. One is plastically deformed to desired shape by applying positive air pressure under the surface when inverted. Shape is maintained by partial vacuum between the membranes.

Size of Facet

$17 \mathrm{~m}$ diameter

Membrane

$0.50 \mathrm{~mm}$ steel

Reflective Surface

Back-silvered 0.7-mm glass bonded onto sheet steel

Reflectance (initial)

$92 \%$

STRUCTURE

Facet Support Structure

Tracking

Ring pin mounted to frame with guy wire tensioners

Azimuth/elevation

Wind Maximum (while operating) $\quad 14 \mathrm{~m} / \mathrm{s}$

Wind Maximum (while stowing) $\quad 22 \mathrm{~m} / \mathrm{s}$

Wind Maximum (survival) $\quad 44 \mathrm{~m} / \mathrm{s}$

PERFORMANCE

Output (thermal)

$178.6 \mathrm{~kW}$ at $1000 \mathrm{~W} / \mathrm{m}^{2}$ insolation

Optical Efficiency

$78.7 \%$

Year

1984

Number Built 3

Manufacturer

Schlaich Bergermann und Partner, Stuttgart, Germany (system integrator)

Source: SBP (1991) 


\section{Concentrators}

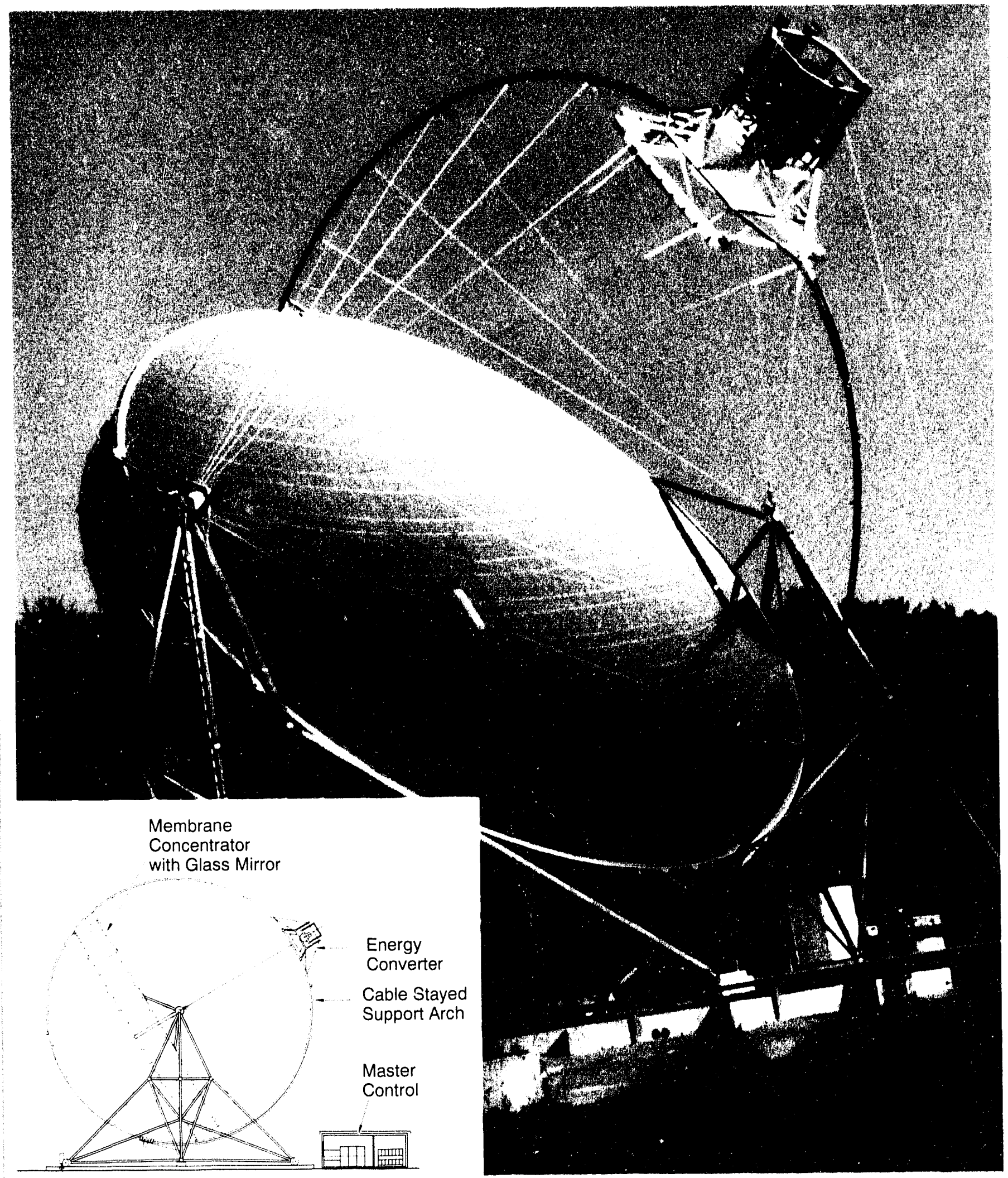

Figure 5-6. Schlaich, Bergermann und Partner 17-m single-facet concentrator. 


\section{Chapter 5}

Table 5-7. Schlaich, Bergermann und Partner 7.5-m Single-Facet Concentrator

Schlaich, Bergermann und Partner downsized their 17-m stretched-membrane concentrator, modified the method of preshaping the reflector membrane, and changed its tracking from az-el to polar. They have constructed six units: one prototype facility at the University of Stuttgart (now dismantled), three at the Plataforma Solar in Almería, Spain, one at Pforzheim, Germany, and one for dish/Stirling testing at the ZSW in Stuttgart.

DESIGN

Aperture Diameter

Total Reflective Area (projected)

Focal Length

Foca! Ratio, $\mathrm{f} / \mathrm{d}$

Recelver Aperture (design)

Concentration Ratio (geometric)

\section{REFLECTOR}

Number of Facets

Facet Design

Size of Facet

Membrane

Reflective Surface

Reflectance (initial)

Nominal Slope Error

STRUCTURE

Facet Support Structure

Tracking

Stow Position

Time to Stow

Wind Maximum (while operating)

Wind Maximum (survival)

PERFORMANCE

Output (thermal)

Optical Efficiency

Peak Optical Concentration Ratio

Year

Number Built

Manufacturer
$7.5 \mathrm{~m}$

$44.18 \mathrm{~m}^{2}$ (does not include receiver shaded area or seam weld area)

$4.5 \mathrm{~m}$

0.60

$130 \mathrm{~mm}$

4000

1

Two sheet-steel membranes stretched across a ring. One is plastically deformed to desired shape by applying negative pressure behind the membrane, and using water above the surface. Shape is maintained by partial vacuum between the membranes.

$7.5 \mathrm{~m}$ diameter $\times 1.2 \mathrm{~mm}$ thick

$0.23 \mathrm{~mm}$ stainless steel

Back-silvered 0.7-mm glass bonded onto sheet steel

$94 \%$

1.3 to $1.8 \mathrm{mrad}$

Membrane/ring-pin-mounted to frame with guy wire tensioners.

Polar drive

Face-down

$3 \mathrm{~min}$.

$14 \mathrm{~m} / \mathrm{s}$

$44 \mathrm{~m} / \mathrm{s}$

$36.2 \mathrm{kWt}$ at $1000 \mathrm{~W} / \mathrm{m}^{2}$ insolation

$82 \%$

$\sim 12,000$

1989

6

Schlaich Bergermann und Partner, Stuttgart, Germany

Source: Keck et al. (1990) and Schiel (1992) 


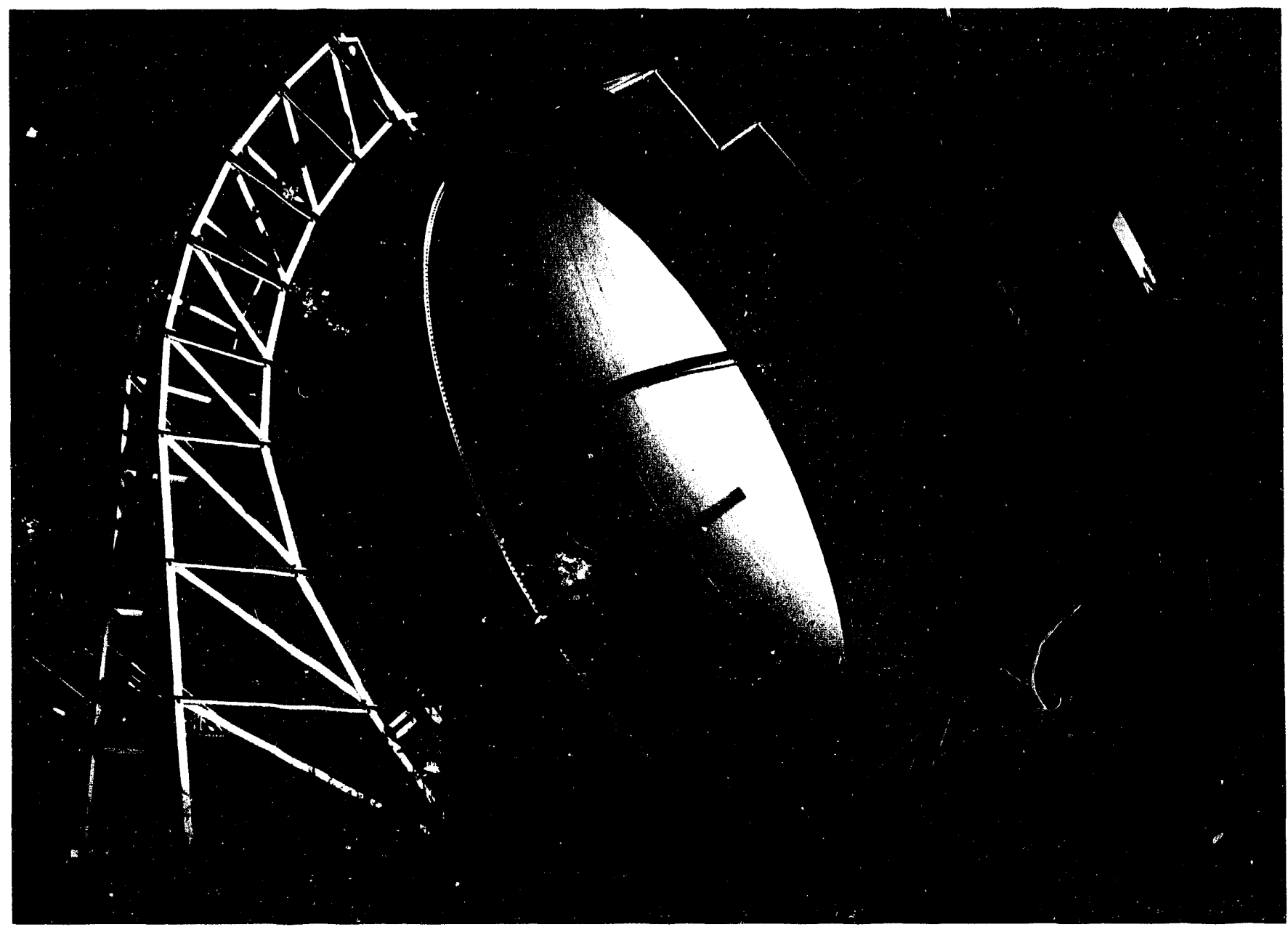

Polar Axis

Polar Tracking

Support Structure Axis

Reflective Membrane

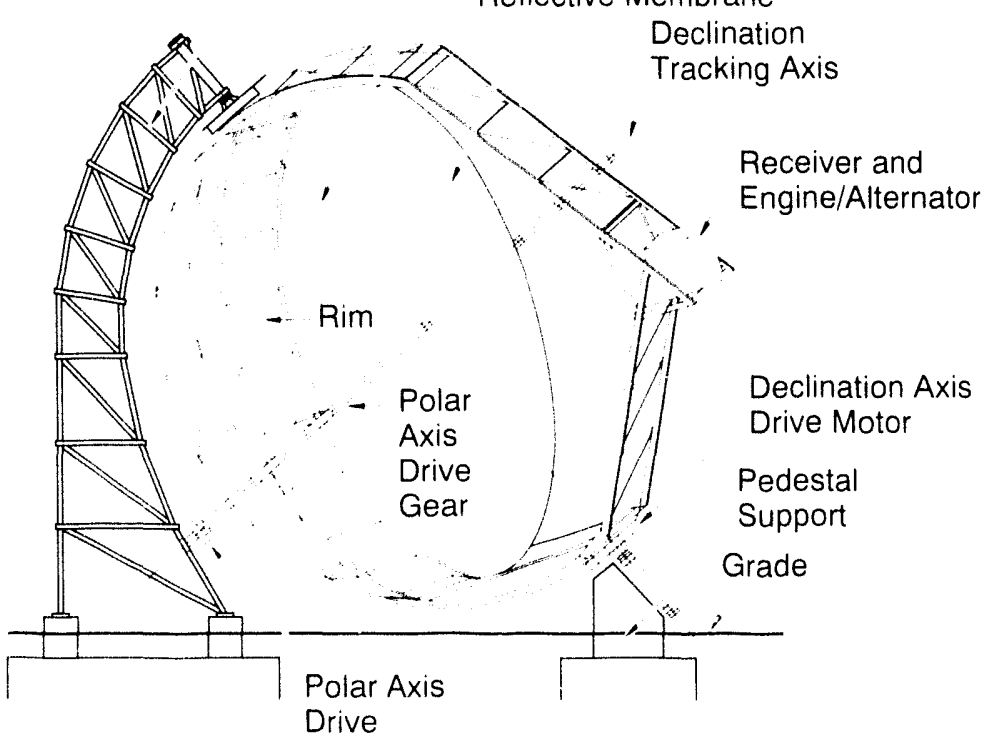

Figure 5-7. Schlaich, Bergermann und Partner 7.5-m single-facet concentrator. 


\section{Chapter 5}

Table 5-8. Solar Kinetics 7.m Prototype Single-Facet Concentrator

\begin{tabular}{|c|c|}
\hline \multicolumn{2}{|c|}{$\begin{array}{l}\text { A program to demonstrate the feasibility of the single-facet dish began at Sandia National Laboratories in } 1987 \text {. Solar Kinetics } \\
\text { Incorporated (SKI) designed and built a } 7-\mathrm{m} \text { dish under a multiphase contract to support this effort. Solar Kinetics is currently } \\
\text { designing an } 11-\mathrm{m} \text { dish that is large enough to power a } 25-\mathrm{kW} \text { Stirling engine. }\end{array}$} \\
\hline \multicolumn{2}{|c|}{ DESICN } \\
\hline Aperture Diameter & $6.6 \mathrm{~m}$ \\
\hline Focal Length & $3.9 \mathrm{~m}$ \\
\hline Focal Ratio, $\mathrm{f} / \mathrm{d}$ & 0.60 \\
\hline \multicolumn{2}{|l|}{ REFLECTOR } \\
\hline Number of Facets & 1 \\
\hline Facet Design & $\begin{array}{l}\text { A preformed stainless steel membrane is stretched across a ring. Shape is } \\
\text { maintained by a partial vacuum between the membranes. The membranes } \\
\text { and ring are supported by a central hub and spokes, similar in concept to a } \\
\text { bicycle wheel. }\end{array}$ \\
\hline Reflective Surface & $\begin{array}{l}\text { Aluminized polymer (prototype only) held to preshaped } 0.1-\mathrm{mm} \text { stainless steel } \\
\text { membrane by the same vacuum that stabilizes the membrane. }\end{array}$ \\
\hline Nominal Slope Error & $2.3 \mathrm{mrad}$ \\
\hline \multicolumn{2}{|l|}{ STRUCTURE } \\
\hline Facet & $\begin{array}{l}\text { A preformed stainless steel membrane stretched across a ring. The rear } \\
\text { membrane is a polymer composite cloth. Shape is maintained by a partial } \\
\text { vacuum between the membranes. }\end{array}$ \\
\hline \multicolumn{2}{|l|}{ PERFORMANCE } \\
\hline Output (thermal) & $23.3 \mathrm{~kW}$ t at $1000 \mathrm{~W} / \mathrm{m}^{2}$ insolation \\
\hline Optical Efficiency & $\begin{array}{l}67 \% \text { (prototype only) significant improvement expected for commercial } \\
\text { design. }\end{array}$ \\
\hline Peak Optical Concentration Ratio & 5500 \\
\hline Year & 1990 \\
\hline Number Built & 1 \\
\hline Manufacturer & Solar Kinetics Inc., Dallas, Texas, USA \\
\hline
\end{tabular}

Source: Solar Kinetics, Inc. (1991); Grossman et al. (1992); Mancini (1991) 


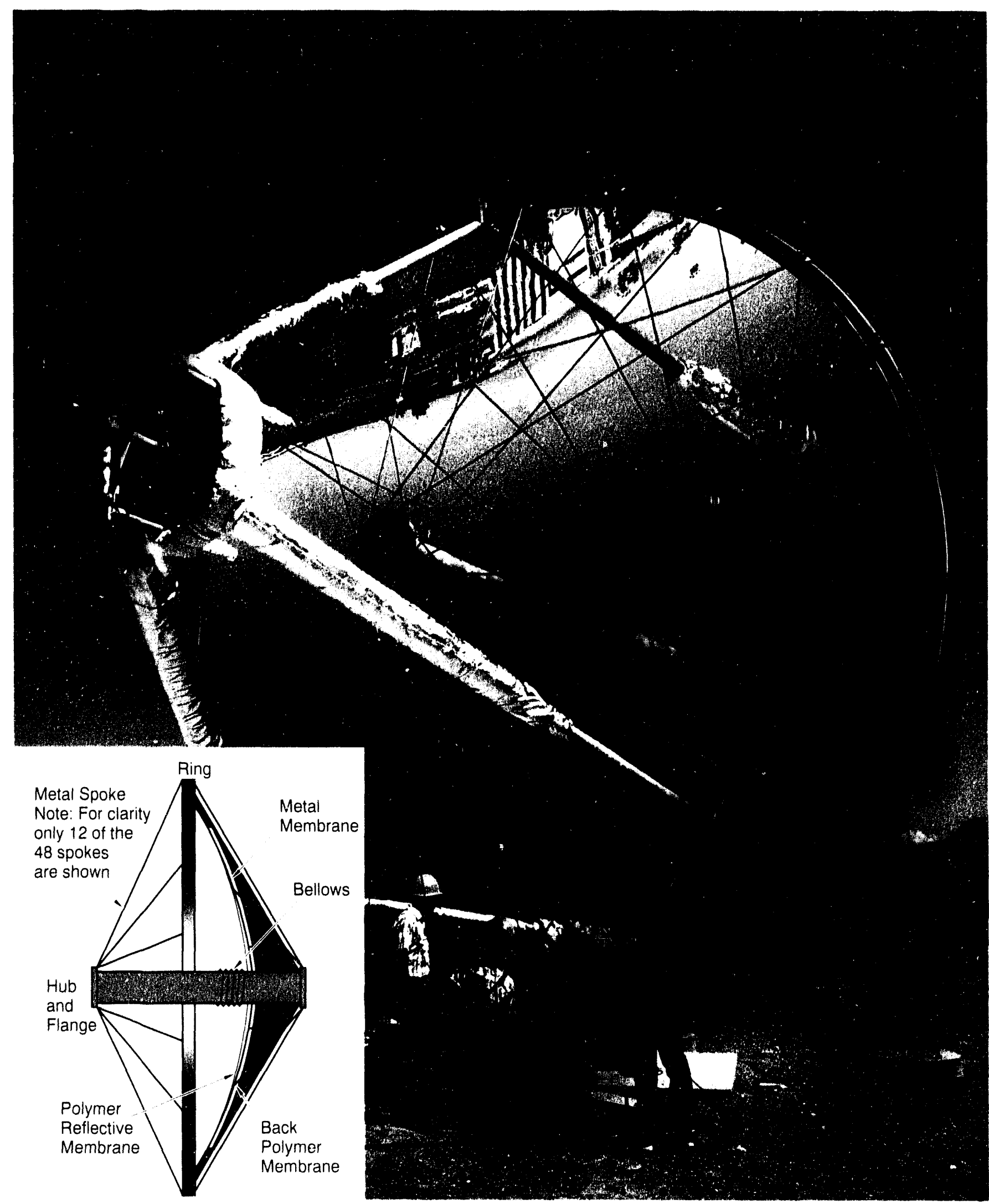

Figure 5-8. Solar Kinetics 7-m prototype single-facet concentrator. 


\title{
Chapter 5
}

Table 5-9. Cummins Power Generation CPG-460 Multifaceted Concentrator

\begin{abstract}
A multifaceted dish was developed for solar thermal power applications by Lajet Energy Company of Abilene, Texas, in the early 1980s. A field of 700 of them were installed in Warner Springs, California, and used as thermal collectors. Cummins Power Generation Co. of Columbus, Indiana, has modified this design for application to their $7.5-\mathrm{kW}$ e dish/Stirling system. Currently, there are four of these modified designs on-test: two in Abilene, Texas, one in Lancaster, Pennsylvania, and one in Pomona, California. In addition, one is in operation at Aisin Seiki's research facility near Valbonne, France, and three more are being installed at the Aisin Seiki Miyako Island Project. Fourteen more concentrators are to be sited around the United States within the next two years as part of the Dish/Stirling Joint Venture Program with Sandia National Laboratories.
\end{abstract}

DESICN

$\begin{array}{ll}\text { Dish Diameter } & 9.6 \mathrm{~m} \text { (max.), } 7.3 \mathrm{~m} \text { (equivalent) } \\ \text { Total Reflective Area } & 43.8 \mathrm{~m}^{2} \\ \text { Projected Area } & 41.5 \mathrm{~m}^{2} \\ \text { Focal Length } & 5.38 \mathrm{~m} \\ \text { Receiver Aperture (design) } & 178 \mathrm{~mm} \\ \text { Concentration Ratio (geometric) } & 1670\end{array}$

FACETS

Number of Facets

24

Facet Design

Facet Diameter

Facet Focal Ratio, $\mathrm{f} / \mathrm{d}$

Reflective Surface

Reflectance

Nominal Slope Error

STRUCTURE

Facet Support Structure

Tracking

Wind Maximum (while operating)

Two polymer membranes stretched across a ring. Shape is maintained by partial vacuum between the membranes.

$1.524 \mathrm{~m}$

3.64

Aluminized polymer film $(0.18 \mathrm{~mm}$ or 7 mils)

$85 \%$ (initial), $78 \%$ (weathered)

$1.5 \mathrm{mrad}$

Wind Maximum (survival)

Time to Defocus

Space frame of structural steel tubing

Polar drive

$15.6 \mathrm{~m} / \mathrm{s}$

$42.5 \mathrm{~m} / \mathrm{s}$

$\sim 30 \mathrm{sec}$

PERFORMANCE

Output (thermal)

$34 \mathrm{~kW}_{\mathrm{t}}$ at $1000 \mathrm{~W} / \mathrm{m}^{2}$ insolation

Optical Efficiency

$78 \%$

Peak Optical Concentration Ratio

5500

Year

1990

Number Built

6 (and 17 planned)

Manufacturer

Cummins Power Generation Inc., Columbus, Indiana, USA

Source: Kubo (1992) and Bean and Diver (1992) 


\section{Concentrators}

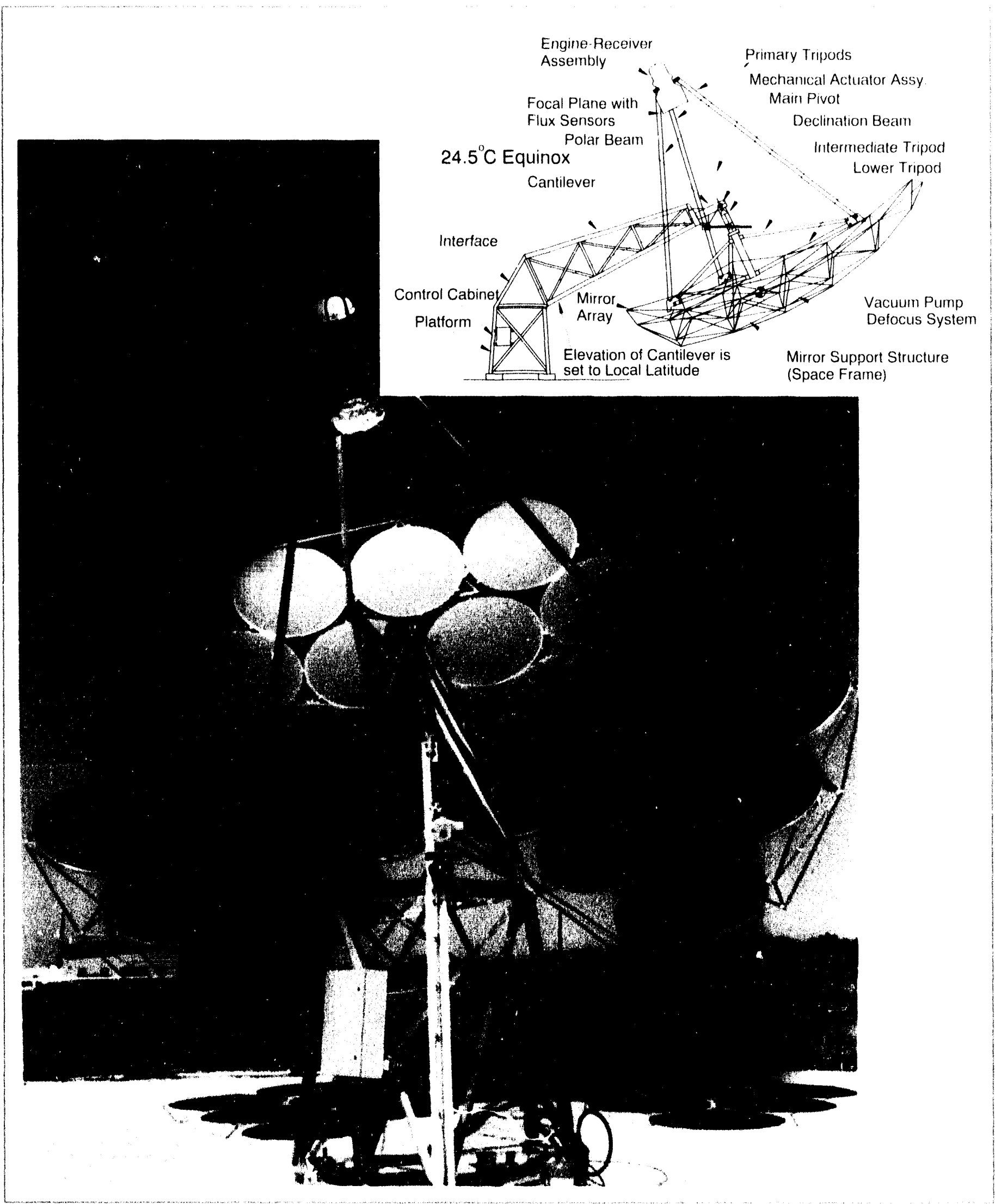

Figure 5-9. Cummins Power Generation CPG-460 multifaceted concentrator. 


\section{Chapter 5}

\section{Table 5-10. DOE Faceted Stretched-Membrane Dish}

In an effort begun in 1989, Sandia National Laboratories is developing a dish using multiple stretched-membrane facets (Mancini, 1991). The approach is to use twelve 3-m-diameter stretched-membrane facets having an f/d ratio of approximately 3. The goal for facet slope error is $\mathbf{2 . 5}$ milliradians. Two approaches to facet design are being used. One is to elastically deform the facet using uniform air pressure loading. The other is to use a combination of uniform (air) and nonuniform (hydrostatic) pressure to plastically form the surface, and use a slight vacuum to maintain it. The reflective surface is a silvered acrylic film in both cases. Fabrication and testing of the first prototypes began at Sandia in 1992.

DESIGN

Equivalent Dish Diameter

Total Power

Optical Efficiency

Number of Facets

Total Reflective Area

Dish Focal Length

Geometric Concentration Ratio

Peak Flux (predicted)

FACETS

Design

Diameter

$f / d$ range

Reflective Surface

Reflectivity

Nominal Slope Error

Design/Manufacture

\section{TRACKING STRUCTURE}

Facet Support Structure

Pedestal

Tracking

Pointing Accuracy

Emergency Off-Sun Tracking

Design

Manufacturer

Source: Mancini (1993)
$10.4 \mathrm{~m}$

$70 \mathrm{~kW}_{\mathrm{t}}$

$\sim 0.88$

12

$84.8 \mathrm{~m}^{2}$

$9.0 \mathrm{~m}$

$\sim 1500$ to 2000

-3500 suns

Stainless steel membranes attached to a steel ring; either preformed or elastically formed.

$3.0 \mathrm{~m}$

2.8 to 3.0

3 M ECP305 silvered acrylic film

0.93 when new

1.2 to 3.5 mrad (measured)

Science Applications International (SAIC) (elastically formed membranes) Solar Kinetics (SKI) (preformed membranes)

Made from welded steel shapes.

Tapered steel tube.

Elevation/Azimuth

1.72 milliradians at 27 miles per hour (goal)

12 seconds

WG Associates, Dallas, TX, USA

TIW, Albuquerque, NM, USA 


\section{Concentrators}
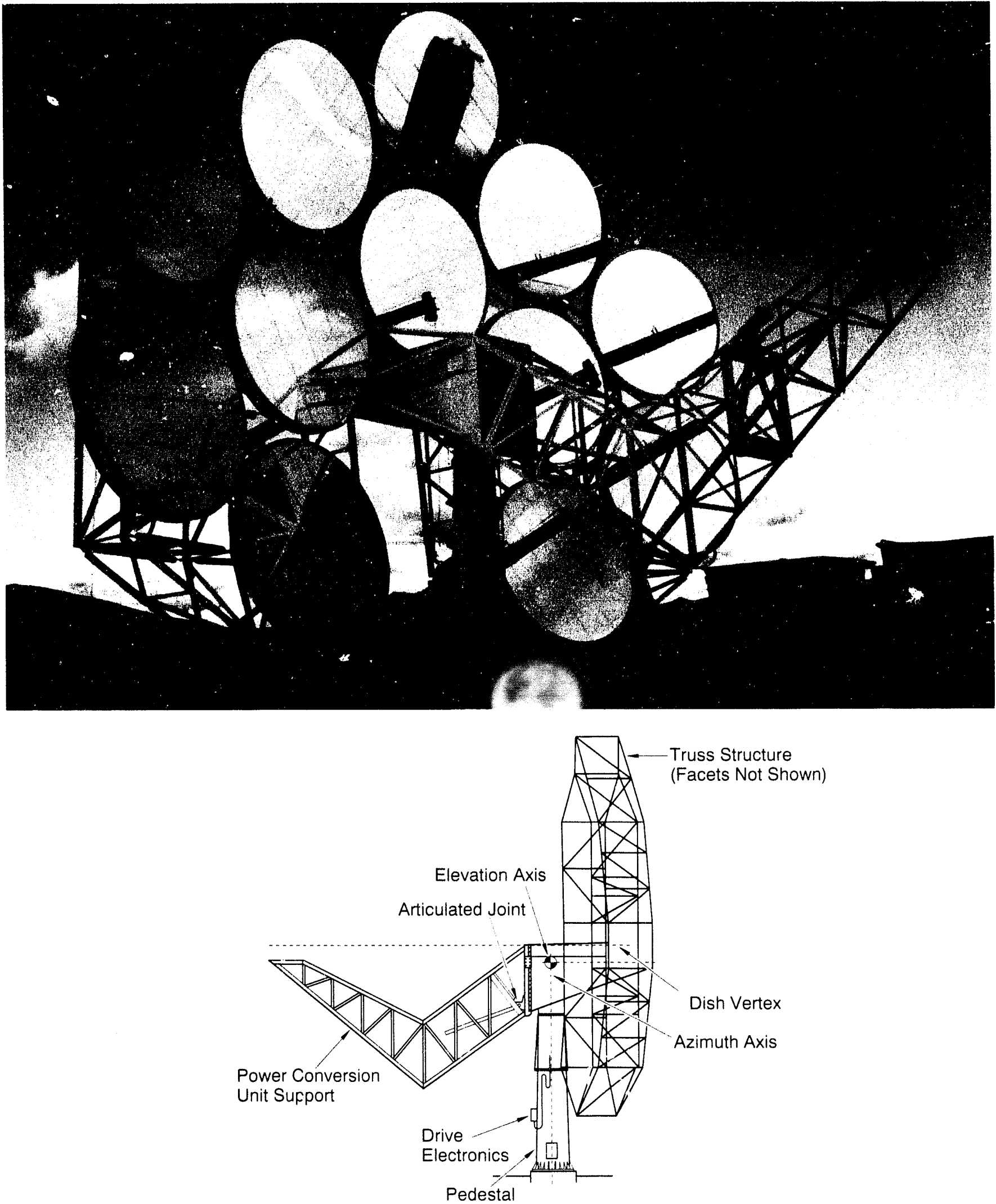

Figure 5-10. DOE faceted stretched-membrane dish development concentrator. 


\section{Chapter 5}

Table 5-11. HTC Solar Research Concentrator

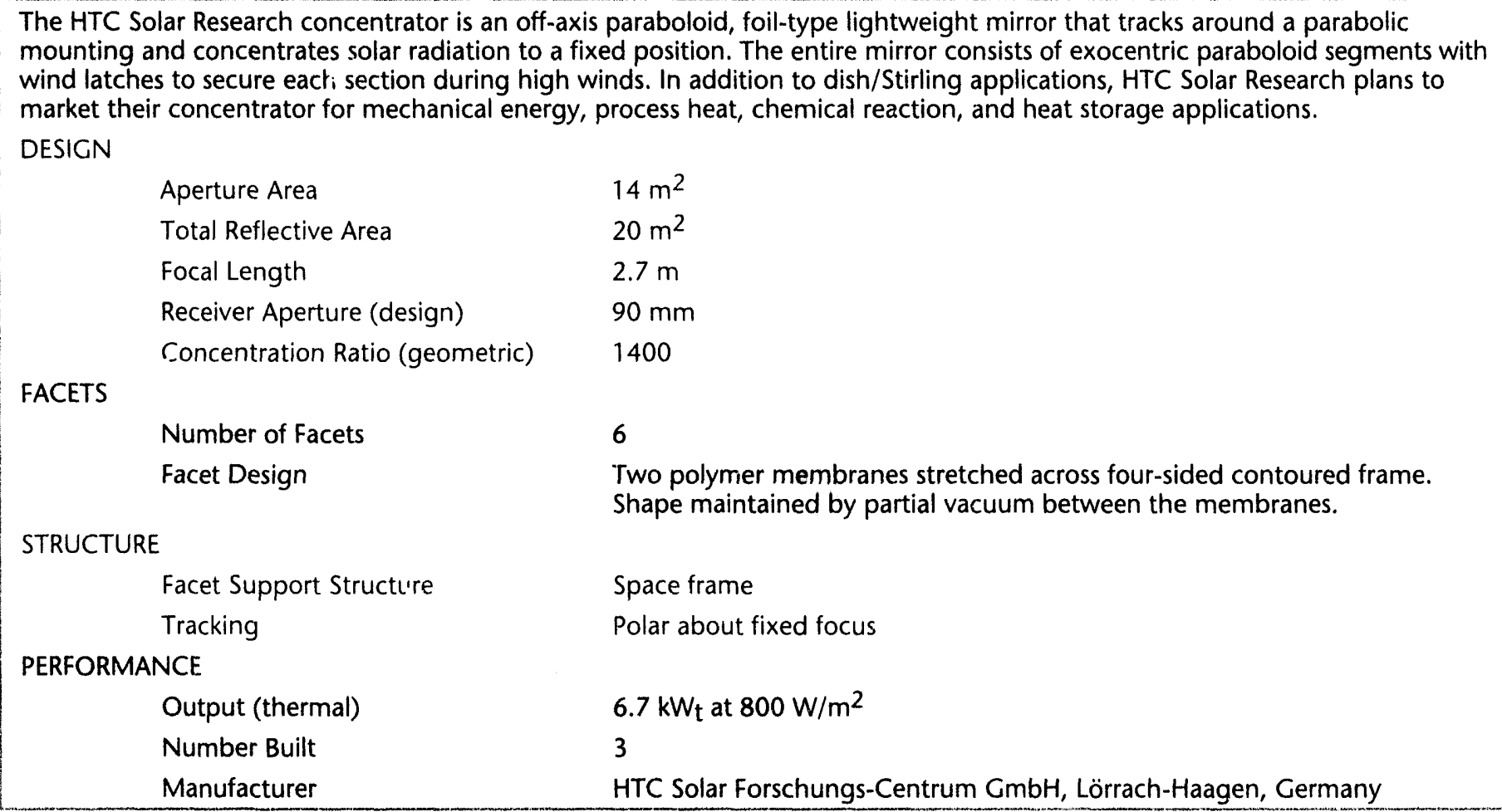

Source: Mitzel (1992) 
Concentrators
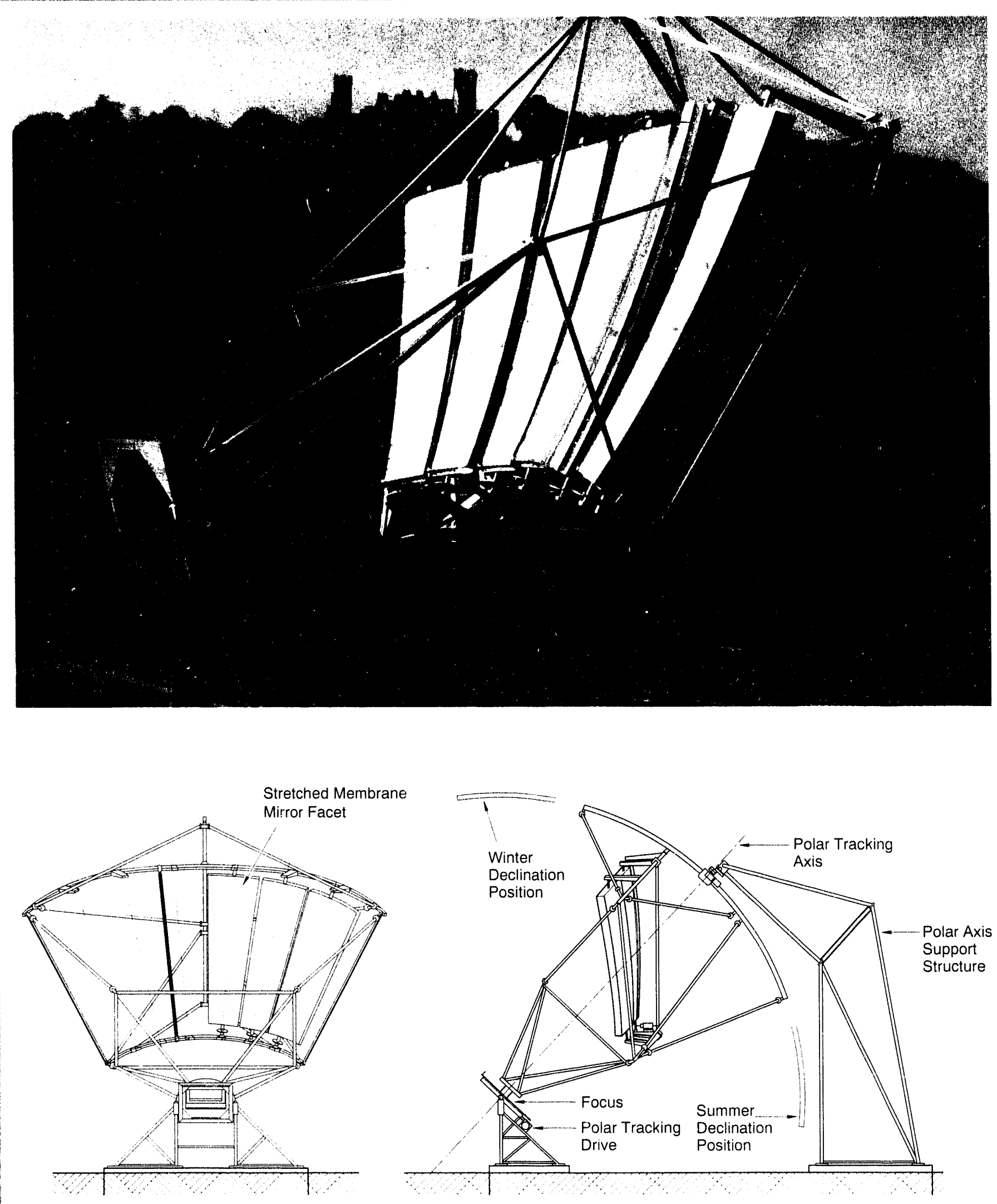

Figure 5-11. HTC Solar Research concentrator. 
Chapter 5

Notes 


\section{Chapter 6: Receivers}

In most Stirling engines, the working gas is heated as it passes through an array of small tubes or fins that are heated externally. The function of the receiver is to efficiently transfer concentrated solar heat from the dish to the Stirling engine's working fluid.

\section{Directly Illuminated Tube Receivers}

In the early dish/Stirling receiver designs, the geometry of the Stirling engine's heater tubes was modified so that they could more readily absorb the direct solar flux. This approach, the directly illuminated tube receiver, is straightforward and has been used successfully in the majority of dish/Stirling systems. The United Stirling of Sweden $\mathrm{AB}$ (USAB) 4-95 receiver used in the Vanguard and McDonnell Douglas dish/Stirling systems (Figures 6-1a and 6-1b, Table 6-1*), the German/Saudi USAB 4-275 receiver (Figure 6-2, Table 6-2), the Schlaich, Bergermann und Partner (SBP) V-160 receiver (Figure 6-3, Table 6-3), the Aisin Seiki Miyako Island NS30A receiver (Figure 6-4, Table 6-4), and the STM/Detroit Diesel 4-120 (STM4-120) receiver (Figure 6-5, Table 6-5) are examples of directly illuminated heater tube receivers.

\section{Reflux Receivers}

Because of the inherent nonuniformities of concentrated sunlight, directly illuminated heater tubes can experience temperature gradients from front to back and along the tube length that degrade performance and limit life. In addition, directly illuminated tube receirers require highly accurate concentrators to produce reasonably uniform incident solar flux distributions and generally result in performance compromises in the engine and receiver designs. To avoid the problems associated with directly heating the Stirling engine's heater tubes, the reflux receiver is being developed for dish/Stirling systems. In a reflux receiver, an intermediate heat-transfer fluid vaporizes on the receiver absorber surface, and condenses on the engine heater tubes, thereby transferring heat at almost constant temperature. The condensed liquid returns by gravity (refluxing) to repeat the process. The heat-transfer fluid is usually a liquid metal.

Two reflux receiver concepts are used to transport liquid metal to the absorber: either the absorber surface is always immersed in a pool of liquid (pool-ioiler receiver) or a wick draws the liquid metal up from a small sump to wet the absorber surface (heat-pipe receiver).

The advantages of the reflux receiver are its extremely high rates of heat transfer (rates as high as $800 \mathrm{~W} / \mathrm{cm}^{2}$ have been demonstrated in other heat-pipe applications), permitting smaller receivers, and nonuniformity in concentrator flux profiles. Higher engine efficiencies are possible because of smaller differences between peak temperature and engine working gas temperature, compared to tube receivers. Also, the use of an intermediate heat-transfer fluid decouples the design of the concentrator from the engine. This makes it possible to design receivers to be more efficient while at the same time optimizing the Stirling engine design.

An added benefit is that it is easier to add a gas burner for hybrid solar/fossil-fuel operation. Combined fossilfuel and solar operation permits a reliable supply of electricity at the times it is needed by the user.

\section{Pool-Boiler Receivers}

Three prototype liquid-metal reflux pool-boiler receivers (see Figures 6-6 through 6-8 and Tables 6-6 through 6-8) have been designed and tested by Sandia National Laboratories, Albuquerque, New Mexico. In these tests, the high performance of these receivers has been proven. Moreno et al. (1993a and 1993b) and Andraka et al. (1992) provide summaries of these designs and test results.

\section{Heat-Pipe Receivers}

A number of heat-pipe receivers have been designed and are being tested for dish/Stirling application. Andraka et al. (1993) summarizes the development and testing of this type of receiver.

The principal advantage of the heat-pipe receiver over the pool boiler is the added safety associated with 


\section{Chapter 6}

smaller inventories of liquid-metal heat-transfer fluid. Because it has less thermal mass than the pool boiler, the heat-pipe receiver responds more rapidly to insolation transients. Heat loss associated with transient cloud cover is therefore less with the heat-pipe receiver. On the other hand, the heat-pipe receiver has an increased number of thermal stress cycles on the receiver and engine during cloudy days, and a greater variation ir: output power.

In addition, the heat pipe receiver more readily allows operation with the polar drive concentrator drive mechanism. As a result, heat pipe receivers can be used with both polar and azimuth-elevation tracking drives, while pool boiler receivers are generally limited to azimuthelevation drives.

Cummins Power Generation uses heat-pipe receivers (Figures 6-8 and 6-9, Tables 6-8 and 6-9) on their 7.5$\mathrm{kW}_{\mathrm{e}}\left(35-\mathrm{kW}_{\mathrm{t}}\right)$ system and $75-\mathrm{kW}_{\mathrm{t}}$ systems. Dynatherm has developed a screen-wick heat-pipe receiver (Figure 6-10 and Table 6-10). Also, the German Aerospace Research Establishment (DLR) has designed and tested a heat-pipe receiver for the Schlaich, Bergermann und Partner V-160 system (Figures 6-11 and 6-12, Tables 6-11 and 6-12).

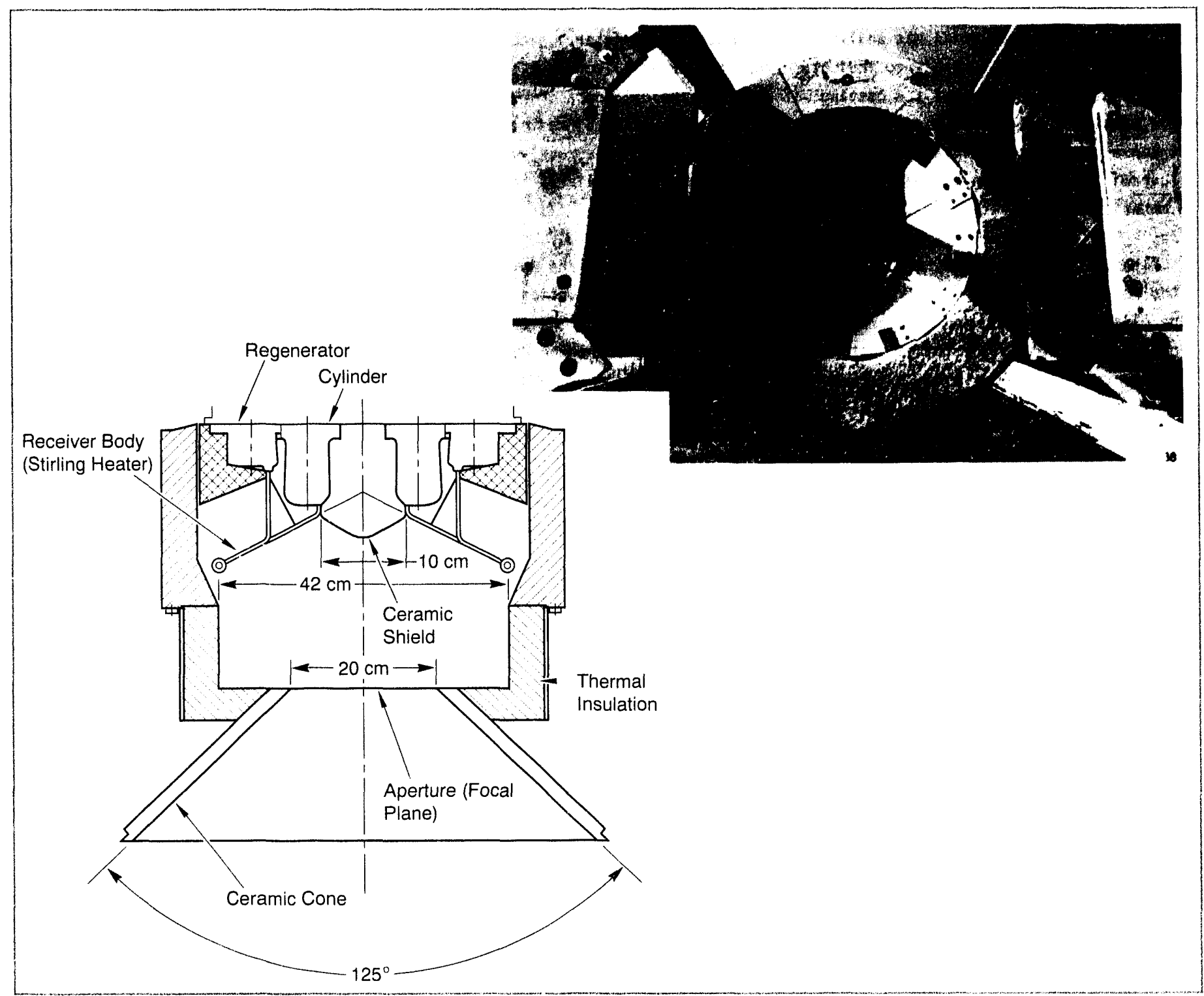

Figure 6-1a. Vanguard I receiver. Note water-cooled aperture protection shutters on either side. 


\section{Receivers}

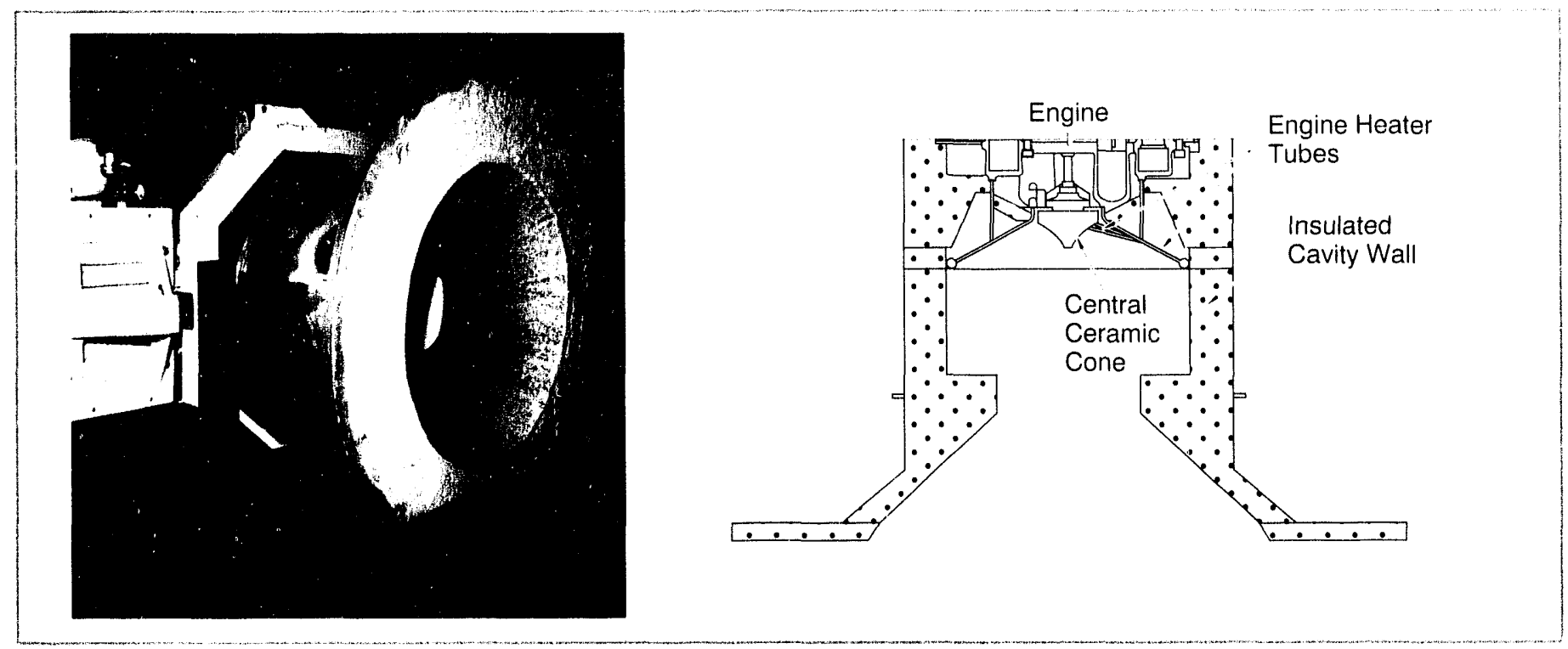

Figure 6-1b. United Stirling 4-95 engine with MDAC receiver.

Table 6-1. United Stirling 4-95 Receiver (Vanguard and MDAC)

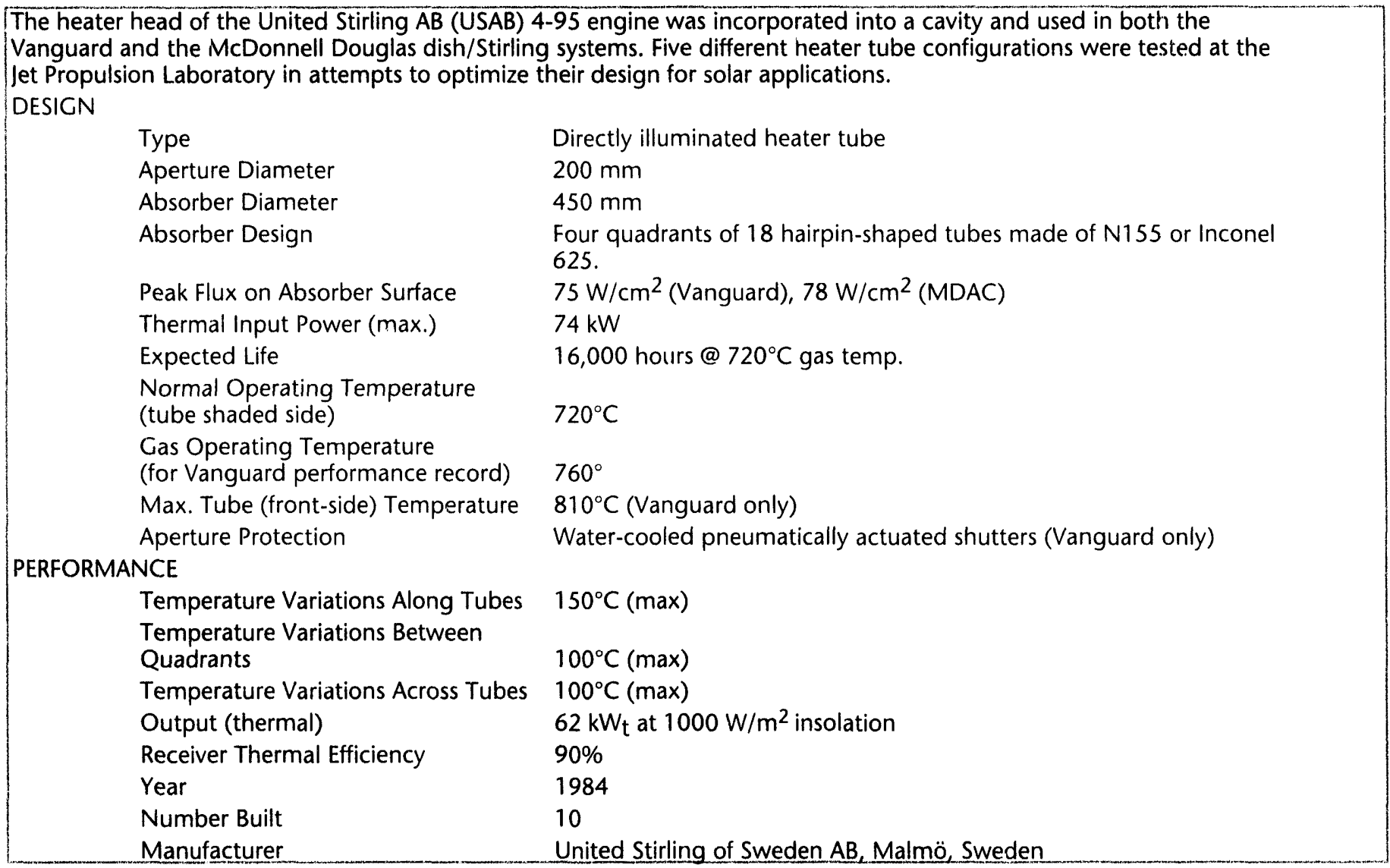

Source: Droher and Squier (1986); Livingston (1985); Lopez and Stone (1992); Washom et al. (1984) 


\section{Chapter 6}

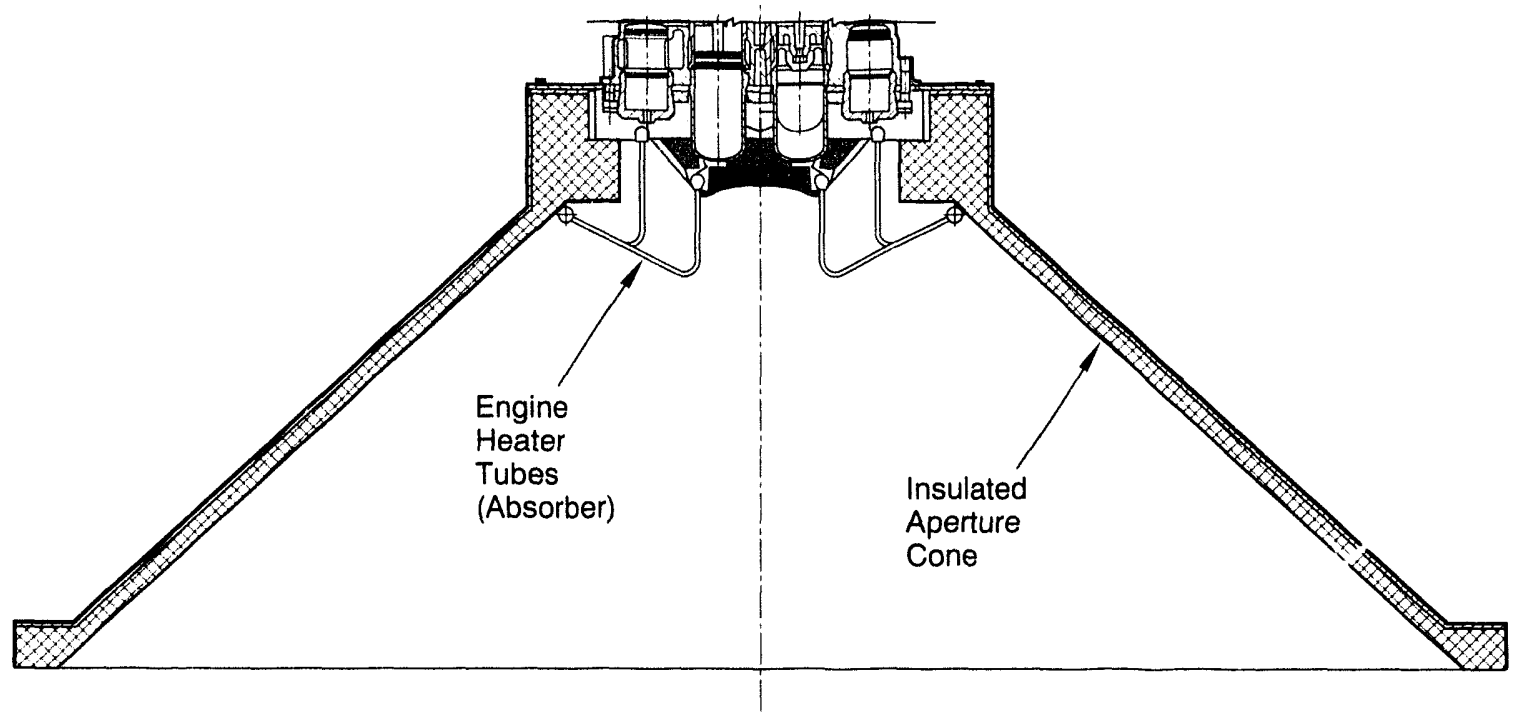

Figure 6-2. United Stirling 4-275 receiver (German/Saudi project).

Table 6-2. United Stirling 4-275 Receiver (German/Saudi Project)

The heater head of the United Stirling AB (USAB) 4-275 engine was surrounded by an insulated cone wind protector. This receiver is a directly illuminated tube receiver. The absorber consists of many small-diameter heater tubes located in the back of the cavity that absorb the concentrated sunlight. An insulated aperture cone provides wind protection for the absorber.

DESIGN

$\begin{array}{ll}\text { Type } & \text { Directly illuminated heater tube } \\ \text { Aperture Diameter } & 700 \mathrm{~mm} \\ \text { Cone Diameter } & 2000 \mathrm{~mm} \\ \text { Absorber Diameter } & 700 \mathrm{~mm} \\ \text { Peak Flux on Absorber Surface } & 50 \mathrm{~W} / \mathrm{cm}^{2} \\ \text { Thermal Input Power (max.) } & 179 \mathrm{~kW} \\ \text { Peak Tube (front-side) Temperature } & 800^{\circ} \mathrm{C} \\ \text { Oper. Temp. (tube shaded side) } & 720^{\circ} \mathrm{C} \\ \text { Gas Temperature (high) } & 620^{\circ} \mathrm{C}\end{array}$

PERFORMANCE

Output (thermal)

$142.6 \mathrm{kWt}$ at $1000 \mathrm{~W} / \mathrm{m}^{2}$ insolation

Receiver Efficiency

$80 \%$

Year

1984

Number Built

2

Manufacturer

United Stirling of Sweden AB, Malmö, Sweden

Source: Schiel (1992) 


\section{Receivers}

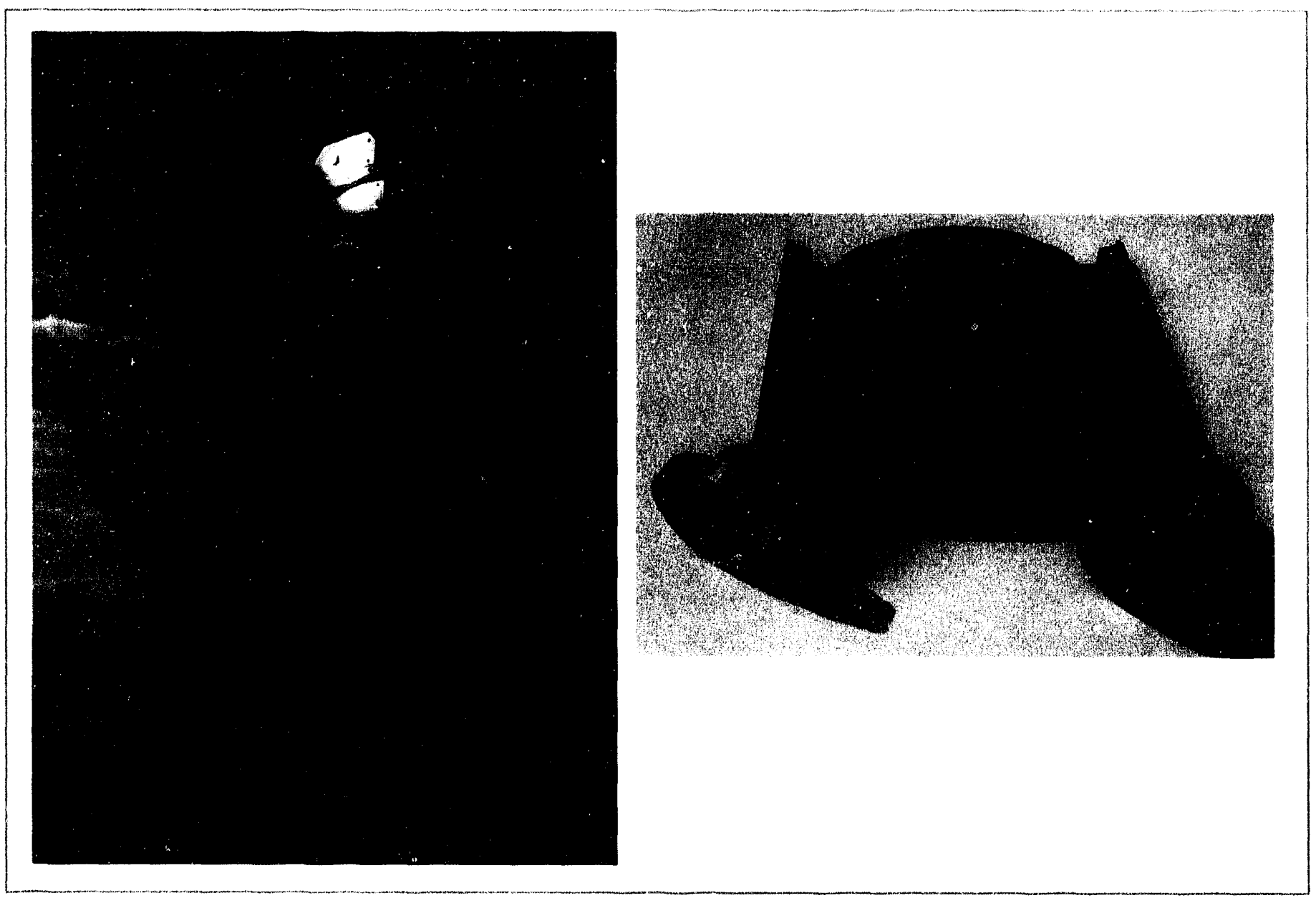

Figure 6-3. Schlaich, Bergermann und Partner V-160 receiver installed in system (left photo) and apart from system (right photo).

Table 6-3. Schlaich, Bergermann und Partner V-160 Receiver

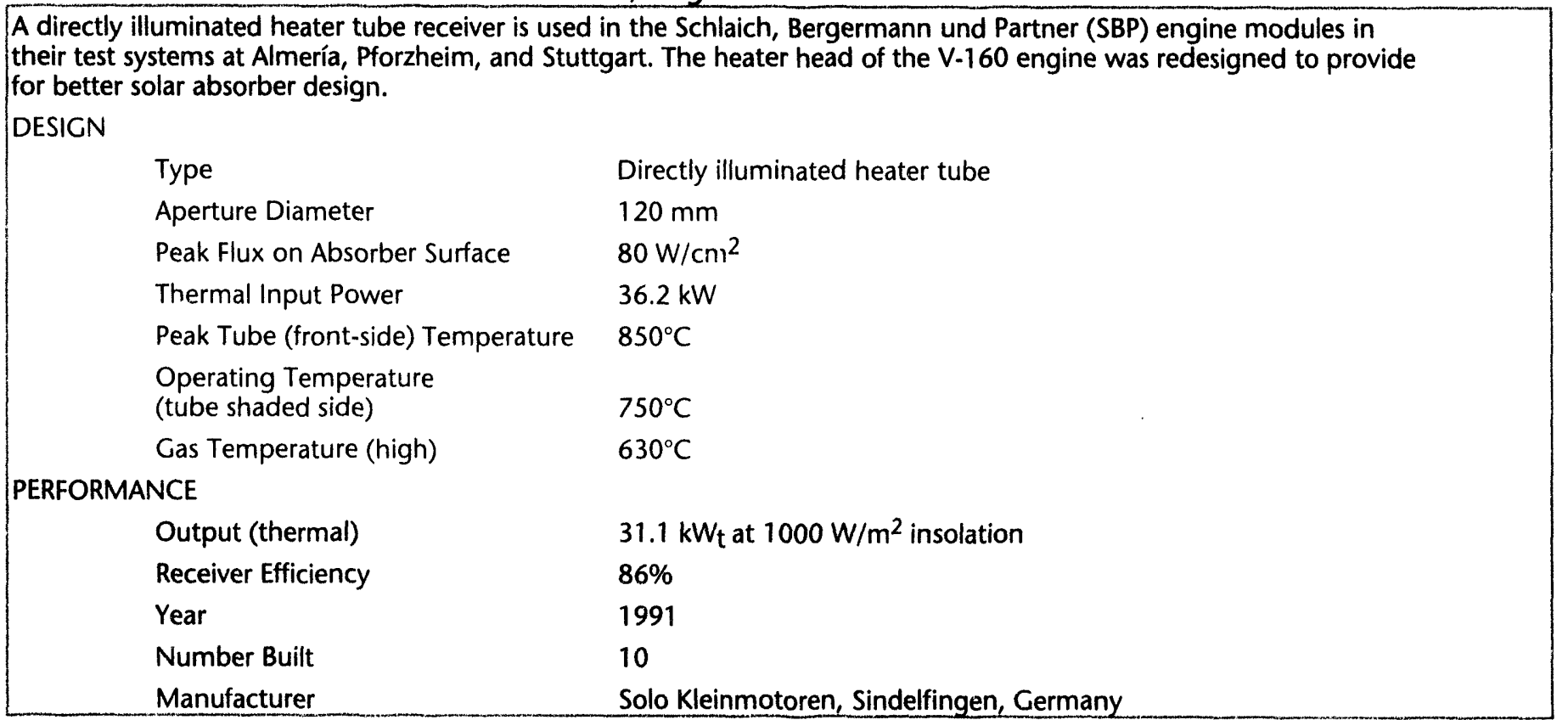

Source: Schiel (1992) 


\section{Chapter 6}
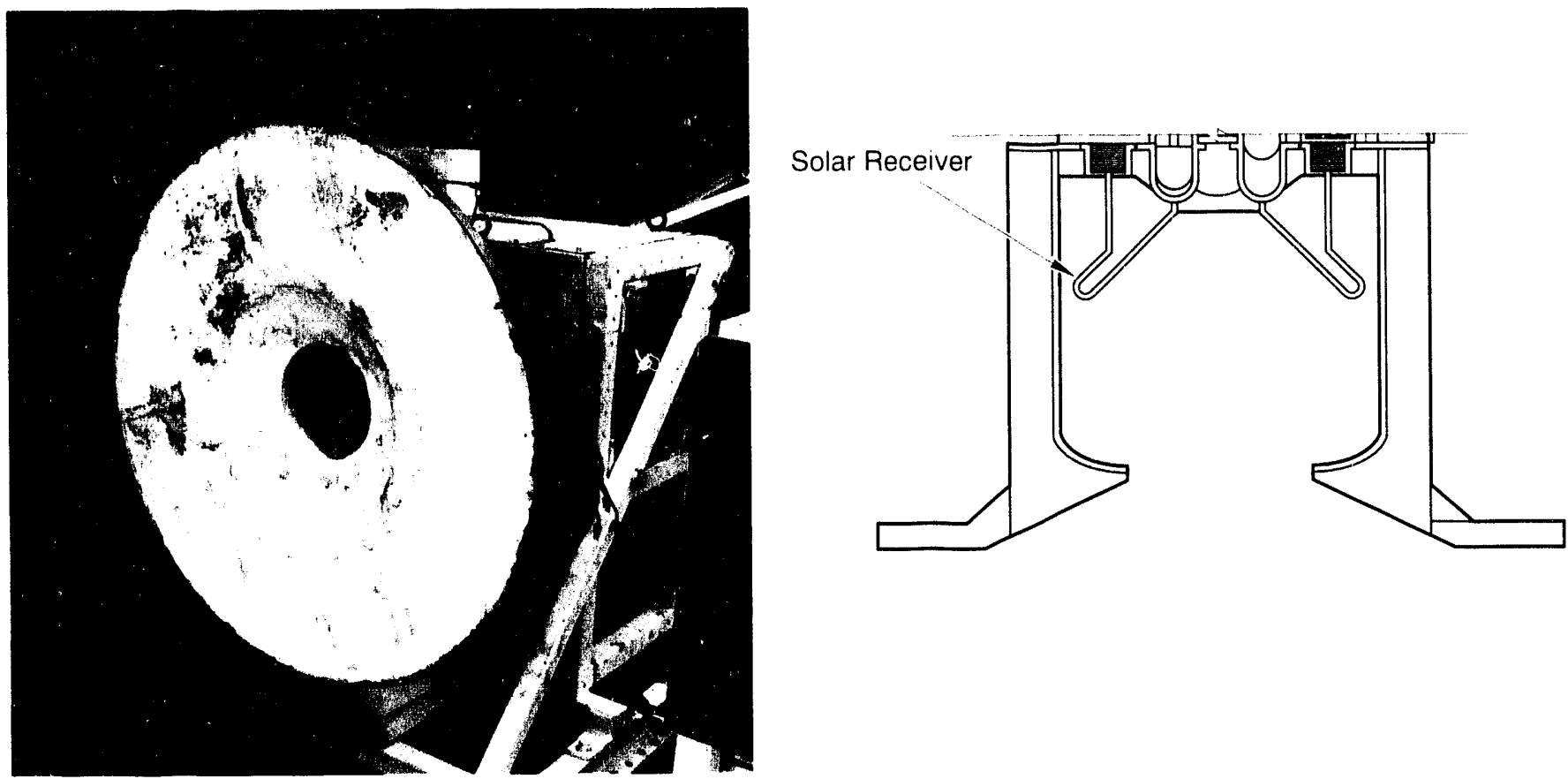

Figure 6-4. Aisin Seiki Miyako Island NS30A receiver.

Table 6-4. Aisin Seiki Miyako NS30A Island Receiver

The heater tubes of the Aisin Seiki NS30A engine are enclosed in an insulated cavity both for the Kariya test system and the system to be installed on Miyako Island.

DESIGN

Type

Aperture Diameter

Absorber Diameter

Thermal Input Power (max.)

Peak Tube (front-side) Temperature

Operating Temperature

(tube shaded side)

Gas Temperature (high)

PERFORMANCE

Output (thermal)

Receiver Efficiency

Year

Number Built

Manufacturer
Directly illuminated heater tube

$185 \mathrm{~mm}$

$320 \mathrm{~mm}$

$53 \mathrm{~kW}$ (Miyako Island)

$780^{\circ} \mathrm{C}$

$750^{\circ} \mathrm{C}$

$683^{\circ} \mathrm{C}$

$35 \mathrm{~kW}$ at $1000 \mathrm{~W} / \mathrm{m}^{2}$ insolation (Miyako Island)

$65 \%$

1992

3

Aisin Seiki, Ltd., Kariya City, Aichi Prefecture, Japan

Source: Momose (1992) 
Receivers
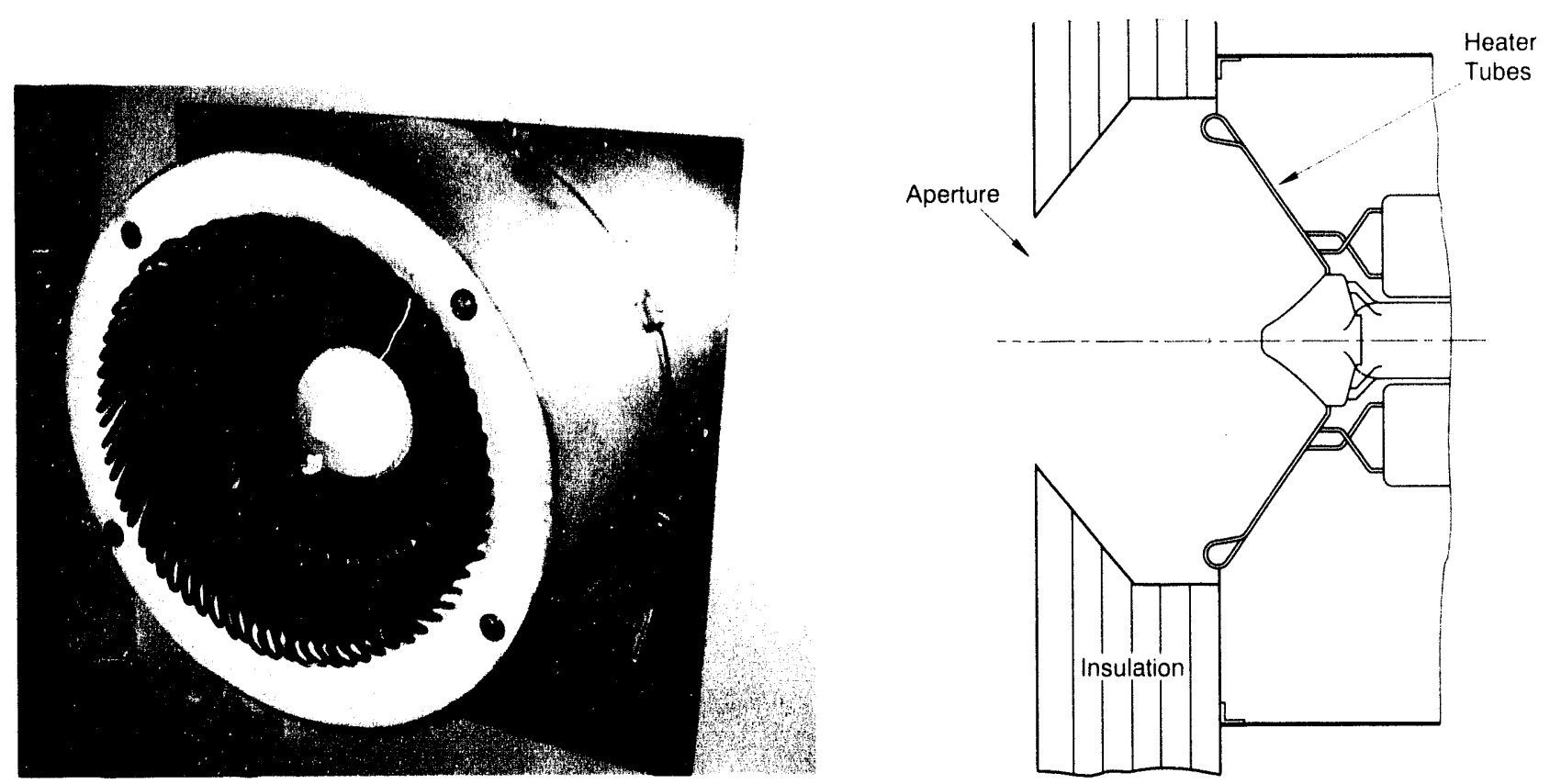

Figure 6-5. Stirling Thermal Motors 4-120 (STM4-120) direct illumination receiver

Table 6-5. Stirling Thermal Motors 4-120 (STM4-120) Direct Illumination Receiver

The heater head of the Stirling Thermal Motors engine has been incorporated into a directly illuminated heater tube receiver.

DESICN

\section{Type}

Aperture Diameter

Absorber Diameter

Absorber Design

Peak Flux on Absorber Surface

Gas Temperature (high)

Maximum Tube Temperature

PERFORMANCE

Receiver Thermal Efficiency (peak)

Year

Number Built

Manufacturer
Directly illuminated heater tube

$220 \mathrm{~mm}$

$400 \mathrm{~mm}$

Tube bank absorber

$75 \mathrm{~W} / \mathrm{cm}^{2}$

$720^{\circ} \mathrm{C}$

$800^{\circ} \mathrm{C}$

$90 \%$

1992

1

Stirling Thermal Motors, Ann Arbor, MI, USA

Source: Godett (1993b) 


\section{Chapter 6}
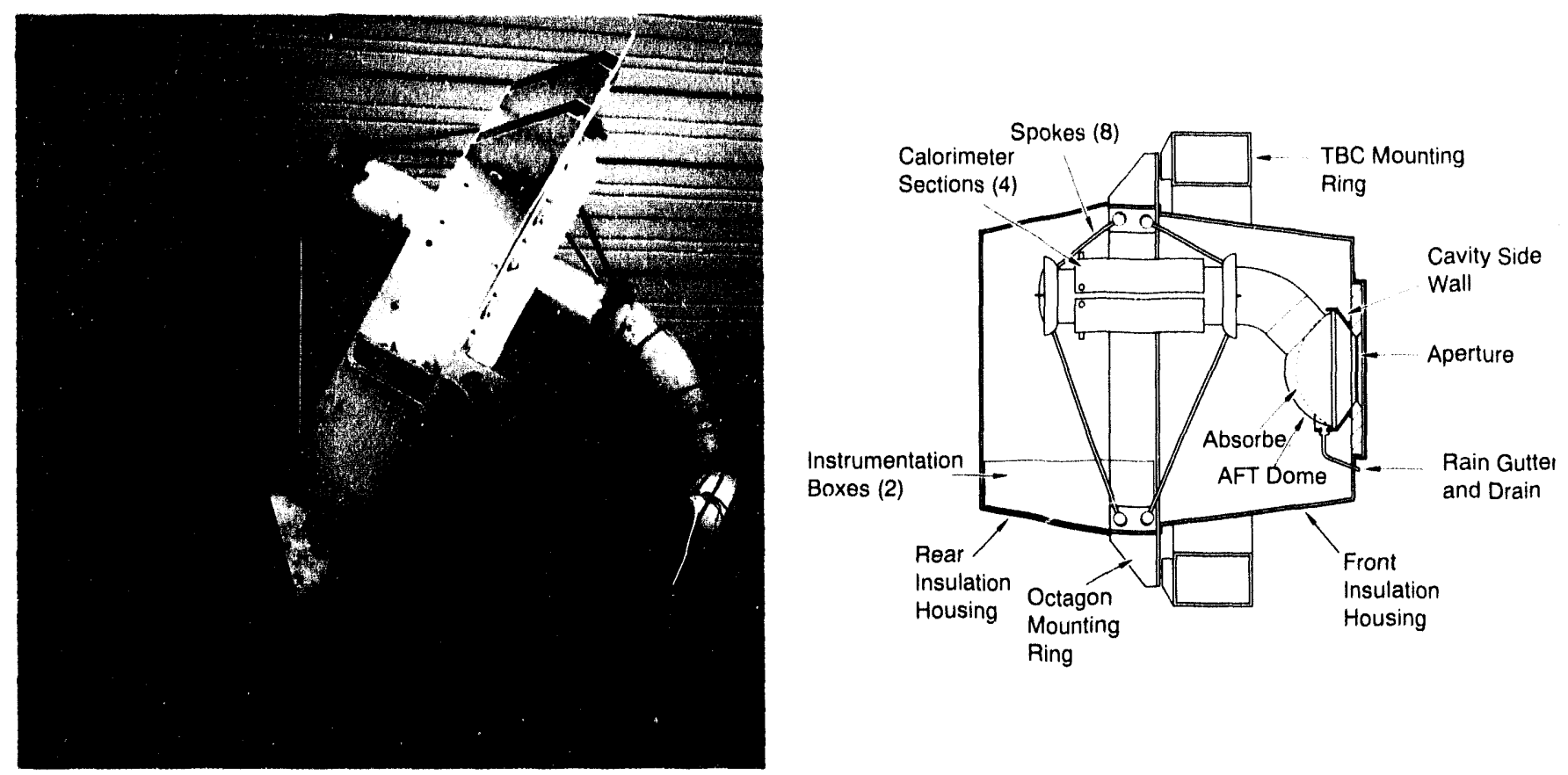

Figure 6-6. Sandia National La suratories pool-boiler receiver.

Table 6-6. Sandia National Laboratories Pool-Boiler Receiver

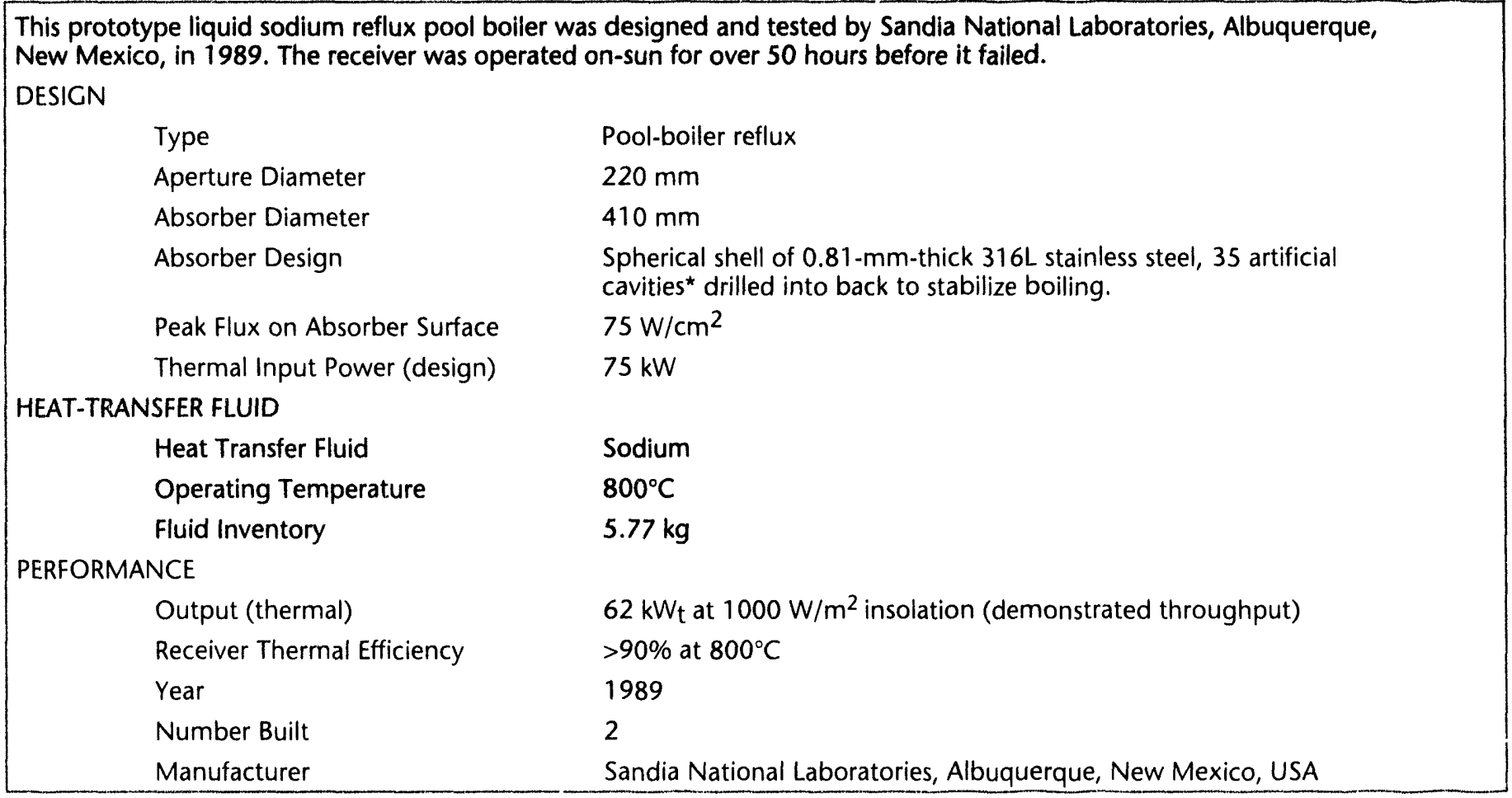

Source: Andraka et al. (1992)

* Another version of this receiver without the additional drilled cavities was tested in 1993 (Moreno et al., 1993a). 


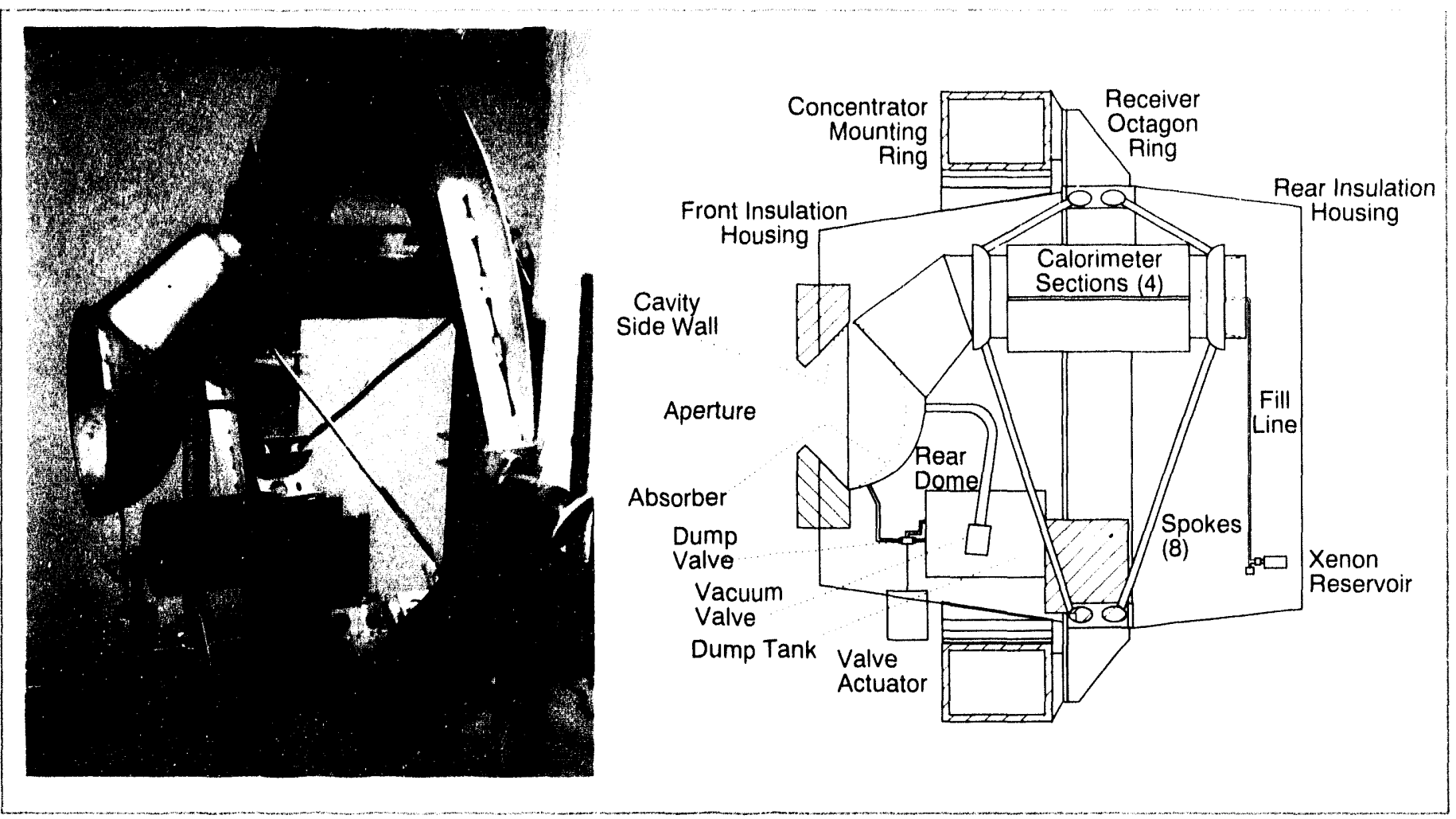

Figure 6-7. Sandia National Laboratories second-generation pool-boiler receiver.

Table 6-7. Sandia National Laboratories Second-Generation Pool-Boiler Receiver

This prototype liquid sodium-potassium alloy reflux pool boiler was designed and tested by Sandia National Laboratories, Albuquerque, New Mexico, in 1993. The receiver was operated on-sun for over 12 hours without any of the restart problems that eventually caused the failure of the first design.

DESICN

Type

Aperture Diameter

Absorber Diameter

Absorber Design

Peak Flux on Absorber Surface ${ }^{*}$

Thermal Input Power (design)

HEAT-TRANSFER FLUID

Heat Transfer Fluid

Operating Temperature

Fluid Inventory

PERFORMANCE

Output (thermal) ${ }^{\star}$

Receiver Thermal Efficiency*

Year

Number Built

Manufacturer
Pool-boiler reflux

$220 \mathrm{~mm}$

$458 \mathrm{~mm}$

Spherical shell of $089-\mathrm{mm}$-thick Haynes alloy $230,0.76-\mathrm{mm}$-thick powder-metal coating brazed to the back to stabilize boiling.

$61 \mathrm{~W} / \mathrm{cm}^{2}$

$75 \mathrm{~kW}$

Sodium-potassium alloy NaK-78

$750^{\circ} \mathrm{C}$

$8.85 \mathrm{~kg}$

$60.7 \mathrm{~kW}$ at $964 \mathrm{~W} / \mathrm{m}^{2}$ insolation (demonstrated throughput)

$>92 \%$ at $750^{\circ} \mathrm{C}$ and $964 \mathrm{~W} / \mathrm{m}^{2}$ insolation

1993

1

Sandia National Laboratories, Albuquerque, New Mexico, USA

Source: Moreno et al. (1993a and 1993b)

* Preliminary. 


\section{Chapter 6}
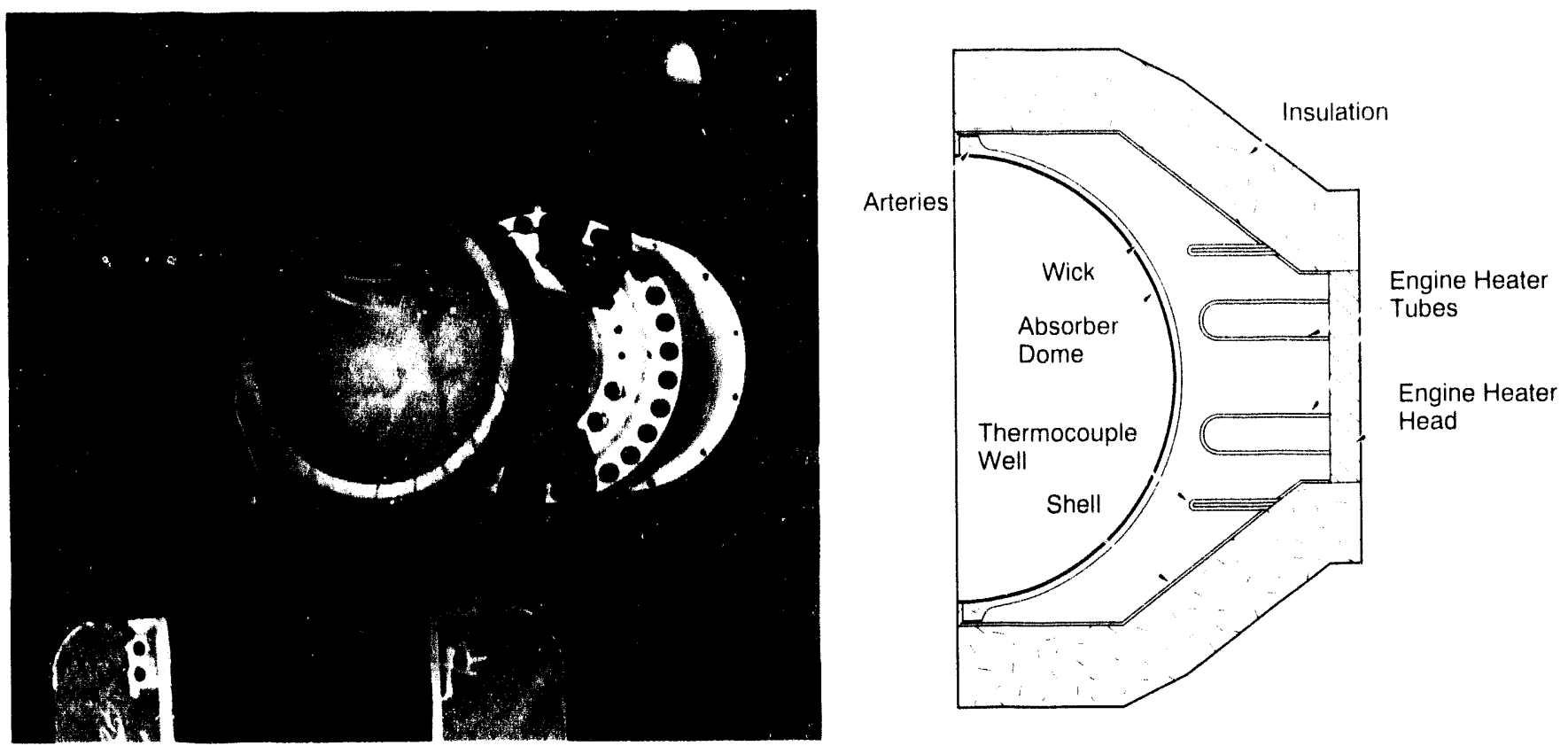

Figure 6-8. Cummins/Thermacore 35-kWt heat-pipe receiver.

Table 6-8. Cummins/Thermacore 35-kW, Heat-Pipe Receiver

Cummins Power Generation, Inc., has incorporated a Thermacore heat-pipe receiver as part of their 7.5-kW $\mathrm{e}$ dish/Stirling system. Three units have been tested with calorimeters and two of these units are currently under on-sun testing with engines. A total of $17 \mathrm{dish} / \mathrm{Sti}$ ling systems incorporating this receiver will be tested over the next 3 years.

DESIGN

Type

Aperture Diameter

Absorber Diameter

Absorber Design

Peak Flux on Absorber Surface (nominal)

\section{HEAT-TRANSFER FLUID}

Heat-Transfer Fluid

Operating Temperature

Fluid Inventory

PERFORMANCE

Output (thermal)

Receiver Thermal Efficiency

Year

Number Built

Manufacturer

Source: Dussinger (1991)
Heat-pipe reflux

$178 \mathrm{~mm}$

$416 \mathrm{~mm}$

0.8-mm-thick Haynes 230 alloy absorber with sintered nickel powder wick. Two circumferential arteries and no radial arteries.

$30 \mathrm{~W} / \mathrm{cm}^{2}$

Sodium

$675^{\circ} \mathrm{C}$ (sodium vapor temperature)

$1.5 \mathrm{~kg}$

$42 \mathrm{~kW}$ (demonstrated throughput)

$86 \%$

1990

5 plus 15 more under fabrication

Thermacore, Inc., Lancaster, Perinsylvania, USA 
Receivers

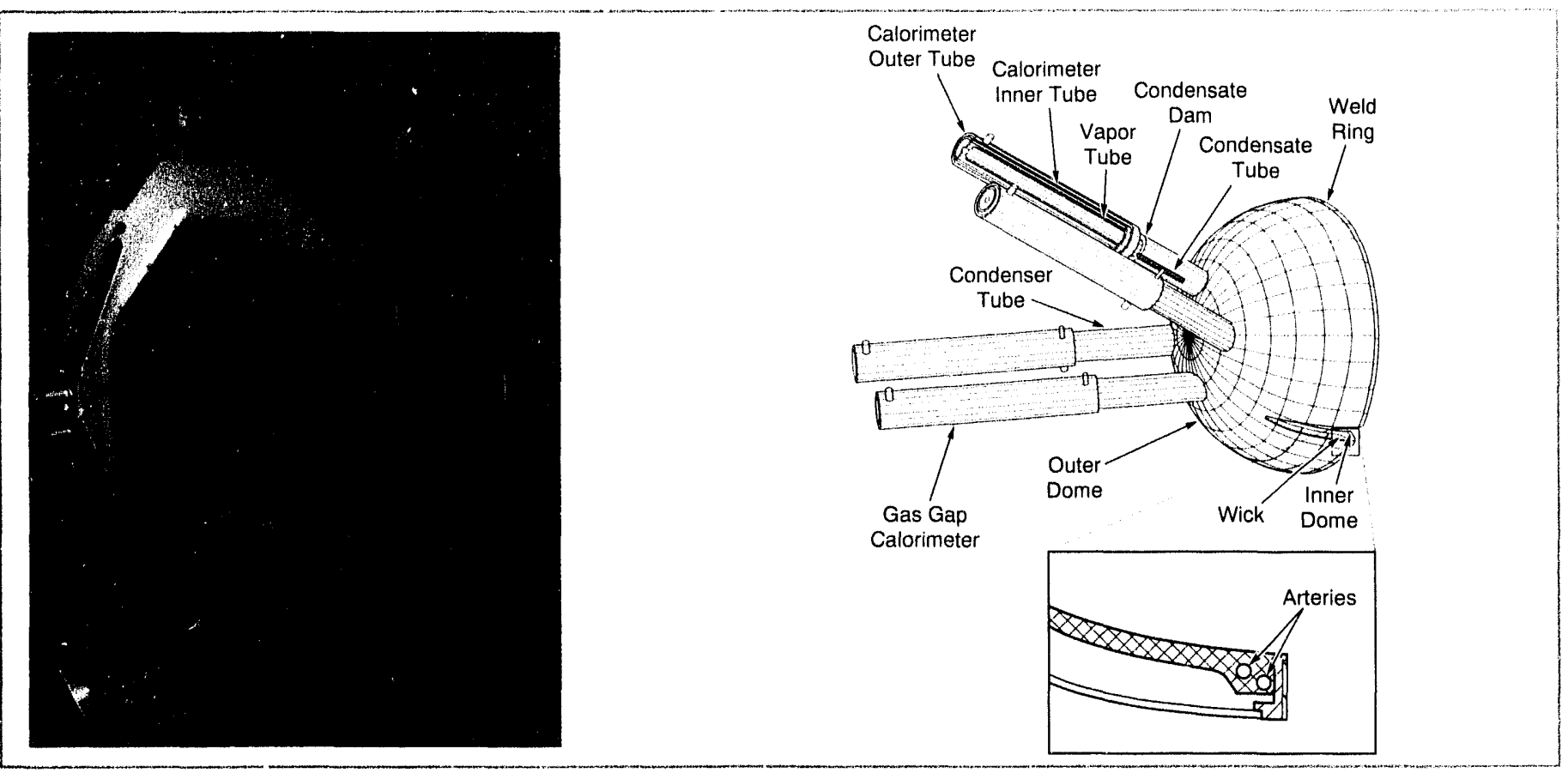

Figure 6-9. Cummins/Thermacore $75-k W_{t}$ heat-pipe receiver.

Table 6-9. Cummins/Thermacore 75-kW, Heat-Pipe Receiver

Cummins Power Generation and Thermacore, Inc., teamed to develop a heat-pipe receiver to demonstrate the potential of this concept for $25-\mathrm{kW}_{\mathrm{e}}$ dish/Stirling systems. The receiver was tested on Sandia's Test Bed Concentrator. Two more of these receivers are being built for Sandia, one of which will be tested with a calorimeter, the other with a 4-cylinder Stirling engine.

DESIGN

Type

Aperture Diameter

Absorber Diameter

Absorber Design

Thermal Input Power

Peak Flux on Absorber (nominal)

HEAT-TRANSFER FLUID

Heat-Transfer Fluid

Operating Temperature

Fluid Inventory

PERFORMANCE

Output (thermal)

Year

Number Built

Manufacturer
Heat-pipe reflux

$220 \mathrm{~mm}$

$508 \mathrm{~mm}$

0.8-mm-thick Haynes 230 alloy absorber with sintered nickel powder wick. Full hemisphere. Redundant circumferential arteries. Conden sate directed to wick rather than pool.

$75 \mathrm{kWt}$ (design)

$58 \mathrm{kWt}$ (demonstrated, dish limited)

$35 \mathrm{~W} / \mathrm{cm}^{2}$

Sodium

$750^{\circ} \mathrm{C}$ (design)

$820^{\circ} \mathrm{C}$ (max).

$2.9 \mathrm{~kg}$

$50 \mathrm{~kW}$ (demonstrated, dish-limited)

1993

1 plus 2 more under fabrication

Thermacore, Inc., Lancaster, Pennsylvania, USA

Source: Andraka et al. (1993) 


\section{Chapter 6}

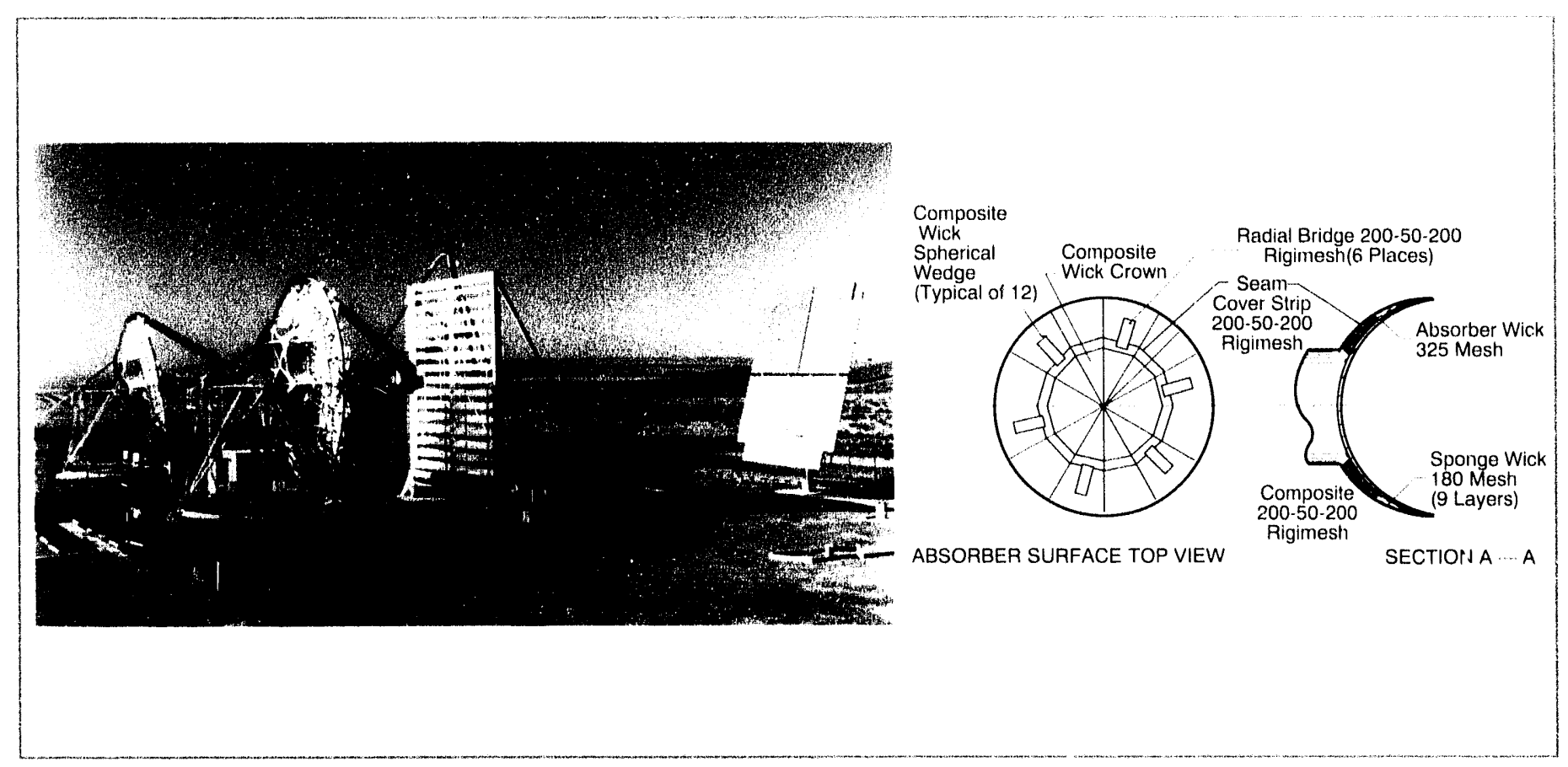

Figure 6-10. Dynatherm heat-pipe receiver.

Table 6-10. Dynatherm Heat-Pipe Receiver

\begin{tabular}{|c|c|c|}
\hline \multicolumn{3}{|c|}{$\begin{array}{l}\text { Dynatherm developed a screen-wick heat-pipe receiver in support of the Cummins Power Generation 4-kW } \mathrm{V}_{\mathrm{e}} \text { dish/ } \\
\text { Stirling system. The heat pipe was limit-tested on Sandia's Test Bed Concentrator. }\end{array}$} \\
\hline \multicolumn{3}{|c|}{ ( } \\
\hline & Type & Heat-pipe reflux \\
\hline & Aperture Diameter & $220 \mathrm{~mm}$ \\
\hline & Absorber Diameter & $410 \mathrm{~mm}$ \\
\hline & Absorber Design & $\begin{array}{l}0.81-\mathrm{mm} \text {-thick } 316 \mathrm{~L} \text { stainless steel with a composite screen wick } \\
\text { structure. Aft dome sponge artery, refluxing to wick surface. }\end{array}$ \\
\hline & Thermal Input Power & $45 \mathrm{~kW}_{\mathrm{t}}$ (demonstrated) \\
\hline HEAT-TRAI & $\begin{array}{l}\text { Peak Flux on Absorber (nominal) } \\
\text { SFER FLUID }\end{array}$ & $35 \mathrm{~W} / \mathrm{cm}^{2}$ \\
\hline & Heat-Transfer Fluid & Sodium \\
\hline & Operating Temperature & $750^{\circ} \mathrm{C}$ \\
\hline & Fluid Inventory & $520 \mathrm{~g}$ \\
\hline \multicolumn{3}{|c|}{ PERFORMANCE } \\
\hline & Output (thermal) & $27.5 \mathrm{~kW}_{\mathrm{t}}$ (demonstrated) \\
\hline & Year & $1991-1992$ \\
\hline & Number Built & 1 \\
\hline & Manufacturer & Dynatherm, Cockeysville, Maryland, USA \\
\hline
\end{tabular}

Source: Andraka et al. (1992) 


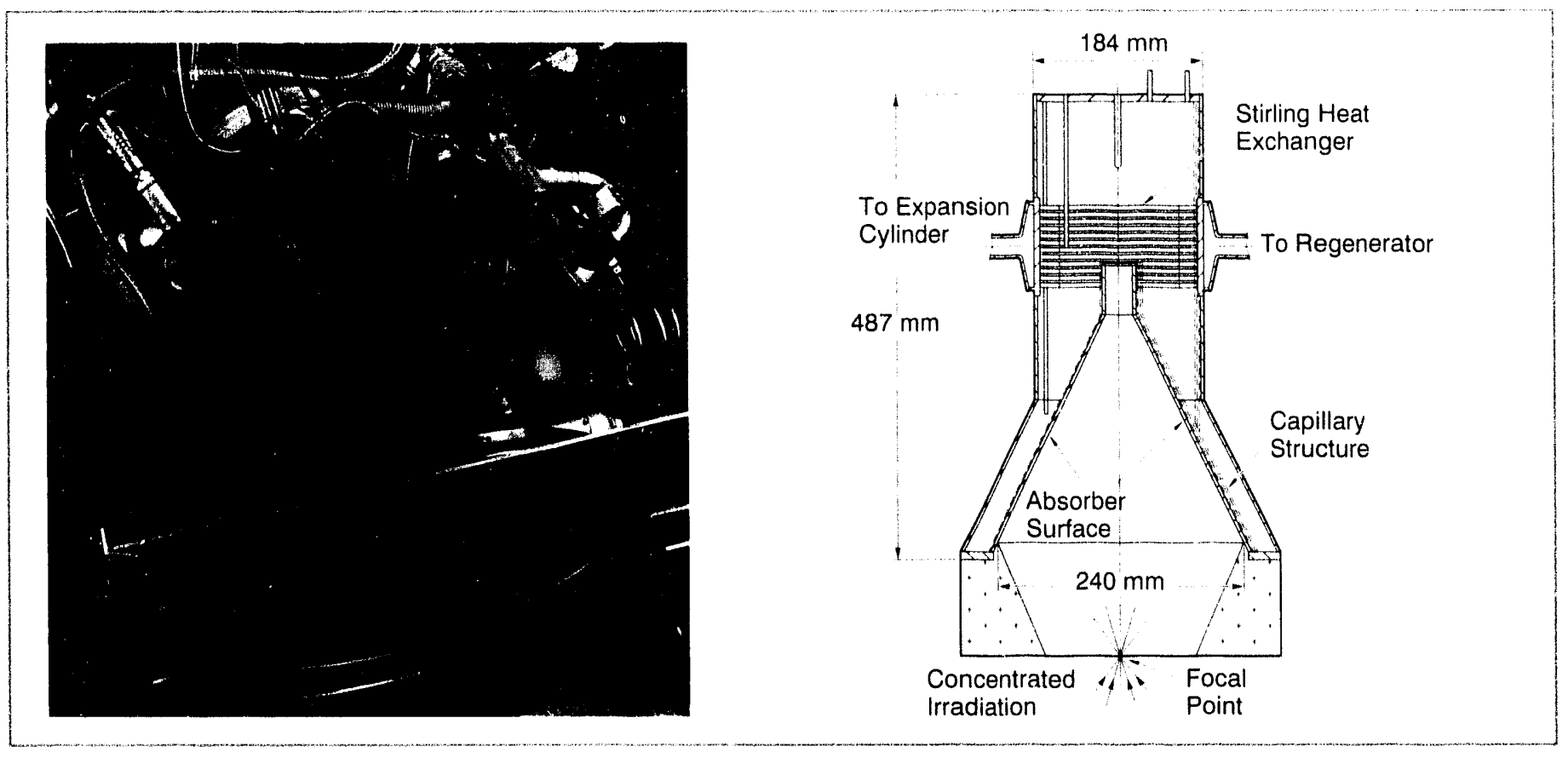

Figure 6-11. German Aerospace Research Establishment (DLR) V-160 heat-pipe receiver (Mod 1).

Table 6-11. Cerman Aerospace Research Establishment (DLR) V-160 Heat-Pipe Receiver (Mod 1)

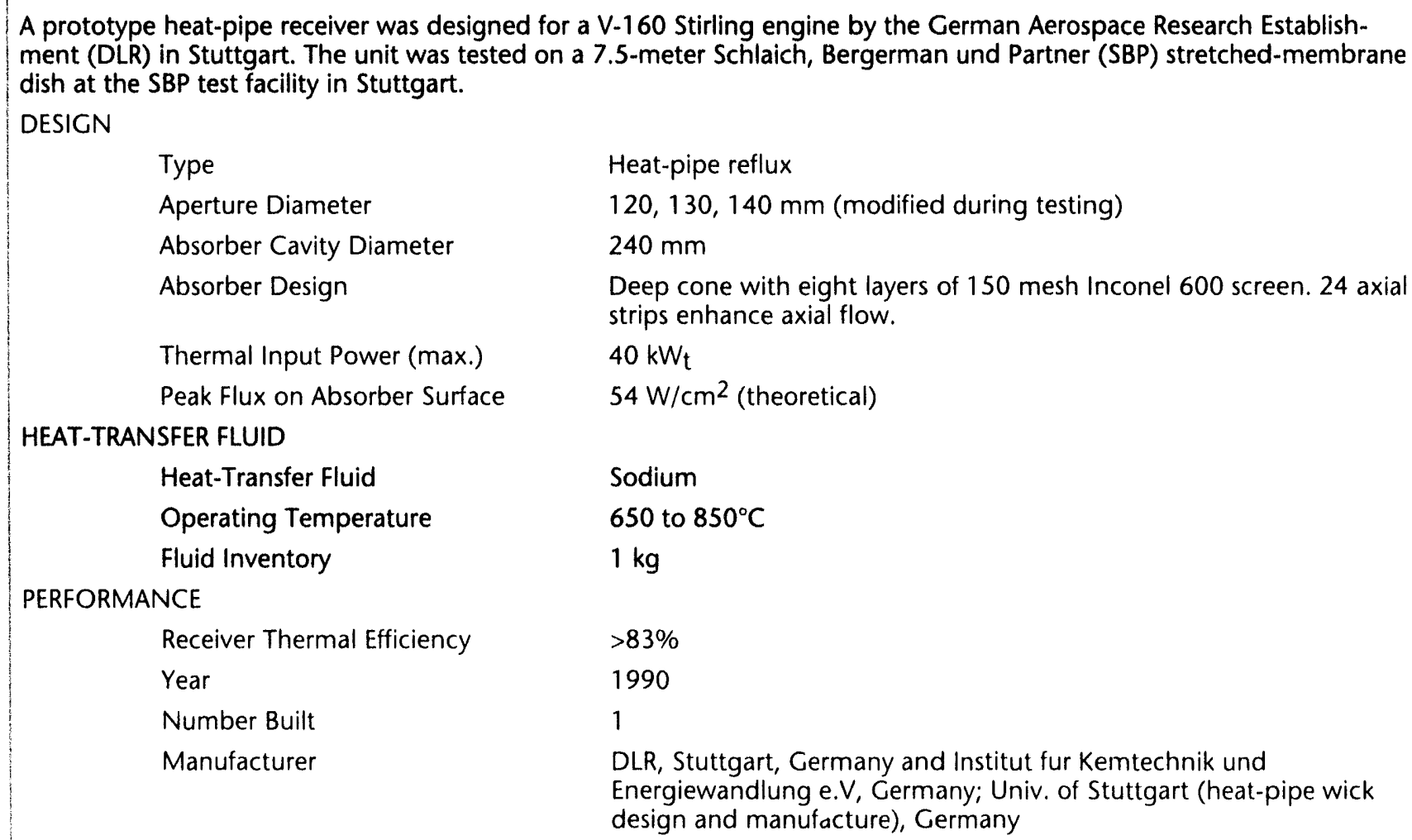

Type

Aperture Diameter

Absorber Cavity Diameter

Absorber Design

Thermal Input Power (max.)

Peak Flux on Absorber Surface

HEAT-TRANSFER FLUID

Heat-Transfer Fluid

Operating Temperature

Fluid Inventory

PERFORMANCE

Receiver Thermal Efficiency

Year

Number Built

Manufacturer

Heat-pipe reflux

$120,130,140 \mathrm{~mm}$ (modified during testing)

$240 \mathrm{~mm}$

Deep cone with eight layers of 150 mesh Inconel 600 screen. 24 axial strips enhance axial flow.

$40 \mathrm{~kW}$

$54 \mathrm{~W} / \mathrm{cm}^{2}$ (theoretical)

Sodium

650 to $850^{\circ} \mathrm{C}$

$1 \mathrm{~kg}$

$>83 \%$

1990

1

DLR, Stuttgart, Germany and Institut fur Kemtechnik und Energiewandlung e.V, Germany; Univ. of Stuttgart (heat-pipe wick design and manufacture), Germany

Source: Laing and Goebel (1991) 


\section{Chapter 6}

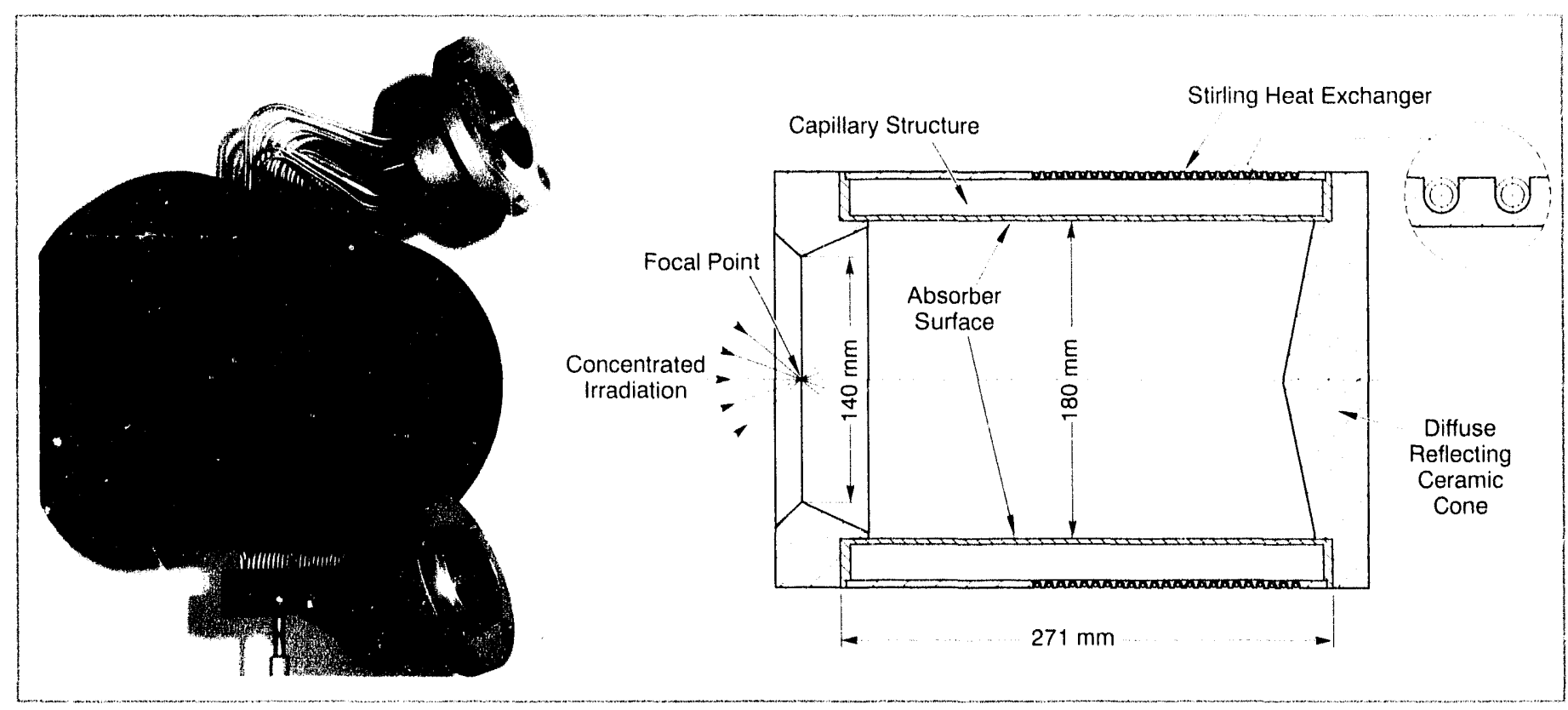

Figure 6-12. German Aerospace Research Establishment (DLR) V-160 heat-pipe receiver (Mod 2).

Table 6-12. German Aerospace Research Establishment (DLR) V-160 Heat-Pipe Receiver (Mod 2)

A second prototype heat-pipe receiver was designed for the V-160 engine by the German Aerospace Research Establishment (DLR). Called the Mod 2, it was designed with production simplification in mind in addition to a more elastic connection between the receiver and the engine, and the added safety of double-wall containment between the high-pressure helium and liquid sodium. The receiver has been tested on-sun with the Schlaich, Bergermann und Partner 7.5-meter stretched-membrane dish at the Plataforma Solar international test facility in Almería, Spain.

DESICN

Type

Aperture Diameter

Engine Heater Tubing Configuration

Absorber Design

Thermal Input Power (max)

Peak Flux on Absorber Surface

Helium Operating Temperature

HEAT-TRANSFER FLUID

Heat-Transfer Fluid

Operating Temperature

Fluid Inventory

Temperature Difference

PERFORMANCE

Efficiency

Year

Number Built

Manufacturer
Heat-pipe reflux

$140 \mathrm{~mm}$

Annular heat pipe with engine heater tubes wrapped around grooves in outside shell and brazed.

2-mm-thick Iconel 625 alloy absorber with screen wick spot welded to heat pipe walls.

$32 \mathrm{kWt}$

$55 \mathrm{~W} / \mathrm{m}^{2}$

$700^{\circ} \mathrm{C}$

Sodium

$820^{\circ} \mathrm{C}$

$400 \mathrm{~g}$

$120^{\circ} \mathrm{C}$ (helium to heat-pipe)

$86 \%$ to $90 \%$ (estimated)

1990

1

DLR, Stuttgart, Germany and Institut fur Kemtechnik und Energiewandlung e.V, Germany; Univ. of Stuttgart (heat-pipe wick design and manufacture), Germany

Source: Goebel and Laing (1993) 


\section{Chapter 7: Engines}

\section{Kinematic Stirling Engines}

Most dish/Stirling systems to date have incorporated kinematic Stirling engines where both the power piston and the displacer (or in the case of the V-160 engine, the compression and the expansion pistons) are mechanically (kinematically) linked to a rotating power output shaft. In most kinematic engines, a rotating crankshaft is driven by the reciprocating motion of the pistons. The crankshaft provides timing of the piston motion, maintains the phase angles required to sustain engine operation, limits piston stroke, and pı Jvides a mechanism for extracting power from the engine. The notable exception to this general configuration uses a swashplate instead of a crankshaft.

The pistons are connected to the crankshaft by an upper connecting rod, a crosshead, and a lower connecting rod. The crosshead is a mechanism that slides back and forth between parallel constraints. This eliminates the sideways motion on the piston. The upper connecting rod is attached to the crosshead and has only a linear motion. The critical sealing between the high-pressure and low-pressure regions of the engine can now be created using a simple sliding seal on the upper connecting rod. This design also keeps most of the lubricated surfaces in the low-pressure region of the engine, reducing the possibility of fouling the heat exchange surfaces in the high-pressure region of the engine.

Most of the engines used in dish/Stirling applications to date are kinematic. These include the United Stirling $A B$ (USAB) 4-95 engine (Table 7-1, Figure 7-1) and the USAB 4-275 engine (Figure 7-2, Table 7-2), the Stirling Power Systems (SPS)/Solo V-160 engine (Figure 7-3, Table 7-3), the Aisin Seiki NS30A engine (Table 7-4, Figure 7-4), and the Stirling Thermal Motors STM4-120 engine (Table 7-5, Figure 7-5).

\section{Free-Piston Stirling Engine/Converters}

A number of companies are currently developing freepiston engines. The free-piston Stirling engine has only two moving parts, the displacer and the power piston, which bounce back and forth between springs. A linear alternator is attached to the power piston to extract work from the cycle. In free-piston engines, the timing of the pistons, phase angle between pistons, and stroke are defined by the dynamics of the system. The pistons are system masses; a spring force is provided by hydrodynamic gas springs or mechanical springs. The engines operate at the natural frequency of the mass-spring system.

A linear alternator is incorporated into the power piston to extract power from the engine. Because electricity is generated internally, there are no sliding seals to the high-pressure region of the engine, and no oil lubrication is required. These designs promise long lifetimes with minimal maintenance. The 9-kW engine and its $6-\mathrm{kW}$ prototype used by Cummins Power Generation are of this type; illustration and specifications for this unit are provided in Table 7-6 and Figure 7-6.

\footnotetext{
* Parameters presented in the tables in this chapter are defined and discussed in Chapter 3.
} 


\section{Chapter 7}

Table 7-1. United Stirling 4-95 MKII Stirling Engine

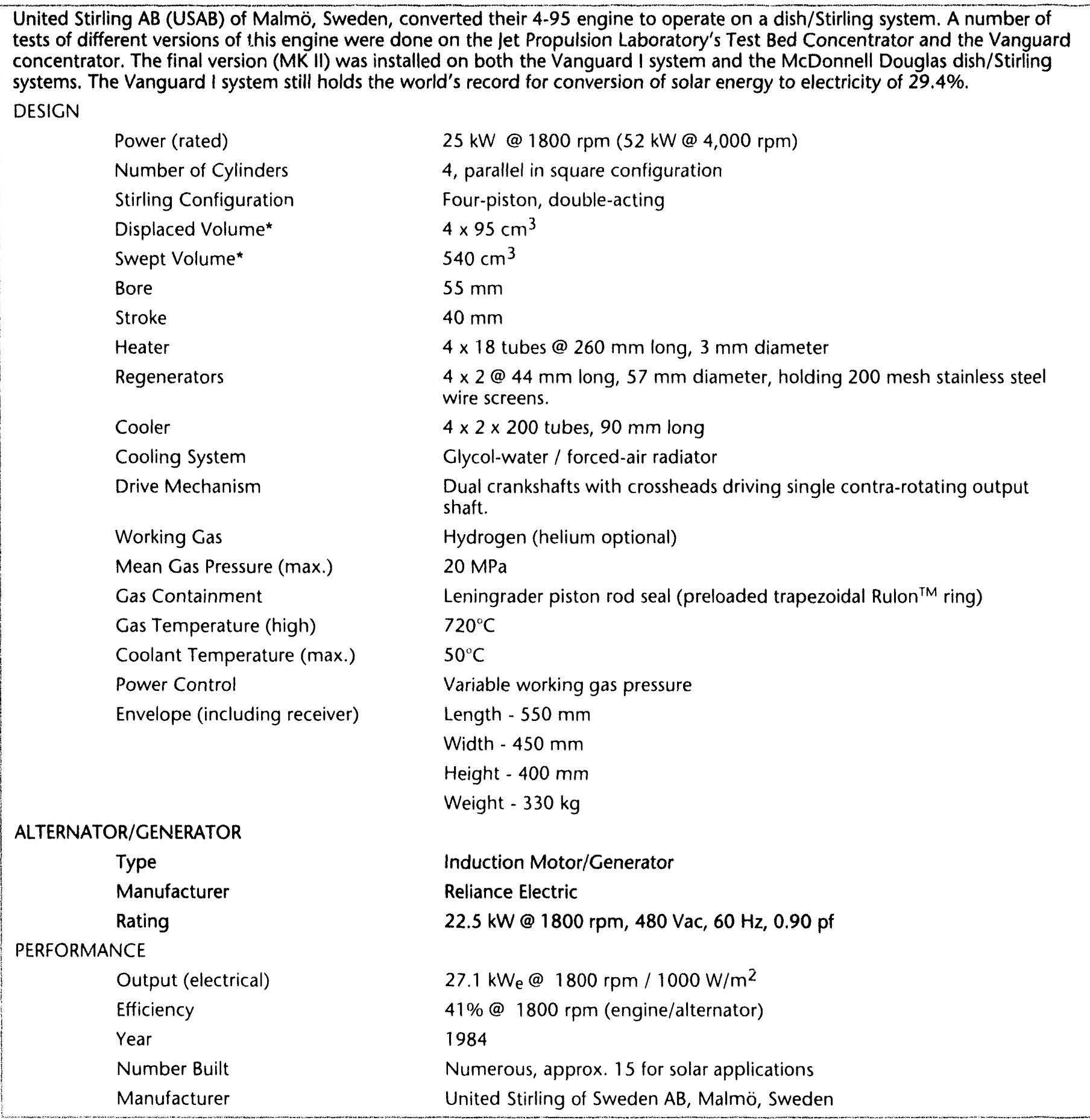

Source: Washom et al. (1984); Droher and Squier (1986)

* "Displaced volume" refers to the volume displaced by a single piston during its maximum stroke. "Swept volume" refers to the difference between the minimum gas volume and the maximum gas volume. In Figure $3-3$, swept volume is the difference between volumes 1,4 and 2,3. For single-piston engines, these volumes are the same. For dual-piston engines or double-acting engines, when the strokes are out of phase, the swept volume between the two pistons will be greater than the displaced volume of any one piston. 


\section{Engines}

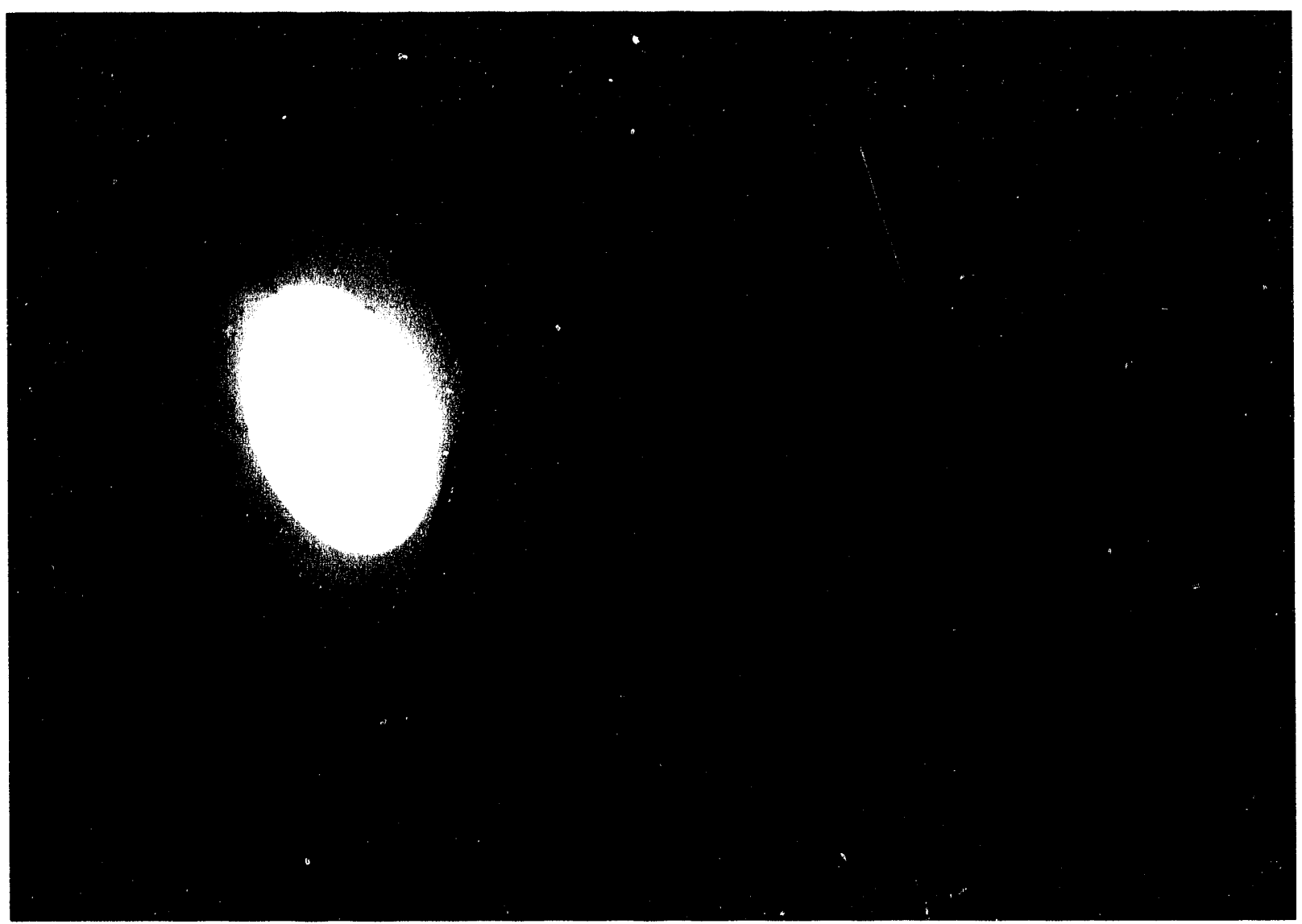

Heater Tubes

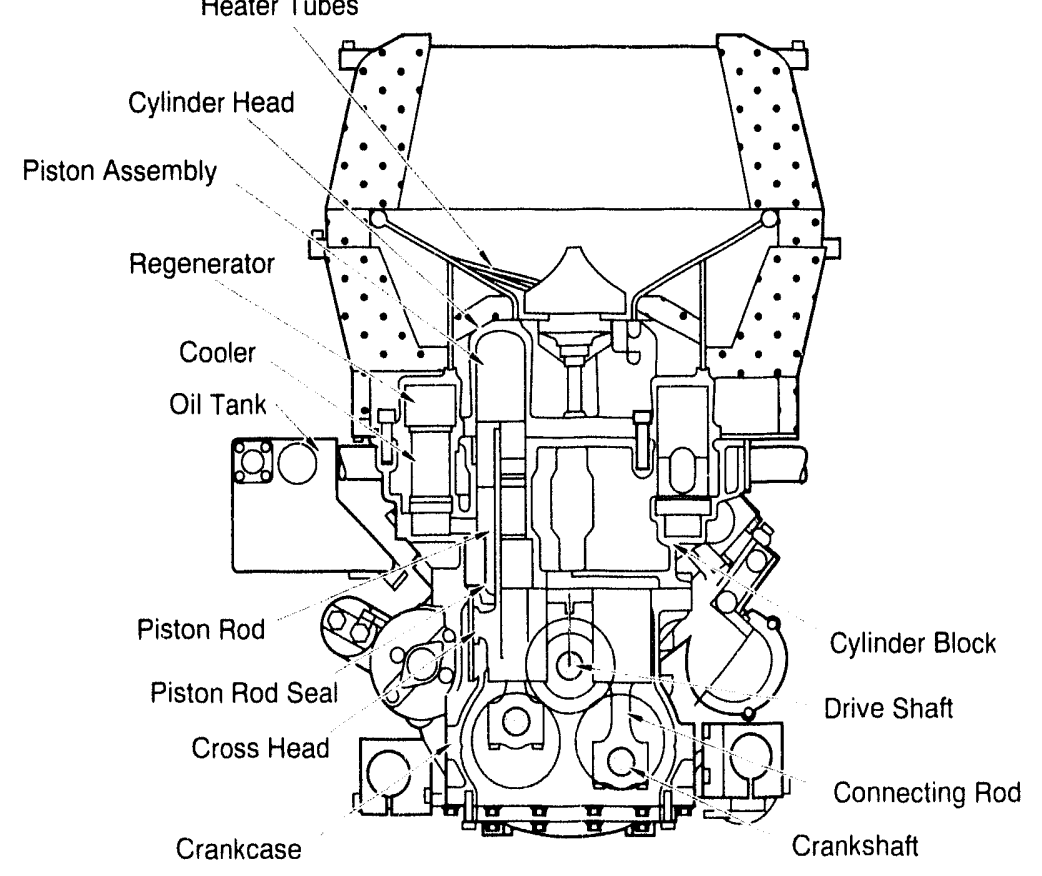

Figure 7-1. United Stirling 4-95 MKII Stirling engine. 


\section{Chapter 7}
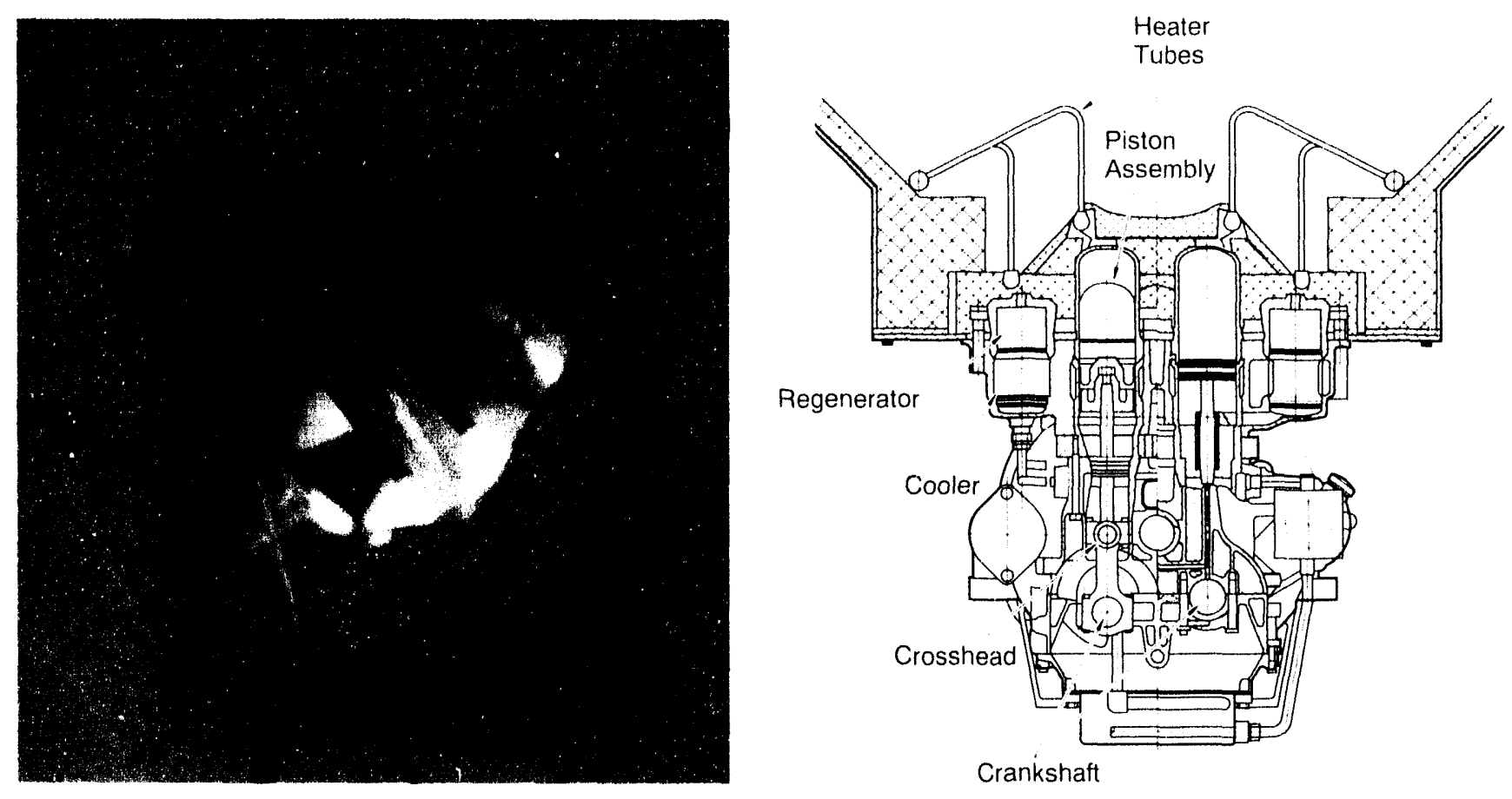

Figure 7-2. United Stirling 4-275 Stirling engine.

Table 7-2. United Stirling 4-275 Stirling Engine

\begin{tabular}{|c|c|c|}
\hline \multicolumn{3}{|c|}{$\begin{array}{l}\text { The United Stirling AB (USAB) } 4-275 \text { engine is the largest engine applied to dish/Stirling systems. } \\
\text { concentrator, two of these engines were tested as part of a joint German/Saudi Arabian dish/Stirlin } \\
\text { DESICN }\end{array}$} \\
\hline \multicolumn{3}{|l|}{ DESIGN } \\
\hline & Power (rated) & 50 kW@ 1500 rpm (118 kW@ 2600 rpm) \\
\hline & Number of Cylinders & 4, parallel in square configuration \\
\hline & Stirling Configuration & Four-piston, double-acting \\
\hline & Displaced Volume & $4 \times 275 \mathrm{~cm}^{3}$ \\
\hline & Swept Volume & $1560 \mathrm{~cm}^{3}$ \\
\hline & Cooling System & Water/forced air radiator \\
\hline & Drive Mechanism & Dual crankshafts with crossheads \\
\hline & Working Gas & Hydrogen \\
\hline & Mean Gas Pressure (max.) & $15 \mathrm{MPa}$ \\
\hline & Gas Temperature (high) & $620 \mathrm{C}$ \\
\hline & Gas Containment & Leningrader piston rod seal \\
\hline & Coolant Temperature (max.) & $65 \mathrm{C}$ \\
\hline & Power Control & Variable working gas pressure \\
\hline \multicolumn{3}{|c|}{ PERFORMANCE } \\
\hline & Output (electrical) & $52.5 \mathrm{kWe} @ 1500 \mathrm{rpm} / 1000 \mathrm{~W} / \mathrm{m}^{2}$ \\
\hline & Efficiency & $42 \% @ 1500 \mathrm{rpm}$ \\
\hline & Year & 1984 \\
\hline & Number Built & Nine, two for solar applications \\
\hline & Manufacturer & United Stirling of Sweden AB, Malmö, Sweden \\
\hline
\end{tabular}

Source: SBP (1991); Schiel (1992) 


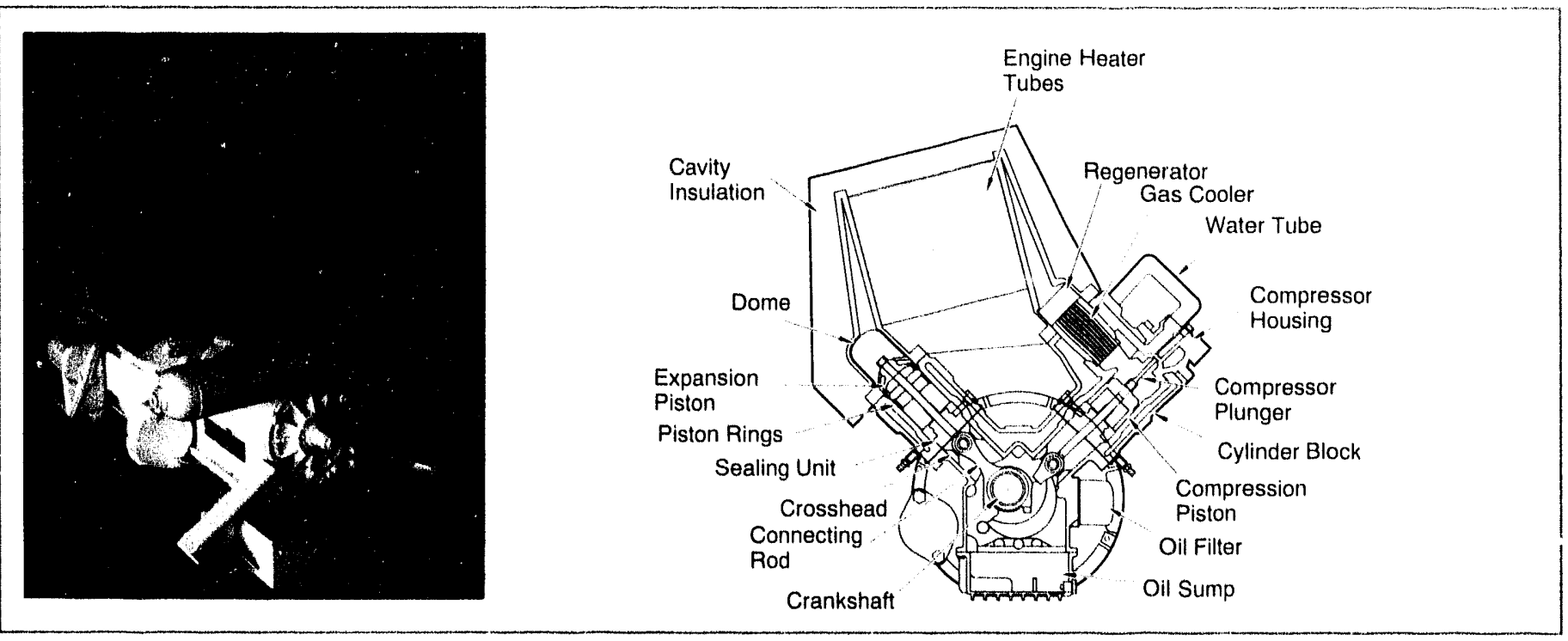

Figure 7-3. Stirling Power Systems/Solo V-160 Stirling engine.

Table 7.3. Stirling Power Systems/Solo V-160 Stirling Engine

Designed by United Stirling (Sweden) and originally manufactured by Stirling Power Systems (now defunct), the V-160 engine is currently part of the Schlaich, Bergermann und Partner 7.5-meter dish system currently under test at the Plataforma Solar in Almería, Spain, and in Germany. Engines for this system will be manufactured by Solo Kleinmotoren of Sindelfingen, Germany.

DESIGN

Power (rated)

Number of Cylinders

Stirling Configuration

Displaced Volume (power piston)

Swept Volume

Bore

Stroke

Cooling System

Drive Mechanism

Working Gas

Mean Gas Pressure (max.)

Gas Temperature (high)

Power Control

Envelope (including receiver)

Weight (bare)

\section{PERFORMANCE}

Output (electrical)

Efficiency

Year

Number Built

Manufacturer
9 kW@ 1500 rpm (15 kW max. @ 3600 rpm)

1 compression (cold) and 1 expansion (hot)

Double-cylinder, $90^{\circ} \mathrm{V}$

$160 \mathrm{~cm}^{3}$

$226 \mathrm{~cm}^{3}$

$68 \mathrm{~mm}$

$44 \mathrm{~mm}$

Water/forced-air radiator

Single crankshaft with crossheads

Helium

$15 \mathrm{MPa}$

$630^{\circ} \mathrm{C}$

Variable working gas pressure

Length - $585 \mathrm{~mm}$; Width - $610 \mathrm{~mm}$; Height - $585 \mathrm{~mm}$

$137 \mathrm{~kg}$

$9 \mathrm{kWe} @ 1500 \mathrm{rpm} / 1000 \mathrm{~W} / \mathrm{m}^{2}$

$30 \%$ @ $1500 \mathrm{rpm}$

1991

Approx. 150, ten for solar applications.

Stirling Power Systems, Ann Arbor, Michigan (now defunct).

Solo Kleinmotoren, Sindelfingen, Germany.

Source: Monahan and Clinch (1988) 


\section{Chapter 7}

\section{Table 7-4. Aisin Seiki NS30A Stirling Engine}

\begin{tabular}{|c|c|}
\hline \multicolumn{2}{|c|}{$\begin{array}{l}\text { Aisin Seiki Co., Ltd., of Kariya City, Japan, built the NS30A 30-kW engine (under the Japanese government's New Energy and } \\
\text { Industrial Development Organization [NEIDO] project). Aisin has modified one of these engines for solar operation and has been } \\
\text { testing it on a McDonnell Douglas Corporation (MDAC) dish at their test facility in Kariya City. Aisin has derated this engine } \\
\text { from its nameplate rating, and is currently installing three of these engines on CPG-460 concentrators at a dish/Stirling electric } \\
\text { power project on Miyako Island, south of Okinawa. }\end{array}$} \\
\hline \multicolumn{2}{|l|}{ DESIGN } \\
\hline Power (rated) & 30 kW @ 500 rpm (52 kW @ 4000 rpm) \\
\hline Power (Miyako System) & 8.5 kW@1500 rpm \\
\hline Number of Cylinders & 4 , paral'el in square configuration \\
\hline Stirling Configuration & Four-piston, double-acting \\
\hline Displaced Volume & $4 \times 147 \mathrm{~cm}^{3}$ \\
\hline Swept Volume & $831 \mathrm{~cm}^{3}$ \\
\hline Bore & $60 \mathrm{~mm}$ \\
\hline Stroke & $52.4 \mathrm{~mm}$ \\
\hline Heater & 18 closed-fin hairpin tubes per cylinder, $6.5 \mathrm{~mm}$ o.d. $/ 3.5 \mathrm{~mm}$ i.d. Hastelloy $X$ \\
\hline Regenerators & Pressed wire mesh \\
\hline Cooler & 37 inner/outer finned aluminum tubes per cylinder, $6.5 \mathrm{~mm}$ o.d. $/ 5.1 \mathrm{~mm}$ i.d. \\
\hline Cooling System & Water \\
\hline Drive Mechanism & Swashplate (fixed angle) driven rotary shaft \\
\hline Working Gas & Helium \\
\hline Mean Gas Pressure (max.) & $14.5 \mathrm{MPa}$ \\
\hline Gas Temperature (high) & $683^{\circ} \mathrm{C}$ \\
\hline Gas Containment & Oil-filled 3-step piston rod seals \\
\hline Heater-Tube Temperature ( $\max$. ) & $780^{\circ} \mathrm{C}$ \\
\hline Coolant Temperature (max.) & $50^{\circ} \mathrm{C}$ \\
\hline Power Control & Variable working gas pressure \\
\hline Weight & $243 \mathrm{~kg}$ \\
\hline \multicolumn{2}{|l|}{ PERFORMANCE } \\
\hline Output (electrical) & $20 \mathrm{kWe} @ 1500 \mathrm{rpm}$ (derated to $8.5 \mathrm{~kW}$ for solar application) \\
\hline Efficiency & 25\%@1500 rpm \\
\hline Year & 1989 \\
\hline Number Built & 1 (Kariya), 3 (Miyako Island) \\
\hline Manufacturer & Aisin Seiki, Kariya City, Aichi Prefecture, Japan \\
\hline
\end{tabular}

Source: Momose (1992) 

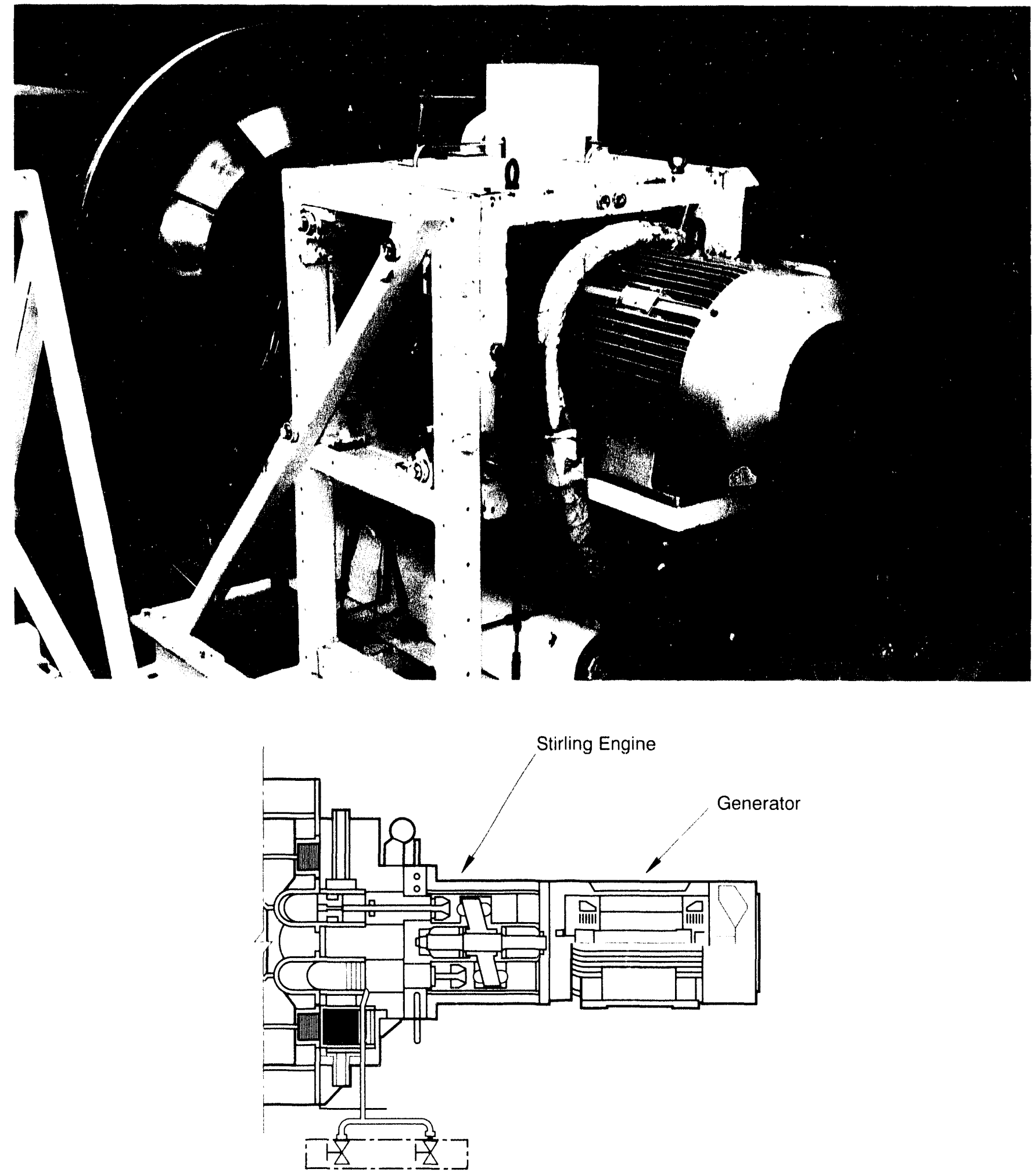

Figure 7-4. Aisin Seiki NS30A Stirling engine. 


\section{Chapter 7}

Table 7-5. Stirling Thermal Motors STM4-120 Stirling Engine

Stirling Thermal Motors (STM) of Ann Arbor, Michigan, and Detroit Diesel Corporation of Detroit, Michigan, have signed a cooperative agreement to develop, manufacture, and market the STM4-120 Stirling engine. Initially this engine will power a 20kW generator set and other nonsolar products. In the design of this engine, STM feels that they have a solution to three major problems of past engine designs: sophisticated and complicated power control systems, seal design for the reciprocating piston rods, and a large heater head that is expensive to manufacture. STM feels that, in their 4-120 engine, these problems have been solved by (1) using a variable angle swashplate drive to regulate output power, (2) pressurizing the crankcase to reduce pressure drop across the rod seals, and (3) designing a stacked heat exchanger heater head.

DESIGN

Power (rated)

Number of Cylinders

Stirling Configuration

Displaced Volume

Swept Volume

Bore

Stroke

Heater (solar)

Regenerators

Cooling System

Drive Mechanism

Working Güs

Mean Gas Pressure (max.)

Gas Containment

Gas Temperature (high)

Coolant Temperature (max.)

Power Control

Envelope (including receiver)

\section{PERFORMANCE}

Output (electrical)

Efficiency

Year

Number Built

Manufacturer
25 kW @ 1800 rpm (52 kW@ 4500 rpm)

4 , parallel in square configuration

Four-piston, double-acting

$4 \times 120 \mathrm{~cm}^{3}$

$680 \mathrm{~cm}^{3}$

$56 \mathrm{~mm}$

$48.5 \mathrm{~mm}$ (maximum)

Sodium heat-pipe or directly illuminated heater tubes.

Wire mesh

Water/glycol

Swashplate-driven rotary shaft. Angle of swashplate can be varied from $0^{\circ}$ to $22^{\circ}$ to change piston stroke.

Helium (hydrogen is alternate)

$12 \mathrm{MPa}$

Crankcase pressurized to mean cycle pressure and power shaft sealed with a rotating seal.

$720^{\circ} \mathrm{C}$

$45 \cdot 70^{\circ} \mathrm{C}$

Piston stroke variation by means of variable swashplate with nıax. angle of $22^{\prime \prime}$.

Length - $810 \mathrm{~mm}$

Largest diameter - $400 \mathrm{~mm}$ (receiver), $300 \mathrm{~mm}$ (crankcase)

Weight - $110 \mathrm{~kg}$ (natural gas-fired configuration)

$26.3 \mathrm{kWe} @ 1840 \mathrm{rpm}$ (measured 9/92)

40 - 45\%@1800 rpm (projected)

1988

5

Stirling Thermal Motors, Ann Arbor, Michigan, USA

Source: STM (1990) 
Engines

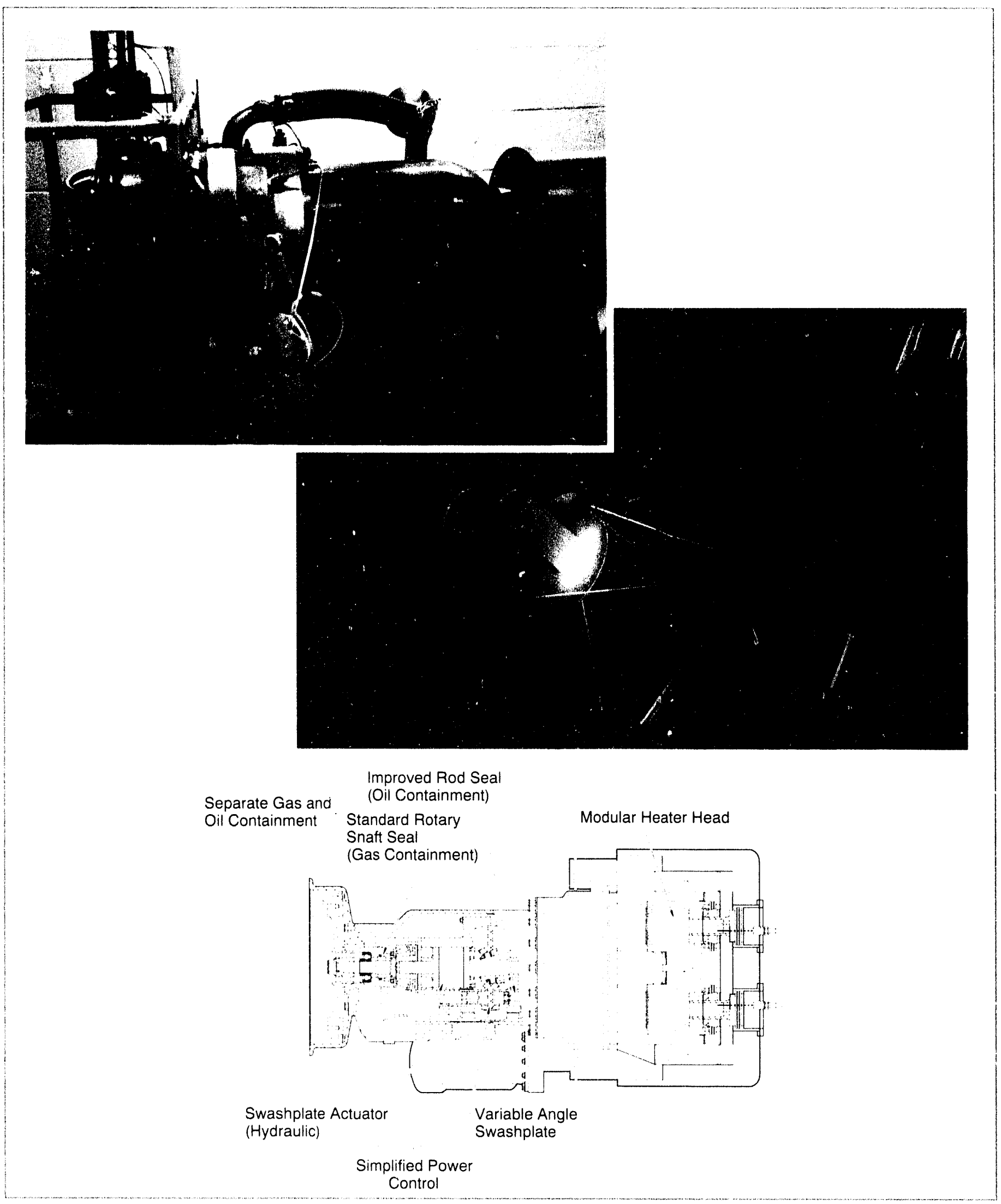

Figure 7-5. Stirling Thermal Motors STM4-120 Stirling engine. (Top photo, dynamometer test; lower photo, on-sun test.) 


\section{Chapter 7}

Table 7-6. Cummins Power Generation 9-kW Free-Piston Stirling Engine/Converter

Cummins Power Generation, Inc., along with Sunpower, Inc., of Athens, Ohio, are developing a 9-kW free-piston Stirling engine/ converter for their $7.5-\mathrm{kW}_{\mathrm{e}}$ (net) dish/Stirling system. Seventeen of these units will be placed on test around the United States over the next three years. Currently, a prototype $6-\mathrm{kW}_{\mathrm{e}}$ engine is under test at three sites.

DESIGN

Power (rated)
Number of Cylinders
Stirling Configuration
Stroke (max)
Power Piston Bearing/Seal
Heater
Regenerators
Cooler
Cooling
Drive Mechanism
Working Gas
Mean Gas Pressure
Gas Containment
Gas Temperacure (high)
Heater Tube Temperature (max.)
Envelope

$9 \mathrm{~kW}_{\mathrm{e}} @ 60 \mathrm{~Hz}$ (prototype is $6.0 \mathrm{~kW}_{\mathrm{e}}$ )

1

Free power piston and displacer

$14.1 \mathrm{~mm}$

Static gas bearings/clearance seal

Tubular heat exchanger

Foil type

Finned

Water/glycol

Linear alternator connected directly to power piston

Helium

$4 \mathrm{MPa}$

Pressurized casing with no moving mechanical penetrations.

$629^{\circ} \mathrm{C}$

$675^{\circ} \mathrm{C}^{*}$

Length $-857 \mathrm{~mm}$

Width - $505 \mathrm{~mm}$ (diameter)

Weight $-420 \mathrm{~kg}$

Internal linear alternator

$7.1 \mathrm{kWe}$ (@670 ${ }^{\circ} \mathrm{C}, 14.1 \mathrm{~mm}$ ) (6-kW prototype)

$33 \%$ (design), 28\% (demonstrated)

1992

$46-\mathrm{kW}_{\mathrm{e}}$ prototypes

Cummins Power Generation Inc., Columbus, Indiana, USA

Source: Bean and Diver (1992)

* Heat pipe internal temperature (Na vapor) 


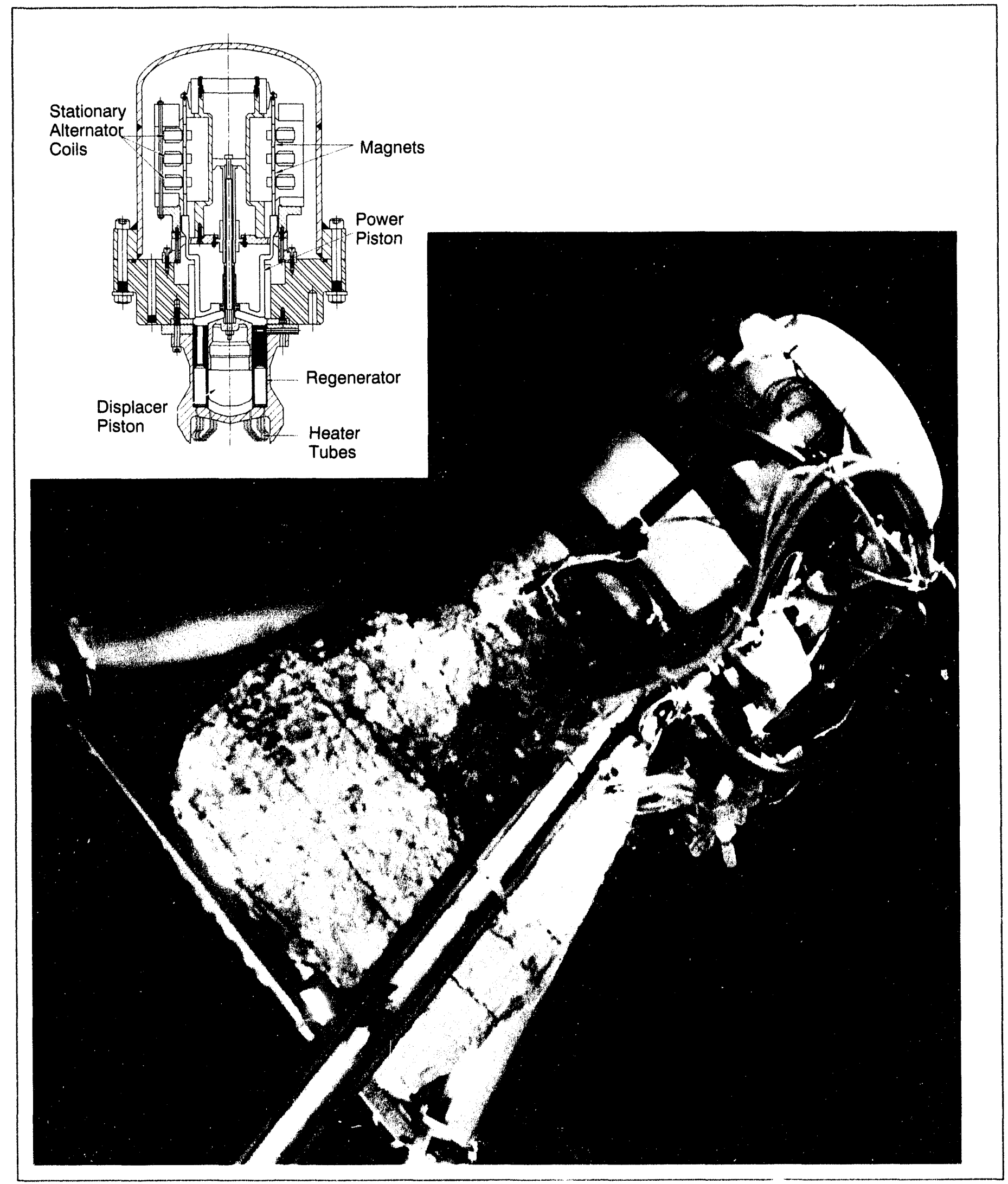

Figure 7-6. Cummins Power Generation (CPG) 6-kW prototype free-piston Stirling engine/converter (similar in design to the $9-k W$ production version). 
Chapter 7

Notes 


\section{References}

Adkins, D.R. 1987. Control Strategies and Hardware Used in Solar Thermal Applications. SAND86-1943. Albuquerque, NM: Sandia National Laboratories. November 1987.

Alpert, D.J., T.R. Mancini, R.M. Houser, J.W. Grossman, P. Schissel, M. Carasso, G. Jorgensen, and M. Scheve. 1991. Solar Concentrator Development in the United States. SAND90-0903. Albuquerque, NM: Sandia National Laboratories. March 1921.

Andraka, C.E., J.B. Moreno, R.B. Diver, and T.A. Moss. 1992. Sodium Reflux Pool-Boiler Solar Receiver On-Sun Test Results. SAND89-2773. Albuquerque, NM: Sandia National Laboratories. June 1992.

Andraka, C.E., R. Diver, D. Adkins, S. Rawlinson, P. Corderio, V. Dudkey, T. Moss. 1993. "Testing of Stirling Engine Solar Reflux Heat-Pipe Receivers," Proceedings of 28th IECEC, Atlanta, (ieorgia, Paper 93295, August 1993. Vol. 2, 525.

Bean, J.R., and R.B. Diver. 1992. "The 5-kW Dish-Stirling Development Program," Proceedings of 27 th IECEC, San Diego, California, Paper 929181, August 1992. Vol. 5, 221.

Bean, J.R., and R.B. Diver. 1993. "Performance of the CPG 7.5-kW, Dish-Stirling System," Proceedings of 28th IECEC, Atlanta, Georgia, Paper 93054, August 1993. Vol. 2, 627.

Bennethum, J.E., T.D. Laymac, L.N. Johansson, and T.M. Godett. 1991. "The Detroit Diesel Corporation/Stirling Thermal Motors Inc. Program to Develop Stirling Based Commercial Products," Proceedings of the 26th IECEC. Boston, MA, August 1991. Vol. 5, 198-204.

Braun, H.W. 1992. "Solar Stirling Gensets for LargeScale Hydrogen Production," Proceedings of the ASME 1992 Winter Anmual Meeting, Anaheim, CA., December 1992.

Cairelli, J.E., D.M. Swec, W.A. Wong, T.J. Doeberling, and F.J. Madi. 1991. "Update on Results of SPRE Testing at NASA Lewis," Proceedings of the 26th IECEC. Boston, MA, August 1991. Vol. 5, 217-222.
Cairelli, J.E., S.M. Geng, W.A. Wong, D.M. Swec, T.J. Doeberling, F.J. Mandi, and D.C. Vora. 1993. "1993 Update on Results of SPRE Testing at NASA Lewis," Proceedings of 28th IECEC, Atlanta, Georgia, Paper 93362, August 1993. Vol. 2, 633.

Dickinson, W.C., and P.N. Cheremisinoff, eds. 1980. Solar Energy Technology Handbook. New York: Marcel Dekker Co.

Diver, R.B., ed. 1986. Proceedings of the Solar Thermal Technology Conference, Albuquerque, New Mexico, Jume 17-19, 1986. SAND86-0536. Albuquerque, NM: Sandia National Laboratories. June 1986.

Diver, R.B., C.E. Andraka, J.B. Moreno, D.R. Adkins, and T.A. Moss. 1990. "Trends in Dish-Stirling Solar Receiver Designs," Proceedings of 25th IECEC, Reno, NV, August 1990. Vol. 5, 310.

DLR, Interatom, SBP, and ZSW. 1992. System Comparison and Potential of Solar Thermal Installations in the Mediterramean Area - Phase I. Eds. H. Klaiss and F. Staiss. Stuttgart, Germany: The German Aerospace Research Establishment (DLR). January 1992.

Droher, J.J., and S.E. Squier. 1986. Performance of the Vanguard Solur Dish-Stirling Engine Module. EPRI AP4608. Palo Alto, CA: Electrical Power Research Institute. July 1986.

Dussinger, P.M. 1991. "Design, Pabrication and Test of a Heat Pipe Receiver for the Cummins Power Generation $5 \mathrm{~kW}$ Dish Stirling System," Procecdings of 26th IECEC, Boston, MA, August 1991. Vol. 5, 171.

Godett, T.M. (of Stirling Thermal Motors). 1993a. Personal communication dated September 1993.

Godett, T.M. (of Stirling Thermal Motors). 1993b. Personal communication dated December 1993.

Goebel, O., and D. Laing. 1993. "Second Generation Sodium Heat Pipe Receiver for a USAB V-160 Stirling Engine: Development and On-Sun Test Results," Proceedings of 28th IECEC, Atlanta, Georgia, Paper 93176, August 1992. Vol. 2, 539. 
Gonnov, I.V., M.N. Ivanovsky, Y.V. Loktionov, N.I. Loginov, S.P. Stoljarov, and B.A. Tchulkov. 1991. "Design and Testing of Heat Exchangers with Liquid Metal Heat Pipes for Stirling Engines," Proceedings of the 26th IECEC, Boston, MA, August 1991. Vol. 5, 229-232.

Grossman, J.W., R.M. Houser, and W.W. Erdman. 1992. Testing of the Single-Element Stretched-Membrane Dish. SAND91-2203. Albuquerque, NM: Sandia National Laboratories. February 1992.

Holtz, R.E., and K.L. Uherka. 1988. A Study of the Reliability of Stirling Engines for Distributed Receiver Systems. SAND88-7028. Albuquerque, NM: Sandia National Laboratories. November 1988.

Jorgenson, G. 1993. "Reflective Coatings for Solar Applications," 36th Annual Technical Conference Proceedings of the Society of Vacuum Coaters, Dallas, TX, April 25-30, 1993. pp. 23-31.

JPL (Jet Propulsion Laboratory). 1980. Proceedings of the First Semi-Annual Distributed Receiver Systems Program Review. DOE/JPL-1060-33. Pasadena, CA: Jet Propulsion Laboratory. April 1980.

Keck, T.W., W. Scheil, and R. Benz. 1990. "An Innovative Dish/Stirling System," Proceedings of the 25th IECEC, Reno, NV, August 1990. Vol. 6, pp. 317-322.

Klaiss, H., F. Staiss, and C.J. Winter, 1991 "System Comparison and Potential of Solar Thermal Installations in the Mediterranean Area," Material for presentation at the Workshop on Prospects for Solar Thermal Power Plants in the Mediterranean Region, 25-26 September 1991, Sophia-Antipolis, France.

Kreider, J.F., and F. Kreith, eds. 1981. Solar Energy Handbook. McGraw-Hill Book Co.: New York.

Kreider, J.F. 1979. Medium and High Temperature Solar Processes. Academic Press, New York.

Kreith, F., and J.F. Kreider. 1978. Principles of Solar Engineering. McGraw-Hill, New York.

Kubo, R. (of Cummins Power Generation, Inc.). 1992. Personal communication dated March 1992.

Laing, D. and O. Goebel. 1991. "Sodium Heat Pipe Solar Receiver for an SPS V-160 Stirling Engine: Development, Laboratory and On-Sun Test Results," Proceedings of 26th IECEC, Boston, MA, August 1991. Vol. 5, 363.
Linker, K.L., K.S. Rawlinson, and G. Smith. 1991. Characteristics, Finite Element Analysis, Test Description and Preliminary Test Results of the STM4-120 Kinematic Stirling Engine. SAND90-1162. Albuquerque, NM: Sandia National Laboratories. October 1991.

Livingston, F.R. 1985. Activity and Accomplishments in Dish/Stirling Electric Power System Development. DOE/ JPL-1060-82. Pasadena, CA: Jet Propulsion Laboratories. February 1985.

Loktionov, Y.V. 1991. "Conceptual Design of FreePiston Stirling Conversion System for Solar Power Units," Proceedings of the 26th IECEC. Boston, MA, August 1991. Vol. 5, 370-375.

Loktionov, Y.V., I.V. Baum, I.V. Gonnov, and A.I. Trofimov. 1993. "Designs of Terrestrial Solar Electric Generating Sets," Proceedings of 28th IECEC, Atlanta, Georgia, Paper 93023, August 1993. Vol. 2, 547.

Lopez, C.W. and Stone, K.W. 1992. "Design and Performance of the Southern California Edison Stirling Dish," Proceedings of the 1992 ASME International Solar Energy Conference, Maui, HI, April 1992. Vol. 2, 945952. Eds. W.B. Stine et al. American Society of Mechanical Engineers, New York.

Mancini, T.R. 1991. "Analysis and Design of Two Stretched-Membrane Parabolic Dish Concentrators," Transactions of ASME, Journal of Solar Energy Engineering. Vol. 113, 180. August 1991.

Mancini, T.R. (of Sandia National Laboratories, Albuquerque). 1993. Private communication.

Mechanical Technology Incorporated, Sanders Associates, Inc., Thermacore, Inc., and Pioneer Engineering and Manufacturing Co. 1988. Conceptual Design of an Advanced Stirling Conversion System for Terrestrial Power Generation. NASA report CR-180890. Cleveland, OH: NASA Lewis Research Center. January 1988.

Meijer, R.F. 1992. "Stirling Engine." McGraw-Hill Encyclopedia of Science and Technology. 7th ed. pp. 440-445.

Mitzel, M. and J. Kleinwachter. 1992. "Stirling Engine Development," Proceedings of the 1992 International Energy Agency SolarPACES Workshop, Working Group for Task 1, Plataforma Solar de Almería, Tabernas/ Almería, Spain, September 24, 1992, 139-142. 
Momose, Y. (of Aisin Seiki Ltd.). 1992. Personal communication dated September 1992.

Monahan, R.E. and J.M. Clinch. 1988. "The Continuing Development of a Natural Gas-Fired Stirling EngineDriven Heat Pump," Proceedings of the 23rd IECEC, Denver, CO, Paper 889038, August 1988. Vol. 1, 21.

Moreno, J.B. C.E. Andraka, T.A. Moss, P.G. Cordeiro, V.E. Dudley, and K.S. Rawlinson 1993a. On-Sun Test Results from Second-Generation and Advanced-Concepts Alkali-Metal Pool-Boiler Receivers. SAND93-1251. Albuquerque, NM: Sandia National Laboratories.

Moreno, J.B., C.E. Andraka, T.A. Moss, P.G. Cordeiro, V.E. Dudley and K.S. Rawlinson 1993b. "First On-Sun Test of a NaK-78 Pool-Boiler Solar Receiver," Proceedings of 28th IECEC, Atlanta, Georgia, Paper 93270, August 1993. Vol. 2.511.

Noyes, G. 1990. "The Effect of Component Efficiency and Operating Conditions on the $50 \mathrm{~kW}$ Dish Stirling System in Riyadh, Saudi Arabia," Transactions of the ASME, Journal of Solar Energy Engineering. Volume 112, No. 4, 244-246.

Panda, P.L., T. Fujita, and J.W. Lucas. 1985. Summary Assessment of Solar Thermal Parabolic Dish Technology for Electrical Power Generation. DOE/JPL-1060-89. Pasadena, CA: Jet Propulsion Laboratories. September 1985.

Powell, M.A., and K S. Rawlinson. 1993. "Performance Mapping of the STM4-120 Kinematic Stirling Engine Using a Statistical Design of Experiments Method," Proceedings of 28th IECEC, Atlanta, Georgia, Paper 93282, August 1993. Vol. 2, 639.

SAIC (Science Applications International Corporation). 1991. Facet Development for a Faceted Stretched-Membrane Dish by SAIC. SAND91-7008. Albuquerque, NM: Sandia National Laboratories. October 1991.

SBP (Schlaich Bergermann und Partner). 1991. Solar Power Plant with a Membrane Concave Mirror, $50 \mathrm{~kW}$, Company brochure dated March 1991.

Schiel, W. (of Schlaich Bergermann und Partner). 1992. Personal communication dated March 1992.
Schertz, J., D.C. Brown, and A. Konnerth III. 1991. Facet Development for a Faceted Stretched-Membrane Dish by Solar Kinetics, Inc. SAND91-7009. Albuquerque, NM: Sandia National Laboratories. July 1991.

Sekiya, H., K. Tsuchiya, K. Eguchi, and H. Watanabe. 1992. "Performance Analysis of Solar Stirling Power System for Terrestrial Use," Proceedings of the 1992 ASME International Solar Energy Conference, Mani, Hawaii, April 1992, 1185-1194. Eds. W.B. Stine et al., American Society of Mechanical Engineers, New York.

Shaltens, R.K., and J.G. Schreiber. 1990. "Preliminary Designs for $25 \mathrm{~kW}$ Advanced Stirling Conversion Systems for Dish Electric Applications, "Proceedings of 25th IECEC, Reno, NV, August 1990. Vol. 6, 310-316.

Shaltens, R.K., and J.G. Schreiber. i991. "Status of the Advanced Stirling Conversion System Project for 25 kW Dish Stirling Applications," Proceedings of 25th IECEC, Reno, NV, August 1990. Vol. 5, 388-394.

SKI (Solar Kinetics, Inc.). 1991. Development of a StretchedMembrane Dish; Phase II, Task 2, Topical Report. SAND90-7036. Albuquerque, NM: Sandia National Laboratories. July 1991.

Stine, W.B. 1987. Power from the Sun, Principles of High Temperature Solar Thermal Technology. SERI/SP-2733054 (US DOE DE87001104). Golden, CO: National Renewable Energy Laboratory.

Stine, W. B. 1989. Progress in Parabolic DishTechnology. SERI/SP-220-3237(US DOE DE89009427). Golden, CO: National Renewable Energy Laboratory. June 1989.

Stine, W. B., and R. W. Harrigan. 1985. Solar Energy Fundamentals and Design: With Computer Applications. John Wiley \& Sons., New York.

Stine, W.B., and M.A. Powell, 1993. "Proposed Guidelines for Reporting Performance of a Solar Dish/ Stirling Electric Generation System," Proceedings of 28th IECEC, Atlanta, Georgia, Paper 93186, August 1993. Vol. 2, 503.

Stone, K.W., C.W. Lopez, and R.E. McAlister. 1993. "Economic Performance of the SCE Stirling Dish," Proceedings of 28th IECEC, Atlanta, Georgia, Paper 93177, August 1993. Vol. 2, 497. 
STM (Stirling Thermal Motors, Inc.). 1990. Breakthrough in Energy Conversion. Fourth Edition. Stirling Thermal Motors, Inc., Ann Arbor, MI, March 1990.

U.S. DOE (U.S. Department of Energy). 1991. National Energy Strategy, First Edition 1991/1992. Gov. Doc. No. E 1.2:St 8/sum. U.S. DOE, Office of Solar Energy Conversion, Washington, DC. February 1991.

U.S. DOE (U.S. Department of Inergy). 1992. SOLAR 2000: A Collaborative Strategy, Vols. 1 \& 2. U.S. DOE, Office of Solar Energy Conversion, Washington, DC. February 1992.

U.S. DOE (U.S. Department of Energy). 1993. Solar Thermal Electric Five-Year Program Plan, FY 1993 through 1997. U.S. DOE, Office of Solar Energy Conversion, Washington, DC. April 1993.

Walker, G. 1973. The Stirling Engine. Scientific American. 229(2):80-87.

Walker, G. 1980. Stirling Engines. Clarendon Press, Oxford, England.

Washom, B.J. 1984. "Parabolic Dish Stirling Module Development and Test Results," Proceedings of the 19th IECEC, San Fransisco: 1688-1694, Paper No. 849516, August 1984.

Washom, B.J., T. Hagen, D. Wells, and W. Wilcox. 1984. Vanguard I Solar Parabolic Dish-Stirling Engine Module, Final Report, May 28, 1982 - September 30, 1984. Advanco Report DOE-AL-16333-2. Advanco Corp., El Segundo, CA. September 1984.

Wendelin, T.J, G.J. Jorgensen, and R.L. Wood. 1991. "SHOT: A Method for Characterizing the Surface Figure and Optical Performance of Point Focus Solar Concentrators," Proceedings of the 1991 ASME International Solar Energy Conference, Reno, Nevada, April 1991.

West, C.D. 1986. Principles and Applications of Stirling Engines. Van Nostrand Reinhold Company, New York.

White, M. 1993. Private communication, Stirling Technology Company, Richland, WA. 


\section{Stirling Engine Bibliography}

Principles and Applications of Stirling Engines by C.D. West; van Nostrand Reinhold Co. New York 1986.

Stirling Engines by G. Walker; Claredon Press, Oxford 1980.

Free-Piston Stirling Engines by G. Walker and J.R. Senft; Springer-Verlag, 1985.

Stirling Engines by G.T. Reader and C. Hooper; E\&F Spoon, London 1983.

Stirling Cycle Engine Analysis by I. Urieli and D.W. Berchowitz; Adam Hilger Ltd., Briston 1984.

Proceedings of the Inter-Society Energy Conversion Engineering Conference (IECEC). Most important engineering advances in Stirling engine development are reported at this annual conference and documented in the proceedings. These date back to the 1960 s.

Stirling-Maschinen Grundlagen, Technik, Anwendung by M. Werdich; Ökobuch Verlag, Staufen bei Freiberg 1991.

Stirling Machine World, a news journal published quarterly by Brad Ross, 1823 Hummingbird Court, West Richland, WA 99354-9542 USA. 
Notes 


\section{Dish/Stirling Technology Organizations}

\section{USA}

Clever Fellows Innovation Consortium Attn: John Cory, ASME Standards 302 Tenth Street

Troy, N' $12: 80$

Cummins Power Generation, Inc.

Attn: Dr. Rockey Kubo

Mail Code 60125

Box 3005

Columbus, Indiana 47202-3005

Detroit Diesel Corporation

Attn: Pete Purdue

13400 Outer Drive West

Detroit, MI 48239-4001

Dynatherm Corporation

Attn: David Wolf

1 Bever Court

P.O. Box 398

Cockersville, MD 21030

Hydrogen Engineering Associates, Inc.

Attn: Dr. Harry W. Braun

540 North May St.

Suite 3078

Mesa, AZ 85201

McDonnell-Douglas Astronautics Co.

Attn: Ken Stone

5301 Bolsa Avenue

Huntington Beach, CA 92647

Mechanical Technologies Incorporated

Attn: George R. Dochat

Stirling Engine Systems

968 Albany-Shaker Road

Latham, NY 12110

NASA Lewis Research Center

Attn: Richard K. Shaltens

MS 301-2

21000 Brookpark Road

Cleveland, $\mathrm{OH} 44135$
National Renewable Energy Laboratory

Attn: Tom Williams

1617 Cole Blvd.

Golden, CO 80407

Sandia National Laboratories

Attn: Paul Klimas

P.O. Box 5800

Albuquerque, NM 87185-0703

Science Applications International Corp.

Attn: Barry Butler

10401 Roselle Street

San Diego, CA 92121

Solar Kinetics, Inc.

Attn: Gus Hutchinson, President

P.O. Box 540636

Dallas, TX 75354-0636

Southern California Edison

Attn: Mark Skowronski

P.O. Box 800

2244 Walnut Grove Ave.

Rosmead, CA 91770

Stirling Technology Company

Attn: Maurice A. White

2952 George Washington Way

Richland, WA 99352

Stirling Thermal Motors

Attn: Lennart $N$. Johansson

275 Metty Drive

Ann Arbor, MI 48103-9444

Sunpower Inc.

Attn: William M. Beale, President

6 Byard Street

Athens, $\mathrm{OH} 445701$

Thermacore, Inc.

Attn: Don M. Ernst,

Vice President, Development

780 Eden Road

Lancaster, PA 1760)1 
W.G. Associates

Attn: Vern Goldberg

6607 Stonebrook Circle

Dallas, TX 75240

\section{Germany}

Deutsche Forschungsanstalt für Luft und Raumfahrt -

Stuttgart

Attn: Reiner Köhne

Pfaffenwaldring 38-40

D-7000 Stuttgart 80

GERMANY

Deutsche Forschungsanstalt für Luft und Raumfahrt -

Köln

Attn: G. Eisenbeiss

Linder Höhe

D-5000 Köln 90

GERMANY

HTC Solar Forschungs-Centrum GmbH

Attn: Jürgen Kleinwächter, General Manager

Industriestr. 8-10

D. 7850 Lörrach-Haagen 6

GERMANY

Schlaich Bergermann und Partner

Attn: Wolfgang Schiel

Hohenzollernstr. 1

D-7000 Stuttgart 1

GERMANY

Solo Kleinmotren

Attn: Andreas Baumüller

Stuttgarter Str. 41

D-7032 Singelfingen 6

GERMANY

ZSW

Attn: Dr. Jürgen Rheinländer

Hessbrühlstrasse 61

D)-7000 Stuttgart 80

GERMANY

\section{Spain}

Plataforma Solar de Almería

Attn: Manuel Sánchez Jiménez

Aptdo. 22

E-04200 Tabernas (Almeria)

ESI'AÑA

\section{Japan}

Aisin Seiki Co. LTD

Attn: Yutaka Momose

Stirling Engine Sect, 2nd R\&l) Center

1, Asahi-Machi, 2-Chome

Kariya City, Aichi Pref. 448

JAPAN

Meiji University

Attn: Prof. Iwane Fujil

Dept. of Mechanical Engineering

1-1-1 Higashi-Mita

Tama-ku, Kawasaki 214

JAPAN

National Aerospace laboratory

Attn: Eguchi Kunihisa

Space Technology Research Group

7-44-1 Iindaiji-Higashi

Chofu Tokyo-182

JAPAN

Nihon University

Attn: Prof. Naotsugu Isshiki

Dept. of Mechanical Engineering

1 Nakagawara Tokusada-Aza, Tamuramachi

Koriyama 963

JAPAN

SANYO Electric Co., Ltd

Attn: Dr. Hiroshi Sekiya

Research \& Development Center

180 Sakata Oizumi-Machi

Ora-Gun, Gunma 370-05

JAPAN

\section{Russia}

Institute of Physics and Power Engineering Attn: Dr. Yury V. Loktionov

Bondarenko Square 1, Obninsk, Kaluga Region

249020 RUSSIA

Russian Academy of Sciences

Attn: 'Jr. Oleg S. Popel

Institute for High Temperatures

IVTAN

Izhorskaya, 13/19

Moscow, 127412

RUSSIA 


\section{International Agencies}

International Energy Agency - OCED

Attn: Jeffery Skeer

2, Rue Andre-Pascal

75775 Paris Cedex 16

FRANCE 
$z$
0
0
0 


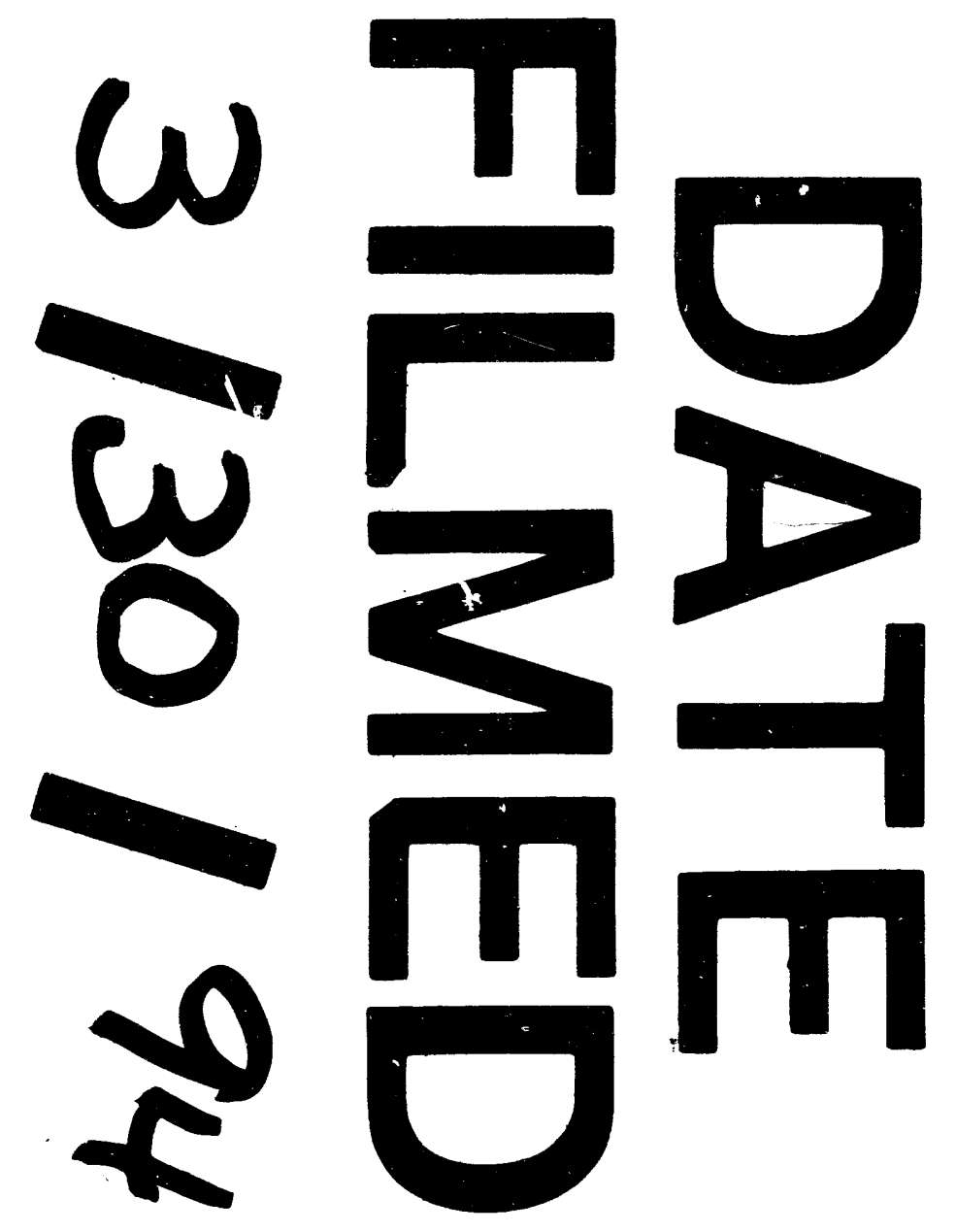


